Universidad Politécnica de Madrid (UPM)

Escuela Técnica Superior de Arquitectura de Madrid (ETSAM)

\title{
La desaparición de la
} exterioridad

en la arquitectura contemporánea.

Una operativa complementaria:

\author{
Redes (ANT) y \\ Espumas (Sloterdijk)
}

Tesis Doctoral. Mauro Gil-Fournier Esquerra

Arquitecto

2016 

Departamento de Proyectos Arquitectónicos ETSAM | UPM | Madrid

La desaparición de la exterioridad en la arquitectura contemporánea.

Una operativa complementaria: Redes (ANT) y Espumas (Sloterdijk)

Mauro Gil-Fournier Esquerra

Arquitecto

Directores:

Federico Soriano Peláez. Doctor en Arquitectura

Almudena Ribot Manzano. Doctora en Arquitectura 

Tribunal nombrado por el Magfco. y Excmo. Sr. Rector de la Universidad Politécnica de Madrid, el día de de 20

Presidente :

Vocal:

Vocal:

Vocal:

Secretario:

Suplente:

Suplente:

Realizado el acto de defensa y lectura de Tesis el día de en la Escuela Técnica Superior de Arquitectura de Madrid.

Calificación:

EL PRESIDENTE

\section{LOS VOCALES}

\section{EL SECRETARIO}



a Irene, León y Manuela 
A 30 de diciembre de 2015

Tipografía: Simoncini Garamond Std. 


\section{Índice Resumido}

Agradecimientos III

Resumen | Abstract $\quad$ V-VI

0. Introducción IX

0.1 Dos herramientas complementarias XIV

0.2 Metodología $\mathrm{XX}$

0.3 En el Interior de la tesis XXIII

0.4 Pertinencia XXXII

1 Redes: la exterioridad adentro 1

1.1 Las diferentes acepciones del concepto red 4

1.2 Asociaciones y mediaciones 9

1.3 El espacio en la red $\quad 18$

1.4 Entidades sin exterior $\quad 32$

1.5 Ensamblajes múltiples $\quad 51$

$\begin{array}{ll}\text { 1.6 Problematizando los límites de la ANT } & 70\end{array}$

2 Espumas: el gran interior $\quad 75$

2.1 Pompas de jabón $\quad 83$

2.2 Covecindad 98

2.3 Multiplicidades-espacio 106

2.4 Entidades sin exterior $\quad 121$

2.5 Coinsistencia 130

2.6 Problematizando los límites de la espuma 148

3 Conclusiones: principios y operatividades 153

3.1 Continuidad, simultaneidad e instantaneidad 157

3.2 Proxicuidad 166

3.3 Extimidad 175

3.4 Contingencia 182

3.5 Aligeramiento 190

3.6 Volatilidad 197

3.7 Disper(x)ión 204

3.8 Interescalaridad 209

3.9 Transparencia 218

3.10 Colocalidad 225

3.11 Set de operaciones 233

4 Índice desarrollado 237

5 Bibliografía 241 


\section{Agradecimientos}

La tesis, como una máquina de pensamiento sin exterior, ni interior, en los términos de Deleuze, es en sí misma una espuma múltiple, un insulamiento, un aislamiento. Pero ese aislamiento está conectado, está mediado. La tesis se ha producido en una situación de coaislamiento y covecindad con otras espumas. Esas otras espumas sois vosotros, a los que agradezco vuestro apoyo y los "soportes de vida" que habéis ofrecido desinteresadamente a esta tesis doctoral. Los soportes se manifiestan en los diferentes capitales que este proceso ha desplegado: capitales afectivos, recursos, información, conocimiento, científico, cuidados, concentración. Cada una sabréis encontraros en vuestra burbuja.

¡Gracias a todas!

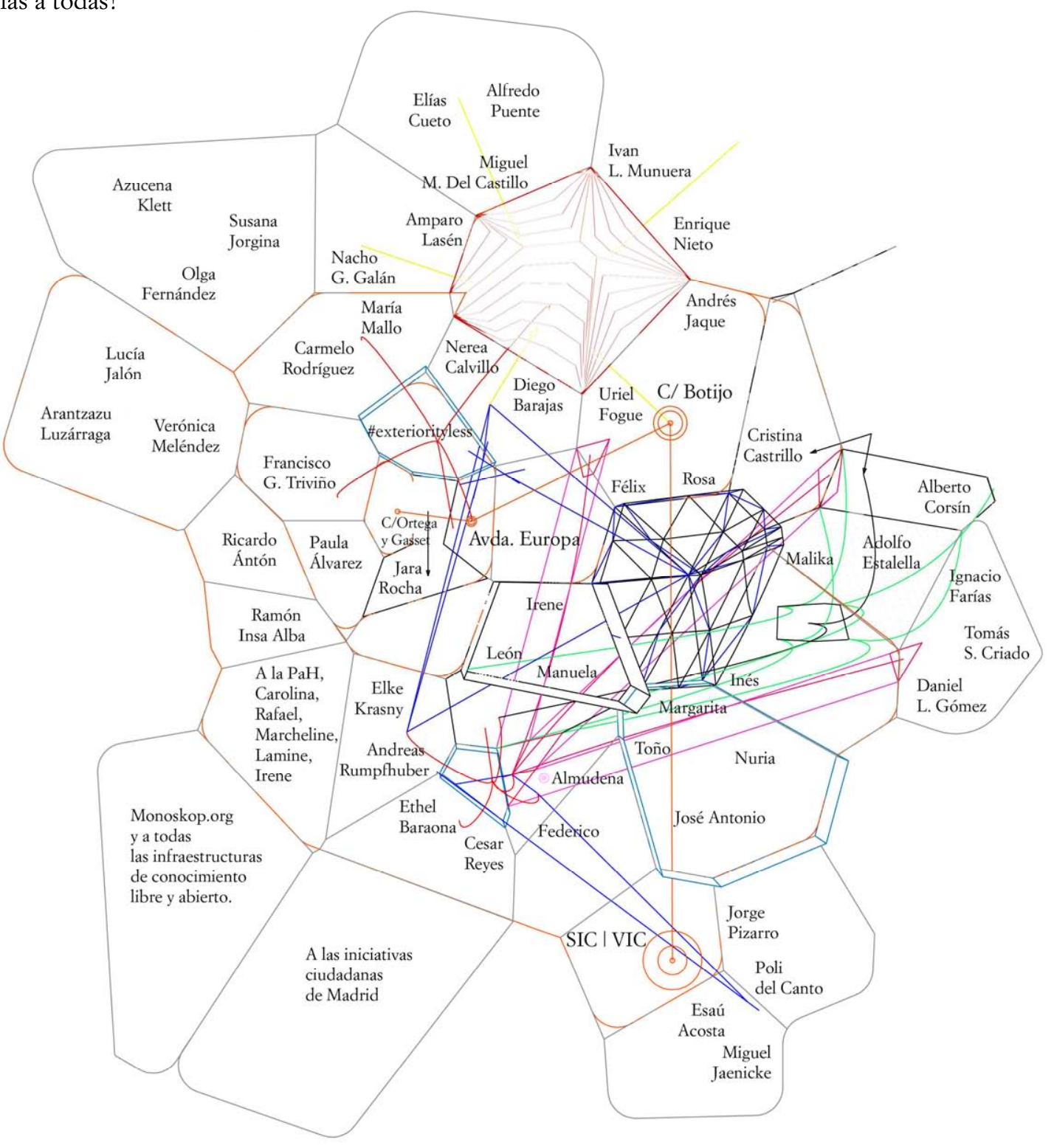




\section{Resumen}

La práctica de la arquitectura está, en muchos casos, separada del ámbito ampliado de lo social, debido a su autonomía disciplinar. Son muchos los conceptos, herramientas y procedimientos que nos han sido enseñados y son tremendamente útiles, pero no suficientes para desenvolverse en el mundo contemporáneo. Las ideas de lugar, de distancia, de escala, de programa, de unidad, de estabilidad, de transparencia o de intimidad, han estado ligadas a las consideraciones duales por oposición, de lo que es respectivamente exterior o interior a un edificio, a una arquitectura o a la propia disciplina. Pero algunas de estas cuestiones pueden redefinirse para poder operar hoy en día, pues quizás nunca funcionaron como exteriores o interiores, pero se establecieron de esta manera en términos discursivos.

La tesis doctoral problematiza estas cuestiones inherentes a nuestra práctica, nuestro modo de pensar en ella y con ello, nuestra manera de atender a las condiciones actuales. Para ello, hemos encontrado en determinadas nociones provenientes del campo sociológico de la Teoría del Actor-Red de Bruno Latour y la ANT; y en el campo antropo-fenomenológico de la Teoría de las Multiplicidades-Espacio de Peter Sloterdijk, una caja de herramientas que, en su complementariedad, pueden aportar significados ampliados y canales extendidos para ampliar el vínculo de las propuestas arquitectónicas con la contemporaneidad.

En base a esta complementariedad, la tesis elabora los principios de continuidad, simultaneidad e instantaneidad y nueve conceptos que a modo de conclusiones abiertas, permiten ampliar el contexto arquitectónico y establecer nuevas operatividades: Proxicuidad, Extimidad, Contingencia, Aligeramiento, Volatilidad, Disper(x)ión, Interescalaridad, Transparencia y Colocalidad. Nueve conceptos que forman un diagrama operativo complementario. Una herramienta necesaria para la cultura del proyecto arquitectónico contemporáneo. 


\section{Abstract}

The practice of architecture is, in many cases, separated from the expanded social sphere due to their disciplinary autonomy. Many concepts, tools and procedures that we have been taught are extremely useful, but not sufficient to succeed in the contemporary world. The idea of location, distance, scale, program, unity, stability, transparency, or privacy have been linked to the dual considerations as opposed, respectively what is outside or inside a building, architecture or discipline. But some of these issues can be redefined to operate today as perhaps never functioned as exterior or interior, but settled in this way in discursive terms.

The dissertation problematizes these issues inherent in our practice, our way of thinking about it and thus the way we respond to existing conditions. So we've found in certain notions from the sociological field of the Actor-Network Theory of Bruno Latour and ANT and the anthropo-phenomenological field Theory of Multiplicities-Spaces of Peter Sloterdijk; a toolbox that in its complementarities can provide extended meanings and channels to expand the link with contemporary architectural proposals.

Based on these complementarities, the thesis elaborate the principles of continuity, simultaneity and instantaneity and nine concepts as open conclusions that can extend the architectural context and establish new operativities: Proxicuity, Extimacy, Contingency, Lightening, Volatility, Disper(x)ion, Interescalarity, Transparency and Colocality. Nine concepts that form a complementary operating diagram. A necessary tool for the culture of contemporary architectural design. 


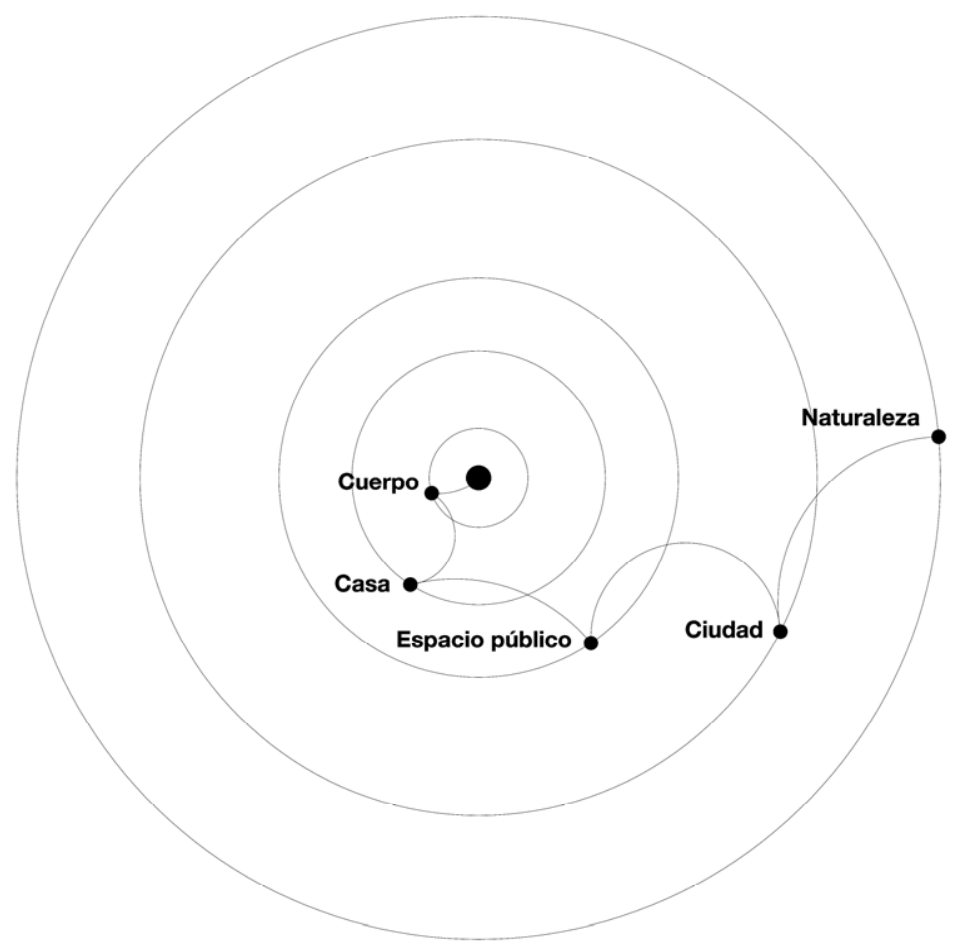

Diagrama del autor según Las formas tradicionales de la exterioridad según J.L. Pardo.

"El Horla de Maupassant explica: tenemos el espacio habitado; la casa, el jardín a la orilla del rio, del bosque circundante, a continuación las localidades más lejanas, que se prolongan los alrededores: Rouen, ciudad próxima, el monte Sant Michael, Paris, Brasil. El relato explora paso a paso, meticulosamente, la cama, la mesilla de noche, la habitación, con sus sillas y su espejo, y va de lo más cercano a los confines del universo. El solitario contempla inmóvil la extensión y luego se desplaza por ella, con una precisión exquisita, de todos los accidentes espaciales debidos a los transportes y las prolongaciones."

Michael Serres, en Atlas sobre el Horla de Guy de Maupassant. 
0. Introducción 
En esta tesis doctoral desarrollamos algunos conceptos posibles desde la complementariedad de dos teorías que son para nosotros una caja de herramientas. ${ }^{1}$ Estas herramientas posibilitan una operatividad ampliada a la cultura del proyecto arquitectónico contemporáneo. Por un lado, la Teoría del Actor-Red (ANT) de Bruno Latour, Michel Callon, John Law y muchas otras aportaciones desde diversos campos disciplinares de los estudios sociales de la ciencia y la tecnología (STS); y por el otro, la Teoría de las Multiplicidades Espacio o Espumas² desarrolladas principalmente por Peter Sloterdijk.

Nos planteamos esta tesis doctoral, como medio para superar o ampliar un entorno arquitectónico en el que sus intervenciones se reducen a una serie de operaciones disciplinariamente consolidadas, aplicadas de manera poco crítica por gran parte de los arquitectos de referencia. Pasaremos de las explicaciones a las descripciones, y de sistemas estratégicos a modos operacionales para intervenir y actualizar la realidad, y ponerla en juego con otros contextos.

La práctica discursiva de la arquitectura ha estado, en muchos casos, separada de lo social, entendido en su sentido ampliado ${ }^{3}$, debido a su autonomía disciplinar. Son muchos los conceptos, herramientas y procedimientos que nos han sido enseñados. Estos son tremendamente útiles, pero no suficientes, para desenvolverse en el mundo contemporáneo. Las ideas de lugar, de distancia, de escala, de programa, de unidad, de estabilidad, de transparencia o de intimidad han estado ligadas a las consideraciones duales por oposición, de lo que es respectivamente exterior o interior a un edificio, a una arquitectura o a la disciplina. Pero hoy en día algunas de estas cuestiones pueden redefinirse y recolocarse para poder operar pues quizás nunca funcionaron como exteriores o interiores pero se establecieron de esta manera en términos discursivos. ${ }^{4}$

Bajo esta necesidad vital como arquitecto, la tesis doctoral propuesta, trata de problematizar algunas cuestiones inherentes a nuestra práctica, nuestro modo de pensar en ella y con ello, nuestra manera de atender a las problemáticas contemporáneas. Para ello, hemos encontrado en la ANT y las Espumas, un contexto de trabajo muy enriquecedor, que parte también de la hipótesis de la desaparición de la exterioridad en el pensamiento contemporáneo. La

\footnotetext{
${ }^{1}$ Sobre la teoría como caja de herramientas ver: Foucault, Michel. Microfísica del poder. Madrid, La Piqueta,1980, p.79.

${ }^{2}$ Espumas es el tercer libro de la trilogía esferas I,II y III que desarrolla una teoría antropológica de la esfereológica.

${ }^{3}$ Lo social, es el colectivo ampliado de humanos y no humanos. Cfr. Latour, Bruno. La esperanza de Pandora. Barcelona, Gedisa, 2001. Esta mirada implica recuperar el “colectivo” de G. Tarde frente a la "sociedad" de E. Durkheim

${ }^{4}$ Cfr. Latour, Bruno. Nunca Fuimos modernos. Buenos Aires, Siglo XXI, 2007.
} 
transferencia y puesta en práctica de determinadas nociones provenientes del campo sociológico de la ANT y el campo antropo-fenomenológico de las Espumas, pueden aportar nuevos significados y canales para vincular las propuestas arquitectónicas con la contemporaneidad.

Desde la sociología pragmática y la "filosofía empírica" propia de la ANT se describen y explicitan procesos de Actores-Red que conforman el mundo contemporáneo. Desde las Espumas, se elabora un entorno antropo-morfológico ligado al desarrollo de los espacios que el hombre ha construido. El lector interesado en los usos operativos de estas metodologías pragmatistas, encontrará en el texto una amplitud de aproximaciones y ejemplos al campo de la arquitectura y los estudios urbanos. Por otro lado, el texto podrá también resultar útil al lector interesado en extender y ampliar las aproximaciones además de a los conceptos citados, a la idea de naturaleza, territorio, ciudad, espacio público, la casa o el cuerpo, como entidades que se desarrollan y construyen en simultaneidad unas con otras.

Esta tesis doctoral, como ejercicio de explicitación, parece útil para extender el significado de estas nociones tradicionales visibilizando las aportaciones que, desde la ANT y las Espumas, pueden dar a la cultura del proyecto arquitectónico. La tesis desarrolla en sus conclusiones los principios y las operatividades que hemos extraído del estudio de ambas teorías, su combinación y la práctica, arquitectónica y urbana, del día a día.

Cuando lo cercano y lo lejano se hacen simultáneos, aparece la "proxicuidad". Cuando la intimidad se produce junto al exterior aparece la "extimidad". Cuando a la estabilidad aparente del programa se le superpone la realidad, aparece la "contingencia". Cuando la ausencia de gravedad aparece en las sociedades, se desarrolla el "aligeramiento". Ante el cambio constante de las situaciones de la vida urbana, la "volatilidad" se convierte en el fenómeno permanente. Cuando no es la cohesión, sino la expansión del ámbito urbano, la "disper(x)ión" aparece como fenómeno. Ante la imposibilidad de estudiar los procesos en una escala fijada, aparece la "interescalaridad" como herramienta operativa. Más allá de la transparencia material, otras nociones de "transparencia" pueden incluirse en el repertorio arquitectónico. Por último, la idea de lugar y localización, puede ampliarse de su posición relacional con el concepto de "colocalidad".

${ }^{5}$ Entrecomillamos los conceptos que vamos a ir introduciendo en la tesis doctoral y formarán el capítulo de operatividades en las conclusiones. 
Esta discusión no solo avanza posibilidades para la arquitectura. También puede aportar nuevos retos a las visiones de la ANT o las espumas. La mirada complementaria de esta tesis doctoral sobre ambas teorías/herramientas también permite aflorar algunas discusiones y algunas confluencias de interés para las tres partes. La arquitectura, la ANT y las Espumas.

La tesis, por lo tanto, revela un potencial en el desarrollo de conceptos que, tratados desde la arquitectura, permite explorar nuevos territorios desde el interior de la disciplina, ampliando su radio de acción y, por lo tanto, tratando de diluir sus propios límites con lo social, lo tecnológico o lo natural.

\section{Hipótesis y objetivos}

Luego nuestra hipótesis de partida es, precisamente, "la desaparición de la exterioridad en la arquitectura contemporánea" desde los presupuestos de la Teoría del Actor-Red (B. Latour et all) y la Teoría de las Espumas (P. Sloterdijk), que da título a esta tesis doctoral.

El objeto de esta tesis es contribuir a una teoría operacional o herramienta para la cultura del proyecto arquitectónico contemporáneo desde la complementariedad de ambas teorías. Para ello:

1. Evaluamos las repercusiones de ambas teorías para la arquitectura y los estudios urbanos.

2. Enunciamos los principios generales que observamos en ambas teorías como garantía de desarrollo posterior.

3. Convertimos estos principios generales en conceptos operativos como herramientas conceptuales para la cultura del proyecto arquitectónico.

4. Explicitamos las herramientas que la arquitectura puede incorporar como propias desde una mirada ampliada e inclusiva hacia lo social y lo tecnológico.

5. Expandimos el ámbito de la arquitectura a un mundo de relaciones más amplio donde los temas disciplinares se conectan con experiencias sociotécnicas complejas. 


\subsection{Dos herramientas complementarias}

La tesis doctoral se enmarca en un contexto de pensamiento situado desde de la segunda mitad del siglo XX hasta la actualidad. Se adentra, principalmente, en los marcos del pensamiento contemporáneo que provienen de las dos teorías enunciadas: por un lado, la Teoría del Actor-Red de Bruno Latour et all; y por el otro, la Teoría de las Multiplicidades Espacio de Peter Sloterdijk. La tesis desarrolla en base a ambas teorías, sus conceptos y temas más operativos, pragmáticos y procedimentales en una labor de extraer un conocimiento útil para la arquitectura. Ambas teorías, de manera diferente, establecen una modificación del lugar desde el que pensar. ${ }^{6}$ De este movimiento se derivan diferentes aproximaciones que diluyen la separación entre sociedad y tecnología, sociedad y naturaleza ${ }^{7}$ o sociedad y arquitectura ${ }^{8}$.

La teoría del actor-red, que abreviaremos como ANT (de sus siglas en Inglés Actor-Network Theory), también conocida como sociología de las asociaciones o sociología de la traducción o como la ontología plana del actante-rizoma, es un enfoque sociológico originado de los estudios sociales de la ciencia y la tecnología que abreviaremos como STS (de sus siglas en Inglés Science, Technology and Society). Esta teoría, pertenece a la rama filosófica del post-estructuralismo y se entiende, no sin controversia, como una teoría constructivista. La teoría, a la que preferimos llamarla caja de herramientas ${ }^{9}$, ha sido elaborada desde campos disciplinares diversos, originados dentro del programa de Sociología de la Innovación en la Escuela de Minas de París, Francia. Bruno Latour es, quizás, su principal exponente, pero es una teoría desarrollada desde investigaciones empíricas en muchas disciplinas y por diversos autores, como Michel Callon, J. Law y muchos otros. Hoy en día sus redes se extienden a una amplia variedad de campos y, en particular, también a los estudios urbanos y la arquitectura.

Si la situamos de una forma elemental, la ANT se basa en la descripción de los procesos, hechos o situaciones como redes de asociaciones y la inclusión de lo nohumano, objetos, tecnologías y los estados de cosas en la construcción del problema de lo social que puede verse en todas sus investigaciones. De manera particular, Bruno Latour lo desarrolla en sus libros" Reensamblando lo social”, "La caja de pandora", "Nunca fuimos modernos" o Las políticas de la naturaleza".

\footnotetext{
${ }^{6}$ Cfr. Morin, Marie-Eve. "Cohabiting in the globalised world: Peter Sloterdijk's global foams and Bruno Latour's cosmopolitics” Environmental and planning D: Society and space, v.27, 2009, p.58-72. ${ }^{7}$ Latour, Bruno. Políticas de la naturaleza. Enric Puig ( trad.). Barcelona, RBA, 2013.

${ }^{8}$ Precisamente esa es la labor de Peter Sloterdijk en su trilogía. Esferas I,II y III.

${ }^{9}$ La ANT no es ningún sistema cerrado, sino una suerte de herramientas en evolución y controversia constante. Cfr. Latour, Bruno. "On Recalling ANT" The Editorial Board of The Sociological Review, 1999.
} 
Y en otros muchos artículos como "Dadme un laboratorio y moveré el mundo", o "La tecnología es la sociedad hecha duradera", o "Sobre la mediación técnica" y otros textos en colaboración con Michel Callon y John Law. De la ANT también son importantes las aportaciones de, L. Law y A. Mol, sobre la performatividad del espacio y los objetos y las topologías, los límites y la otredad en la ANT. Igualmente la problematización relativa a la ausencia de exterioridad ontológica realizada por uno de sus fundadores J. Law y $\mathrm{K}$. Hetherington en artículos como After Networks. Asimismo, se enmarca la interesante evolución de los conceptos de Deleuze sobre el "agenciamiento" que en manos de Manuel de Landa da lugar a la noción de "ensamblajes". También las transferencias que autores como Miquel Domenech, Tirado y Montaner, o Daniel López hacen de las fuentes originales. En especial, el esfuerzo de Ignacio Farías y Colin McFarlane por extender el repertorio de la ANT cuando se utiliza para los estudios de la ciudad con la aproximación de los "ensamblajes urbanos". En general, los estudios sociales de la ciencia y la tecnología (STS) y los estudios feministas de Donna Haraway, D. Massey y otras.

Por otro lado, la Teoría de las Multiplicidades Espacio o Espumas de Peter Sloterdijk se enmarca dentro de lo que se denomina post-humanismo ${ }^{10}$. Este término define un gran abanico de estudios que, ante la dificultad de mantener una distinción entre lo natural y lo artificial, el sujeto y el objeto, desarrollan un pensamiento híbrido y relacional sobre la tecnología y lo humano. En su desarrollo de la trilogía de esferas I,II y III Sloterdijk aborda el giro post-humanista en una aproximación al concepto antropológico de esfera como entidad constitutiva de la sociedad, junto a sus construcciones o arquitecturas de aislamiento. Pudiendo enmarcarse en un pensamiento antropocéntrico e histórico, Sloterdijk, prefiere enmarcarse en la filosofía del post-humanismo y post-histórica. ${ }^{11}$ En particular sus libros, "Esferas I Macroinsulamientos", "Esferas II Microinsulamientos", y "Esferas III espumas", son una trilogía de la globalización mediante construcciones de globos, burbujas y espumas; y en lo que entendemos como su continuación en "En el Mundo interior del capital," y artículos como "El Palacio de Cristal" o "Normas para el parque humano". Asimismo, otros dedicados al pensamiento del diseño forman el aparato teórico para evaluar las implicaciones de su teoría a la arquitectura y los estudios urbanos. Con él podemos enmarcar a,

\footnotetext{
${ }^{10}$ Según el propio Peter Sloterdijk hay que prescindir de una interpretación (humanista) del mundo estructurado sobre la dicotomía sujeto-objeto, porque "los hombres necesitan relacionarse entre ellos pero también con las máquinas, los animales, las plantas..., y deben aprender a tener una relación polivalente con el entorno" desarrollado en Normas para el parque humano y explicado en la conferencia "El post-humanismo: sus fuentes teológicas, sus medios técnicos” de Peter Sloterdijk en el Aula del Rectorado de la Universidad Internacional de Andalucía, el 9 de mayo de 2003.

${ }^{11}$ Cfr. Sloterdijk Peter. "Posthistorie". En el mundo interior del capital. Para una teoría filosófica de la globalización. Madrid, Siruela, 2007, pp.198-203.
} 
Lucy Irigaray y su pensamiento feminista, en la consideración de "sociedades de a dos". Igualmente artículos, como los de Marie Eve Morin sobre la globalización en Sloterdijk, o fuentes secundarias como Adolfo Vásquez Roca, u otros estudiosos de Peter Sloterdijk son relevantes para esta tesis doctoral.

De esta manera, Redes (ANT) y Espumas (Sloterdijk), manifiestan constantemente en sus investigaciones la absorción de la exterioridad o su desaparición como un axioma contemporáneo. Bruno Latour hablará de la desaparición de la exterioridad como un asunto primordial de nuestra época. ${ }^{12}$ En especial, de la anulación de la naturaleza como exterior, la construcción de los hechos científicos, anulando las relaciones intro-exo del laboratorio, o el exterior moderno que separa a "los otros" no europeos. Peter Sloterdijk se dedicará a describir y conformar el gran interior, cuando ha desaparecido el exterior. ${ }^{13}$ La globalización ha saturado el planeta y lo ha conformado como una gran espuma múltiple. Esta saturación ha provocado la acomodación de un gran invernadero para la vida en el interior. Ambos autores, complementan también sus aportaciones en textos investigados donde interpelan sus argumentaciones, se complementan o se discuten sus posiciones.

Ambas teorías son, como hemos mencionado, una caja de herramientas para esta tesis doctoral, que permiten afrontar un problema implícito en la hipótesis como es, la desaparición de las "formas de la exterioridad" que atraviesa toda la tesis. Esta situación es enunciada por José Luis Pardo, en su libro "Las formas de la exterioridad", como la llegada a "una cultura sin exterior". ${ }^{14}$ En el libro se describe la conformación de la exterioridad mediante límites y pieles como son el cuerpo, la casa, el espacio público, la ciudad, el territorio o la naturaleza. Estas formas, como objetos conformadores de límites claros y explícitos, se deshacen en redes de mediación ${ }^{15}$ y en aislamientos conectados ${ }^{16}$ una vez investigadas desde la ANT y las Espumas. Las formas de la exterioridad a través de esta tesis doctoral, pasan de ser entidades nominativas a procesos verbalizables. ${ }^{17}$ Por ejemplo, el espacio público no será más una entidad nominativa, sino que el espacio público será un proceso que se desarrolla simultáneamente con la construcción de la intimidad y lo doméstico. Y esa entidad nominativa tendrá un verbo: "espacializar"; y unas características, pues será "interescalar", se dará en

\footnotetext{
${ }^{12}$ Latour, Bruno. "Spheres and networks: two ways to reinterpret globalization". Harvard Design Magazine, n.3, 2009, pp.138-144.

${ }^{13}$ Sloterdijk. Peter. En el mundo interior del capital. Para una teoría filosófica de la globalización. Madrid, Siruela, 2007.

${ }^{14}$ Cfr. Pardo, José Luis. Las formas de la exterioridad. Valencia, Pre-textos,1992.

${ }^{15}$ Cfr. Serres, Michael. Atlas. Madrid, Cátedra, 1995.

${ }^{16}$ Cfr. Sloterdijk, Peter.Esferas III. Espumas.Esferología plural. Madrid, Siruela, 2006.

${ }^{17}$ Latour hablará de "Spacing", "Timing", "Acting”. en Latour, Bruno."Trains of thought. Piaget, formalism and the fifth dimension." Common Knowledge, 1996, v.3, p.179.
} 
"proxicuidad", y constituirá la "extimidad", que pueden ser procedimientos operativos para el proyectos arquitectónico.

Dentro del campo disciplinar de la arquitectura y los estudios urbanos, la incorporación de estas teorías y sus presupuestos, ha venido elaborándose recientemente. Se han venido desarrollando los estudios urbanos en lo que se denomina la Teoría de la Crítica Urbana Postmarxista originados con H. Lefevbre en los años 60 y representada por D. Harvey, M. Davis, S. Sassen, E.W. Soja y N. Brennen a partir de los años 70. No es hasta mediados de los años 90 cuando, el geógrafo Nigel Thrift, diagnosticó en 1995 una modificación en la forma de atender a lo urbano desde una perspectiva relacional y descentrada de la ciudad como objeto único de estudio"18; y no es hasta la publicación del libro "Cities. Reimagining the urban", de A. Amin y Nigel Thrift en el año 2002, cuando los estudios urbanos comienzan a modificar un sistema estructuralista a una mirada de relacionalidad heterogénea. ${ }^{19}$

Desde ambas posiciones en los estudios urbanos, primero desde la sociología y luego desde la geografía crítica, se han repensado las nociones de escala, de las agencias y las formas no materiales de la exterioridad como lo nacional, lo regional, lo urbano, la comunidad o lo doméstico. Por otro lado, las ampliaciones del repertorio de la ANT para los estudios urbanos, han derivado en el desarrollo de herramientas como los "ensamblajes urbanos"20, las ideas sobre la "performación" del espacio ${ }^{21}$ o las actuales miradas "cosmopolíticas" sobre lo urbano. $^{22}$

En el campo disciplinar de la arquitectura, son algunos escritos de Bruno Latour y Alvena Yaneba ${ }^{23}$, los que han interrogado a la arquitectura sobre su autonomía. Por ejemplo, las investigaciones de la socióloga Alvena Yaneva sobre la producción arquitectónica de Rem Koolhaas/OMA y las redes híbridas que lo conforman. ${ }^{24}$ Por otro lado, Alejandro Zaera-Polo, desde su posición en Princeton en el año 2008, viene desarrollando una investigación sobre la envolvente como elemento político de la arquitectura. Su posicionamiento está enunciado en el

\footnotetext{
${ }^{18}$ Farías, Ignacio. "Descentring the object of urban studies” Farías Ignacio. \& Bender, Thomas. (Eds.) Urban Assemblages. How actor-network theory change urban studies. London, NY, Routledge, 2010. p.1.

${ }^{19}$ Cfr. Farías, Ignacio. "Ensamblajes urbanos: la TAR y el examen de la ciudad”. Athenea Digital, 2011, v.11, n.1, p.15-40.

${ }^{20}$ Ibidem.

${ }^{21}$ Cfr. Law, John \& Mol, Annemarie. "Spacialities of globality . Situating technoscience: An inquiry into spatialities." Environment and Planning D: Society and Space, n.19, p.609-621.

${ }^{22}$ Cfr. Yaneba, Albena \& Zaera-Polo, Alejandro. What Is Cosmopolitical Design? Design, Nature and the Built Environment. Surrey/Burligton, Ashgate, 2015.

${ }^{23}$ Latour, Bruno \& Yaneva, Albena. "Give me a gun and I will make all buildings move: an ant's view of architecture.” en Geiser, Reto (ed.), Explorations in Architecture: Teaching, Design, Research, Basel, Birkhäuser, 2008, pp.80-89.

${ }^{24}$ Cfr. Yaneba, Albena. Mapping controversies in Architecture. Surrey/Burlington, Ashgate, 2012.
} 
texto "The politics of the envelope. A political critique of materialism." que marca el inicio de su investigación bajo las acepciones de la ANT hasta la fecha. Además, en la Universidad de Columbia, se realiza el congreso sobre Architecture Inside/out ${ }^{25}$ que problematiza algunas cuestiones discutidas en esta tesis doctoral.

En particular, desde la Escuela de Arquitectura de Madrid, son numerosos los ejemplos de arquitectos/as que bajo estos presupuestos desarrollan su labor práctica y teórica tratando de extender las herramientas de la arquitectura. Desde la labor docente de la unidad dirigida por Andrés Perea, en el Grupo de Exploración Proyectual (GEP), arquitectos/as como Andrés Jaque, Izaskun Chinchilla vienen implicándose en el desarrollo de las transferencias de la ANT a la arquitectura. ${ }^{26}$ Tesis doctorales en la UPM como "Aerópolis" de Nerea Calvillo, o "Ecología política y economía de la visibilidad de los dispositivos tecnológicos de la escala urbana durante el siglo XX" de Uriel Fogué, desarrollan las implicaciones técnicas y materiales de los fenómenos estudiados bajos las herramientas de la ANT y algunos presupuestos de Peter Sloterdijk y Lucy Irigaray en el caso de N. Calvillo. En España, desde la Escuela de Arquitectura de Alicante, dirigida por J.M. Torres Nadal, se han desplegado nuevos modos de abrir la caja de herramientas para el proyecto de arquitectura, como por ejemplo, en las tesis doctorales de Enrique Nieto "Prescindible Organizado. Agenda docente para una formulación afectiva y disidente del proyecto arquitectónico" o del arquitecto Miguel Mesa del Castillo "Víctimas de un Mapa. Arquitectura y Resistencia en el Tiempo de la Cultura Flexible."

Tres publicaciones recientes nos parece que sitúan el estado de la cuestión en esta investigación. La primera "Ensamblajes urbanos" del desarrollan investigaciones empíricas y teóricas sobre la cuestión (2008). La segunda "Cosmopolítica Urbana" avanza en la noción del ensamblaje hacia una teoría cosmopolítica aplicada a lo urbano (2015). Por último, la publicación del libro "What Is Cosmopolitical Design? Design, Nature and the Built Environment" cuya edición corre a cargo de los ya citados Alejandro Zaera-Polo y Albena Yaneba (2016). En particular, son numerosos los proyectos, estudios o investigaciones que como ejemplos podemos dar en este estado de la cuestión y que se desarrollan en las conclusiones de la tesis como ejemplos operativos.

\footnotetext{
${ }^{25}$ En la universidad de Columbia GASSAP los estudiantes de doctorado organizan con el soporte de GSAPP, the Temple Hoyne Buell Center for the Study of American Architecture, and the Graham Foundation for Advanced Studies in the Fine Arts el congreso Architecture Inside/out donde también participan numerosos arquitectos desde los presupuestos de la ANT

${ }^{26}$ Cfr. Muniesa, F. Luque, E. Chinchilla, I. Jaque, A. "Ejercicios de empirismo conceptual en Arquitectura” Publicado en AIRB, Revista de Antropología Iberoamericana, Madrid, Ed. Electrónica, Nov-Dic, 2005.
} 
Por último, y no por ello menos importante, hay dos circunstancias que han sido para el autor, motor de investigaciones empíricas ${ }^{27}$ que han detonado la aparición de algunos conceptos investigados en la ANT y las Espumas. Primero, la creación de un contexto de innovación ciudadana en la ciudad de Madrid. Segundo, la investigación y coproducción urbana junto a la ciudadanía. Estas situaciones de coproducción arquitectónica y urbana explicitan que algunos de los conceptos investigados se materializan diariamente en múltiples prácticas ciudadanas de la ciudad de Madrid. Por lo tanto, una separación entre teoría y empirismo, entre herramientas conceptuales y prácticas, sería pretenciosa y limitante para determinar el estado de la cuestión sobre la operatividad de los conceptos desarrollados en la tesis como conclusión. Cuando además, estas investigaciones empíricas, han sido presentadas en numerosos congresos nacionales e internacionales por el autor de esta tesis doctoral y pueden verse en el día a día de la ciudad de Madrid.

${ }^{27}$ Todas ellas se pueden encontrar en la plataforma de investigación urbana VIC viveroiniciativasciudadanas-.net que el autor desarrolla junto a Miguel Jaenicke y Esaú Acosta. 


\subsection{Metodología}

Esta tesis doctoral se ha elaborado en el cruce multi-disciplinar de la arquitectura y el pensamiento contemporáneo: sociología, filosofía, antropología. Principalmente pone de relieve la importancia de la Teoría del Actor-Red y la Teoría de las Multiplicidades-Espacio como fuentes de herramientas para pensar el proyecto arquitectónico. De esta manera, la tesis ofrece una mirada ampliada para leer la arquitectura como parte de un fenómeno urbano extendido del que forma parte. Luego más allá de la arquitectura como edificio o como construcción, la arquitectura estará ligada también a otros programas como las prácticas discursivas de los arquitectos, las redes que componen su práctica, la labor editorial y comunicativa de la misma, los fenómenos urbanos, formales o informales, o simplemente las situaciones interconectadas que se dan en las experiencias cotidianas.

La investigación tiene una dimensión teórica y operacional. Por un lado, se desarrollan los conceptos que modifican la posición desde la que plantear los problemas arquitectónicos como problemas socio-técnicos. ${ }^{28}$ Por el otro, se desarrollan las situaciones arquitectónicas desde las que pensar lo social como "colectivo ampliado". Es un camino de ida y vuelta al mismo tiempo.

Primero. Las redes (ANT), nos acompañan para enunciar los puntos de partida que irán desde la propia definición del término de red, al concepto de agencia, programa de acción como resultado de asociaciones y mediaciones entre entidades sociales, sean estas humanas o no-humanas; para situar entonces el concepto de espacio que vamos a utilizar que dará lugar a la noción de "espacializar" o "performar". Una vez hemos desarrollado estos conceptos, la tesis introduce el ejemplo del laboratorio como una entidad sin exterior, para extenderlo a otras formas como el cuerpo, la casa o la ciudad. En base a lo desarrollado, la tesis explicita los "ensamblajes urbanos" como una herramienta para la descripción y la puesta en acción de los procesos urbanos. Todas ellas se muestran como operatividades que hacen participar lo antes alejado y exterior, naturaleza, tecnología, estados de cosas, como entidades que en su hibridación con lo social, internalizan el exterior, según B. Latour.

${ }^{28}$ Cfr. Zaera-Polo, Alejandro. "Politics of the envelope". Volume, n.17, 2008, p.76-105. 
Segundo. Las espumas (Sloterdijk), nos sirven de soporte para una investigación teórica que se basa en una analogía biológica con el propio concepto de espuma y una metáfora, espacial y arquitectónica, de los invernaderos, donde forma y mensaje son lo mismo. ${ }^{29}$ Sloterdijk, parte de la construcción espacial del hombre, para explicitar la composición de lo social y, por ende, la composición de la globalización de este proceso arquitectónico. Para situar esta teoría, se investiga la conformación de las primeras burbujas en el siglo XIX, que dan paso en el siglo $\mathrm{XX}$ a las espumas. Con ellas, se desarrolla el proceso de aislamiento del individuo moderno. Procesos de co-aislamiento y de co-vecindad se explicitan como la situación tanto de la espuma, como de la sociedad, como del individuo en procesos de "autoemparejamiento", tanto humano como tecnológico. ${ }^{30} \mathrm{La}$ arquitectura es el detonante de estos supuestos teóricos. Tras situar las bases conceptuales de las espumas, se desarrollan lo que denominamos entidades sin exterior. En este capítulo se introduce el apartamento y el cuerpo acondicionado como dos entidades sin exterior desde las Espumas. En base a todo lo anterior, la tesis explicita la condición de simultaneidad que se da en las espumas transfiriéndolo a ámbitos arquitectónicos, definidos por los escritos de "la ciudad genérica" y el "espacio basura" de Rem Koolhaas. Los conceptos operativos desarrollados en la tesis reelaboran un pensamiento, por parte de Sloterdijk, de la saturación del globo por las Espumas y sus espacialidades múltiples, que hacen del mundo globalizado, para él, una entidad sin exterior. ${ }^{31}$

Tercero. Ambas teorías o herramientas no pretenden dar una única visión del mundo, sino posibilitar otros lugares desde los que pensar-en-el-mundo. Ambas tienen límites y estos se problematizan en la tesis al final de cada capítulo. Los límites de cada teoría, también permiten pensar en sus situaciones complementarias. Frente a la "anorexia espacial" de la ANT, Sloterdijk provee de espacio para situarse. ${ }^{32}$ Frente al más escaso proceso relacional de las espumas, la ANT ofrece más herramientas para establecer las continuidades, relaciones y mediaciones entre entidades. Cada una ofrece una aproximación topológica que en esta tesis se desarrolla en base a la conjunción con los conceptos arquitectónicos desarrollados.

\footnotetext{
${ }^{29}$ Sloterdijk Peter. En el mundo interior del capital. Para una teoría filosófica de la globalización. Madrid, Siruela, 200, p.210.

${ }^{30}$ Cfr. Sloterdijk, Peter. Esferas III. Espumas.Esferología plural. Madrid, Siruela, 2006.

${ }^{31}$ Ibídem.

${ }^{32}$ Ibid., p.197.
} 
Durante la elaboración de los capítulos 1 y 2 se extraen ejemplos más desarrollados que puedan hacer explícitas las situaciones teóricas descritas, pues estas a su vez, se basan en la descripción de prácticas empíricas cotidianas o del día a día, sean estas en casa, en un laboratorio o en un invernadero.

Cuarto. En base a las diferentes investigaciones que se desarrollan, aparecen en el capítulo 1 y 2 diversos enunciados y supuestos teóricos y empíricos que formulan concepciones diferentes en conceptos como la distancia, lo íntimo, la escala, el programa, lo pesado, la estabilidad, la cohesión, lo local y lo global; que apuntan los conceptos operativos que la tesis va extraer como conclusiones. Se elabora, entonces, un diagrama topológico que incorpora los procesos operativos que se desarrollan como conclusiones y que se articulan en base a tres principios generales para su operatividad que se enuncian como: el principio de continuidad, el de simultaneidad, y el de instantaneidad. Este diagrama operativo resulta de la complementariedad de ambas teorías (ANT-Espumas).

El diagrama se articula en base a la disolución de las dualidades, para pensar en los conceptos enunciados como conceptos en continuidad, simultaneidad o instantaneidad. La Proxicuidad, como la simultaneidad de lo próximo y lo ubicuo, lo cercano y lo lejano. La Extimidad, como la simultaneidad de lo público y lo íntimo. La Contingencia, como sustitución instantánea a la idea de programa, acontecimiento y fenómeno. El Aligeramiento, como proceso en continuidad de un proceso de carga y descarga. La Volatilidad, como un proceso continuo de cambios sucesivos y repentinos o la Disper(x)ión, como separación y conexión simultánea. La Interescalaridad, como el proceso de continuidad espacial y temporal en escalas simultáneas. La Transparencia, no solo como la percepción simultánea o superpuesta de distintas localizaciones espaciales en continuidad, sino también como el grado de acceso al conocimiento de un objeto o entidad. O la Colocalidad, como una situación englobante de localidades simultáneas y/o continuas. Estas características se ejemplifican como procesos operativos que son también procedimientos de proyecto, y resultan de la extracción de conceptos útiles para la tesis. Pues, Redes (ANT) y Esferas (Sloterdijk) operan también bajo estos conceptos. 


\subsection{En el Interior de la tesis}

La tesis doctoral se organiza en torno a tres capítulos. Los dos primeros capítulos, funcionan dentro de cada teoría-herramienta, como una aproximación pragmática y operativa múltiple para el desarrollo de las nociones básicas como la distancia, el programa, la escala, etc. que desarrolla esta tesis. Podemos ver como la aproximación a ambas teorías, si bien no se desarrolla desde un estudio comparado, una y otra van sugiriendo sus conexiones y sus distanciamientos. Hasta complementarse en el capítulo 3 en base a los principios generales que se enuncian y en los conceptos operativos que se desarrollan o ejemplifican.

El primer capítulo desarrolla las nociones claves para la ANT y los conceptos que entendemos son útiles para la arquitectura. Comienza por acotar lo que se entiende dentro de la ANT por el concepto de Red. Este, desde la filosofía de la mediación de Michel Serres se tornará una noción que avanza día a día y ciertamente mutante y problematizada. De ahí que su primera acepción como Actor-Red, pase a denominarse más tarde como Actante-Rizoma. La agencia distribuida y compartida de humanos y no humanos, es una cuestión clave para situar el proceso de la acción y la mediación entre agentes o entidades. Asociaciones y mediaciones, se desarrollan como herramientas básicas para la ANT que disuelven las fronteras entre lo natural, lo social, lo tecnológico o lo arquitectónico. Asimismo, la modificación del concepto nominal de "Espacio" al proceso dinámico y heterogéneo de "espacializar". Cuerpos, ciudades, naturalezas o lo doméstico se ejemplifican en la ANT como entidades sin exterior. Este primer capítulo elabora con más detalle la idea de "ensamblaje urbano" como herramienta importante para los estudios urbanos y la arquitectura. Por último, este primer capítulo problematiza las ideas desarrolladas en base a algunos de los propios autores de la ANT y desde otras posiciones críticas con ellas, como la de Sloterdijk.

El segundo capítulo, elabora una articulación particular de las ideas desarrolladas por P. Sloterdijk. De la amplitud de temas tratados por el autor, la tesis se centra en el origen de las espumas, como burbujas en el siglo XIX. Los invernaderos se explicitan como micro-mundos que engloban un futuro próximo que Sloterdijk desarrolla como metáfora de la sociedad. Forma y mensaje, serán lo mismo desde el invernadero inglés del Crystal Palace. ${ }^{33}$ El capitulo desarrolla, en el punto 2.1, los principios generales de la articulación de la espuma en covecindad. Este punto, refleja la coincidencia, no así la forma de llegar a ella, de lo que Sloterdijk

${ }^{33}$ Sloterdijk. Peter. "El palacio de Cristal". Conferencia trascrita de "Traumas urbanos. La ciudad y los desastres". Centro de Cultura Contemporánea de Barcelona, 7-11 julio, 2004. 
denomina autoemparejamientos, sean estos humanos o tecnológicos, y que son un acercamiento simétrico a la relacionalidad híbrida y agencias compartidas de la ANT. Sloterdijk, desarrolla el interés por la explicitación de la autovecindad individual como ser constitutivo del "ser-con" ${ }^{34}$ Una vez desarrollada la unidad binaria (biunidad) para la Sloterdijk, se desarrollan las nociones espaciales de su teoría. "Aislamientos conectados" y "sistemas coincidentes" son los principios en los que el sistema de Espumas se desarrolla. De estos conceptos se extraen muchas de las características que luego desarrollamos. En este punto se desarrollan las arquitecturas de la espuma o la cohabitación como islas absolutas, o islas atmosféricas, para dar paso a la explicitación, según los supuestos de Sloterdijk, del apartamento y el cuerpo acondicionado como entidades sin exterior. El capítulo termina con la coinsistencia en las propiedades simultáneas e instantáneas de conformación de la espuma en la sociedad y sus arquitecturas entendiendo la "ciudad genérica" y el "espacio basura" de R. Koolhaas como espumas genéricas que dan lugar al desarrollo de tecnologías urbanas ubicuas. Por último, este segundo capítulo, al igual que el primero, problematiza las ideas desarrolladas en base al propio Sloterdijk y otros autores críticos con algunas de las posiciones de su pensamiento, también en las propias contradicciones acerca del gran interior que Sloterdijk elabora en ausencia del exterior.

\section{Conclusiones}

El tercer capítulo, muestra la operatividad de esta tesis doctoral. Una vez desarrolladas ambas aproximaciones, los principios enunciados expresan la complementariedad de ambas teorías y sus confluencias. Esta confluencia, también posee sus propios conflictos que permiten encontrar sus aproximaciones y diferencias en el diagrama topológico que la tesis elabora.

Los principios que ayudan a construir la desaparición de la exterioridad, según la ANT y Sloterdijk, aparecen enunciados como el principio de continuidad, el principio de simultaneidad y el principio de instantaneidad. Estos principios no están definidos por ningún autor específico, ni desarrollados en un marco teórico completo sobre su definición, pero sí aparecen como entornos teóricos repetidos por muchos autores como principios existentes en la realidad contemporánea. Desde el principio de Simetría generalizada ${ }^{35}$ de Bruno Latour y el Principio de extensión asimétrica ${ }^{36}$ de Sloterdijk, se enmarcan los tres principios enunciados.

${ }^{34}$ Morin, Marie-Eve. "Cohabiting in the globalised world: Peter Sloterdijk's global foams and Bruno Latour's cosmopolitics" Environmental and planning D: Society and space. v.27, 2009, p.58-72.

${ }^{35}$ Latour, Bruno. Nunca Fuimos modernos. Ensayo de antropología simétrica. Buenos Aires, Siglo XXI, 2007, p.141.

${ }^{36}$ Sloterdijk. Peter. En el mundo interior del capital. Para una teoría filosófica de la globalización. Madrid, Siruela, 2007, p.309. 
Principios axiomáticos ${ }^{37}$ que permiten describir la realidad contemporánea. De esta manera la tesis enuncia los principios de continuidad, simultaneidad e instantaneidad desde los presupuestos de las ANT y las Espumas como:

El principio de continuidad ${ }^{38}$ establece que las formas de la exterioridad como el cuerpo, la casa, el espacio público, el territorio o la naturaleza, más que entidades nominativas separadas, son procesos que se forman en continuidad a través de redes de mediaciones socio-técnicas y aislamientos conectados.

El principio de simultaneidad ${ }^{39}$, establece que las formas de la exterioridad ligadas al espacio, lo que denominamos el cuerpo, la casa, el espacio público, la ciudad o la naturaleza son procesos que se construyen simultáneamente a través de entidades híbridas, en agencias compartidas que operan como sistemas coincidentes.

El principio de instantaneidad ${ }^{40}$, establece que las formas de la exterioridad son entidades procesuales que se forman cada vez de manera más instantánea desde la conjunción de entidades híbridas diversas, con agencias distribuidas y temporales que aparecen y desaparecen cada vez con mayor rapidez y fugacidad.

Estos tres principios y los procedimientos asociados a ellos se interrelacionan totalmente. Esto no hace más que expresar la constante formación múltiple de los procesos donde estas condiciones se hacen cada día más presentes. Se hace, por lo tanto, necesario abordar estos temas para intervenir en un mundo cada día más complejo y donde la arquitectura no puede separarse del ámbito social y tecnológico. La Arquitectura no puede seguir manteniendo las exterioridades que ha construido.

Por último, los conceptos elaborados en base a los desarrollos del capítulo 1 y 2 y a los principios, permiten que aparezcan estos como conceptos que diluyen las dualidades subyacentes a los conceptos tradicionales. La separación opuesta, será tan solo un estado en el gradiente de posibilidades múltiples. Para ello, se desarrollan los conceptos enunciados como operativas en continuidad, simultaneidad o instantaneidad. Los conceptos que hemos desarrollado, como la conjunción de sus significados para las redes (ANT) y para las espumas (Sloterdijk), son los siguientes.

\footnotetext{
${ }^{37}$ Como por ejemplo, la globalización terrestre que Sloterdijk considera un axioma. Una consideración evidente, que aceptamos sin demostración, como punto de partida para demostrar otros conceptos. Tradicionalmente los axiomas se eligen de las consideradas «afirmaciones evidentes»

${ }^{38}$ Ver el desarrollo en el epígrafe 3.1.2 de esta tesis doctoral.

${ }^{39}$ Ver en 3.1 .3

${ }^{40}$ Ver en 3.1 .4
} 
Proxicuidad. Los límites de las formas de la exterioridad, el cuerpo, la casa, el espacio público, la ciudad y la naturaleza se han dispuesto por su proximidad o su lejanía. La condición de simultaneidad aplicada a la distancia, nos hace proponer en base a las experiencias de las redes sobre la agencia compartida, la continuidad de la acción y los "ensamblajes urbanos" por un lado; y desde los sistemas coincidentes y la inauguración de la covecindad en las espumas por el otro la noción de "proxicuidad". Esta noción parte de la idea de las distancias pragmáticas ${ }^{41}$ y relacionales para determinar su operatividad en el campo de la arquitectura.

Extimidad. El concepto transforma su origen lacaniano como la modificación de la intimidad cuando esta se compone desde el exterior. La intimidad como un concepto que la modernidad confrontó con lo público. ${ }^{42}$. Pero lo íntimo y lo público no son categorías opuestas. Tampoco categorías independientes y enfrentadas. Sino procesos que se construyen simultáneamente. Lo íntimo, ya se compone en Sloterdijk, desde la idea de los "autoemparejamientos" sean estos humanos o tecnológicos. En las redes (ANT), la construcción de lo íntimo se conforma atravesado por múltiples redes de asociación y mediación.

Contingencia. El programa arquitectónico, en términos de función como entidad determinista ligada a la necesidad, muestra sus debilidades en el día a día. La contingencia como acontecimiento abre posibilidades abiertas, variables, flexibles e interpretativas a la red de acontecimientos humanos y no humanos. Las espumas (Sloterdijk) son contingentes por su naturaleza. Desde las redes(ANT) y los (STS) se sostiene que todos los productos de la ciencia son contingentes. Esto también es aplicable a la idea del programa en arquitectura.

Aligeramiento. Si las categorías tradicionales de la exterioridad han podido subsistir hasta nuestros días, es debido al peso y su relación con la materia (pesada) Los objetos arquitectónicos, las infraestructuras han sido constructos pesados, inmutables, inamovibles y relativamente estables que han condicionado la estabilidad, por ejemplo, de las instituciones. ${ }^{43}$ Por otro lado, el aligeramiento de la sociedad se materializa en las arquitecturas ligadas al divertimento, la fiesta, lo efímero y lo celebrativo.

\footnotetext{
${ }^{41}$ Cfr. Harvey, David Explanation in geography. E. Arnold, London,1969.

${ }^{42}$ Cfr. Pardo, José Luis. Políticas de la intimidad. Ensayo sobre la falta de excepciones. Madrid, Escolar y Mayo, 2012.

${ }^{43}$ Cfr. Foucault, Michel. Vigilar y castigar: Madrid, Siglo XXI, 2004.
} 
Volatilidad. Hablar de las condiciones de estabilidad es hablar del mantenimiento de las condiciones iniciales en el tiempo. Es hablar de procesos duraderos. La ciudad es, de por sí, un proceso duradero en muchos casos, que no estable ni inestable, sino sujeto a consideraciones variables en el tiempo. Las espumas ( Sloterdijk), como la sociedad, se mantienen en condiciones de volatilidad. Adquieren su estabilidad debido a sus cambios de estado; se forman y se destruyen en continuidad y circularidad. Las redes (ANT) expresarán la volatilidad en la incapacidad del estudio de la virtualidad ${ }^{44}$, por ejemplo, en los estudios urbanos y de la ciudad.

Disper(x)ión Las tradicionales formas de la exterioridad se han representado mediante la concentración y la cohesión cuando hablamos de la ciudad, las casas, y los cuerpos. Las espumas (Sloterdijk), llevan la dispersión en su raíz genética; estas son dispersiones coloidales, es decir, se mantienen debido a sus cambios de estado. Por otro lado, las redes (ANT) no son dispersas en sí mismas; estas distribuyen, reparten, enlazan, pero no dispersan por sí mismas. Lo que permiten es visibilizar la dispersión existente por cualquier medio, sea este económico, territorial, tecnológico o social. La noción de móviles Inmutables es la herramienta que la ANT desarrolla para la explicar la dispersión en las redes.

Interescalaridad. La escala geográfica ha definido la construcción de nuestros exteriores. De la casa al territorio, o de la región a lo doméstico. Es decir, las escalas se han utilizado como un objeto de estudio establecido y estable. Lo micro y lo macro, lo local y lo global, devienen de relaciones de proxicuidad. Esto sucede tanto para la ANT, en su crítica a lo global, como para Sloterdijk, en su crítica a lo "Glocal". Los procesos arquitectónicos y urbanos tienen continuidades en el espacio y en el tiempo, y estos a su vez, afectan a diversas escalas al mismo tiempo. La interescalaridad es el estudio de la escala en continuidad y simultaneidad.

Transparencia. Los límites entre el interior y el exterior se han materializado en muros y fachadas. "Y una fachada revela en la misma medida que oculta" ${ }^{45}$. A su vez, los límites separan de la misma manera que unen. Sloterdijk, defiende la condición en las espumas de una transparencia turbia. Esta idea proviene de la mirada sobre los sistemas de vecindades, sus aislamientos y sus conexiones que, al igual que las sociedades, son medio transparentes medio opacas. ${ }^{46}$ Para Latour

\footnotetext{
${ }^{44}$ En la relación Actual-Virtual deleuziana.

${ }^{45} \mathrm{Cfr}$. Pardo, José Luis. Las formas de la exterioridad. Valencia, Pre-textos,1992.

${ }^{46}$ Sloterdijk, Peter. Esferas III. Espumas. Esferología plural. Madrid, Siruela, 2006, p.53.
} 
(ANT), el proceso de descripción de una red, lleva consigo un proceso de descajanegrización $\mathrm{n}^{47}$, como proceso de transparencia.

Colocalidad. . Esta situación puede explicitarse como un fenómeno de localidad múltiple. Y este fenómeno podemos darle al menos dos sentidos. El primero, como la colocalidad de una entidad, pues esta se sitúa simultáneamente en dos o más lugares. La segunda, como la colocalidad de un lugar, pues de este, participan múltiples redes o ensamblajes simultáneamente. Ambas situaciones pueden encontrarse en las redes (ANT) y las espumas de Sloterdijk.

Cada uno de estos conceptos se desarrolla de manera sistemática en el capítulo tercero. Su situación, sus aproximaciones y descripciones y una propuesta de definición se elaboran en la primera parte de cada concepto. En la segunda, un sistema de diferentes operatividades se despliega a modo de pequeños casos y ejemplos donde esta condición operativa se desarrolla; bien en un fenómeno urbano, bien en una situación cotidiana o bien en un proyecto de arquitectura que explicita esta condición. Acontecimientos, prácticas y arquitecturas explicitan su operatividad.

Las nueve operaciones forman un "set de operaciones" que la tesis elabora a modo de conclusiones abiertas, pues estos conceptos podrán problematizarse, expandirse o contraerse si se han extendido demasiado. A estos conceptos podrán sumarse otros que puedan elaborar nuevas prospecciones investigadoras en base a ambas teorías o al menos a partes de las enunciadas. El "set de operaciones" compone un diagrama-topológico completo aplicable a multitud de situaciones cotidianas, fenómenos urbanos o proyectos de arquitectura, que quieren desarrollar y continuar este proceso. Este diagrama topológico problematiza en sí mismo la hipótesis de partida. El "set de operaciones" podrá leerse por algunos como una situación cerrada, aunque está no lo sea; como una situación única, aunque esta es múltiple; como una situación aislada, aunque esta esté conectada; como una situación fragmentada, aunque esta sea continua; como una situación estable, aunque esta sea instantánea.

La desaparición de la exterioridad, por lo tanto, no remitirá a una ausencia, sino a una inclusión de todo lo previamente no conectado; aunque queden entidades desconectadas. La internalización del exterior de la ANT se convertirá en un proceso explícito de externalización, de una nueva exterioridad. ${ }^{48} \mathrm{El}$ gran interior transparente de Sloterdijk, se materializará en ciertos lugares como construcciones

\footnotetext{
${ }^{47}$ Desde la construcción del término de cajanegrizar en Latour, Bruno. La esperanza de Pandora. Barcelona, Gedisa, 2001, p.362.

${ }^{48}$ Latour, Bruno. Políticas de la naturaleza. Enric Puig (trad.). Barcelona, RBA, 2013, p.191.
} 
de nuevos exteriores. ${ }^{49}$ Así que, lo importante no será si la exterioridad desaparece, y con ella la interioridad; sino como hemos desarrollado en esta tesis, cómo se conforman, cómo operan, cómo se pliegan y despliegan o cómo se reensamblan en proceso de continuidad, simultaneidad e instantaneidad. La hipótesis ha funcionado como un poderoso detonante, que ha retornado al origen. Pero ese retorno se ha producido por una mediación. La tesis ha operado como una mediadora. Y todo proceso de mediación, es un proceso de transformación. ${ }^{50}$ La tesis, como una máquina conceptual, sin exterior ni interior, ${ }^{51}$ está lista para ser utilizada, prototipada y reconfigurada.

${ }^{49}$ Sloterdijk. Peter. En el mundo interior del capital. Para una teoría filosófica de la globalización. Madrid, Siruela, 2007.

${ }^{50}$ Latour, Bruno. "De la mediación técnica: filosofía, sociología y genealogía". Revista Oeste, 2003, n.16, p.130.

${ }^{51}$ Deleuze y Guattari hablan del libro como una entidad-máquina sin exterior ni interior. En Deleuze, Gilles \& Guattari Felix. Mil mesetas, capitalismo y esquizofrenia. Valencia, Pre-textos, 1980, pp.9-32. 


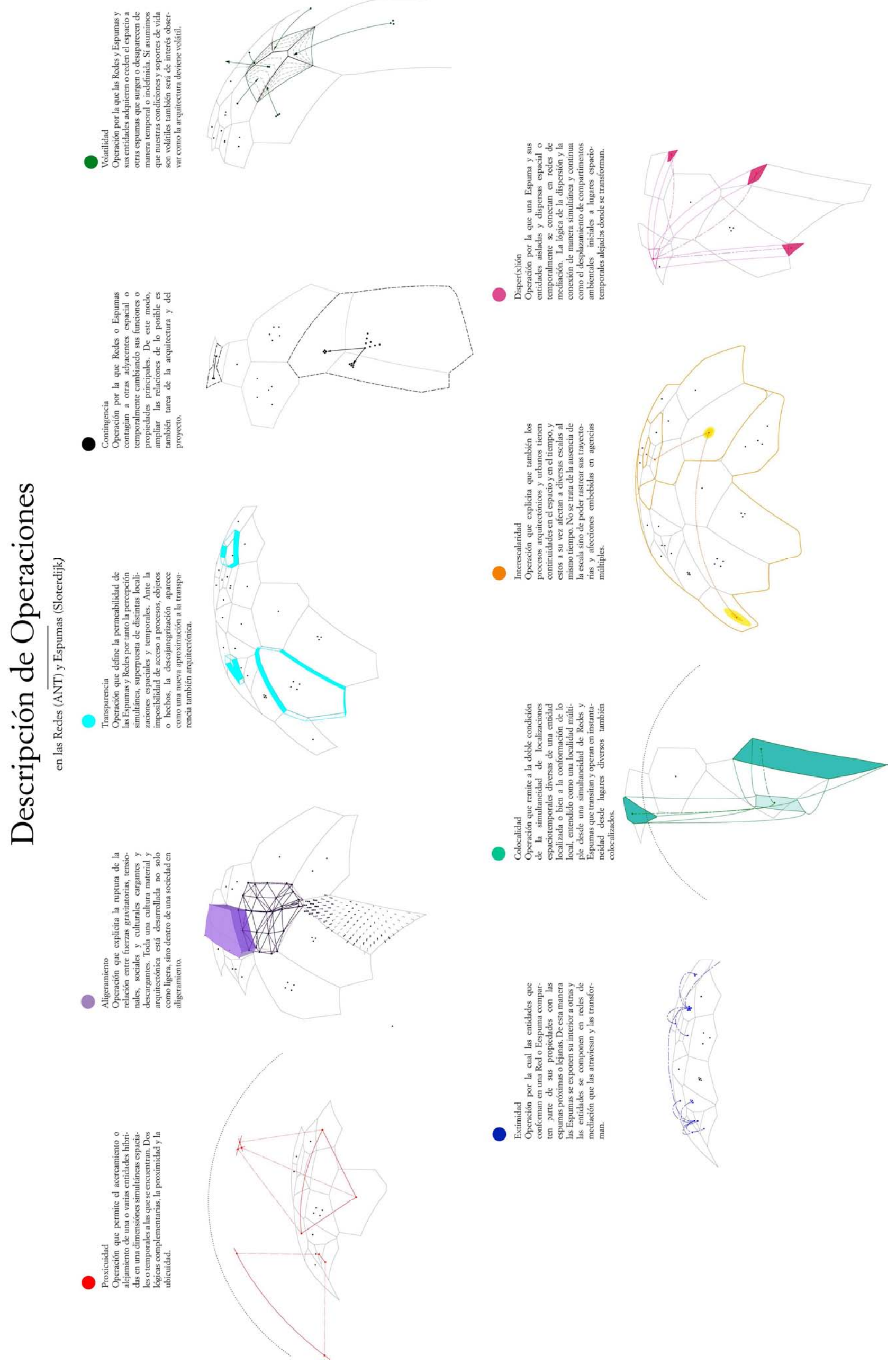



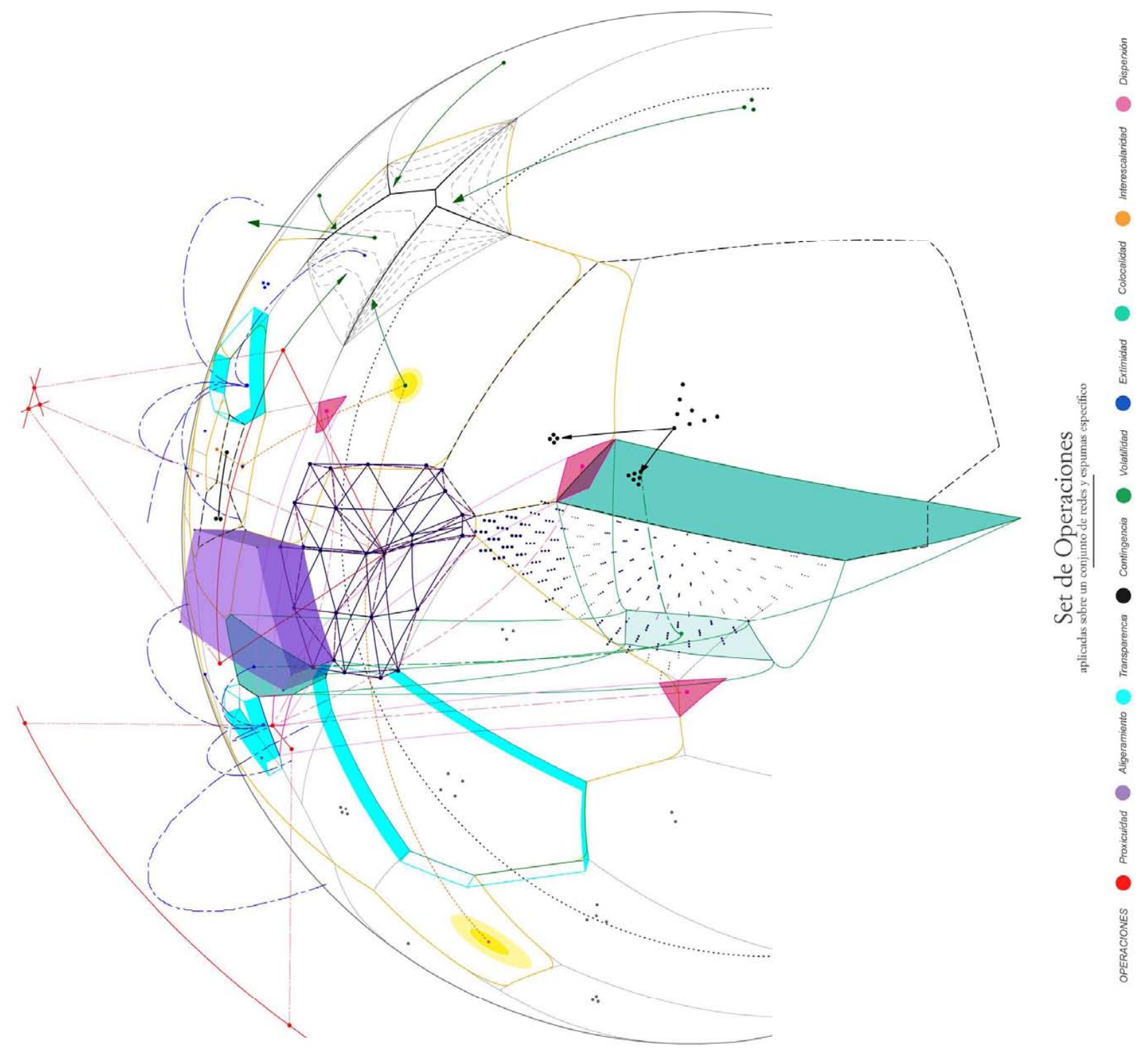


\subsection{Pertinencia}

Como hemos mencionado en el comienzo de la introducción "la desaparición del exterior es, sin duda, el rasgo definitorio de nuestra época". ${ }^{2}$ Durante la elaboración de esta tesis, nos hemos sentido interpelados en la construcción de un marco de pensamiento y operatividad relacionado con los procesos urbanos que se dan hoy en día y a los que la arquitectura puede responder con herramientas que surgen de la interdependencia y coexistencia en la que desarrollamos nuestra práctica.

Esta tesis es, hoy en día, una obviedad. Toda teoría hoy no puede ser más que un axioma. Por eso, la globalización terrestre es comparable a un axioma. ${ }^{53} \mathrm{La}$ ausencia de exterioridad podemos encontrarla en cualquier resumen de noticias de 4 minutos de cualquier cadena televisiva. Pero para comprender la interrelación de los procesos urbanos, sociotécnicos y materiales-ambientales y su impacto a escala planetaria necesitamos herramientas para elaborar una descripción completa. Incluso así, siempre habrá otros que lo puedan ver precisamente al revés, como un mundo sin interioridad, como pura exterioridad desplegada.

Quizás los caminos de los que partíamos no hayan sido alcanzados, y aún serán otros quien lleguen a ellos. Pero esta tesis doctoral se ha sentido interpelada por enunciaciones como estas, que si no han sido resueltas, sí han sido suficientemente planteadas.

De esta manera sobre la elección de este tema de investigación, su marco teórico y su pertinencia parten de estas consideraciones:

1. El proceso de desaparición de la exterioridad, como explica Bruno Latour, "Se detecta como el rasgo definitorio de nuestra época”. Es un fenómeno relevante de grandes repercusiones arquitectónicas y urbanas.

2. La dificultad de acotar esta condición, ampliamente expuesta pero poco desarrollada en su especificidad, hace de él un campo productivo para ampliar sus consideraciones en la cultura del proyecto arquitectónico.

3. Hoy en día, parece necesario una aproximación socio-técnica diversa sobre el carácter de lo social, lo natural, lo tecnológico, y con ello la cultura de lo material y

${ }^{52}$ Latour, Bruno. "Spheres and networks: two ways to reinterpret globalization". Harvard Design Magazine, 2009, n.30, p.144.

${ }^{53}$ Sloterdijk. Peter. En el mundo interior del capital. Para una teoría filosófica de la globalización. Madrid, Siruela, 2007, p.170. 
lo espacial-ambiental, para comprender el alcance interrelacionado de todas ellas y su afectación a la arquitectura.

4. La hipótesis de partida, desde los desarrollos de las redes (ANT) y las espumas (Sloterdijk), no es un fenómeno tratado ampliamente desde el campo disciplinar de la arquitectura. Se hace por ello pertinente la profundización relacional en este campo.

5. El investigador, desarrolla su trabajo profesional y académico, bajo las teorías y herramientas desarrolladas en esta tesis. En particular, su trabajo anula la exterioridad del ciudadano como agente no productivo en la arquitectura y desarrolla herramientas-metodologías e instrumentos para la coproducción urbana y arquitectónica de la ciudadanía.

\section{Michael Foucault}

"Se podría suponer, no digo una ciencia, porque es una palabra demasiado prostituida ahora, sino una especie de descripción sistemática que tuviera por objeto, en una sociedad dada, el estudio, el análisis, la descripción, la "lectura", como se gusta decir ahora, de estos espacios diferentes, estos otros lugares, algo así como una polémica a la vez mítica y real del espacio en que vivimos; esta descripción podría llamarse la heterotopología. Pues bien, hay que dar los primero rudimentos de esta ciencia cuyo alumbramiento está aconteciendo" ${ }^{54}$

\section{Peter Sloterdijk}

"Si hubiera que ampliar las investigaciones de Benjamin al siglo XX y principios del XXI, sería necesario - a parte de algunas correcciones en el método- tomar como punto de partida los modelos arquitectónicos del presente: centros comerciales, recintos feriales, estadios, espacios lúdicos cubiertos, estaciones orbitales y gated communities, los nuevos trabajos tendrían títulos como Los palacios de cristal, Los invernaderos, y, si los lleváramos a sus últimas consecuencias, quizá también Las estaciones orbitales." ${ }^{155}$

\section{Neil Brennen}

"Necesitamos primero de unas nuevas categorías teóricas a través del cual a investigar la producción incesante y la transformación de la organización socio-espacial a través de escalas y territorios. Con este fin, un nuevo léxico conceptual debe ser creada para identificar la amplia variedad de procesos de urbanización que actualmente están remodelando el mundo urbano y, relacionado con lo anterior, para descifrar los nuevos paisajes emergentes de diferencia socio-espacial que se han cristalizan en las últimas décadas. Por último, pero no menos importante, que requieren estrategias metodológicas:

\footnotetext{
${ }^{54}$ Foucault, Michel. "Des espaces autres” \& "Le Corps utopique.” Architecture, Mouvement, Continuité, n.5, 1984

${ }^{55}$ Cfr. Sloterdijk. Peter. "El palacio de Cristal". Conferencia trascrita de "Traumas urbanos. La ciudad y los desastres". Centro de Cultura Contemporánea de Barcelona , 7-11 julio 2004.
} 
aventureros, experimentales, y estrategias en la frontera para facilitar la investigación empírica de estos procesos. ${ }^{\circ 6}$

Ignacio Farías.

"El concepto de ensamblajes urbanos, y la pregunta por el ensamblaje de los ensamblajes, resultan particularmente adecuados para dar cuenta del papel clave que juegan fuerzas, capacidades y procesos virtuales en la ciudad. La teoría del actor-red está diseñada para dar cuenta simétricamente, por medio de la noción de actante, del papel que juegan entidades humanas y no humanas en la producción de lo social. Ahora bien, tal como el concepto de actante denota, se trata entonces de las complicadas asociaciones entre entidades actuales. $\mathrm{La}[\mathrm{ANT}]$ carece de herramientas conceptuales para dar cuenta de lo virtual. El concepto de ensamblajes urbanos, en la medida que se deriva de la filosofía deleuziana, permite además dar cuenta del papel que juegan los afectos, las capacidades y, en general, las tendencias virtuales inherentes a las entidades y ensamblajes que conjuntamente producen la ciudad" 57 .

${ }^{56}$ Brenenn, Neil. Implosions/Explosions: Towards a Study of Planetary Urbanization. Berlín, Jovis Berlag, 2014, p.14.

${ }^{57}$ Farías, Ignacio. "Ensamblajes urbanos: la TAR y el examen de la ciudad". Athenea Digital, 2011, v.11, n.1, pp.15-40. 
1.Redes (ANT)

La exterioridad adentro 
Quizás la palabra red no sea la más adecuada para abordar la cuestión acerca de cómo se establecen las conexiones heterogéneas y en movimiento para “internalizar" dentro de la red todo elemento aparentemente ajeno a la misma. Esta internalización es el motor que permite que aparezca un conocimiento inexplorado de algo que podríamos llamar trazabilidad de la incertidumbre o rastreo de lo posible. En esta tesis doctoral la conocida como, Teoría del ActorRed (ANT), es de acuerdo a la definición que da uno de sus fundadores:

Una dispersa familia de herramientas, sensibilidades y métodos de análisis que se caracterizan por tratar, tanto el mundo social como el natural, como un efecto continuamente generado de redes de relaciones entre elementos heterogéneos: objetos, sujetos, seres humanos, máquinas, animales, ideas, organizaciones, etc. ${ }^{1}$

En general, el término red puede referirse a las redes desarrolladas en infraestructuras: electricidad, trenes, cloacas, internet, etc. Otra significación viene de la sociología de la organización que introduce diferencias entre mercados y estados. ${ }^{2}$ En este caso, la red representa una manera informal de asociar agentes humanos. Manuel Castells hace que ambas nociones se fusionen. "La red es un modo de organización ampliado gracias a la extensión de la tecnología” ${ }^{3}$. Pero esta definición es insuficiente para desarrollar la red como la herramienta relacional de elementos heterogéneos; pues no permite internalizar la cultura, la naturaleza o la tecnología para analizar las relaciones sociales ${ }^{4}$ que se componen en las redes que empíricamente pueden desarrollarse.

Tal como indica el sociólogo y filósofo Ignacio Farías sobre la noción de red, esta "ha sido ampliamente usada en los últimos años para hacer referencia a redes técnicas, informáticas y cibernéticas, con lo que ha perdido toda relación con la noción francesa original, de reseaux, más cercana a la idea de rizoma o de entrelazamiento" ${ }^{5}$. Esta última acepción de reseaux por un lado, en la idea de red que definía Diderot, hace de la red un agregado de “asuntos y cuerpos” para separarla de las divisiones cartesianas entre res extensa (materia) y la res cogitans (espíritu). La red (ANT), es referida a la ampliación y conexión ontológica de la reseaux de Diderot. ${ }^{6}$

\footnotetext{
${ }^{1}$ Law, John “Actor-Network Theory and Material Semiotics”. En S.Turner, Bryan. The New Blackwell Companion to Social Theory Blackwell. London, 2008, p.141.

${ }^{2}$ Latour, Bruno. Reensamblar lo social. Buenos Aires, Manantial, 2008, p.188.

${ }^{3}$ Cfr. Castells, Manuel. La sociedad Red. Madrid, Alianza, 2006.

${ }^{4}$ Utilizamos relaciones sociales entendiendo lo social como el colectivo ampliado de entidades no sociales. En Latour, Bruno. La esperanza de Pandora. Barcelona, Gedisa, 2001, p.208.

${ }^{5}$ Farías, Ignacio. "Ensamblajes urbanos: la TAR y el examen de la ciudad". Athenea Digital. 2011. v.11, n.1, p.17.

${ }^{6}$ Latour. Bruno. "On actor-network theory. A few clarifications plus more than a few complications".

Soziale Welt, v.47, 1996, p.371.
} 


\subsection{Las diferentes acepciones del concepto red}

La red, ha pasado de ser una idea sencilla, como metáfora para explicar un juego de relaciones entre el actor y la red, a ser un concepto filosófico actualmente en debate. Las diferentes acepciones del término, no hacen sino abrir el concepto y mantenerlo vivo. Permitiendo de esta manera comprender la complejidad de lo que el término red quiere expresar.

La noción más establecida comúnmente pero no por ello la que puede definir la red de la ANT es la debida las investigaciones del Ingeniero Paul Baran. ${ }^{7} \mathrm{Si}$ observamos los diagramas de topología clásicos de $\operatorname{Baran}^{8}$ vemos que existen tres clases principales de redes.

La primera es la red clásica centralizada donde todos los nodos menos uno son periféricos. Entre ellos, solo pueden comunicarse a través del nodo central. Esta topología sitúa un nodo principal, jerárquico, único y con poder sobre los demás como una topología centralizada. Este sistema no tiene capacidad de enriquecimiento o de agregación mas que en una posición central respecto a las demás. Por lo tanto, esta topología necesita de un exterior para que pueda suceder. Es un esquema clásico de funcionamiento de poder: cae el centro, cae la red. La caída del nodo central priva del flujo a todos los demás nodos. Un ejemplo de estas redes son el nacimiento de los periódicos y la esfera pública.

La segunda topología sería la descentralizada. No existe un único nodo central sino un centro colectivo de conectores. La caída de uno de los nodos centralizadores conlleva la desconexión de uno o más nodos del conjunto de la red mientras que la caída del clúster centralizador produce necesariamente la ruptura y práctica desaparición de la red. Una topología que sí asume un posible crecimiento y enriquecimiento dado que un nodo periférico es capaz de convertirse en un nodo de distribución. Aún así es, una red jerarquiza y multicéntrica. Asume por lo tanto, la existencia de exteriores a la propia red. Un ejemplo podría suceder en el nacimiento del telégrafo y la posterior red telefónica.

\footnotetext{
${ }^{7}$ Paul Baran fue uno de los impulsores de las redes de conmutación de paquetes junto a Donald Davies y Leonard Kleinrock.

${ }^{8}$ El análisis de las redes de P. Baran que hacemos está basado en el que describe David de Ugarte de Las Indias Electrónicas. De Ugarte, David. Trilogía de las Redes. Barcelona, El Cobre, 2009.
} 
La tercera topología es la red distribuida. La extracción de cualquiera de los nodos no desconectaría de la red a ningún otro, pues un nodo está conectado a otros varios nodos. Todos los nodos se conectan entre sí sin que tengan que pasar necesariamente por uno o varios centros locales. En este tipo de redes desaparece la división centro periferia y por tanto el poder de filtro sobre la información que fluye por ella. Es decir, construye una red sin exterior: su límite viene dado por el tamaño que adquiere la red y la capacidad de agregar otras redes similares. En teoría una red distribuida podría no tener límite, es decir, carecer verdaderamente de exterior. Es esta última, el tipo de red que nos interesa al pensar en la manera que los nodos, y los vectores se orientan y adquieren su mayor potencial. El clásico ejemplo sería internet. ${ }^{9}$

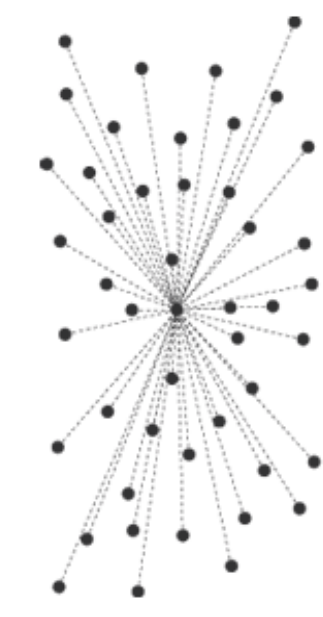

CENTRALIZED

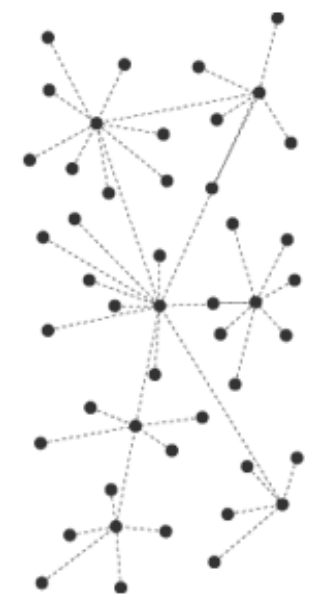

DECENTRALIZED

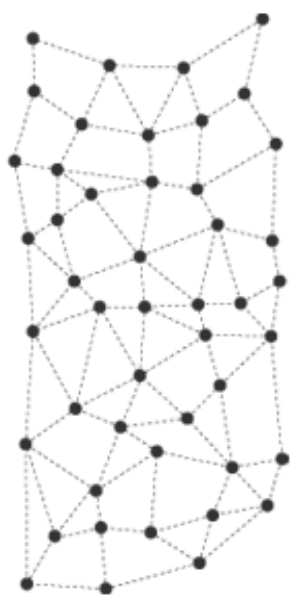

DISTRIBUTED

Fig. 01. Topologías de la red. Paul Baran. 1964

Ninguna de estas representaciones puede acercarnos al conocimiento de las redes de vinculación heterogénea y agencia que estamos desarrollando en este punto, pero pueden situarnos en la complejidad que determinadas entidades tienen de una manera híbrida. Es decir, determinadas redes podrán tener puntos de mucha centralización u otros más distribuidos, y viceversa.

A partir de aquí, ya podemos rastrear las definiciones de red para situar la de actor-red que es la que nos interesa en esta tesis. Dentro de la teoría del Actor-Red (ANT) también existen diferentes aproximaciones y críticas de la misma.

\footnotetext{
${ }^{9}$ Internet tiene la capacidad de ser una red distribuida. Actualmente es una red descentralizada. Según J. Perry Barlow los protocolos http tienden a centralizarla frente a los protocolos ipfs que tienden a distribuirla https://ipfs.io/ipfs/QmNhFJjGcMPqpuYfxL62VVB9528NXqDNMFXiqN5bgFYiZ1/itstime-for-the-permanent-web.html
} 


\subsubsection{Actor-Red}

Hay una etimología de la red que se acerca más al interés tratado aquí y que ya hemos mencionado. Tiene que ver, en su origen, con la Reve D'Alembert, la "red de la naturaleza" de Diderot. Para Bruno Latour esta acepción de red narra contextos ampliados más allá de lo social y de los vínculos humanos. ${ }^{10}$ Así, podemos definir una red como una expresión que sirve para verificar cuanta energía, movimiento y especificidad puede contener una situación particular.

Según Latour, "red es un concepto, no una cosa que existe ahí afuera. Una herramienta para describir algo que no se está describiendo". ${ }^{11}$ La red como herramienta tiene 3 procedimientos básicos según Latour ${ }^{12}$ :

1. Establece conexión punto a punto que es rastreable físicamente y por lo tanto, puede ser registrada empíricamente.

2. Tal conexión deja vacía la mayor parte de lo que no está conectado.

3. La red no está hecha de hilo de nailon, sino que es el rastro que deja un agente en movimiento.

De esta forma la red es una noción debilitada en sus representaciones visuales más bien simplificadas, por muy complejas que parezcan, en un primer caso. La mejor de las representaciones precisamente no es una red.

La mejor manera de entender las redes de relaciones heterogéneas es vincularlas a las herramientas de la Teoría del actor-red. A partir de ahora abreviaremos esta teoría como ANT (Actor NetworkTheory) para expresar la multiplicidad de acepciones y de autores diversos bajo sus siglas. Estas siglas, observa Latour, contienen la idea de una hormiga y ofrece así un modelo sugerente para pensar la perspectiva metodológica y analítica necesaria para estudiar lo social; "una perspectiva que se basa en el seguimiento de los rastros que dejan los actores con una mirada micro, casi corta de vista, pero que lleva a cubrir grandes distancias." ${ }^{13}$

La propia definición de esta teoría es la de Actor-Red que no es ni actor, ni red por separado, sino la fusión, temporal o espacial de la misma. "[un actor-red] no es reducible ni a un simple actor ni a una red. [...] Un actor-red es, simultáneamente, un actor cuya actividad consiste en entrelazar elementos

\footnotetext{
${ }^{10}$ Sobre la filosofía de la red de Diderot podemos ver Anderson, Wilda. Didertós dream. Baltimore, The Johns Hopkins University Press, 1990.

${ }^{11}$ Latour, Bruno. Reensamblar lo social. Buenos Aires, Manantial, 2008, p.190.

${ }^{12}$ Latour habla de 4 puntos, pero el último: la conexión no es gratis, hace hincapié en el esfuerzo que requiere construir las conexiones.

${ }^{13}$ Farías, Ignacio. "Ensamblajes urbanos: la TAR y el examen de la ciudad". Athenea Digital, 2011, v.11, n.1, pp.21-22.
} 
heterogéneos y una red que es capaz de redefinir y transformar aquello de lo que está hecha"14

Las redes en la ANT se caracterizan también por no tener un centro estable y bien definido. La red es movimiento, no porque se desplace la red, sino porque se desplazan los actores, que conforman entidades diversas y esto hace de la red un espacio topológico dinámico.

Las redes son disposiciones espaciales complejas sin un centro claro ni dependientes de relaciones de diferencia jerárquicas. Por consiguiente, la metáfora de la red encaja bien con una aproximación relacional del espacio que ponga el acento en un modo no jerárquico; de pensar sobre la diferencia y de entender el espacio que constituye como algo aparentemente fluido, complejo e inacabado. ${ }^{15}$

La red, es red siempre que se componga bajo el principio de relacionalidad híbrida, es decir, las relaciones entre puntos (o entidades) se dan en una relación que no es solamente entre actores humanos sino en relaciones donde los actores (humanos y no humanos) componen entidades que conforman la propia red. Red y actor, son dos caras de la misma moneda. De esta forma, la red no es una noción que interconecte, organice o reparta entidades previamente existentes. Las redes describen las relaciones híbridas que se componen con el guión que las enlaza. La red no establece jerarquías ni relaciones fundamentales entre las entidades en relación.

Sin embargo, la noción de actor es problemática por varias causas. Primero, porque parece que remite a una "actoría" solamente humana. Segundo, porque su enunciación en singular, no le vincula con la multiplicidad de entidades que pueden ser un actor. Y por último porque parece que actor y red difieren en sus capacidades de acción dentro de un contexto dado.

La noción de actor es problemática especialmente dado el guión que vincula la agencia, la red captura el contexto social en el cual la acción tiene lugar. ${ }^{16}$

Para expresar mejor esta consideración, la teoría del actor-red se hace específica denominándose más tarde como Teoría del Actante-Rizoma complementando una noción que pretende esclarecer esta problemática.

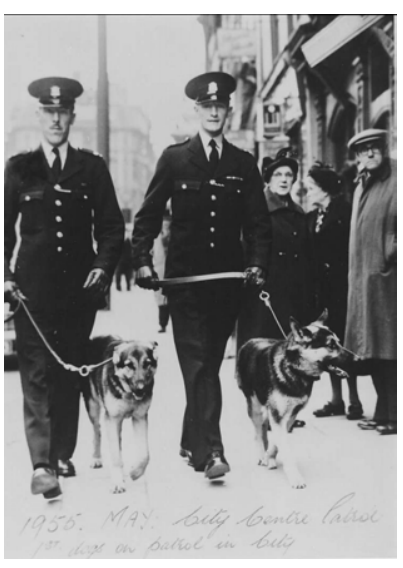

Img.01

El policía como entidad híbrida o Actor-Red de diversas entidades humanas ( el propio policía) y no humanas (el perro, las armas, las tecnologías de comunicación, ...) Imagen:. Nottingham City Police Dogs. Del archivo UK Police Dog History

\footnotetext{
${ }^{14}$ Callon, Michel The Laws of the Markets. Oxford, Blackwell and the Sociological Review, 1998, p.156.

${ }^{15}$ Law, J \& Hetherington, K. "After Networks". Guest editorial en Environment and Planning D:

Society and Space, 2000, v.18, p.127.

${ }^{16}$ Farías, Ignacio. Op. Cit., p.18.
} 


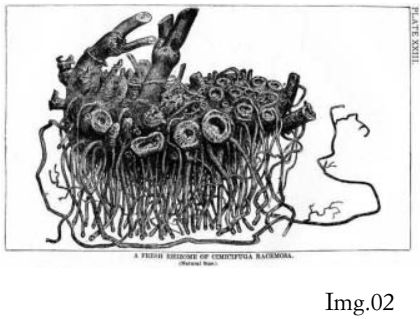

El término rizoma, es un concepto que explicaremos en el capítulo 1.5.1 desarrollado por G. Deleuze y F. Guattari en el proyecto Capitalismo y Esquizofrenia.(1972,1980). Deleuze lo llama "imagen del pensamiento" basada en el rizoma botánico.

\subsubsection{Actante-Rizoma}

Modificar la noción de actor por actante y la de red por rizoma ${ }^{17}$, podría aclarar algunas cuestiones generales. Para incorporar el papel que juega la materialidad en las sociedades que describimos, la ANT rompe las imágenes que se han utilizado para pensar por separado el sujeto humano, el objeto y la capacidad de agencia del primero. Entonces, cualquier entidad que genere un efecto de relación es considerado un agente. Los agentes-actores, en la medida en que tal palabra hace referencia a sujetos humanos y no humanos, se denominan entonces actantes.

Actante: lo que sea que actúa o mueve a la acción, siendo definida la acción como una lista de ejecuciones a través de ensayos; de esas ejecuciones son deducidas un conjunto de competencias con las que se dota al actante... ${ }^{18}$

Por otro lado la modificación del término red por el de rizoma, tendría que ver con la capacidad de cambio y mutabilidad de los actores-actantes. Para no caer en la tentación de ver la red como una estructura fija y estable, la noción de rizoma pretende dotar de continuidad al movimiento de la red. Los agentes-actantes están continuamente apareciendo, intercambiando sus lugares con otro, desplazándose, entrando en juegos de relaciones constantes dentro de la red-rizoma. Por lo tanto la agencia que se puede atribuir a un actante en un momento determinado se ve distribuida a otro actante en este juego de relaciones dentro del rizoma.

La denominación de la ANT como teoría del actante-rizoma, aunque más encriptada en su denominación, aclara dos cosas: la primera, que actor no es una entidad humana sino que se compone en una relacionalidad híbrida humana-no humana con la noción de actante; los objetos, tienen agencia y esta se denomina agencia material. Y la segunda, la red no es una entidad estable ni permanente. Está constantemente mutando en cada situación concreta donde se desvele.

El actor-red [actante-rizoma] no es reducible ni a un simple actor ni a una red. Está compuesto, igual que las redes, de series de elementos heterogéneos, animados e inanimados, que han sido ligados mutuamente durante un cierto período de tiempo. Así, el actor-red se distingue del actor tradicional de la sociología, una categoría que generalmente excluye cualquier componente no humano, y cuya estructura interna muy raramente es asimilada a una red. Pero el actor-red no debería, por otro lado, ser confundido con una red que liga de manera más o menos predecible elementos estables que están perfectamente definidos, ya que las entidades de las que se compone, sean estas naturales o

\footnotetext{
${ }^{17}$ Cfr. Latour, Bruno. "On Recalling ANT" The Editorial Board of The Sociological Review, 1999.

${ }^{18}$ Akrich, M.\& Latour, B "A Summary of a Convenient Vocabulary for the Semiotics of Human and Nonhuman Assemblies" en Bijker \& Law en Shaping Technology/Building Society: Studies in Sociotechnical Change. Cambridge, London, The MIT Press, 1992, p.259.
} 
sociales, pueden en cualquier momento redefinir sus identidades y relaciones mutuas y traer nuevos elementos a la red. ${ }^{19}$

Una vez acotada la noción de red que vamos a utilizar, su conformación por actores-actantes de entidades híbridas humanas y no humanas y su capacidad de movimiento y diseminación temporal, podemos comenzar a enunciar las bases metodológicas y las herramientas que la ANT pone a nuestra disposición.

\subsection{Asociaciones y mediaciones}

La teoría del actor-red o actante-rizoma también se denomina frecuentemente como "teoría de las asociaciones o sociología de la traducción" ${ }^{20}$ En este entorno definimos lo social como las asociaciones que elementos muy diversos establecen entre sí en un momento determinado. Es decir," lo social es la relación que se establece entre un conjunto de elementos heterogéneos." ${ }^{21}$ Entre estos elementos están los seres humanos, los significados que producimos, símbolos, discursos, objetos, artefactos técnicos, artilugios, etc. Podemos denominar a estas asociaciones como "colectivo" o "sistemas de cosas" frente a la etiqueta de una sociedad solo de humanos. Por lo tanto, la diferencia entre materialidad y socialidad se convierte desde este punto de vista en inexistente. $\mathrm{Y}$ esto es debido al proceso dinámico de significación de cualquier entidad que genere un efecto en el establecimiento de relaciones.

Las asociaciones como forma de componer la red, nos permiten dislocar las metáforas espaciales duales que han hecho del estudio de la naturaleza, la cultura, lo urbano o la sociedad como entidades separadas algo ya agotado.

Cerca y lejos, arriba y abajo, local y global, interior y exterior. Se reemplazan por asociaciones y conexiones. Esto no quiere decir que no haya nada como la sociedad "macro", o una naturaleza "fuera" como se le acusa a la ANT a menudo, pero con el fin de obtener los efectos sobre la distancia, la proximidad, las jerarquías, la conectividad, el afuera o las superficies, hay un enorme trabajo suplementario por hacer. ${ }^{22}$

\footnotetext{
${ }^{19}$ Callon, Michel. "Society in the Making: the Study of Technology as a Tool for Sociological Analysis." en Bijker, W, E. Hughes T. P. y Pinch T. J. (Eds.). The Social Construction of Technical Systems: New Directions in the Sociology and History of Technology. Cambridge, Mass, London, The MIT Press, 1987, p.93.

${ }^{20}$ Latour, Bruno. Reensamblar lo social. Buenos Aires, Manantial, 2008, p.24.

${ }^{21}$ Tirado F. \& Domenech M. "Asociaciones heterogéneas y actantes: el gripo postsocial de la teoría del actor-red" AIBR, Revista de Antropología Iberoamericana, 2005, p.10.

${ }^{22}$ Latour. Bruno. "On actor-network theory. A few clarifications plus more than a few complications." Soziale Welt, v.47, 1996, p.373.
} 

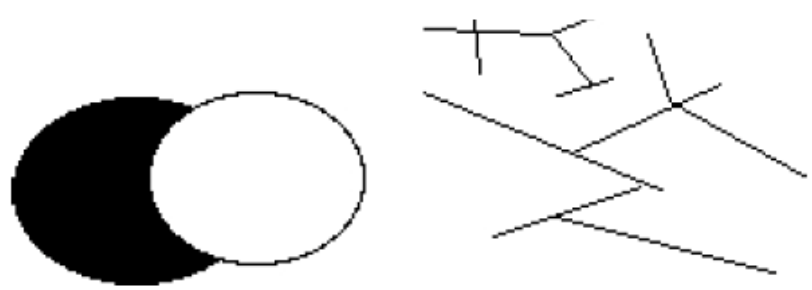

Fig. 02. Diagrama explicativo disolución exterior-interior Bruno Latour en "On actor-network theory. A few clarifications plus more than a few complications" p373

Asociaciones y mediaciones se hacen visibles en la ANT a través de los objetoscosas. Los objetos, desde esta perspectiva aparecen como una suerte de conectores que generan ensamblajes ${ }^{23}$ o agenciamientos en los que la realidad adquiere inteligibilidad. Es ahí donde aparece nuestro trabajo de investigación que no será más una explicación del por qué, ni el desarrollo de un cómo. Será más bien una descripción donde ambas preguntas están insertas. Explicar será describir, dice Latour, y la explicación emerge cuando la descripción este saturada. Entonces observaremos la definición de trayectorias, mediante la sustitución y asociaciones de agentes, definiendo agentes a través de trayectorias, siguiendo los efectos que producen, los contornos que proporcionan las conexiones-mediaciones que facilita y los efectos que inducen. No será necesario para la ANT buscar causas originales o exteriores a tal despliegue."Explicar es pliegue, es decir, despliegue, así que descripción.” ${ }^{24}$

Este sentido de la mediación en la ANT proviene de la filosofía de Michel Serres. La mediación se entiende como arbitraje, moderación, paso, comunicación, combinación, intercambio, traducción, transformación, sustitución. M. Serres ha realizado una máquina para mediar entre las mediaciones. Y está máquina da pie a la elaboración de la ANT y del concepto de mediación dando lugar a, por lo menos, tres significados: una perspectiva ontológica, una metodología y una serie de procedimientos o mecanismos como la delegación, la articulación, la traducción. ${ }^{25}$

Las mediaciones, sean estas las de traducción, composición, cajanegrización o delegación $^{26}$, son las que hacen crecer la red. Sus articulaciones pueden ser ilimitadas, conexiones de conexiones y vinculaciones y conectividades entre redes diversas. Esta situación nos plantea una pregunta importante ¿Hasta dónde llegamos con las redes? ¿Tienen límites estas mediaciones? ¿Dependen de cada

\footnotetext{
${ }^{23}$ Este término se desarrolla en el epígrafe 1.5. Ensamblajes urbanos.

24 Tirado y Montaner. Op. Cit., p.21.

${ }^{25}$ Cfr. Moreira, Gonzalo, C. "El concepto de mediación técnica en Bruno Latour. Una aproximación a la teoría del actor-red.” Psicología, Conocimiento y Sociedad, v.2, n.1, 2012, pp.54-79.

${ }^{26}$ Cfr. Latour. Bruno. "Mediaciones técnicas. Filosofía, sociología y genealogía." en Sociología

Simétrica: ensayos sobre ciencia, tecnología y sociedad. Ed. Tirado y Montaner.
} 
situación estudiada? A estas preguntas podremos responder al final de este capítulo. Hasta llegar a él, avanzamos en el desarrollo de los conceptos que nos permitirán más tarde problematizarlos.

Por el momento, en el camino de componer una red de asociaciones y mediaciones, es necesario rastrear las continuidades y discontinuidades sobre las que se forman las entidades y se genera la agencia de las mismas. La ANT ofrece una serie de herramientas para construir las redes en base a las labores de mediación que se produce en la continuidad de la acción que se investiga y la distribución de la agencia dentro de una red.

\subsubsection{La continuidad de la acción}

Habitualmente entendemos la acción como "la competencia de un sujeto que acompañado por un objeto convierte algo intencional en algo actual: llamar por teléfono, escribir una carta, etc." ${ }^{27}$ El ejercicio de la acción tiene un punto de origen y genera un movimiento que transforma un estado de cosas. En la sociología tradicional se considera a la acción del sujeto el núcleo duro de la investigación.

En la ANT, las relaciones entre entidades o actores-actantes debemos entenderlas como un proceso de mediación. La acción no puede ser estudiada en sí misma sino, como escriben Tirado y Domenech, para que la acción pueda estudiarse, esta debe hacerse sin la necesidad de un sujeto propio para la misma. "Si colocamos a la acción como el núcleo central se genera un efecto "big bang" que nos hará pensar que el origen de cualquier transformación, movimiento o definición reside en la misma." ${ }^{28}$ Entonces buscaremos causas para determinar consecuencias.

La acción en la teoría del actor red, es mediación. La acción aparece como mediación de la acción de otro. La acción, por lo tanto, es el efecto inteligible de la mediación. Las diferencias de las mediaciones o de los agentes será posible medirla entonces en términos de conectividad.

Mediación, esto es, como algo que sucede pero no es plenamente causa, ni plenamente consecuencia, algo que ocurre sin ser del todo un medio ni del todo fin. ${ }^{29}$

\footnotetext{
${ }^{27}$ Tirado y Montaner. Op. Cit., p.24.

${ }^{28}$ Ibid., p.14

${ }^{29}$ Latour, Bruno. La esperanza de Pandora. Barcelona, Gedisa, 2001, p.183.
} 
La mediación, ni principio ni fin, es entonces el proceso que garantiza también la continuidad de la acción. Esta continuidad podremos centrarla en el análisis de la disolución de los dualismos de la acción: potencia-actual o input-output. Como describe la publicación de Boltanski-Latour citada por Gaston Marmisolle sobre la hipótesis de continuidad para la ANT:

Su publicación presenta, en términos epistemológicos, una concepción de la investigación antiesencialista y dirigida a superar los dualismos fundantes de la teoría social tales como: individual- colectivo, micro- macro, adentro- afuera, sujeto- objeto, entre otros. El recurso pragmático para superar estos dualismos es el establecimiento de lo que se denomina una hipótesis de continuidad, haciendo referencia por tal a una concepción continuista de la acción que establece que, antes que como dicotomías estos dualismos, y otros, deben pensarse como uniones que se suceden en el desarrollo de la acción. ${ }^{30}$

Si las relaciones, las formas y las espacialidades se transforman en continuidad mediante la acción y la agencia de cada entidad, podemos tratar de encontrar qué mecanismos, qué entidades y qué mediaciones se producen. Estas desencadenan la continuidad de los procesos entre dichas dualidades que por lo tanto ya no lo son más. Las dualidades se reensamblan pudiéndose nombrar de otros modos. Vemos un ejemplo sencillo que elabora Boltanski en relación al dualismo individualcolectivo en su hipótesis de continuidad.

Es así que, por ejemplo, el dualismo individual-colectivo puede transformarse en el sufrimiento individual de una situación de injusticia que se instala en el espacio público con pretensiones de generalidad a través de una denuncia y, entonces, se generaliza en situación colectiva. ${ }^{31}$

En este ejemplo, la acción de la denuncia, mediada por otros actores y actantes, explicita esta condición. La acción-mediación redescribe las relaciones dualistas conformadas a priori. Esto nos permitirá enunciar en esta tesis un principio de continuidad de la acción que da lugar al reensamblamiento intro-exo.

\footnotetext{
${ }^{30}$ Marmisolle, Gaston. "La sociología pragmática de Bruno Latour" Jornadas de Sociología de la UNLP. La Plata. 2012.

${ }^{31}$ Ibid., citando a Boltanski, Luc. El amor y la justicia como competencias. Tres ensayos de sociología de la acción. Buenos Aires. Editorial Amorrortu. 2000 p.4
} 


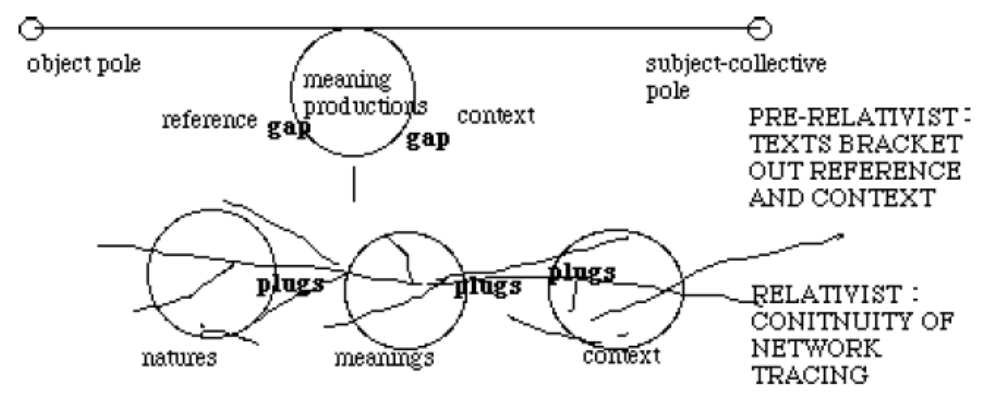

Fig. 03. Diagrama explicativo sobre la continuidad de la red. Bruno Latour en "On actor-network theory. A few clarifications plus more than a few complications" p.388

Estas relaciones intro-exo se forman por la capacidad de los agentes de detonar una acción y sus mediaciones. Dado que los agentes y las mediaciones se pueden visibilizar por su movimiento constante, es propósito de la hipótesis de BoltanskyLatour encontrar sus continuidades en esos cambios, mutaciones e interacciones. Como explica Latour:

Las relaciones entre grupos que forman asociaciones son un proceso continuo. Las interacciones están en continuo cambio. Lo social solo es rastreable cuando está experimentando modificaciones. Para que haya percepción se necesitan movimientos y ajustes continuos. Si no hay movimiento no hay sensación. ${ }^{32}$

La primera aproximación a un posible principio de continuidad es, por tanto, rastrear las continuidades que se dan en los movimientos de los actores-actantes con capacidad de acción. Como explica Tirado: "La acción está siempre desbordada, continuamente es interceptada por algún actor inesperado.[...] La acción es un nodo, un nudo en el que se encuentran diversas agencias. Es decir, la acción siempre está tomada, es traducida por otro." ${ }^{33}$ Por ejemplo: una entidadobjeto. La máxima de la teoría de las asociaciones o ANT es Follow the object! o Follow the actors! ${ }^{34}$ Rastreando el objeto y su trayectoria junto con el encuentro con otros agentes-actantes se detonan las acciones que conforman en el proceso de descripción de una red. Siguiendo las acciones podremos también describir sus lugares, sus formas, dónde se encuentran, con quién o con qué otras entidades se producen las mediaciones y en qué espacialidades y temporalidades se actualizan.

\footnotetext{
${ }^{32}$ Latour Bruno. Reensamblar lo social. Buenos Aires, Manantial, 2008, p.102.

33 Tirado, Francisco. Recensión crítica sobre el libro de Latour "Reensamblando lo social" Publicado en AIBR, Revista de Antropología Iberoamericana. Ed. Electrónica. Núm. Especial. NoviembreDiciembre, 2005, p.5.

${ }^{34}$ Cfr. Callon, Michel. "Some Elements of a Sociology of Translation: Domestication of the Scallops and the Fishermen of St Brieuc Bay." in Power, Action and Belief: A New Sociology of Knowledge. Edited by John Law. London, Routledge \& Kegan Paul, 1986, pp.196-233.
} 


\section{Ejemplo 01: Fracking, escala y continuidad de la acción ${ }^{35}$}

El concepto de escala ha diferenciado los ámbitos de la ciudad y el territorio, nombrando a estas categorías como escala urbana o escala territorial. La ubicación de una acción en una escala determinada, no nos permite entender la propia complejidad de la misma y sus derivaciones o transformaciones en continuidad. No será muy preciso entonces definir una escala concreta donde un acción ocurre cuando esta múltiplemente mediada. Será preferible describir las conexiones en continuidad de las diferentes escalas espaciales y temporales que las atraviesan. La continuidad nos dará un proceso y una trayectoria espaciotemporal que trasciende los límites tradicionales de la escala para intervenir en un proceso que se desarrolla interescalarmente ${ }^{36}$. La interescalaridad no se refiere a estar entre las diferentes escalas, sino conectado y atravesado por escalas diferentes pero continuas en la agencia de la entidad humana, objetual o no humana.

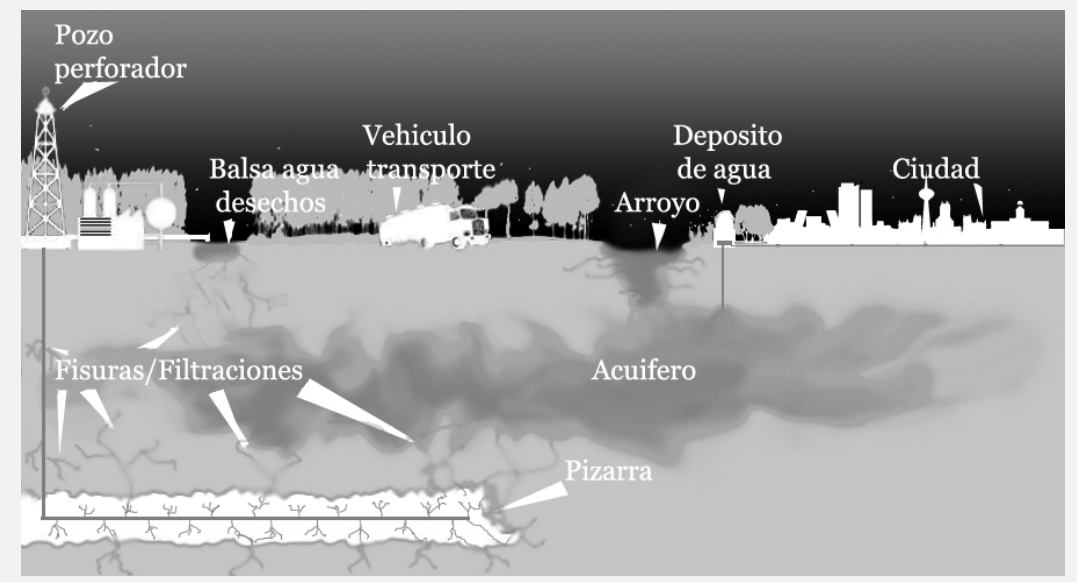

Fig. 04. Diagrama explicativo sobre la contaminación debido a la fractura hidráulica. Fuente: autopistaelectricano.blogspot.com

Un ejemplo es el de una acción (medir la contaminación del agua en el campo donde se extrae gas por la técnica del fraking o fractura hidraúlica) y dotarle de un marco escalar concreto (un territorio de un campo de cultivo: punto A) por medio de tecnologías de medición de la calidad del agua (establecer un nivel de contaminación concreto) y ofrecer un resultado concluyente (el campo no está contaminado). Pero si por el contrario, pensamos en términos de interescalaridad, la medición puede resultar muy diferente. Si desplazamos la acción de medir la contaminación de la fractura hidráulica (punto A) a un territorio más alejado (punto B) y esperamos unos meses, los resultados de la medición serán distintos.

\footnotetext{
${ }^{35}$ Para Interescalaridad ver capítulo 3.8 operatividades: Interescalaridad. El ejemplo, fue discutido por la arquitecta Nerea Calvillo en la sesión de "Contaminación del Aire" del ciclo "6 ciudades" organizado por el autor junto al Vivero de Iniciativas Ciudadanas en Madrid, La Casa Encendida, Mayo, 2014.
} 
La contaminación del agua en el punto B a distancia de la acción en el punto A y pasados dos meses, ofrece otro resultado concluyente: el agua y el campo están contaminados. Se produce entonces un resultado totalmente diferente.

Leer las continuidades de la acción en términos de interescalaridad nos permite no remitirnos a la toma de decisiones en un lugar espaciotemporal único (el campo específico y su temporalidad en punto A) sino dejar de pensar que lo distante en el tiempo y en el espacio es exterior a la acción y pensar en ella como parte de la misma acción, como el devenir de la acción.

\subsubsection{Agencia distribuida}

La continuidad de la acción entre entidades relacionales nos permite anticipar la controvertida tesis de la teoría de la ANT. Si, según el concepto de actor-red (actante-rizoma), las cosas son lo que son por las relaciones que componen y no por ninguna cualidad esencial, deberemos pensar en cuestiones clave como la agencia o la intencionalidad.

Objetos, entidades, actores, procesos -todos son efectos semióticos: nodos de una red que no son más que conjuntos de relaciones; o conjuntos de relaciones entre relaciones. ${ }^{37}$

La agencia o la capacidad de acción es una propiedad que normalmente se atribuye a los sujetos humanos en una visión sociológica tradicional, a los objetos en una visión materialista. Bruno Latour pone el ejemplo de la acción de matar con un arma al mostrar una primera posición, "Las armas matan", enfrentada a otra posición, "La gente mata a la gente, no las armas" Tanto la posición materialista como la sociológica erran en concebir un planteamiento dual y exclusivo de la acción relativa a un solo agente. Para Latour, la agencia no la posee ni el humano (agente 1), ni el arma (agente 2) sino la entidad híbrida (agente 3) que se conforma como ciudadano-pistola. La agencia o la capacidad de acción se distribuyen en la ANT entre ambas entidades humanas y no humanas.

\footnotetext{
${ }^{37}$ Law, J \& Mol, A. "Notes on Materiality and Sociality". The Sociological Review, 1995, n.43, p.277.
} 


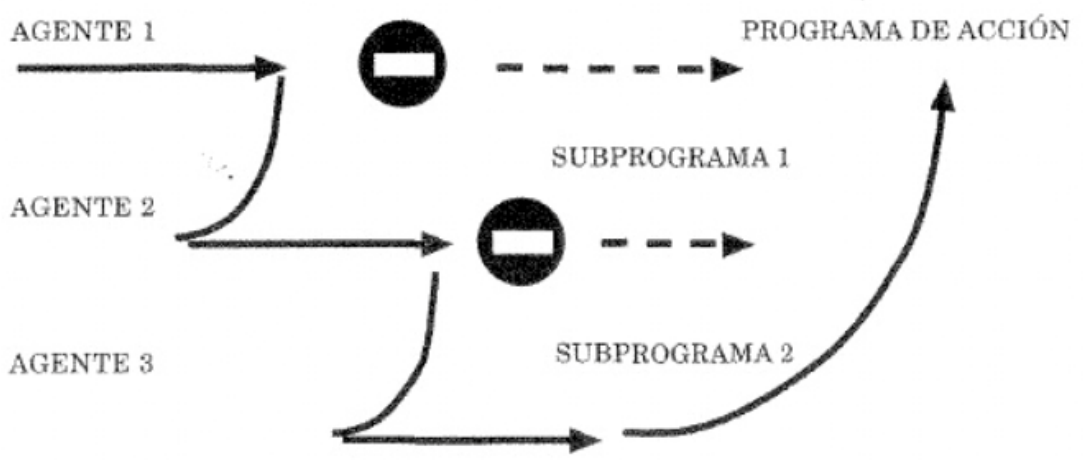

Figura 2. Segundo significado de mediación: composición

Fig. 05. Diagrama de Bruno Latour sobre el significado de mediación como composición de agentes. En Latour, Bruno. "De la mediación técnica: filosofía, sociología y genealogía." en Sociología Simétrica: ensayos sobre ciencia, tecnología y sociedad. Tirado y Montaner.(Eds). Barcelona. Gedisa.1998. p.260

Lo importante de la cuestión es poder medir o evaluar las mediaciones que el arma produce en el humano y el humano en el arma. El sujeto no permanece inalterado por el arma, al igual que el arma como objeto tampoco permanece inerte. Ambos conforman una entidad híbrida que comparten agencia y se produce una "mediación donde medios y fines se componen al mismo tiempo". ${ }^{38}$

Como este ejemplo, tenemos muchos en la vida cotidiana. Un ciudadano al volante de un coche no es igual al mismo ciudadano paseando. La agencia es diferente en ambas situaciones. Luego es muy difícil hablar solo del humano como la entidad que posee plenamente la agencia. La agencia distribuida explicita una vez más la anulación de la división sujeto-objeto. El estatus del agente-actante es susceptible de cambiar, por lo que las entidades cambian un estado real a un constructo social o viceversa. La agencia atribuible a estos actores es contextual y ajena a las rígidas categorías tradicionales. Sujeto y objeto no son más que productos localizados puntuales y emergentes en un juego de relaciones. El objeto y el sujeto se disuelven en redes de mediaciones. Es decir, los objetos también tienen agencia y en ella, un mundo. De alguna manera, "el objeto lleva inscrito un mundo, es todo un mundo y describe un mundo cuando se desplaza." ${ }^{39}$

Por otro lado, la agencia compartida o co-agencia material de un actor-actante en la ANT, tampoco es una propiedad atribuible permanentemente a una entidad. La agencia se distribuye constantemente, y esta condición puede explicitarse por la asociación y la mediación de entidades diversas. También la agencia se actualiza en el uso diario de entidades en usos no tan previstos. Por ejemplo, en el uso del

\footnotetext{
${ }^{38}$ Latour. Bruno. "Mediaciones técnicas. Filosofía, sociología y genealogía". en Sociología Simétrica: ensayos sobre ciencia, tecnología y sociedad. Tirado y Montaner. (Eds.). Barcelona, Gedisa, p. 284.

${ }^{39}$ Ibid., Recordemos aquí que la noción de "objeto" se parece más a la de "cosa" del inglés things.
} 
teléfono móvil que se diseña para hablar a distancia desde una posición no fija y termina por ser una tecnología que se usa más para escribir que para hablar.

Replantearse la figura del actor como una entidad inestable, cambiante, que se conecta y desconecta a un ensamblaje determinado, que produce una agencia también distribuida y que se compone de múltiples elementos es interesante para modificar la noción de actor (singular) por la de una entidad (que puede estar compuesta de múltiples actores) que hemos llamado actante. ${ }^{40}$ Por ejemplo, la entidad caballo, estribo, mujer amazona ${ }^{41}$ que se compone en el momento en que la mujer amazona cabalga y se descompone cuando deja de montar. Cada sujeto se ve envuelto en múltiples programas de acción junto a otros actantes cambiantes en una determinada práctica. Otro ejemplo contemporáneo muy claro lo tenemos en el policía, cuando en una labor de rastreo y vigilancia se compone una entidad formada por el humano policía, el pastor alemán, la porra y la pistola, los dispositivos de telecomunicación, etc. Componen una entidad híbrida o actante formada por varios actores.

Un único actante puede tomar diversas formas "actanciales” y, a la inversa, el mismo actor puede representar varios papeles "actoriales" . Lo mismo puede decirse de las metas y las funciones, las primeras asociadas generalmente a humanos y las segundas a no-humanos, pero ambas susceptibles de ser descritas como programas de acción-un término neutral útil cuando no se ha establecido una atribución de metas humanas o de funciones no-humanas. ${ }^{42}$

Hemos entendido que las asociaciones de entidades diversas producen mediaciones en procesos de agencia compartida y en acciones que se producen en continuidad. Vamos a ver ahora, como estas condiciones de repensar el proceso de la acción afectan a la noción de espacio en el caso concreto de las redes de la ANT.

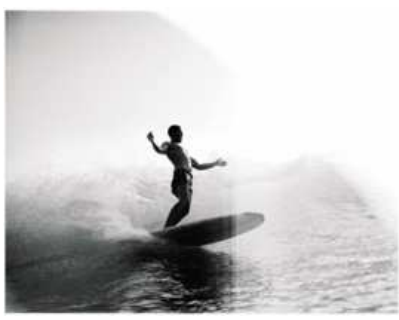

Img.03

La agencia compartida del surfista, su tabla y la ola, permite explicitar que la acción no tiene que ver con puntos de comienzo o llegada. Practicar el surf es gestionar el movimiento en la forma de entrar en una acción ya existente, como la ola. Ejemplo extraído de Tirado. F. Los objetos y el acontecimiento. Teoría de la socialidad mínima. Tesis doctoral. UAB. p 273 Imagen del libro Ron Church: California to Hawaii 1960 to 1965 .

\footnotetext{
${ }^{40}$ Esta problemática está desarrollada en Farías, Ignacio "Ensamblajes urbanos: la TAR y el examen de la ciudad". Athenea Digital, 2011, v.11, n.1, p.17.

${ }^{41}$ Ejemplo dado por Deleuze, Gilles \& Guattari Felix. Mil mesetas, capitalismo y esquizofrenia

Valencia, Pre-textos, 1980, p.93.

${ }^{42}$ Latour, Bruno. Op.Cit., p.255.
} 


\subsection{El espacio en la red}

La cuestión clave en nuestro desarrollo, una vez acotadas las aproximaciones al Actor-Red de la acción y de las atribuciones de la agencia de los actores y entidades, es la de circular por la red conformada y enunciar sus atribuciones topológicas y espaciales.

Para Michel Serres la red es una superficie imposible de geometrizar y un entorno de posiciones de entidades.

Las redes no tienen ni «dentro» ni «fuera», son sólo límite, elementos que pueden conectarse o no. Pueden entenderse como superficies imposible de geometrizar, más bien es una amalgama de conexiones y asociaciones cambiantes. Su materia son las posiciones, los vecindarios, las proximidades, las distancias, las adherencias o las acumulaciones de relaciones. ${ }^{43}$

M. Serres enuncia una condición fundamental ante la imposibilidad de geometrizar la red o dotarle de una entidad material. Sin embargo al igual que la realidad, la red es más fácilmente describible por sus conexiones, sus posiciones y estas serán difícilmente medibles, acotables o definibles.

Por ejemplo, salir de la casa, atravesar el patio o el jardín que la rodea, cruzar la puerta que da al exterior,... exigen la atención concentrada que ocurre en esos lugares saturados de pequeños hechos refinados. Para describirlos hay que utilizar con circunspección entre, en, por, ... operadores de flexiones o de declinaciones que designan, no los lugares como tales, contenidos y continentes, definidos delimitados, recortados, es decir, métricos o mensurables, sino las relaciones de vecindad, de proximidad, de alejamiento, de adherencia o de acumulación, es decir, las posiciones. El estar-ahí y sus relaciones con el exterior. ${ }^{44}$

La red se define entonces por las posiciones y su modificación. Pero si las entidades "circulan" por la red de manera continua ¿Cómo entender las dinámicas de movimientos en la propia red si es precisamente esta condición dinámica la que las conforma? La topología es la ciencia que estudia las relaciones de continuidad en las formas. La exploración de las relaciones ya no es solamente en términos de agencia y mediación, sino que la topología ofrece también explicaciones a estas transformaciones en continuidad.

\footnotetext{
${ }^{43}$ Tirado, F. J. \& Domènech, M. "Extituciones: Del poder y sus anatomías". Política y Sociedad, n.36, 2001, p. 201. Sobre las topologías en Serres, Michael. Atlas. Madrid, Cátedra, 1995.

${ }^{44}$ Ibid., p.69.
} 
La topología se ciñe al espacio, de otra forma y mejor. Para ello, utiliza lo cerrado (dentro), lo abierto (fuera) los intervalos (entre) la orientación y la dirección (hacia, delante, detrás) la cercanía y la adherencia (cerca, sobre, contra, cabe, adyacente) la inmersión (en), la dimensión,... y así sucesivamente; todas ellas realidades sin medida pero con relaciones. Antiguamente llamada por Leibniz analysis situs, la topología describe las posiciones y tiene su mejor expresión en las expresiones preposicionales. ${ }^{45}$

Lo interesante en esta cuestión es como Serres enmarca su descripción enlazando con una topología de estas relaciones-posiciones continuas. Introducir la topología como herramienta para definir las continuidades, es un ejemplo fundamental para romper las categorías de lo inmutable o inmóvil.

\subsubsection{Topología y espacialidades de la red}

La cuestión de la topología y las espacialidades de la red, ha sido un tema ampliamente desarrollado por la ANT. En especial, los trabajos de Law y Mol han incidido en las diferentes condiciones topológicas que permiten "aterrizar" los supuestos de la ANT a la realidad material. John Law, autor también de la teoría del actor red junto con Bruno Latour, Michael Callón y otros utiliza la topología para hablar de las continuidades de las formas-objetos y las relaciones y las espacialidades.

Por lo tanto, no podemos separar la cuestión topológica, de la cuestión espacial, ni esta de las entidades híbridas de humanos-objetos-cosas que hemos presentado en los puntos anteriores. Tenemos que enunciar las nociones tradicionales del espacio como algo no constitutivo de lo social, sino como un contenedor de actividades sociales, al que la arquitectura ha dedicado sus mayores esfuerzos. El espacio aparece como un fenómeno exterior que condiciona los procesos sociales, pero no que no forma parte de ellos.

Newton anunció que lo que debíamos suprimir del espacio era precisamente nuestra mirada, para poder observarlo como un mundo sin sujeto, un espectáculo sin espectadores. Aunque de esta manera, no eliminaríamos nuestra propia acción subjetiva que produce las enriquecidas miradas multifocales. Kant realiza una categorización donde sitúa al espacio como exterioridad a la que se dedican las ciencias objetivas y al tiempo como interioridad, como medida de la subjetividad, de sujeto. ${ }^{46}$ Esta posición dualiza y separa el espacio y el tiempo como objetivo-

\footnotetext{
${ }^{45}$ Connor, Steve. "Topologies: Michael Serres and the shapes of thought." Anglistik, n.15, 2004, pp. 105-107.

${ }^{46}$ Cfr. Pardo, José Luis. Las formas de la exterioridad. Valencia, Pre-textos, 1992, p.19.
} 
sujetivo. El espacio es algo independiente y exterior al sujeto para Kant. Desde la teoría de la relatividad, ya no hay observador privilegiado en el universo. Esto, en nuestra cuestión, no debe significar una ausencia de observadores, sino una ausencia del observador único y por lo tanto del objeto único a observar.

Jean Paris anuncia que "el hombre no está nunca ausente de las cosas"47 y el espacio, decimos nosotros, nunca es algo vacío. Tenemos ya dos posiciones claras. Hay miradas múltiples de muchos observadores, de objetos que son sujetos y en espacios de múltiples significados. Y nos apoyamos entonces en la fenomenología de Husserl cuando afirma que lo único que no podemos retirar del espacio es nuestra mirada, pues es ella quien lo sostiene.

Por otro lado, este problema ha sido tratado por la geografía humana y la sociología urbana. Autores como Henri Lefvbre, David Harvey, o los contemporáneos de la teoría urbana postmarxista como Eduard W. Soja o Neil Brennen han estudiado esta disyuntiva. También desde autores cercanos a los estudios sociales de la ciencia y la tecnología (STS) como Doreen Massey o Niguel Thrift. En todos ellos, hay una crítica a la concepción exterior del espacio como contenedor de las actividades y como entidad no definitoria de lo social y argumentan una concepción relativista en el que el espacio constituye "el modo como actuamos en el mundo." ${ }^{48}$

El filósofo José Luis Pardo, sostiene que el espacio aparece como la exterioridad en sentido radical. Exterior a la subjetividad, exterior al sentido y a la verdad. El espacio no existe como vacío, como contenedor.

El espacio está siempre lleno: no es nunca el receptáculo indiferente en el que un sujeto o un individuo volcarían su presencia manifiesta, su dimensión corporal o su espontaneidad discursiva, creativa o "artística" -fónica, gráfica, visual-, está antes poblado de un rumor anónimo y multitudinario, el murmullo del lenguaje mudo de la muchedumbre de las cosas (naturales y artificiales), del tráfico de los objetos y de las colecciones nómadas de hábitos. Inscribirse en él como individuo es cuestión de marcar las distancias. ${ }^{49}$

Pardo se refiere, al igual que lo hacía Serres, a la cuestión topológica de las posiciones y las distancias como "realidades sin medida, pero relacionales" ${ }^{50} \mathrm{La}$ cuestión fundamental es la distancia, pues como explica D. Harvey lo que queda

${ }^{47}$ Cfr. Paris, Jean. El espacio y la mirada. Madrid, Taurus, 1967.

${ }^{48}$ Cfr. Malpas, Jeff "Uncovering the space of disclosedness: Heidegger, technology and the problem of spatiality in being and time." en Heidegger, authenticity and modernity. Mark A. Wrathall y Jeff Malpas, (Eds.). Oxford, MIT Press, 2000.

${ }^{49}$ Pardo, José Luis. Op. Cit., p.19.

${ }^{50}$ M. Serres. Op. Cit., Atlas. 
cuestionado fundamentalmente es la noción de distancia, pues no hay un punto de vista externo desde el que determinar absolutamente las distancias. ${ }^{51}$ Estas distancias sólo pueden medirse en términos de procesos y actividad. "Las relaciones de cercanía o lejanía, propiedad o de exterioridad no son distancias objetivas medibles ni distancias mentales. Son distancias pragmáticas que dependen de los modos de hacer propios de una época, es decir, de sus prácticas, discursos y tecnologías" ${ }^{52}$ La ANT, por lo tanto, se aventura como una caja de herramientas que también tiene mucho que decir sobre esta cuestión. El "paradigma relacional" y las nociones de distancia que situaba Harvey se ve desafiado por la ANT de diversos modos.

-Como hemos argumentado, la heterogeneidad de entidades y la mirada simétrica humana-no humana sobre la composición de actantes, mediaciones y agencias distribuidas reelabora las nociones de distancia. Esto supone un desafío para repensar las espacializaciones del Actor-Red

-El segundo desafío está en el argumento de Law sobre pensar el espacio, más allá del espacio absoluto y abstracto, como una topología social. "El espacio aparece como el producto de una articulación de elementos heterogéneos sin presuponer de antemano ninguna relación ontológicamente más fundamental entre ellos"s3

Pero ¿por qué referirnos a nuestro entorno como espacialidades en vez de simplemente espacio? $\mathrm{Si}$, en el mundo contemporáneo, podemos argumentar que no nos es posible habitar la casa en el sentido de Heidegger o habitar la ciudad, como entidades estables, ni el espacio público y ni siquiera nuestro espacio doméstico, solo nos es posible hoy habitar nuestras prácticas ${ }^{54}$. "Y ellas se desarrollan en espacialidades y temporalidades múltiples y con agencias y materialidades diversas" $" 55$.

Podemos entonces observar cómo se componen las prácticas urbanas y cómo entonces pueden defender empíricamente las consideraciones que estamos haciendo a través de las herramientas de la ANT. Por un lado, al hablar de las prácticas, debemos considerar no sólo el espacio, sino también el tiempo como un producto en el proceso de la acción. No entender el espacio ni el tiempo sin la

\footnotetext{
${ }^{51}$ Para ampliar estas nociones de distancia también ver Fdez. Valderrama, Luz. La construcción de la mirada: tres distancias. Sevilla, Universidad de Sevilla, 2004.

52 Cfr. Harvey, David. Explanation in geography. E. Arnold, London, 1969.

${ }^{53}$ López, Daniel. "Aplicación de la teoría del actor-red al análisis espacial de un servicio de teleasistencia domiciliaria.” AIBR. Revista de Antropología Iberoamericana, Ed. Electrónica. Num. Especial, Noviembre-Diciembre, 2005, p.3.

54 Gil-Fournier, Mauro. "HotRods y Lowrider: habitando una práctica" La Ciudad Vida, Rev. electrónica, 2013. Descargable en: http://www.laciudadviva.org/blogs/?p=17529

${ }^{5}$ Nos serviremos del caso de estudio de Daniel López Gómez. Op.Cit., López, Daniel.
} 
experiencia de la acción. Cada práctica, relación o experiencia, por lo tanto, produce su propio espacio-tiempo junto al resto de entidades.

Las prácticas involucran personas y su entorno material reconfigurando los ritmos y tiempos biológicos del día a día, así como diferentes lugares y espacios, de la esfera doméstica a los espacios públicos urbanos. Objetos y cuerpos, con sus trayectorias y sus sentidos, constituyen y particularizan espacios, produciendo ensamblajes particulares de continuidades y discontinuidades, en un proceso de cambio dinámico, donde las controversias y los conflictos pueden emerger cuando los movimientos, e intenciones de la pluralidad de objetos y cuerpos se encuentran. ${ }^{56}$

Para desarrollar esta condición de las espacialidades de las prácticas lo mejor es que lo desarrollemos con un ejemplo: la práctica del tuneo de coches.

\section{Ejemplo 02: El tuning como práctica espacial ${ }^{57}$}

La práctica se configura como un ensamblamiento de múltiples agencias: un individuo (y su autoemparejamiento humano ${ }^{58}$ ), una comunidad de intereses y afectos entorno a la práctica, el coche un objeto móvil (autoemparejamiento tecnológico), unos conocimientos (los propios del tuneo), unos media asociados, programas de TV, internet, etc. El proceso de puesta en marcha de esta práctica construye un espacio dinámico no a partir de la supresión del espacio objetivo sino como la resultante de diversas articulaciones singulares entre elementos heterogéneos.

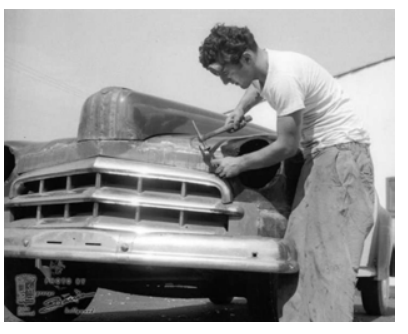

Img.04

George Barry, trabajando en la conversión de su auto en los años 30 en California, EEUU. Su práctica espacial, esta descrita en el libro de Tom Wolfe,

El coqueto, aerodinámico rocanrol, color caramelo de ron. Barcelona. Tusquets. 1972

\footnotetext{
${ }^{56}$ Lasén, Amparo. "Rhythms and flow. Timing and spacing the digitally mediated everyday." Forthcoming publication. Handbook of children and youth studies. London, 2015, p.1.

${ }^{57}$ Presentado por el autor en el congreso de sociología ordinaria II. Madrid, Mayo, 2014.

${ }^{58}$ La noción de autoemparejamiento humano y tecnológico de Peter Sloterdijk se argumenta en el capítulo 2.2 Covecindad. Pero consideramos interesarte referenciarlo ya aquí sobre esta práctica del Tuneo para comenzar a entender la complementariedad de la ANT y las Espumas.
} 
Si situamos la práctica en la ciudad de Madrid, por ejemplo, podremos ver como muchas de estas personas habitan en la periferia de la ciudad, en las suburbanizaciones que son tan urbanas o más que la ciudad misma. Su práctica diaria se desarrolla en torno al tuneo. En el coche, transitan por múltiples territorios, dando lugar a una primera espacialidad territoriales diversa. Allí comen en los Mac-auto y todos sus derivados, cines drive-in, ir de compras. En el coche comen, duermen, fornican, es decir, muchas acciones asociadas a lo doméstico suceden en el objeto móvil coche que se configura como mediador, un dispositivo con agencia propia. El coche se convierte entonces en el lugar de lo doméstico. Por otro lado, el coche transita por las gasolineras, donde se consume más que la gasolina que los alimenta. Los talleres de coches que se convierten en lugares de estancia donde se aprende y se experimenta con los tuneos. Los descampados de la periferia donde se crean nuevos espacios públicos asociados a la noche y al coche. Las carreras y la velocidad como motor de la práctica.

En definitiva, una multitud de espacialidades a diferentes velocidades que se convierten en el tránsito y puntos de paso de su habitar contemporáneo no asociado ya a una casa o un territorio concreto sino a las trayectorias entre ellos. La casa familiar de los jóvenes ha dejado de ser el lugar de configuración y desarrollo identitario personal que se ha trasladado al coche. El coche opera, como diría Sloterdijk, en la cápsula móvil de insulamiento. Y el coche es también el objeto de estudio que desvela la red de espacialidades que construye la práctica. La entidad humano-coche-tuning se produce en la performación de diferentes espacialidades en dicha práctica.

De esta manera, el espacio al igual que la red, se convierte en algo imposible de geometrizar. Entender el espacio como una superficie que se contrae y se expande lo convierte en algo dinámico. Pero siguiendo a Law y Mol podemos configurar otra topología para entender cómo se constituyen aparecen y desaparecen las diferentes espacialidades por las que transitan nuestros tuneadores. Al igual que la continuidad de la acción en la ANT la topología del espacio también tiene sus continuidades. Para Law y Mol las espacialidades podrían presentarse con los atributos de una topología del fuego.

El primero: continuidad como un efecto de la discontinuidad; Segundo: continuidad como la presencia y la ausencia de la otredad; y tercero continuidad como el efecto de un patrón estelar de esta simultaneidad entre ausencia y 
presencia: estos son los atributos de la constancia que imaginamos en una topología del fuego. ${ }^{59}$

En el primer atributo podemos pensar en cómo la continuidad en la conformación híbrida del ciudadano-coche que se produce en el tránsito de diferentes discontinuidades territoriales y físicas. En un segundo lugar, la continuidad la presencia y la ausencia de la otredad la podemos ver manifestada en el propio coche tuneado por el sistema de medios, talleres y conocimientos que han hecho de ese coche en particular lo que es. Y por último la continuidad como efecto de un patrón estelar donde la unidad ciudadano-coche es el centro de todas las diferentes presencias y ausencias de las espacialidades por las que ha transitado en su práctica.

Entonces no significa solo que la circulación de la entidad ciudadano-coche en las carreteras, gasolineras, talleres, espacios públicos y domésticos se realiza a través de diferentes espacialidades, sino que en cada caso, lugar, proceso, el ciudadanocoche junto al resto de entidades producen un "espacializar". Una atmósfera particular, que se coproduce en esta relacionalidad híbrida de entidades.

\subsubsection{Espacializar ${ }^{60}$ y la topología fluida de la red}

Podemos concretar en tres puntos las condiciones de coproducción de estas espacialidades dentro de la red de actores específica que se describa. Estos puntos pueden aportar los atributos necesarios para llegar a una concepción de la red, como topología fluida.

Primero tendríamos que decir siguiendo a Law y los teóricos de la ANT, que el espacio no está a priori en el orden de cosas: esta performado: "El espacio se hace. Es una creación. Es un resultado material. Como los objetos, los lugares o los obligatorios puntos de paso. Es un efecto. No existe fuera de su performatividad." ${ }^{\prime 1}$

Segundo, que los objetos, como el material del que está hecha la continuidad, son heterogéneos y están ensamblados en redes. El argumento de los teóricos de la ANT es que cuando un objeto-red esta performado todo un mundo-red está siendo enactado ${ }^{62}$. El mundo-red es un topos.

\footnotetext{
${ }^{59}$ Law, John, \& Mol, Annemarie. "Situating technoscience: An inquiry into spatialities". Environment and Planning D: Society and Space, n.19, 2003, p.619.

${ }^{60}$ Latour, Bruno. "Trains of thought. Piaget, formalism and the fifth dimension." Common Knowledge. 1996, v.3, p.179

${ }^{61}$ Law, John. "Materialities, spacialities, globalities" Centre for Science Studies. Lancaster, 2003, p.9.

${ }^{62}$ Enactado es una traducción del Inglés Enact que se asume en los textos científicos en castellano de

la ANT, que podría situarse también como sinónimo de performar.
} 
Tercero, que los objetos no se mueven en el espacio, sino que lo crean. Pero desde que los objetos son entidades en red cuyos elementos incluyen espacialidad, los espacios crean también lo que el objeto es. La co-construcción de espacios y objetos permite indefinidas posibilidades de continuidad.

Law, en base a estos tres modos de repensar la noción de espacio se pregunta por la continuidad de las mismos y las posibilidades para poderlos definir. "La topología es un juego matemático que explora las posibilidades y propiedades de diferentes formas de continuidad-y los diferentes espacios que expresan o permiten esas continuidades. $\mathrm{Y}$ hay, en principio, un número de caminos indefinidos para definir la continuidad espacial” ${ }^{33}$ Así que si establecemos una continuidad también entre objetos y espacios, pues ambos se co-construyen mutuamente en una relación de topología, debemos asumir los siguientes puntos ${ }^{64}$.

1. Un nodo (cualquiera de la red) y su territorialidad, donde el actor establece su red relacional, está simultáneamente enactado. No hay nodos en la red por un lado y objetos sin espacio por otro. hay redes heterogéneas de entidadesnodos y espacios performativamente enactados.

2. Tenemos que aceptar que el resultado de esta co-construccion es indefinida, o más bien, no hay un ensamblaje de un actor-espacio que existe, sino un actante múltiple. La forma, el contenido y la extensión depende de la performatividad continua establecida por los nodos y su co-creada espacialidad.

3. También tenemos que aceptar que la definición de nodo y espacio es oblicua. Si objetos y espacios están juntos al mismo tiempo en un campo topológico que multiplica y redefine espacialidad y objetividad, entonces los objetos y espacios son ellos mismos una constelación fluida de elementos en constante re-delineación.

Estas tres últimas acepciones apoyadas en las investigaciones teóricas de John Law 65 nos argumentan la continuidad entre objeto y espacio como relaciones topológicas en un sistema de redes de relaciones, performatividades y enactaciones.

\footnotetext{
${ }^{63}$ Law, John. After Method: Mess in Social Science Research. London, Routledge, 2004, p.4.

${ }^{64}$ Estos puntos están explicados por Manuel Tironi en Urban Assemblages. How actor-network theory change urban studies. Farías Ignacio. \& Bender, Thomas. (Eds.). London, NY, Routledge, 2010, pp. $27-52$.

${ }^{65}$ Los textos fundamentales en este desarrollo son los tres citados anteriores de John Law.
} 
Luego para la ANT el espacio es parte del juego de relaciones y no existe fuera como algo exterior a ella. De este modo, hemos pasado de la noción de espacio de la modernidad a hablar de las determinadas espacialidades que se conforman en una práctica-red (como los tuneadores). Y junto con J. Law a mirar el espacio como una coproducción de relaciones híbridas que se performa en cada juego de relaciones. Luego el siguiente modo de entender el espacio pasaría por no pensarlo desde un atributo nominativo, ni descriptivo, sino como una acción que se puede verbalizar. Un proceso dinámico, de apariciones y desapariciones que, sucede en las prácticas cotidianas.

Según la ANT, la cuestión del espacio es también una cuestión del "espacializar". Esta noción es intrínseca al actor-red y a la constitución de las topologías que hemos descrito para la red.

Las redes son disposiciones espaciales complejas sin un centro claro ni dependientes de relaciones de diferencia jerárquicas. Por consiguiente, la metáfora de la red encaja bien con una aproximación relacional del espacio que ponga el acento en un modo no jerárquico de pensar sobre la diferencia y de entender el espacio que constituye como algo aparentemente fluido, complejo e inacabado. ${ }^{66}$

De esta manera, la concepción del espacio que ofrece la ANT es flexible, compleja y fluida pero también singular, ordinaria y cotidiana. El espacio es una superficie que se pliega o se estría pero siempre lo hace en una configuración o bajo un guión determinado y específico de entidades heterogéneas. El espacio-red es una composición de elementos técnicos, políticos, naturales que lo constituyen.

Para argumentar esta idea, retomamos la preocupación de la ANT por la espacialidad y su continuidad, en el sentido de que estas continuidades tienen formas muy variadas. "El punto importante aquí es que la espacialidad no viene dada. No viene fijada de antemano. Más bien, tiene lugar de formas muy variadas." ${ }^{" 67}$

Este interés de la ANT no es nuevo. Lo que sí es novedoso es la particular investigación de Law y Mol para "aterrizar" la universalidad de los hechos científicos y desmontar las normatividades de la epistemología clásica. "La novedad que introduce la topología, sin embargo, es tratar esta espacialidad de las redes como una forma privilegiada de explorar la relacionalidad de las mismas, es

\footnotetext{
${ }^{66}$ Law, J \& Hetherington, K. "After Networks". Guest editorial en Environment and Planning D: Society and Space, 2000, v.18, p.121.

${ }^{67}$ Law, John y Hassard, John, (Eds). Actor network theory and after. Oxford, Blackwell, 1999, p.6.
} 
decir, de abordar empíricamente, y a partir de su conectividad espacial, su amplia performatividad." ${ }^{\prime \prime}$

Como hemos mencionado en el punto anterior, es importante resaltar que la condición del "espacializar" va ligada a la noción de la temporalidad. En una topología fluida tenemos que manejar el concepto temporal pues los cambios, sean estos rápidos o lentos, se producen en su performatividad.

Los tiempos y los espacios, si aparecen, están performados juntos. Este es un hecho de gran importancia [...] que revela que las espacilidades se pueden manifestar solo en relaciones de uno con otra. ${ }^{69}$

Hemos hecho un breve recorrido que nos ha llevado de la noción de espacio como contenedor abstracto y euclidiano, a las nociones de espacialidad topológica dentro de una red para llegar a proponer una noción no nominativa del espacio como algo verbalizable. "El espacializar" (Spacing) se coproduce con el temporalizar (timing) en la acción (acting) ${ }^{70}$ que forman la performación de estos dos procesos junto con las entidades híbridas, cosas, objetos, etc que la componen. Podemos confirmar este supuesto con el siguiente ejemplo de práctica o acontecimiento urbano.

\footnotetext{
${ }^{68}$ Rodríguez-Giralt Israel. "De redes y otros enredos: acerca de la ontología política de la red". en Teoría del Actor Red. Más allá de los estudios de la ciencia y la tecnología. Tirado, Francisco y López Daniel (Eds.). Barcelona, Amentia, 2012, pp.370-395.

${ }^{69}$ Law, J. \& Mol, A. "Spacialities of globality . Situating technoscience: An inquiry into spatialities." Environment and Planning D: Society and Space, n19, 2003, p.615.

${ }^{70}$ Cfr. Lasén, Amparo. "Rhythms and flow. Timing and spacing the digitally mediated everyday". Forthcoming publication. Handbook of children and youth studies. London, 2015.
} 


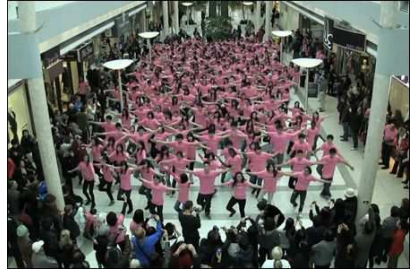

Img.05

Imagen de una flashMob en el interior de un centro comercial de Corea de Sur. 2012.

\section{Ejemplo 03: Las FlashMobs ${ }^{71}$}

$\mathrm{Si}$ pensamos en las actuales flashMobs como prácticas o acontecimientos performados en cualquier lugar y tiempo podemos entender la idea de acontecimiento ya no asociados a un programa determinado sino a la agencia distribuida de entidades múltiples que componen el evento, en cualquier situación previamente dada. De hecho, la experiencia de las flashMobs es interesante pues como dispositivo efímero y translocal, ofrece una visibilización de esferas no compartidas en otros ámbitos, como son los interiores de las oficinas, universidades, casas, etc. poco visibilizadas en otros ámbitos. Es decir las flashmob como acontecimiento múltiple, son transversales a cualquiera de las tradicionales formas de la exterioridad ${ }^{72}$ y presentan la imbricación y materialidades de las tecnologías digitales en el espacio público.

Las flashMobs traducidos literalmente como "multitud relámpago" son "un encuentro público de gente extraña organizado desde internet que se concentra para hacer un acto inusual e inútil para después dispersarse de nuevo"73 Estas performaciones son globales, aparecen en casi cualquier lugar del planeta, y a la vez se localizan específicamente con la presencia física de los cuerpos que las encactan. Son efímeras, casi inmediatas en su convocatoria e instantáneas en su presencia. Más tarde se distribuirán y compartirán mediante los dispositivos tecnológicos que permitirán que otros públicos no presentes en el evento participen a distancia espacial y temporal del mismo. Estas flashMobs instantáneas podrían ejemplarizarse como la maximización de la idea de acontecimiento en la tecnosociedad urbana de la inmediatez. Las flashmobs son acontecimientos volátiles y prácticas urbanas que visibilizan la idea del "espacializar" como acontecimiento performado por múltiples actantes, humanos, objetos, tecnologías, que a priori no conforman ningún espacio en particular. El espacializar es la aparición del hecho espacial en relación híbrida con el resto de entidades, agencias y mediaciones. Podemos entonces considerar a las flashmobs como un acontecimiento global que se performa en entornos locales bajo la mutabilidad de una topología fluida en los términos argumentados por J. Law.

\footnotetext{
${ }^{71}$ Ibid.,

${ }^{72}$ Insistimos en que denominamos Formas de la exterioridad, a las enunciadas por José Luis Pardo como cuerpo, casa, espacio público, ciudad, territorio y naturaleza.

${ }^{73}$ Definición de wikipedia en castellano. https://es.wikipedia.org/wiki/Flashmob
} 


\subsubsection{In/Mutables In/móviles}

Hemos argumentado hasta ahora una idea de espacio en movimiento, unas espacialidades en la red y un "espacializar" como resultado de una performación de entidades heterogéneas. Pero en este proceso, nos hemos dejado algo que no mute, que conserve las propiedades de comunicación de un punto a otro, que sea capaz de transportar la información para sostener la configuración inicial. Algo que sea inmutable, pero también capaz de desplazarse en el espacio y en el tiempo: el "móvil inmutable."

En el mismo momento que la ciencia se fue regionalizando surgió un nuevo problema. ¿Cómo se propaga? ¿Cómo podría ser transportado? Haciéndose eco de un tropo contemporáneo común, la primera respuesta importante a esta pregunta era hablar de las redes. [...] Esto, entonces, fue una segunda expresión de la metáfora de la red. La configuración heterogénea de personas y dispositivos que componen un laboratorio - esto también tuvo que ser transportado. Lo que llevó a la noción del móvil inmutable: la que se mueve a través del espacio regional mientras mantiene su forma. De esta manera, entonces, 'lo global "se entendía como una red para transportar formas invariables: información, descubrimientos científicos, artefactos tecnológicos. Una nueva forma de lo espacial nació. ${ }^{75}$

En el caso de la ANT, las redes científicas, centralizadas y descentralizadas, privadas y estrechas y los dispositivos de telecomunicación y tele-acción, son, al mismo tiempo, las que extienden las formas de representación y performación de la ciencia. La noción que la ANT tiene para esto, es la de móvil inmutable. Los móviles inmutables viajan en el espacio de las redes, para aparecer de nuevo en otras espacialidades y localizaciones en puntos dispersos de lo global. Para situar la definición de Móviles Inmutables tenemos que desarrollarlo en términos de lo que es una inscripción, en términos de mediación que hace la sociología de la traducción.

Inscripción, es un término general que hace referencia a todo tipo de transformaciones. A través de las cuales una entidad se materializa en un signo, en un archivo, en un documento, en un trozo de papel, en una huella. Siempre son móviles, es decir, permiten nuevas traducciones y articulaciones, aunque dejan intactos algunos tipos de relaciones. De ahí que se llamen móviles inmutables. $^{76}$

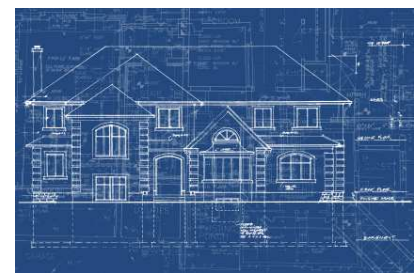

Img.06

Un plano de arquitectura es un móvil inmutable, una inscripción mediante la cual se conservan y se da continuidad a las decisiones de diseño de un proyecto, al igual que un archivo digital de cad.

\footnotetext{
${ }^{74}$ Cfr. Latour, Bruno Science in Action: How to Follow Scientists and Engineers Through Society. Milton Keynes, Open University Press, 1987.

${ }^{75}$ Law \& Mol." Spacialities of globality. Situating Technoscience: an Inquiry into Spatialities"

Environment and Planning D: Society and Space. n.19, 2003, p.619.

${ }^{76}$ Latour, Bruno. La esperanza de Pandora. Op. Cit., p.365.
} 
Si los edificios y las arquitecturas son tecnologías ${ }^{77}$ pueden referirse a la misma categoría ontológica que los móviles inmutables de Latour como objetos estabilizados mediante inscripciones, para performar las mismas acciones en localizaciones diferentes, que operan de manera independiente a su contexto. Pero la noción de móvil inmutable, es algo que no se puede explicar sin la noción de red y viceversa, pues también implica una forma de espacialidad.

El argumento es que una red de actantes también implica una forma estable junto con el espacio de la red. Los dos se sostienen juntos. La espacialidad es un aspecto de la estabilidad de la red. ${ }^{78}$

En el ejemplo que describe J. Law sobre los barcos Portugueses que hacían la ruta de Lisboa a Calcuta en el siglo XV, explicita la "trampa" de Latour con esta noción. El móvil inmutable participa de dos espacios diferentes. El barco se mueve en un espacio euclidiano, y a su vez el barco es una entidad que compone la red. La inmutabilidad pertenece al espacio de la red, pero también es la que posibilita que el barco llegue a Calcuta y se desplace, pues el barco en sí mismo no cambia, es inmutable. La movilidad pertenece al espacio euclidiano, pues permite enlazar dos localizaciones distantes. De este dilema entre ambos tipos de espacio, el euclidiano y el de la red, nace la noción de topología fluida, que hemos explicado en el punto anterior.

Si pensamos en la idea del móvil inmutable y la transferimos a la arquitectura podemos ver como una de las características de la arquitectura, como forma construida estable, es precisamente su inmovilidad euclidiana. Su anclaje al suelo, por medio de las cimentaciones, hace de ella un objeto inmóvil. Se sitúa en un entorno fijado aunque cambiante, pero sus referencias geográficas se mantienen estables. Es por ello un Inmóvil mutable ${ }^{79}$. Pues en el espacio de la red tiene capacidad de cambio y adaptación aunque está limitada su capacidad de movilidad geográfica. Son estables localmente por su anclaje geográfico pero son mutables y por lo tanto inestables debido a las redes de co-vecindad que las sitúan. Las condiciones de uso, apropiación o apertura están conectadas a un entorno cambiante, local y globalmente, y actúan con un grado de singularidad mayor o menor según el caso.

\footnotetext{
${ }^{77}$ Cfr. Guggenhaim, Michael. "Inmovile mutable. Building conversion as a problem of quasitechnologies." en Urban Assemblages. How actor-network theory change urban studies. Farías, Ignacio. \& Bender, Thomas.(eds.). London, NY, Routledge, 2010.

${ }^{78}$ Law \& Mol. Op. Cit., p.612.

${ }^{79}$ Guggenhaim, Michael. Op. Cit., p.163.
} 
Cabría preguntarnos que, en las condiciones contemporáneas donde los edificios aparecen de manera simultánea y ubicua en cualquier parte del globo, ¿Cómo se construyen los enlaces en la red para considerar a la arquitectura como un inmutable móvil cuando a su vez aparecen en objetos que se desarrollan como inmóviles mutables? Pues cada edificio o construcción puede variar de muchos modos diferentes y adaptarse a localizaciones geográficas y culturales diferentes

McDonalds, con frecuencia citado como el estándar de oro para la uniformidad global, revela variaciones impresionantes ya que se mueve de un sitio al siguiente. Si tiene éxito, no es porque la fórmula es rígida. Es precisamente debido a que puede cambiar de forma. Estos son, pues, los desplazamientos que dependen de la mutabilidad en lugar de, o además de, la inmutabilidad. Entendido de esta manera, la globalización no es solo acerca de las redes sino de los sistemas fluidos. Acerca de los movimientos que van más fácilmente si hay menos control. Sobre las cosas que asumen la forma de su entorno. Que son adaptables. ${ }^{80}$

Luego la idea del móvil inmutable, es también una idea arquitectónica para su discusión y configuración. Los móviles no son solo objetos, son protocolos, ficheros, hojas de datos, que permiten extender un determinado conocimiento a otros lugares. Al igual que en la ciencia la arquitectura opera por un control desde la lejanía: planos, protocolos de diseño, etc. A su vez, los propios edificios son también objetos que inscriben las políticas y conocimiento de cada estudio, oficina o arquitecto junto con el resto de entidades que participan en ella. El móvil inmutable o el inmóvil mutable son de nuevo, dos caras de la misma moneda, como el actor y la red. ${ }^{81}$

Tras haber argumentado las nociones de red que vamos a utilizar y la idea de espacio que estamos tratando, podemos explorar ahora qué tipo de entidades se constituyen como entidades sin exterior que nos ayuden a comprender como las redes de la ANT despliegan herramientas aplicables a casos concretos y que pueden ser transferidas también al ámbito de la arquitectura.

\footnotetext{
${ }^{80}$ Law \& Mol. Op. Cit., p.619.

${ }^{81}$ Sobre los móviles inmutables e inscripciones de las oficinas de arquitectura ver: Yaneva, Albena. The Making of a Building: A Pragmatist Approach to Architecture. Berna, Peter Lang, 2009.
} 


\subsection{Entidades sin exterior}

Podemos entender un laboratorio como una isla-invernadero ${ }^{82}$ climáticamente controlada que se cierra a un contexto existente, aséptico, encerrado, encapsulado, interior y aislado del mundo. Un lugar al que llegan recortados fragmentos de realidad de afuera y donde se analizan estas muestras recortadas desde la posición de un observador exterior. Es decir, un lugar que se cierra al exterior delimitando claramente su perímetro físico y observacional: un lugar aislado. Pero esta es una noción imposible por tres motivos: no es posible recortar fragmentos de realidad, tampoco es posible trasladarlos ni observarlos desde el exterior.

Por el contrario, el laboratorio es un lugar sin exterioridad tal como explica B. Latour. Un lugar que nos interesa por la manera que tienen de interactuar las cosas, los objetos, los hechos científicos, los protocolos y las tecnologías para describir ciertas realidades y ponerlas en juego con otros contextos. De manera, esquemática, ejemplificaremos esta ausencia de exterioridad en el caso del laboratorio Pasteur de París, donde en 1881 desarrolla la invención de la primera vacuna, y que investiga Bruno Latour ${ }^{83}$.

En el estudio de este caso, vemos que las categorías dentro-fuera, micro-macro o escala grande-pequeña son poco útiles para la descripción de lo que allí pasaba. En el laboratorio se daban una serie de acontecimientos que diluían estas categorías.

El laboratorio tenía un interés social sin precedentes: la interferencia de periodistas, científicos, médicos e higienistas que entraban cada día en el laboratorio para interesarse por el estado de las colonias de microbios; la capacidad de Pasteur de conseguir recursos para su investigación; la innovación de escalar, visibilizar y aislar el bacilo para la vacuna; la implementación de la vacuna en las primeras granjas francesas. Es decir, toda una serie de relaciones mediadas que reubican constantemente el lugar del laboratorio. Tras el aislamiento del bacilo y la puesta en marcha de la vacuna, el laboratorio de Pasteur está ahora en medio de unos intereses agrícolas con los que antes no tenía ninguna relación. En las granjas se ha añadido un elemento que viene de París: los frascos de la vacuna. Los veterinarios han cambiado su estatuto al promocionar la ciencia de Pasteur y los frascos de vacunas. Ahora tienen un arma más en sus maletines, y ovejas y vacas

\footnotetext{
${ }^{82}$ En el capítulo siguiente Espumas se define con detalle las concepciones que hacemos en esta tesis sobre el significado de Isla y la de Invernadero en sus diversas acepciones.

${ }^{83}$ Cfr, Latour, Bruno. "Give me a laboratory and I will raise the world" Science observed: Perspectives on the social study on science. London, Sage, 1983, pp.141-170.
} 
se han librado de una muerte terrible. ${ }^{\$ 4}$ De todo esto podemos ver como el laboratorio se colocaliza ${ }^{85}$ en múltiples localidades.

La indistinción dentro-fuera es irrelevante porque "el laboratorio se sitúa de tal modo que puede reproducir con precisión dentro de sus muros un evento que parece estar sucediendo sólo fuera (primer movimiento) y luego, extender fuera, a todas las granjas, lo que parece estar sucediendo sólo dentro de los laboratorios. Como en algún teorema topológico, el mundo interior y exterior puede intercambiarse mutuamente con facilidad. Obviamente, en sus tres relaciones: fuera, dentro, fuera de nuevo." ${ }^{86}$ Por último, "para que la vacuna sea efectiva, tiene que extenderse fuera, en el mundo real de ahí fuera, como dice la gente. Esta es la mejor muestra de lo absurdo de la dicotomía dentro/ fuera y de la utilidad de los micro estudios de la ciencia para comprender macro problemas." ${ }^{" 77}$ De aquí la idea del arquitecto Andrés Jaque de la casa, lo domestico o lo hogareño es el laboratorio donde se ponen a prueba los objetos, las políticas o las disidencias.

Para Latour hay dos ideas principales sobre la ausencia de exterior del laboratorio a parte de las ya mencionadas. La primera es que la vacuna al principio no funcionaba fuera del laboratorio. Los hechos salen del laboratorio con la extensión de las prácticas del laboratorio. La segunda es la existencia misma de la enfermedad del ántrax, en primer lugar, y la eficacia de la vacuna al final de la historia, no son hechos "externos" dados para que todos los puedan ver. Son, en ambos casos, el resultado de la existencia previa de instituciones estadísticas que han construido un instrumento (en este caso la estadística), han extendido sus redes a través de toda la administración francesa para recoger datos, y han convencido a todos de que había una " "enfermedad", una "enfermedad terrible", y de que había una "vacuna", una vacuna "eficaz". Normalmente, cuando hablamos del mundo externo, estamos simplemente dando por supuesta la extensión previa de una ciencia anterior construida sobre el mismo principio que vamos a estudiar. Por esto, los estudios de laboratorio, al final, tienen la clave para comprender también los macro problemas.

Hemos podido argumentar con este ejemplo cómo el laboratorio no es un lugar encerrado que marca un exterior. Es decir que no es un lugar aislado, sino

\footnotetext{
${ }^{84}$ Ibid., p.34

${ }^{85}$ Este concepto se desarrolla en el epígrafe 3.10 de las conclusiones como colocalidad.

${ }^{86}$ Bruno Latour. "Give me a laboratory and I will raise the world" Op. Cit., p.35.

${ }^{87}$ Ibid., p.36.
} 
conectado con múltiples redes que recomponen lo que consideramos exterior e interior. $^{88}$

\subsubsection{El mundo es un laboratorio}

Si asumimos ya que la conformación de las sociedades y las multiplicidadesespacio de Sloterdijk se da en forma de aislamientos conectados o coaislamientos, y que el laboratorio es una forma privilegiada de eso, observamos cómo hoy todo el planeta es un laboratorio.

Si Sloterdijk, nos hace conscientes que hoy ya hemos dado una definición ensamblada de objetos y sujetos, aún nos queda la tarea de pensar en qué condiciones climáticas, atmosféricas vamos a desarrollar nuestro modo de estaren-el-mundo. El control climático a todos los niveles comienza a desarrollarse como una nueva filosofía o teoría del aislamiento climático. Continuando con esta idea, Latour pone en evidencia cómo en esta nueva situación de control climático hemos convertido el mundo en un laboratorio sin exterioridad ni interioridad.

$$
\begin{aligned}
& \text { Desde que las ciencias se han expandido tanto han transformado } \\
& \text { todo el mundo en un laboratorio, también todos nosotros nos hemos } \\
& \text { involucrado en el mismo experimento colectivo en el control climático del } \\
& \text { laboratorio mundial }{ }^{89}
\end{aligned}
$$

Del mismo modo que hemos argumentado el reensamblamiento intro-exo por la simultaneidad del laboratorio como entidad sin exterior, argumentamos, siguiendo a Latour $^{90}$, su pliegue en el mundo como laboratorio por el siguiente motivo: que todos estamos comprometidos en una serie de experimentos colectivos que han desbordado los límites estrictos de los laboratorios no necesita una prueba más que la lectura de los periódicos o la observación de las noticias de la televisión. Lo vemos diariamente en experimentos, accidentales o no, como el Prestige, en las costas españolas, el mal de las vacas locas inglesas, la producción de alimentos en China, el transporte de petróleo en Europa, el ganado no vacunado en Gran Bretaña, etc.

Que el mundo sea un laboratorio implica que si antes podíamos controlar lo que sucede en un laboratorio pequeño y aislado, y una vez controlado expandir sus protocolos al resto de la sociedad, hoy es incontrolable, precisamente porque las prácticas experimentales han salido del laboratorio. Anteriormente, los

\footnotetext{
${ }^{88}$ En palabras de Sloterdijk, sería una entidad que opera en régimen de coaislamiento o aislamiento conectado según se explica en el epígrafe 2.3.1.

${ }^{89}$ Latour, Bruno. "Atmospheres, atmospheres. Laboratory inside out". Introducción al catálogo de Olafur Eliasson en la exposición de la Tate Modern. Susan May editor, London, Tate Modern, 2002.

${ }^{90}$ Ibid., p.3.
} 
experimentos eran sufridos por animales, materiales, software, etc. Más tarde, la sociedad comenzaba a acceder a esa experiencia innovadora y no al experimento. Latour ofrece tres aproximaciones por los que hoy no podemos controlar lo que sucede en la interconexión y los procesos interescalares de los experimentos planetarios.

En primer lugar, el laboratorio ha extendido sus paredes a todo el planeta. Los instrumentos están en todas partes: casas, industrias, hospitales se han convertido en tantas filiales de los laboratorios. La diferencia entre historia natural (al aire libre) y la ciencia del laboratorio se ha erosionado. Hoy se realizan viajes de campo proyectando datos en las salas de conferencias de los laboratorios sin salir al exterior.

En segundo lugar, es un tema de escala. La producción de los experimentos se hace a escala uno-uno y en tiempo real. Por ejemplo, como sucede con el calentamiento global. Se desarrollan muchas simulaciones, pero la realidad del experimento se ejercita con nosotros, a través de la acción de cada uno de nosotros, de todos nosotros, con los océanos y la atmósfera. Este es, de hecho, un experimento que no tiene exterior: la sociedad, como colectivo ampliado, está embarcada en el mismo.

La clara distinción entre, por un lado, laboratorios científicos que experimentan en las teorías y fenómenos dentro sus paredes, y, por el otro, un afuera político donde no expertos están recibiendo con valores humanos, opiniones y pasiones, simplemente se ha evaporado ante nuestros ojos. ${ }^{91}$

Esta desaparición no implica, para Latour, que ahora todo sea político, sino que las controversias científicas contemporáneas no se dan solamente en los ámbitos académicos, sino que la sociedad afectada por los experimentos planetarios, deben entrar en el debate simultáneamente constituyendo Forums Híbridos ${ }^{22}$ compuestos de sistemas de cosas y humanos que toman decisiones y humanos que son afectados por esas decisiones. En palabras de Isabelle Stengers, deben participar y tener en cuenta tanto a los agentes interesados (stakeholders) como a los agentes afectados (shareholders). ${ }^{93} \mathrm{Si}$ el mundo, también es un laboratorio, también debe cumplir las condiciones del reensamblamiento intro-exo del laboratorio de Pasteur.

\footnotetext{
${ }^{91}$ Ibid., p.5

${ }^{92}$ Sobre este concepto para la simultaneidad de la representación. Cfr. Callon, Michael. Rip Ariel. Acting in an uncertain world. Cambride, London, The MIT Press, 2009.

${ }^{93}$ Cfr. Stengers, Isabelle. "La propuesta cosmopolítica." Pléyade. n.14, 2014, pp.17-41.
} 


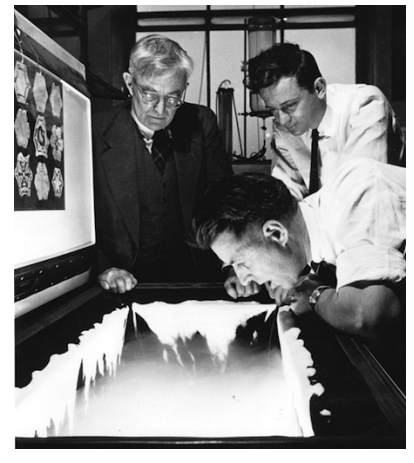

Img.07

Esta imagen, propiedad de General Electrics, muestra a dos premios nobel, Irving Langmuir, Bernard Vonnegut, y a Vincent Schaefer en 1940 en un prototipo de "siembra de nubes" para provocar nieve con el objetivo de intensificar precipitaciones artificialmente. Es lo que hoy se denomina geoingenieria.
Para Latour, la teoría meteorológica de Sloterdijk hace entender que el histórico exterior solo existe en la mente. Las cosas interesantes suceden en el interior, no en el exterior. Precisamente, gracias al entrelazamiento simultáneo de la extensión de la ciencia y las actividades humanas con el sistema de cosas, deja "el afuera" aparcado por un tiempo. Con lo que el interior, que ha incluido el exterior, es el lugar desde donde extender el conocimiento.

El interior restante debe ser explorado con gran detalle y con mucha cautela, ya que no es ni una mente ni un 'mundo exterior' como tendría la vieja disputa moderna, sino más bien una esfera delicada del control climático. Lo que Sloterdijk nos ayuda a todos a descubrir es que incluso la política necesita aire acondicionado $^{94}$

Si hemos podido argumentar que el mundo también es un laboratorio, podemos esclarecer que es en el reensamblamiento de ambas esferas la que construye en simultaneidad las nociones del co-aislamiento. El control climático, por un lado, es el resultado de las acciones de los humanos y los sistemas de cosas en el planeta que reacciona a esas acciones con modificaciones constantes. Por otro lado, los humanos vuelven a intervenir en la atmósfera desde la llamada geoingeniería ${ }^{95}$ para revertir los cambios que él mismo junto al sistema de cosas ha producido, modificando en esa imposibilidad de control, de nuevo nuestros cielos y atmósferas. En esa batalla por el control del clima, todos nosotros somos parte activa en nuestras casas, las industrias, la gestión de recursos y a la vez parte afectada, lo cual convierte al planeta en un laboratorio donde se reensamblan nuestra exterioridad e interioridad en sistemas de co-aislamientos simultáneos.

\subsubsection{Ciudades sin afuera}

La ciudad como lugar emancipador de la naturaleza se compone de hábitos y de formas. José Luis Pardo nos pregunta ¿Es la ciudad la que destruye a la naturaleza, o es la naturaleza la que engulle la ciudad?96 Seguramente, ninguna de las dos. Si tenemos claro en esta tesis que todo hoy es urbano, con diferentes grados de complejidad, veremos a la naturaleza como un elemento en construcción y degradación permanente por la acción humana y tecnológica. Lo mismo podríamos disponer sobre la ciudad, como una entidad en construcción y degradación permanente. Pero esta pregunta antagónica no nos ayuda a profundizar en la construcción mediada de estos procesos. Si la época de la

\footnotetext{
${ }^{94}$ Bruno Latour "Atmospheres, atmospheres. Laboratory inside out "Op. Cit., p.15.

${ }^{95}$ Para entender otras posiciones en un Foro Híbrido y saber más del control climático de los cielos desde un punto de vista de los afectados ver http://anecieloslimpios.blogspot.com.es/

${ }^{96} \mathrm{La}$ tesis doctoral del arquitecto Uriel Fogué Ecología política y economía de la visibilidad de los dispositivos tecnológicos de la escala urbana durante el siglo XX. abriendo la caja negra. Madrid. UPM. 2015 explora la construcción simultánea de estas relaciones entre naturaleza y ciudad desde las infraestructuras urbanas y su mediación técnica.
} 
naturaleza la llamamos hoy antropoceno ${ }^{97}$ y pluralizamos su nombre, a la ciudad debemos dejar de nombrarla para entenderla como el lugar de maximización de los procesos urbanos. La ciudad podemos definirla como el lugar múltiple donde se intensifica en mayor grado la complejidad. Todo entonces son procesos urbanos independientemente de que estos sucedan en el campo, la ciudad o la exosfera. Los límites tradicionales de las formas de la exterioridad se han diluido para entender el proceso urbano en continuidad y simultaneidad.

¿Por qué entonces seguir hablando de naturaleza en singular? pregunta Bruno Latour. Con ello dejamos lugar para un exterior, que no es naturaleza. Es decir, "calificamos a un ser por su pertenencia a cierta esfera de realidad." ${ }^{18}$ Entonces en un mundo sin exterioridad ¿Cómo se puede justificar la utilización del singular "la" naturaleza? ¿Por qué no se presenta como una multiplicidad? Y entonces Latour nos interroga: ¿Aceptáis la exterioridad de la naturaleza o, por lo contrario, yacéis en lo más profundo del calabozo de la caverna? O más adecuadamente ¿Habláis de cosas o de sus representaciones simbólicas? "Desde que añadimos a los dinosaurios sus paleontólogos, a las partículas sus aceleradores, a los ecosistemas sus herbarios, a los balances genéticos sus unidades de referencia y sus hipótesis de cálculo, a los agujeros de ozono sus meteorólogos y sus químicos, ya no hablamos de toda de naturaleza, sino de eso que se produce, se construye, se decide o se define en una ciudad especialista en ecología, casi tan compleja como la del mundo que desea conocer." 99

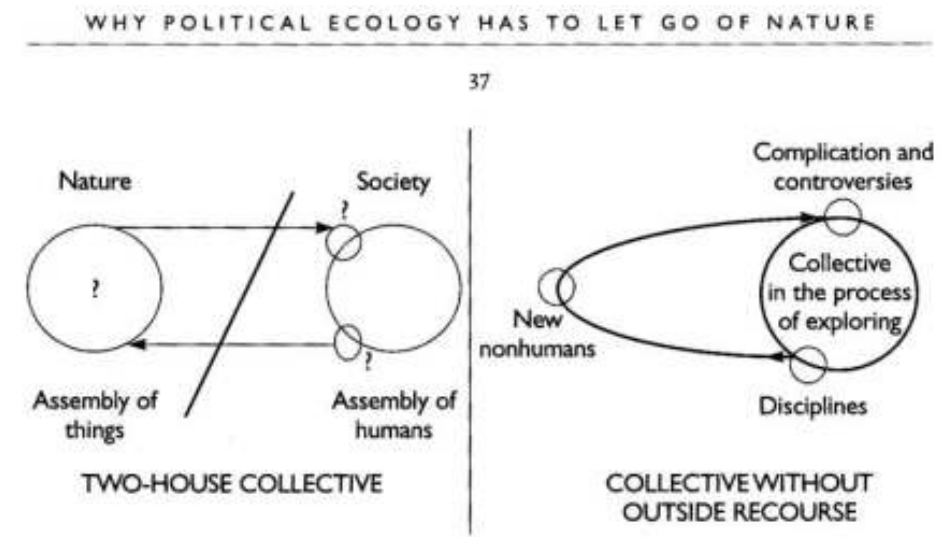

Fig. 07. Diagrama de lo social como colectivo ampliado sin recurso exterior. Bruno Latour en Políticas de la Naturaleza p.67.

\footnotetext{
${ }^{97}$ El término Antropoceno ha sido propuesto por algunos científicos para sustituir al de Holoceno, la actual época del periodo Cuaternario en la historia terrestre, debido al significativo impacto global que las actividades humanas tienen sobre los ecosistemas terrestres.

${ }^{98}$ Cfr. Latour, Bruno. Políticas de la naturaleza. Barcelona, RBA, 2013.

${ }^{99}$ Ibid., p.57.
} 


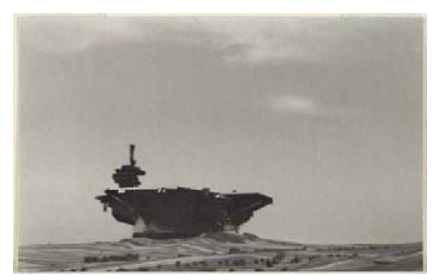

Img.08

El portaviones como una ciudad contemporánea fortificada. Hans Hollein. AirCraft Carrier City in the Landscape. 1964. Transformations series (1963-1968)
Este esquema sobre el modelo político de la doble cámara naturaleza-sociedad y el modelo del colectivo ampliado sobre una extensión simple de humano y no humanos, podemos transferirlo a la relación de separación que estamos intentando construir sobre la triple separación naturaleza-no humanos-ciudad. Doble porque es la separación física de sus formas (naturaleza-sociedad) y triple porque separa sus agentes humanos, no humanos y la del conjunto de las cosas como parte de la realidad urbana a tratar.

Tomemos el ejemplo de la ciudad como frontera del mundo.

Que la forma que permite a los seres humanos estar entre ellos conjunta e "interiormente", no solo en un vago sentido metafórico aporte inmunidad y cobijo, sino que también desde el punto de vista técnico pueda ser la condición de su salvación como de su supervivencia. [...] Con el concepto de arca (como el arca de Noé) se introduce en el mundo un proyecto novedoso: la idea del autocobijo y el autoencierro de un grupo frente a un mundo externo que ha devenido en imposible ${ }^{100}$

La idea de establecer formas, como islas autónomas, independientes del exterior, pero totalmente vinculadas a él, sea por su hostilidad o por su bienvenida, es inherente al ser humano. El edificio sin vecindad, como dirá Sloterdijk, encarna la negación del mundo-entorno por una configuración artificial. Pero la encarnación formal de esta idea no será el arca sino la ciudad. Históricamente la ciudad como embarcación de supervivencia terrestre ha determinado las condiciones de exterioridad de la misma.

La ciudad antigua tiene que concentrarse hacia dentro, [...] que señala a los suyos como el signo de preferencia; hacia afuera, ha de afirmarse mediante murallas triunfales y torres dominantes, para desvanecer cualquier duda respecto a su derecho a estar instalada donde está y de extender su influjo en la distancia desde este lugar eminente. ${ }^{101}$

La ciudad primitiva, ha de ser el mundo en el espacio interior de la misma. Fuera de ella la naturaleza. Dentro de ella, el caserío. La muralla establece el límite del exterior y el interior. Los cuerpos, son cuerpos en el interior de la ciudad, pues no hay nada exterior a él que esté dentro de las murallas. Y esta ciudad es concéntrica. Su valor y su identidad reside en su corazón, y se construye porque es interior a ella, un microcosmos. No existe el concepto de periferia. Hay tan solo un centro y un límite.

\footnotetext{
${ }^{100}$ Sloterdijk, Peter. Esferas II. Madrid, Siruela, 2004, p.219.

${ }^{101}$ Ibid., p.231.
} 
Volvemos a referirnos a la pregunta ¿Es la ciudad la que destruye a la naturaleza, o es la naturaleza la que engulle la ciudad? J.L. Pardo nos sugiere que si entendemos la ciudad como maquinaria social, económica y política y la naturaleza como ente formado por paquetes de hábitos (lo natural en nosotros, nuestros hábitos) para entender que sin separar las entidades en sí mismas, para no crear un exterior ficticio y artificial, ninguna destruye ni engulle a otra. Ambas son las que se destruyen mutuamente en nuevos procesos en continuidad entre las naturalezas y las ciudades. Mejor dicho, deberemos valorar los procesos urbanos en un sentido ampliado para comprender sus vectores, sus trazas y evaluar sus impactos, niveles de destrucción o las características políticas, económicas, sociales o ecológicas de los hábitos individuales y colectivos. Este segundo punto es importante para entender las nuevas relaciones heterogéneas entre las formas de la exterioridad (naturaleza-ciudad) que aquí desarrollamos.

Si nos remitimos unos siglos atrás vemos como G. B. Piranesi ya trató una manera particular de entender la relación ciudad-naturaleza. La idea de la ruina le permite construir otros paisajes híbridos donde la arquitectura y la naturaleza forman ciudades otras que construyen de nuevo relaciones

diversas entre ambas formas. Un atlas de tipologías clásicas imbricadas con la naturaleza construye quizás una de las primeras representaciones eco-sistémicas donde animales, naturalezas y arquitectura coexisten en un grabado. No son sólo sus representaciones simbólicas, sino los acuerdos que se dan para que sucedan. Piranesi es capaz de reconstruir, mediante su imaginario de las ruinas, nuevas formas de enlazar la naturaleza y la ciudad como una sola materialidad constituida por el ensamblamiento del tiempo como elemento constructor de otras posibilidades naturaleza-ciudad.

\section{Ejemplo 04: La ciudad resiliente}

Hoy en día, comenzamos a proyectar la ciudad desde perspectivas más abiertas e inclusivas con la naturaleza. El proyecto City Plus de $\mathrm{OMA}^{102}$ ya no construye una ciudad sino ilustra un entorno urbano en el océano como una isla autónoma desconectada no solo del territorio sino de las fluctuaciones de los niveles del agua dependientes de los huracanes. El proyecto para el concurso Rebuild by Design, en Nueva Orleans en la costa Este de EEUU tras el huracán Sandy en 2013, conceptualiza una ciudad sin afuera evaluando el riesgo de lo natural, en este caso los grandes huracanes y lluvias torrenciales, para construir una ciudad más

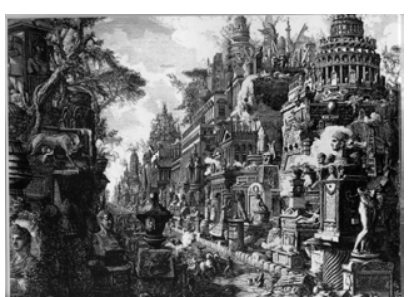

Img 09

Giovanni Battista Piranessi. Le Antichità Romane. Rome, 1756.

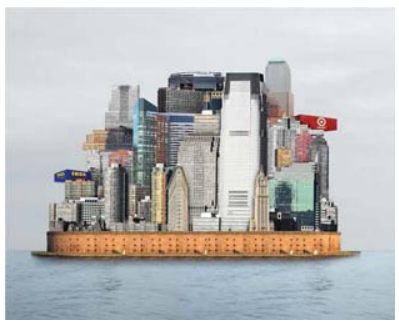

Img 10

La ciudad con afuera. Una ciudadfortaleza como Isla autónoma flotante. La antítesis a la idea-propuesta de City Plus. Imagen: OMA. 2013

\footnotetext{
${ }^{102}$ City Plus: This means further densification and defense of high value, high impact, high potential sites-cities. OMA with Royal HaskoningDHV; Balmori Associates; and HR\&A Advisors. Rebuild by design. http://www.rebuildbydesign.org/project/646/
} 


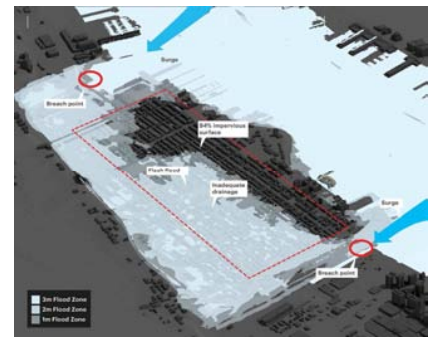

Img. 11

Ciudad resiliente sin exterior. Imagen de las diferentes fases de inundación de determinadas zonas de la ciudad. Proyecto City Plus. Imagen: OMA. resiliente. En este caso OMA produce la idea de ciudad anfibia, no como una Isla autónoma en términos de Sloterdijk. Isla como prototipo en el mundo, autónomo por su desconexión con el territorio y diferenciación de la isla absoluta como lugar en el que no solo se está aislado, sino que crean las condiciones de vida del entorno, una nave espacial por ejemplo. Pero el caso del proyecto de OMA explicita nuevas relaciones de diseño cuando se compone un mundo junto con las manifestaciones naturales, como en este caso el huracán Sandy. La ciudad, en vez de acumularse, protegerse y densificarse en altura, pasa a ser una ciudad que se distribuye en el territorio para estar cerca del mar, sin estar aislada de él, y llegar a ser más resiliente con los niveles de agua del océano. Es decir, la ciudad no se constituye como una protección frente a un exterior, sino que nace con él, con su indeterminación y sus riesgos para ponerlos en valor y adaptase junto al exterior. No se protege del exterior sino que se alía con él, para de esta manera incorporarlo como primer motor de proyecto urbano. Como dicen en la memoria del proyecto "Citadel cities versus amphibious villages." Ciudades anfibias frente a ciudades fortificadas.

Otro ejemplo podemos verlo en la investigación que produce Ignacio Farías sobre la re-planificación urbana en las zonas costeras de Chile ${ }^{103}$ tras el terremoto y posterior Tsunami del año 2010. En este proceso de reconstrucción de ciudades y pueblos costeros se plantea una nueva pregunta. ¿Cómo articular la vida en asentamientos costeros conviviendo con futuros Tsunamis? En este proceso se articulan conocimientos diversos que no se habían dado cita desde hace mucho tiempo, si alguna vez sucedió. El de los geógrafos expertos en modelación oceanográfica y los arquitectos expertos en diseño urbano. En este caso, arquitectos, geógrafos oceanógrafos, ciudades, tsunamis, terremotos, la ciudad y la naturaleza de una sola vez en sus conflictos y agencias, que no se consideran como algo exterior lo uno a lo otro, sino que forman parte de una manera de pensar que pone en juego lo que Latour denomina el modelo del colectivo ampliado sobre una disolución naturaleza-ciudad en una extensión simple de humanos y no humanos. La ciudad se convierte entonces en una ciudad sin afuera.

\footnotetext{
${ }^{103}$ Farías, Ignacio. "Planes Maestros como cosmogramas: la articulación de fuerzas oceánicas y formas urbanas tras el Tsunami de 2010 en Chile.” Revista Pléyade. 2014, Julio-Diciembre, p.119.
} 


\subsubsection{La intimidad en el espacio público}

La casa, también ha sido y sigue siendo un laboratorio que opera como entidad sin exterior. Para argumentar esto, pensemos en ella como lugar que ha sido límite de las grandes esferas de lo público y lo íntimo o lo socialmente relevante. La casa conformaba el límite con la exterioridad sin ser la interioridad. El espacio de aislamiento por excelencia, autónomo: la casa era una "máquina para habitar" el confort. El espacio público, la ciudad y la naturaleza quedaban fuera de su alcance, mientras el cuerpo y la piel eran entidades que se conformaban como el límite natural de la interioridad. No ha sido siempre así, aunque así se nos ha presentado en el contexto de la modernidad. Las primeras construcciones modernas de la intimidad se daban desde la construcción del aparato habitacional como lugar de seguridad y confort.

La vivienda del moderno es la extensión del cuerpo por la que se exhibe expresamente su preocupación por sí mismo, convertida en hábito y en posición a la defensiva. [...] Con ello la vivienda pasa a formar parte del proceso nuclear de la modernización: articula la emergencia - o el volverse explícitos -de los sistemas de inmunidad. [...] En ella encuentra su apoyo arquitectónico el derecho fundamental a no-prestar-atención al mundo exterior. ${ }^{104}$

Si aparcamos la casa moderna por unos momentos y nos quedamos solo con la intimidad, quizás podamos deshacernos de ciertos hábitos de relación espaciales para entenderla mejor. Hablamos de lo íntimo y no de lo privado pues, como dice J.L. Pardo, lo público y lo privado es un continuo. Y a diferencia de lo privado, lo íntimo es un proceso que puede hacerse con el otro sin que este se haga explícito. Entonces lo íntimo no es solo lo personal, sino que también es un proceso que se enlaza con el otro. Por otro lado hablaremos de la ciudad, que como objeto múltiple, aglutina muchas de las experiencias de lo público, sin ser ella misma algo exactamente público. La ciudad también contiene los espacios privados y entre ellos y sus entrelazamientos aparece también la intimidad.

Ciudad e intimidad son conceptos mutuamente irreductibles pero radicalmente inseparables; allí donde no hay política, no puede haber en sentido estricto intimidad; y allí donde la intimidad está amenazada, estas amenazas expresan una crisis del espacio civil. Sin embargo, esta distinción-solidaridad entre Ciudad e intimidad no puede confundirse con - ni superponerse a - la distinción “clásica” de lo público y lo privado. ${ }^{105}$

\footnotetext{
${ }^{104}$ Sloterdijk. Peter. Esferas III. Espumas.Esferología plural. Madrid, Siruela, 2006, p.412.

${ }^{105}$ Pardo, J.L. Politicas de la intimidad. Ensayo sobre la falta de excepciones. Madrid, Escolar y Mayo, 2012, p.145.
} 


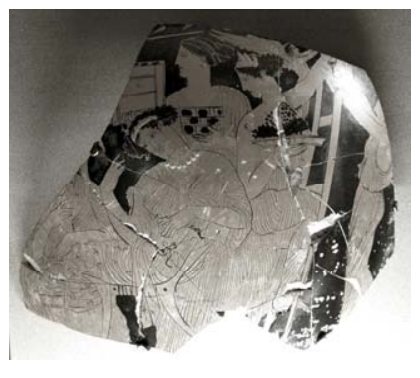

$\operatorname{Img.12}$

Celebrando la Adonia en las fiestas griegas instituidas en honor de Afrodita y Adonis. Imagen:

Fragmento de una vasija nupcial ática de figuras rojas, c. 430

420 a. C.
José Luis Pardo ofrece en este ensayo dos aspectos claves para no confundir lo público y lo privado con la ciudad y lo íntimo. Primero, que la ciudad no es un territorio siempre de lo público. Pensemos en las ciudades dirigidas por un soberano-dictador que hace de la ciudad su casa y su lugar de decisiones. Y por otro lado, que la categoría de lo íntimo no siempre pertenece a sujetos humanos y ciudadanos. El esclavo, la mujer o el hijo, antiguamente no tenían vida privada pues eran en sí mismos la vida privada de otros. Luego pertenecían a un género que no es posible delimitarlo como público ni privado y que para él, constituyen una forma humana de ser animal. A esto José Luís pardo en el ensayo lo llama intimidad.

Mujeres, esclavos y niños, también fueron en la antigua Grecia cuerpos excluidos de la polis, y del espacio público del Ágora. Pero son estos cuerpos los que reensamblaban la significación de los espacios calificados como pertenecientes a la polis o lo doméstico. Tal como relata R. Sennett, en las fiestas de Adonis, las mujeres se congregaban en torno a los tejados de las casas, para enfrentarse al rechazo como agentes activos en lugar de víctimas pasivas.

Las mujeres iban de una casa a otra, oían que las llamaban desde arriba en la oscuridad, y subían por escaleras a los tejados para encontrarse con extrañas. En la antigua ciudad los tejados solían estar vacíos. Además, esta festividad se celebraba por la noche en distritos residenciales donde no había iluminación en las calles. Los espacios dominantes-como el ágora, el gimnasio, la Acrópolis, la colina de Pnyx- eran espacios de exposición a la luz del día. [...] se tiene la impresión de que el ritual estaba dedicado al placer temporal entre extrañas que se reunían en la oscuridad [...] para hablar a extrañas de sus deseos íntimos. ${ }^{106}$

En el contexto de las Fiestas de Adonis, podemos entender que la construcción de la intimidad, bajo la oscuridad, en las cubiertas de las casas de la ciudad, se establece por confrontación al espacio público de la polis. La intimidad no es algo individual, no sucede en espacios domésticos y aprovecha la oscuridad para revelarse. No pertenece al terreno de lo privado, porque las mujeres carecían, como explica Pardo, de esa esfera.

Una vez realizada brevemente la distinción entre lo privado y lo íntimo, lo que queremos demostrar en este punto, es que lo íntimo es un proceso, y como tal proceso se construye de manera simultánea con la ciudad. La intimidad solo existe como concepto cuando sale de su aislamiento y se convierte en algo conocido por otro, sea esto accesible o no. En ese momento es cuando la

\footnotetext{
${ }^{106}$ Sennett, Richard. Carne y piedra. El cuerpo y la ciudad en la civilización occidental. Madrid,
} Alianza, 2010, pp.84-85. 
intimidad aparece. La intimidad, por lo tanto, resulta también del proceso de coaislamiento.

No nos preocupa tanto el origen histórico de la intimidad que algunos, como Felipe Beltrán, sitúan en la revelación de las confesiones de la literatura epistolar. ${ }^{107}$ Más recientemente con la violación del artículo 18 (18.1 y 18.4 de la cuarta enmienda a la constitución de los Estados Unidos de América cuando Samuel Warren y Louis Brandeis en 1890 son fotografiados por los periodistas que publican y difunden las fotos sin su consentimiento. Lo que se relaciona con la intimidad en esta situación es la noción de aislamiento físico que sentará las bases para el desarrollo del concepto de intimidad a nivel administrativo internacional en la Declaración Universal de los Derechos Humanos de 10 de diciembre de 1948, en especial en su artículo $12^{108}$.

Resulta entonces pertinente estudiar las relaciones de simultaneidad que se dan en la construcción de la esfera de lo íntimo con la ciudad porque la ciudad, a su vez, también se construye haciéndose íntima. Es decir, la emergencia de la ciudad es simultánea a la emergencia de lo íntimo. El proceso de intimidad se da entonces como "extimidad". 109

Si retomamos la diferenciación sobre lo privado y lo íntimo que hace José Luis Pardo, atendiendo al estatus apolítico de las mujeres, esclavos y niños en la antigüedad, podemos ver como lo público y lo privado no son categorías definitorias para estos cuerpos. Del mismo modo, erróneamente, los espacios domésticos se leen como espacios desprovistos de política pues está se encuentra fuera en la esfera pública. Por el contrario los espacios domésticos se piensan hoy en día como los lugares de la estabilidad ${ }^{110}$, la seguridad, el confort e intimidad.

La construcción de lo colectivo se ha desplazado de manera prioritaria a los entornos de domesticidad en red que habitamos. Pensamos que son estos urbanismos de lo doméstico los entornos en los que nuestra intimidad confronta las grades preocupaciones, controversias y activismos que se discuten en las sociedades. No existe un divorcio entre lo hogareño y el espacio público. ${ }^{111}$

Luego ambas esferas, la ciudad como espacio público y lo íntimo en el espacio doméstico, se encuentran enlazadas y se construyen al mismo tiempo haciendo

\footnotetext{
${ }^{107}$ En la conferencia de Andrés Jaque. "Dadme un cuarto de estar y moveré el mundo. Habitaciones, paisajes y experimentos de andar por casa.” Medialab-Prado, Madrid, Mayo, 2008.

${ }^{108}$ Es interesante las diferencias que se dan en la definición de la intimidad desde el aspecto legislativo y de los derechos fundamentales del hombre. Para más información: Garriga, Ana. Tratamiento de datos personales y derechos fundamentales. Madrid, Dyckinson, 2004.

${ }^{109}$ Este término se desarrolla en el epígrafe 3.3 de las conclusiones.

${ }^{110}$ Ver definición de Federico Soriano sobre espacio público y privado en Diccionario Metápolis de arquitectura avanzada. Barcelona, Actar, 2001, p.203.

${ }^{111}$ Jaque, Andrés. Dulces Arenas Cotidianas. Sevilla, Lugadero, 2013, p.12.
} 
desaparecer las relaciones de exterioridad tradicional entre ellas. Nos interesa entonces la definición que podemos dar de lo público no como espacio sino como "proceso que se da allí donde confrontamos la otredad y desarticulamos los consensos" ${ }^{112}$ Lo público es entonces el lugar donde anulamos la exterioridad con el otro y de lo otro, y de esta manera construimos también nuestras propias intimaciones.

Intimaciones que podemos definir como los procesos de construcción de la intimidad con los otros. Por ejemplo, las casas compartidas que se dan hoy en día, estudiadas por Andrés Jaque en muchos proyectos, como casa de Erasmus, casas de cuidadores, de mayores, de emigrantes que usan las cosas por turnos horarios, camas calientes, etc. hacen que la dialéctica ciudad-intimidad o público-doméstico pierda sentido.

En las casas compartidas, los otros no están fuera, sino en el mismo cuarto de estar y compartimos ducha con ellos. [...] La ciudad se construye entonces uniendo un interior a otro. ${ }^{113}$

Si aceptamos que estos interiores construyen la ciudad desde las intimaciones. Y estos interiores tienen una alta capacidad de aislamiento para el surgimiento de la intimidad, también tienen la misma capacidad de conectarse. Tal como Martha Stewart, directora del programa de televisión y la editorial Living Omnimedia sobre recetas, DIY y toda clase de decoración doméstica, afirma: "la ciudad es un lugar de interiores conectados"114 Luego la construcción de la intimidad como proceso con los otros también se da en la simultaneidad de co-aislamientos.

Por último, los procesos de intimaciones no se dan solo en los espacios domésticos y aislados como unidades burbujas-celdas. También se dan en ciertos territorios de la esfera pública. Si tomamos el caso de las citas por plataformas de internet como Grinder o Tinder o de parejas gays en lugares concurridos también entenderemos que los procesos de construcción de la intimidad se desarrollan en el territorio de lo público. Por lo tanto, la construcción de la ciudad como objeto múltiple y simultáneo también se da desde la construcción de las intimaciones multiespaciales.

Para concluir, queremos recuperar la primera afirmación en este punto de que la casa es un laboratorio, y por lo tanto también reúne las condiciones expuestas del

\footnotetext{
${ }^{112}$ Ibid,. p.12

${ }^{113}$ Ibid., p. 57

${ }^{114}$ Picozzi, Sofía. "El urbanismo de lo doméstico" comentarios a la entrevista a Martha Stewart. de Beatriz Colomina y Rem Koolhaas. Buenos Aires, Ramona, n.51, 2005, p.36-37.
} 
laboratorio co-aislado de Pasteur en 1881 como entidad sin exterior. El trabajo de Marta Stewart que acabamos de citar puede argumentar esta afirmación.

Para Martha Stewart la casa es el escenario donde pasa todo, el lugar desde donde se transmiten los programas de TV, se sacan las fotos para las revistas y se cuela la vida doméstica. Sus propias casas son los estudios de televisión y las usan para mostrar las tendencias en decoración o para probar recetas frente a las cámaras. Son como campos de operaciones donde se crean ambientes, uno sobre el otro, una máquina de producir espacialidad. La casa se multiplica, se desproporciona, explota y se desborda en la pantalla del televisor; lo doméstico invade el espacio público. El gusto y los productos de Martha Stewart se desparraman en los hogares de los televidentes. ${ }^{115}$

Marta Stewart no hace más que actualizar lo que ya hacían en la época de Pasteur lo que podemos llamar las primeras ingenieras domésticas americanas, que incorporaron al repertorio de lo doméstico las tecnologías que se fabricaban en las incipientes industrias, que en principio nada tenían que ver con la casa. Los manuales de Householding ${ }^{116}$ o de la economía del hogar, las recetas, y los diseños forman parte de la construcción de la ciudad desde estos interiores que operan como laboratorios. Martha Stewart hace del laboratorio de diseño su propia casa que expande sus protocolos mediante la TV, las revistas y páginas web al resto de interiores domésticos del planeta, de Estados Unidos a China. La diferencia con el laboratorio de Pasteur es que ella misma es la investigadora, la observadora, la que experimenta y la que tiene las experiencias. Lo mismo para sus televidentes y lectores que intercambian soluciones de diseño con ella.

Mi vida privada, mi vida laboral, mi trabajo, mis reflexiones son todos públicos. La gente aprende de ver algo bueno que pasa frente a ellos. ${ }^{117}$

Todos ellos forman una comunidad "colocalizada" ${ }^{118}$ y afectiva que construye, en el interés por dotar de diseño a los espacios domésticos, una ciudad de interiores co-localizada en diferentes lugares a la vez, de casas, fotos, imágenes, videos en la red y desde sus respectivas celdas de aislamiento conformando una ciudad de intimaciones espaciales conectadas y coexistentes.

\footnotetext{
115 Ibid., p.37

${ }^{116}$ Estos manuales, se convirtieron con la época higienista en manuales de ingeniería doméstica y científicos sobre el hogar. En los años 50 pasaron a ser manuales económicos y hoy en día se han convertido en manuales financieros para soportar las finanzas del hogar. Estos manuales ponen de relieve la relación directa del espacio doméstico y la ciudad. Hoy en día la imposibilidad de manejar las finanzas desde el interior del hogar es una manifestación de la ausencia de autonomía y exterioridad del hogar. Los desahucios son un claro ejemplo de esto. Sobre Househoolding ver el proyecto "Gropius Evicted" desarrollado por el autor junto a estudio SIC y VIC para la Household Fair en la Bauhaus de Dessau. (Alemania)

${ }^{117}$ Entrevista a Martha Stewart por Rem Koolhaas y Beatriz Colomina. Content. London, Taschen, 2004.

${ }^{118}$ Concepto desarrollado en el epígrafe 3.10 de de las conclusiones.
} 


\subsubsection{El cuerpo urbano sociotécnico}

La tercera entidad, que nos sirve para explicar otra de las disoluciones de las formas tradicionales de la exterioridad, es la del cuerpo. El cuerpo era el centro tradicional de las formas de la exterioridad. Hoy su límite, la piel, ya no es ese lugar impermeable que separa, de hecho nunca lo ha sido. La piel es un órgano de intercambio permanente. En todo caso, no es el cuerpo como entidad independiente y natural de la que hablamos aquí. El cuerpo es también una composición socio-técnica que es atravesado por la trayectoria de múltiples redes configurado por entornos que son al a vez climáticos y atmosféricos. Un cuerpo es múltiple en sí mismo y está conformado por múltiples asociaciones y ensamblajes. El cuerpo hoy manifiesta un desplazamiento de su rol principal como entidad individual a una entidad que en agencia compartida opera dentro de un sistema más complejo. De hecho, el cuerpo son ya los cuerpos, humanos y no humanos, técnicos y artificiales, socialmente y tecnológicamente conformados.

Si como hemos dicho antes, el espacio está siempre 11 eno ${ }^{119}$, el cuerpo es también, como la propia idea de red, un límite en sí mismo. Son el espacio abierto.

Los cuerpos son el lugar, son lugares de existencia. No hay existencia sin lugar, aquí y ahora. El cuerpo no es ni lleno ni vacío, no tiene fuera ni dentro como tampoco tiene partes, totalidad, funciones o finalidad. ${ }^{120}$

La afirmación que modifica la existencia hoy del cuerpo es que no tenemos un cuerpo, sino que somos cuerpos ${ }^{121}$. Y esos cuerpos poseen una piel que, como dice JL Nancy, está plegada, replegada, desplegada, multiplicada, invaginada, exogastrulada, orificiada, evasiva, tersa, relajada, excitada, confundida, ligada y desligada. "Bajo todos y muchos más modos, el cuerpo da lugar a la existencia. No hay formas a priori de la intuición, ni tabla de categorías." ${ }^{22}$

Jean Luc Nancy propone una ontología del cuerpo donde los vectores que lo atraviesan son "las prácticas médicas asociadas a las experiencias traumáticas y límites del mismo, con particular atención al trasplante, donde se ausculta el debate entre quienes pretenden ver en este una aventura metafísica y quienes lo conciben como una proeza técnica, donde no sólo conforman nuevas formas de subjetividad, sino también una "nueva carne".

\footnotetext{
${ }^{119}$ Pardo. J.L. Las formas de la exterioridad. Op. Cit, p.20.

${ }^{120}$ Nancy, Jean Luc. Corpus. Arena. Madrid, 2013, p.16.

${ }^{121}$ Declaraba Wilhelm Reich. En Virilio, Paul. Estética de la desaparición. Barcelona, Anagrama, 2003 p. 47

${ }^{122}$ J. L. Nancy. Corpus. Op. Cit., p.18.
} 
Así en las fronteras entre lo natural y lo artificial surge la posibilidad pensar en un cuerpo fragmentado, en un cuerpo cuyos órganos se hayan emancipado. ${ }^{123}$

$\mathrm{Y}$ es esa emancipación, la que proviene del exterior, la que provoca la desaparición de la exterioridad del cuerpo. El cuerpo deja de ser el territorio de un interior separado para establecer relaciones de dependencia permanente con el exterior. Sus órganos no serán más, dependientes del propio ecosistema cuerpo y sus intercambios biológicos con el exterior

Hemos de abrazar el vacío y lo exterior: los últimos seres humanos se han convertido en exteriores a sí mismos. Incluso su inteligencia se busca ahora en el exterior neurológico, en un aparato biológico, el celebro, que se sustrae a su poseedor por todos lados. ${ }^{124}$

Esta dependencia corporal, física y ontológica del exterior, nos convierte en tecnohumanos ${ }^{125}$. Más allá de las herramientas exosomáticas que el humano ha inventado y desarrollado a lo largo de su existencia, el humano hoy es cuerpo-contecnología permanentemente conectada a él. Tenemos que mencionar aquí los trabajos de Donna Haraway que ya hace treinta años explicó como todos somos cyborgs. Todos somos un conjunto de carne y metal, información, plásticos y productos farmacéuticos y así sucesivamente. Con el cyborg tanto el sujeto como el objeto han desaparecido como ontologías y es la información lo que marca los límites.

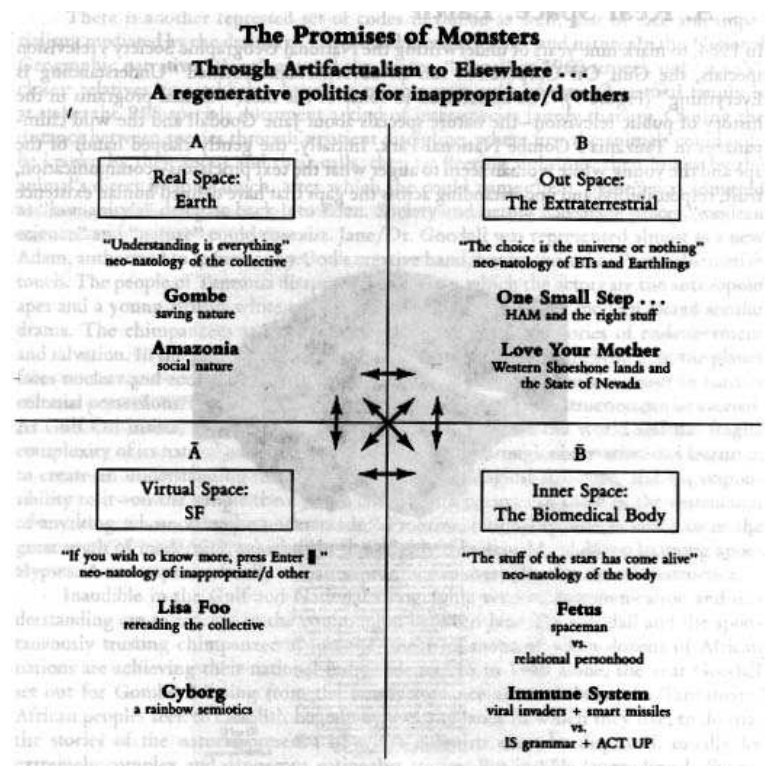

Fig. 08 Relaciones intro-exo del ciborg y otros seres socio-técnicos Donna Haraway en La promesa de los monstruos.

\footnotetext{
${ }^{123}$ Ibid., p.16

${ }^{124}$ Sloterdijk, Peter. Esferas II. Globos. Macrosferología. Madrid, Siruela, 2004, p.560.

${ }^{125} \mathrm{O}$ en los términos de la filósofa Braidotti sobre la condición posthumana.
}

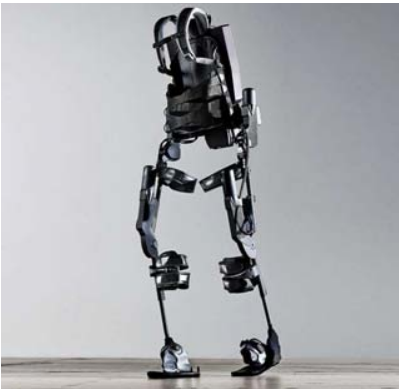

Img. 13

Un exoesqueleto, es un esqueleto externo que permite como dispositivo tecnológico no solo soportar un cuerpo que no puede soportarse a sí mismo, sino detectar la intencionalidad de los movimientos del cuerpo. 


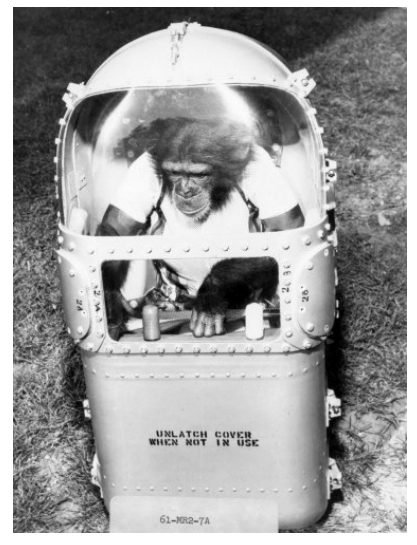

Img. 14

Ham 1956-1983, el primer homínido en volar al espacio exterior en 1961 dentro del proyecto Mercury. Imagen: Archivos NASA.
La primera cuestión interesante para nosotros en la definición de un cuerpo sin exterior como un cuerpo urbano, es la condición que no son ya solo los cuerpos humanos los que definimos como cuerpos urbanos. El caso de Ham, explicado por Haraway, es de especial relevancia. Un cuerpo urbano no humano que participa de las hibridaciones socio-técnicas, en este caso, en el espacio exterior. El 31 de enero de 1961, como parte del programa hombre-en-el-espacio de Estados Unidos, el chimpancé Ham fue lanzado en un vuelo suborbital. Ham era el nombre socio-técnico de la institución científico-militar que lo envió al espacio: Holloman AeroMedical. Los chimpancés, antesala de los humanos en la carrera aeroespacial, se articularon como cyborgs en un ensamblaje de naves espaciales, cápsulas a medida, tecnologías de grabación y localización, seres humanos, máquinas anti-gravedad el espacio terrestre y el espacio exterior, todo esto en el contexto de la Guerra Fría. Como dice Haraway:

No podía haber otro cyborg más icónico que un chimpancé telemétricamente implantado, sustituto del hombre, lanzado desde la tierra en un programa espacial, mientras su compañero de especie está en la selva. ${ }^{126}$

La segunda cuestión es que el cyborg, al igual que el flaneur ${ }^{127}$ es una figura que emerge en situaciones específicas. No es un cuerpo-máquina directamente visible. No resulta solo de la adición de prótesis que se acoplan a su cuerpo, sean estas mecánicas, electrónicas o digitales. El cuerpo cyborg emerge en cada situación y es diferente en cada lugar ${ }^{128}$ : en la casa, en la oficina, etc. Es en la ciudad donde encontramos más concentración de devenires cyborgs. Los sistemas de transporte urbano son un ejemplo posible de este devenir.

Pero este cyborg no es solo producto de artefactos tecnológicos visibles. También es el cuerpo ligado a objetos de baja tecnología ${ }^{129}$. Pensemos en el ejemplo descrito por Beatriz Preciado de Hugh Hefner. Un cuerpo ligado a una cama redonda, a un teléfono y unas drogas para estar despierto. El cuerpo ligado a artefactosobjetos altera la metafísica distancia entre máquina y hombre. No hay objetos exteriores a los cuerpos, sino continuidades y simultaneidades entre ambos.

Otro cuerpo sería el cuerpo ligado a tecnologías de modificación del propio cuerpo. Biotecnologías que alteran y modifican el estado de los cuerpos. Tan solo pensemos en los cuerpos de la biomujer Hippe de los años 70 o los cuerpos

\footnotetext{
${ }^{126}$ Haraway, Donna. "Las promesas de los monstruos: una ploítica regeneradora para otros inapropiados/bles". Política y sociedad, n.30, 1999, p.12.

${ }^{127}$ Flaneur: Paseante callejero. Fue Walter Benjamin, quien lo elevó a objeto de estudio como la figura esencial del moderno espectador urbano, un detective aficionado y un investigador de la ciudad.

${ }^{128}$ Cfr. Shields, Rob. "Flanerie for cyborgs". Theory, Culture \& Society. 2006, London. Thousand Oaks and New Delhi, v.23, n.7-8, pp.209-220.

${ }^{129}$ Es más preciso el concepto en inglés de Soft Power.
} 
neumáticos de Pamela Anderson y Arnold Schwarzenegger. Los cuerpos se modifican mediante procesos de implantación y explantación de prótesis mamarias u órganos genitales.

El mismo Arnold será en la ficción un cuerpo cyborg representado por Terminator como organismo híbrido cibernético. Terminator nos permite explicar de una manera sencilla el concepto de híbrido planteado por Bruno Latour. Según él, "el error del paradigma dualista radicaba en su definición de humanidad. Incluso la forma de los humanos, nuestro propio cuerpo, se compone en gran medida de negociaciones y artefactos socio-técnicos. Concebir la humanidad y la tecnología como polos opuestos significa en efecto, desear que la humanidad se despida" ${ }^{130}$ Y lo que hace precisamente Terminator es explicitar una nueva convergencia entre lo humano-la máquina y la nueva sociedad híbrida que ensambla multitud de agentes diversos, no ya sujetos y objetos, sino cuerpos híbridos en distintas asociaciones y mediaciones.

Podemos decir, siguiendo a Foucault, que el cuerpo moderno se formó en las celdas de los monjes medievales. La celda monacal medieval como ese reducido laboratorio de lo individual; cuerpo y alma, separados y en exo-pertenencia, ponían a prueba los límites del cuerpo en exclusión y separación. Sin embargo, hoy en día el individuo moderno ultra conectado alberga en su cuerpo un diseño también dado: un cuerpo biopolítico, es decir configurado y normativizado por las leyes de estado, del mercado y de los múltiples vectores que lo atraviesan.

Sin embargo, el avance tecnológico también abre la posibilidad de diseñar el cuerpo biológico. Ortega y Gasset hablaba del intracuerpo y el extracuerpo ${ }^{131}$. El cuerpo del monje y el alma. Sujeto (conciencia) y objeto (cuerpo). El ahora sujeto-cuerpo-objeto biomecánico y biopolítico proviene principalmente de la medicina, la ingeniería y la industria farmacotecnológica que se unen disolviendo la exterioridad que le era dada a priori.

Este desarrollo simultáneo del sujeto-cuerpo-objeto hace operar al cuerpo como entidad mediadora con su propia agencia y en múltiples procesos. El cuerpo es medio, receptor y productor de imágenes, de diseños, de atmósferas. Por eso es interesante esta relación del cuerpo en la producción de imágenes.

Mi cuerpo es una cosa para los otros, quienes me convierten en objeto con su mirada, porque me ubican en un espacio tiempo en relación a su propia percepción. Yo, como objeto y sujeto, por el mero hecho de existir y estar

\footnotetext{
${ }^{130}$ Latour, Bruno. La esperanza de Pandora. Barcelona, Gedisa, 2001, p.256.

${ }^{131} \mathrm{~S}$ in entenderlos en un sentido espacial, sino como cuerpo vivido y cuerpo objetivo. Cfr. López-Ibor, J.J. El cuerpo y la corporalidad. Madrid, Gredos, 1974.
} 


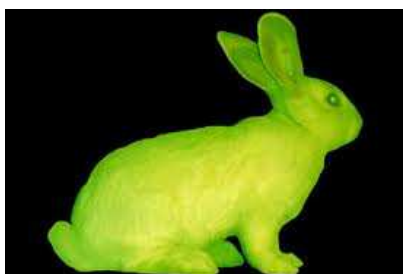

Img. 15

Alba, cuerpo animal de un conejo de piel Fosforescente. Desarrollado con técnicas biotecnológicas por el artista chileno Eduardo Kac. 2000. expuesto a la mirada de los otros, me constituyo en imagen, una imagen de mí mismo. Y a su vez yo, convierto otros cuerpos en objetos y mediatizo los cuerpos que me rodean. ${ }^{132}$

En este contexto cabría mencionar los diferentes modos de clasificación de los objetos-sujetos que generan en su trayectoria otros cuerpos posibles. En su teoría esfereológica Peter Sloterdijk nombra tres tipos: "Los objetos inventados, como los automóviles o tamagochis. Los objetos descubiertos como las feromonas o el virus del sida, y los objetos mixtos, híbridos como bacterias recombinables, enzimas, transgénicos o los conejos fosforescentes mencionados. Estos objetossujetos pueden también explicitar otros cuerpos complementarios a los ya mencionados en este capítulo. Lo explicamos en el capítulo 2.2.2

En un tiempo donde existía un exterior referente al cuerpo, es el cuerpo el que sucumbe o se sirve del medio que lo acoge. El cuerpo se transforma en función de las condiciones del entorno, climáticas, atmosféricas. Hoy en día son los ambientes los que se adaptan a los cuerpos. Se controlan los entornos, se diseñan y se convierten en lugares habitables. Explicaremos más tarde estas relaciones que enuncia Peter Sloterdijk.

Por último, los límites tradicionales entre los cuerpos y la ciudad, pasando por otras esferas tradicionalmente concéntricas como la casa, el espacio público, etc. se diluyen. Si la ciudad, como enunciamos antes puede ser un objeto, también puede ser un fenómeno, un lugar de acontecimientos interconectados. Está noción de ciudad modifica el significado de los cuerpos. "La ciudad como fenómeno es la ciudad como información y también la ciudad virtual como acontecimiento. Esta última no tiene tiempo ni espacio estable que se da en la ciudad como objeto material, y es una ciudad donde tampoco hay jerarquías teniendo una expansión topológica en cuanto al espacio y al tiempo." ${ }^{133}$ De esta forma el cuerpo es la entidad atravesada por estas trayectorias. "El cuerpo se embriaga y se disuelve en la ciudad como fenómeno. El cuerpo, que se resistía a ser consumido, está a punto de ser tragado, sin darse cuenta por una ciudad sin sustancia. La ciudad como fenómeno es una ciudad sin tiempo y sin lugar" ${ }^{134}$

A esta ciudad, el arquitecto japonés Toyo Ito, le atribuye una serie de principios como son el de la homogeneidad, transparencia, fluidez, relatividad y fragmentación. Estos principios también son aplicables al cuerpo. Los principios que esta tesis enumera, son principios que tratan de hacer comprensible y visible la

\footnotetext{
${ }^{132}$ Santana, Aristides. El cuerpo Medial. Lugar de la biopolítica. Tenerife, la Piscina, 2013.

${ }^{133}$ Ibid., p.116 .

${ }^{134}$ Ito, Toyo. Escritos. Murcia, Colegio Oficial de Aparejadores y Arquitectos Técnicos de Murcia, 2000, p.117.
} 
ausencia de exterioridad y nos hacen preguntas sobre como operar con ellos. Por ejemplo, si el mundo se nos presenta como una realidad fragmentada, son nuevas herramientas las que nos pueden ayudar a buscar las continuidades $\mathrm{y}$ simultaneidades en esta realidad. Reconstruir o reconstituir las relaciones que provocan la fragmentación, nos ayuda a encontrar nuevas herramientas de proyecto. Y esta realidad es la que conforma estos otros cuerpos: "La visión del mundo cambia radicalmente según se interprete el cuerpo humano. Por un lado podemos considerarlo como un cuerpo sólido, estático y simétrico y por otro como un movimiento dentro de un flujo.” ${ }^{135}$

El espacio urbano no es ya entonces algo dado, sino que citando a Toyo Ito "son los cuerpos, los que crean dentro de sí mismos, el espacio urbano como su propia metamorfosis, escogiendo los lugares y uniéndolos" 136 en una metamorfosis constante. Por lo tanto no puede existir exterioridad cuando una categoría está contenida en otras. Como explica Toyo Ito, el espacio urbano está contenido ya en los cuerpos.

\subsection{Ensamblajes múltiples}

Para entender el alcance que puede tener la ANT o Teoría de las asociaciones, la sociología de la mediación o la ontología plana, en nuestro propósito de demostrar la desaparición de la exterioridad debido a su internalización, debemos desarrollar el concepto de ensamblaje como herramienta para la sustitución de redes prolongadas por redes más situadas.

El repertorio de la ANT y conceptos clave que hemos desarrollado como la composición de entidades híbridas, la agencia compartida o las entidades sin exterior, nos permiten abrir un grado de complejidad para entender las aportaciones que la ANT puede hacer a los estudios urbanos y la arquitectura.

Para ello, elaboramos una aproximación al ensamblaje urbano desde la ANT, para hacer un desplazamiento de la ciudad como objeto de estudio al estudio de las entidades múltiples y heterogéneas que lo componen. También para desvelar la capacidad de los ensamblajes para dar cuenta de lo actual y lo virtual. Y por último entender su alcance para temporalidades reducidas.

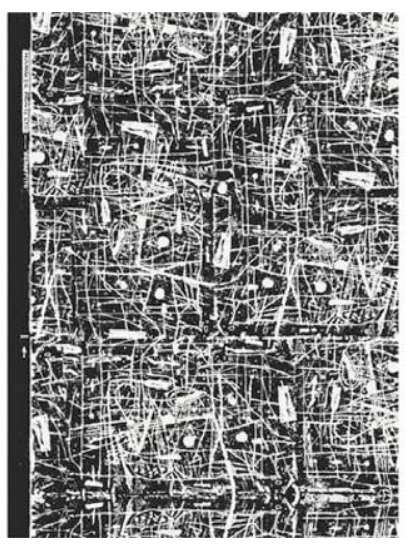

Img. 16

Nigel Henderson y Eduardo Paolozzi. Hammer Prints. 1954.

\footnotetext{
${ }^{135}$ Ibid., p.70.

${ }^{136}$ Ibid., p.91
} 
La noción de ensamblaje será interesante para extender el ámbito de la arquitectura contemporánea e internalizar también entidades que aún son exteriores a la misma.

\subsubsection{Agenciamientos}

Agenciamiento $^{137}$ es un concepto que remite a la relación de las capacidades de acción de las diferentes entidades, objetos, procesos, discursos, de componer agencias múltiples en su conjunto. Deleuze y Guattari desarrollaron el concepto a partir de la construcción de la topología de los estratos, territorios y procesos de agenciamientos múltiples entre ambos. Como entidad que aglutina a todas las demás entidades, asociaciones y sus mediaciones, a un agenciamiento podemos atribuirle ciertas características ${ }^{138}$ :

1. Lo primero que hay en un agenciamiento es algo así como dos caras o dos cabezas. Estados de cosas, estados de cuerpos; pero también enunciados, regímenes de enunciados.

2. La unidad real mínima no es la palabra, ni la idea, ni el concepto, ni tampoco el significante. La unidad real mínima es el agenciamiento.

3. Un agenciamiento, sólo está en conexión con otros agenciamientos.

4. Un agenciamiento es precisamente ese aumento de dimensiones en una multiplicidad que cambia necesariamente de naturaleza a medida que aumenta sus conexiones.

5. Se necesita un agenciamiento para que se produzca la relación entre dos estratos.

6. Los agenciamientos no cesan de variar, de estar ellos mismos sometidos a transformaciones.

7. Un agenciamiento no conlleva ni infraestructura y superestructura, ni estructura profunda y estructura superficial, sino que aplana todas sus dimensiones.

En base a estas características, Deleuze define un agenciamiento como:

Una multiplicidad compuesta de muchos elementos heterogéneos en la cual se establecen vínculos, relaciones entre ellos a través de diferentes naturalezas. Así, la única unidad del ensamblaje es la cofuncionalidad: es una simbiosis. ${ }^{139}$

\footnotetext{
${ }^{137}$ La noción de ensamblaje (o agenciamiento) no proviene del repertorio conceptual de la ANT, sino de los trabajos de Deleuze y Guattari sobre el agenciamiento y el rizoma. Agenciamiento ha sido traducida de diversas maneras: Agenciamiento (tad.cast. de D,R,MP) dispositivo (trad.cast. de K), componenda (Pardo, 2000) y también disposición (Pardo 1992 y trad. cast. de QPH)

${ }^{138}$ Características extraídas de la introducción que hacen Deleuze y Guattari del concepto de Rizoma. en Mil mesetas, capitalismo y esquizofrenia Valencia, Pre-textos, 1980.

${ }^{139}$ Deleuze, G. \& Parnet, C. Dialogues. NY, Columbia University Press, 1987, p.52.
} 
Los agenciamientos, para Deleuze y Guattari están formados por el plan de consistencia (inmanencia) y el plan de organización (desarrollo) y en estos las relaciones de exterioridad se internalizan en su selección y se externalizan en su proyección "lo interior es tan solo un exterior seleccionado, y lo exterior un interior proyectado" ${ }^{140}$ Son entonces planos que se relacionan en una exterioridad, la del plan de consistencia. Ambos planes dan cuenta de lo actual y lo virtual. El agenciamiento en Deleuze y Guattari relacionan las capacidades, los afectos, el deseo como tendencias virtuales, es decir, real sin ser virtual. Ambos se presentan en relaciones entre el plan de consistencia y el inmanencia.

Las multiplicidades se definen por el afuera: la línea abstracta, de fuga o de desterritorialización según la cual cambian de naturaleza por medio de su conexión con otras. Así, el afuera de todas las multiplicidades recibe el nombre de plan de consistencia. Se trata de un afuera carente de imagen, significación y subjetividad, vale decir de una ruptura asignificante. ${ }^{141}$

Para Deleuze y Guattari, el agenciamiento se produce en conexión con otras entidades que forman lo que llama el plan de consistencia [exterioridad]: "acontecimientos vividos, determinaciones históricas, conceptos pensados, individuos, grupos y formaciones sociales" ${ }^{142}$ Deleuze lo explica en los principios que establece para situar el rizoma, como entidad aglutinante de agenciamientos múltiples.

Los rizomas se caracterizan por no responder a un modelo estructural o generativo alguno y tiene los siguientes principios: ${ }^{143}$

$1 .^{\circ}$ y $2 .^{\circ}$ Principios de conexión y de heterogeneidad: cualquier punto del rizoma puede ser conectado con cualquier otro, y debe serlo. Eso no sucede en el árbol ni en la raíz, que siempre fijan un punto, un orden.

3. Principio de multiplicidad: solo cuando lo múltiple es tratado efectivamente como sustantivo, multiplicidad, deja de tener relación con lo Uno como sujeto o como objeto, como realidad natural o espiritual, como imagen y mundo.[...] Una multiplicidad no tiene ni sujeto ni objeto, sino únicamente determinaciones, tamaños, dimensiones que no pueden aumentar sin que ella cambie de naturaleza (las leyes de combinación aumentan, pues, con la multiplicidad).

\footnotetext{
${ }^{140}$ Ibid., p.52.

${ }^{141}$ Deleuze \& Guattari. Op. Cit., p.14.

${ }^{142}$ Ibid., p.14.

${ }^{143}$ Ibid., pp.13-16.
} 
4. ${ }^{\circ}$ Principio de ruptura asignificante: frente a los cortes excesivamente significantes que separan las estructuras o atraviesan una. Un rizoma puede ser roto, interrumpido en cualquier parte, pero siempre recomienza según ésta o aquella de sus líneas, y según otras.

5. ${ }^{\circ}$ y $6 .{ }^{\circ}$ Principio de cartografía y de calcomanía: un rizoma no responde a ningún modelo estructural o generativo. Es ajeno a toda idea de eje genético, como también de estructura profunda. Un eje genético es como una unidad pivotal objetiva a partir de la cual se organizan estadios sucesivos; una estructura profunda es como una serie cuya base se puede descomponer en constituyentes inmediatos, mientras que la unidad del producto está en otra dimensión, transformacional y subjetiva.

Los agenciamientos de Deleuze operan desde el entendimiento que hacen de las relaciones entre la totalidad y las partes. En este desarrollo la totalidad para Deleuze y Guattari se caracteriza por relaciones de exterioridad frente a las teorías hegelianas de las relaciones de interioridad. El pensamiento sistémico se da desde un aspecto organicista, es decir, como totalidades sin interrupciones. Si tradicionalmente cuando en una relación entre partes y totalidad se separa una del conjunto, este deja de serlo porque la parte particular es una de sus propiedades constitutivas. Estas relaciones producen relaciones de interioridad. Pero Deleuze y Guattari introducen el concepto de relaciones de exterioridad donde estas relaciones caracterizan totalidades otras.

Cuando decimos que son relaciones de exterioridad, son relaciones que hasta el momento se han considerado como fuerzas exteriores. Es importante esta noción para comprender, en el punto que continúa, como los ensamblajes se basan en relaciones de exterioridad; aunque como veremos ellos mismos no remiten un exterior al que referenciarse.

\subsubsection{Ensamblajes}

Manuel de Landa recoge las investigaciones de Deleuze para reelaborar el concepto de agenciamiento como ensamblaje. M. De Landa re-elabora y sitúa las relaciones de exterioridad e interioridad respecto al agenciamiento.

Basadas en la teoría de las asociaciones de Bruno Latour pero con diferencias particulares, y en la noción de agenciamiento de Deleuze, Manuel de Landa propone una sociología del ensamblaje de heterogéneas redes de componentes materiales ya asociados. 
Continuando con el trabajo de ampliar la asociación de relaciones sin reducir las acciones a un todo individuo racional o a la experiencia fenomenológica o a un todo como estructura social, Manuel de Landa explicita la posición relativa de las entidades individuo-colectivo o micro-macro en función de la escala o posición que ocupan en una relación parte-todo:

La distinción micro/macro puede ser mantenida mientras sea relativa a cierta escala: las personas son micro como componentes de comunidades, las cuales serían macro; pero las comunidades son micro si hablamos de coaliciones de comunidades, como se dan en los movimientos de justicia social. Por usar otro ejemplo, las personas son micro en la medida en que son componentes de organizaciones institucionales, pero las últimas son micro si estamos estudiando un gobierno federal compuesto de muchas organizaciones. No hay micro o macro absolutos, sólo relativos a cierta escala, la cual es a su vez relativa a la relación parte/todo. ${ }^{144}$

Por lo tanto, las relaciones se producen en niveles que no son ni micro, ni macro sino en una multiplicidad de relaciones entre ellos y con ellos simultáneamente y no referidos directamente a una escala espacial sino a todas ellas, indistintamente. La introducción de una variedad de niveles intermedios produce que un conjunto pueda constituir la entidad más pequeña para ensamblajes cada vez más grandes. De landa propone una doble serie ascendente de ensamblajes.

[En la primera] pasamos del sujeto-interacciones-redes-organizacionesgobiernos-comunidades que emergen en virtud de la intensidad de relaciones sociales. [La segunda] casas-edificios-barrios-ciudades-estados-nación encuentra en extensiones espaciales su fuente de estabilidad. ${ }^{145}$

Esto es interesante porque Manuel de Landa ofrece una perspectiva escalar para manejar los ensamblajes pero esta vinculación es independiente del espacio, por ejemplo, un amigo puede estar unido por teléfono o internet estando dispersos geográficamente. Manuel de landa separa el componente espacial de los demás componentes. Esta condición es importante para distinguir también las relaciones que se producen entre las partes y el todo.

$\mathrm{Si}$ como decíamos antes estas las relaciones se producen como procesos de interioridad en un sistema orgánico en la aproximación de De Landa. Estas se producen como relaciones de exterioridad en un ensamblaje:

\footnotetext{
${ }^{144}$ Farías, Ignacio. Entrevista a Manuel de Landa. "Hacia una nueva ontología de lo social”. Persona y sociedad. Universidad Alberto Hurtado, v.23, n1, 2008. pp.75-85.

${ }^{145}$ Ibid., p82-83 sobre el libro De Landa, Manuel. A New Philosophy of Society. Assemblage Theory and Social Complexity. London, New York, Continuum, 2006.
} 
Las relaciones entre partes son de interioridad si las partes son constituidas como tales por el papel que juegan en el todo. En otras palabras, si las partes se constituyen mutuamente por sus relaciones de interioridad, entonces son inseparables del todo (una parte separada deja de ser lo que es) y todo se vuelve indivisible. Pero en un ensamblaje, un componente sí se puede separar y volverse parte de otro ensamblaje. Las relaciones de exterioridad entre partes son interacciones en las que las partes ejercitan ciertas capacidades de afectar y de ser afectadas por, otros partes, pero el ejercicio de esas capacidades no determina su identidad. ${ }^{146}$

Las relaciones que argumenta entonces, devienen exteriores o interiores de una totalidad dependiendo de las distinciones entre sus propiedades y capacidades. Si la separación de un fragmento del todo hace que este pierda sus propiedades, capacidades o su identidad, estas relaciones se dan en situación de interioridad. Pero, si por el contrario estas relaciones entre el todo y las partes son múltiples, es decir, que el todo no genera la identidad de cada parte ni la parte la identidad del todo, el ensamblaje se produce en condiciones de exterioridad entre las partes y el todo. Ignacio Farías lo explica de otro modo:

La noción de ensamblaje, como explica Manuela de Landa, permite pensar todos como constituidos por partes heterogéneas. La noción clásica veteroeuropea de unitas multiplex concibe relaciones de interioridad entre las partes y el todo, en el sentido que las partes se constituyen por el papel que juegan en el todo. Ahora bien, esto implica que las partes devienen inseparables del todo que las constituye y que el todo deviene una totalidad indivisible. Los ensamblajes no constituyen totalidades en ese sentido, pues las relaciones entre partes y todo se basan en un principio de exterioridad [por el papel que juegan en el todo]. ${ }^{147}$

Será el propio Ignacio Farías, el que en base a esta aproximación, desarrolle el concepto de ensamblajes urbanos. Esta noción permitirá dotar al ensamblaje de cualidades para componer relaciones entre lo actual y lo virtual entre entidades diferentes. Los ensamblajes urbanos tendrán la capacidad de dar cuenta de una actualización de lo virtual en la ciudad. Y, en esa relación, también elaborar una ontología alternativa de la ciudad.

\footnotetext{
${ }^{146}$ Ibid., pp.79-80.

${ }^{147}$ Farías, Ignacio. "Ensamblajes urbanos: la TAR y el examen de la ciudad". Athenea Digital, 2011, v.11, n.1, p.30
} 


\subsubsection{Ensamblajes urbanos}

Entendida la relación de exterioridad entre las partes y el todo del ensamblaje y la actualización de lo virtual, podemos reubicarlo ahora en el campo de los estudios urbanos para valorar sus potencialidades.

Los ensamblajes son las formas líquidas o fluidas, dinámicas y por ello cambiantes permanentemente de entender los asuntos urbanos. Después de cuestionarnos poder describir la ciudad como forma estructurada, con límites, tamaños, escalas, etc. podemos entenderla como un objeto y un proceso a la vez. Cuando hablamos entonces de ciudad hablamos de objetos urbanos, naturalezas, medios-ambientes construidos y cuerpos que se performan en ella. Por esto, el foco en la ciudad o en sus espacios es solo contingente ${ }^{148}$.

La primera aproximación a los ensamblajes urbanos es que las relaciones de producción de estos ensamblajes, tal como ha explicado Manuel de Landa, se hagan en condiciones de exterioridad. Esto no significa que el ensamblaje posea en sí mismo exterioridad. El ensamblaje es un concepto sin exterioridad pues ha internalizado su exterior constitutivo.

La consecuencia más importante de esta ontología es que tal vez la noción de ensamblaje no implica un exterior, no implica una exterioridad. [...] Los ensamblajes son auto-contenidos [self contained] de asociaciones heterogéneas que solicitan una descripción positiva de su devenir, sin explicaciones externas. $^{149}$

Por otro lado, el ensamblaje, como herramienta metodológica, nos ayuda a hacer descripciones empíricas desde una ontología de lo múltiple. Nos ayuda a comprender la ciudad no como un todo, sino como una noción de lo múltiple.

La ciudad se viene investigando como el estudio del medio urbano y podemos pasar a describirlo como el estudio de los ensamblajes urbanos múltiples. ${ }^{150}$

La noción de ensamblaje urbano situada por Ignacio Farías y Mc Farlane también nos permite pensar en el concepto de la agencia distribuida de sus componentes o entidades. Es decir, que las capacidades de agencia de un objeto, por ejemplo, no le pertenecen permanentemente. La capacidad de agencia puede desplazarse, y de hecho lo hace. La ciudad de esta manera, es el entorno que contiene el mayor número de múltiples agencias distribuidas. Definirla de esta manera es definirla

\footnotetext{
${ }^{148}$ Farías, Ignacio."The politics of urban assemblages." City: analysis of urban trends, culture, theory, policy, action. n.15, v.3-4, 2011, p.369.

${ }^{149}$ Ibid., p.369.

${ }^{150} \mathrm{Ibidem}$
} 
fuera de un sistema estructurado y formal. Por lo tanto, la ciudad adquiere su sentido como lugar de máxima intensidad en un espacio de relacionalidad híbrida.

En tal espacio, las nociones de actor y red designan dos caras de una misma moneda, dos formas complementarias de dar cuenta de lo social y su incrustación en un principio de relacionalidad híbrida. ${ }^{151}$

Pero la ciudad no se compone solo de actores, humanos y objetos, edificios, infraestructuras y redes. Es importante para el concepto de ensamblaje pensar en, por ejemplo, las capacidades de agencia del conocimiento, como indica Farías sobre la observación de Koray Calışkan y Michel Callon. Un ejemplo sería el investigado en los procesos de mercadización pues no solo dependen de una multiplicidad de actores y agentes situados en espacios diversos, sino que dependen además de tipos de conocimiento económico. La ANT transforma así radicalmente la forma de pensar la relación entre ciudad y economía. En vez de partir desde la ciudad para estudiar el sistema económico-productivo que se constituye en su interior. "La ANT obliga a partir con el estudio de redes tecnoeconómicas translocales para observar como estas atraviesan la ciudad constituyendo tanto industrias como mercados." ${ }^{152}$

Para entender el alcance de los ensamblajes en los temas urbanos, nos preguntamos ¿Por qué podemos entender que la ciudad no puede ser concebida como una de las formas de la exterioridad en cualquiera de sus modalidades? Según Ignacio Farías podemos encontrar tres principios que argumenten esta idea y relacionar los ensamblajes con la ausencia de exterioridad. ${ }^{153}$ El primero sería precisamente ese:

1. La ciudad no existe en un afuera. Una de las consecuencias más importantes de los ensamblajes es que no implican un exterior. Hacen de la ciudad una forma sin exterioridad. Los ensamblajes son procesos de asociaciones heterogéneas independientes de aclaraciones externas a ella.

2. El segundo principio, consecuencia del anterior, es que la ciudad no está construida socialmente, sino que implica un trabajo de composición. La ciudad entonces no solo se actualiza en redes heterogéneas y depende de la acción colectiva de entidades heterogéneas, sino que resulta además de un

\footnotetext{
${ }^{151}$ Farías, Ignacio. "Ensamblajes urbanos: la TAR y el examen de la ciudad." Op. Cit., p.18.

${ }^{152}$ Ibid., p.23.

${ }^{153}$ Ibidem.
} 
trabajo composicional por el cual se definen las formas de convivencia entre distintos tipos de objetos y agentes.

3. El tercer principio es que la ciudad constituye un objeto múltiple, esto es, compuesto simultáneamente de múltiples maneras.

Frente a la definición clásica de la ciudad, como objeto que opera por superposiciones de capas independientes, establecemos una definición de entidad donde esas capas operan de manera interdependiente y se afectan unas a otras. Más allá de la definición cartográfica de la ciudad desde sus redes, por ejemplo, desde sus infraestructuras de movilidad, su proxémica escalar, su definición concéntrica, etc. La ciudad opera también desde el conflicto de estas infraestructuras junto con otras acciones y prácticas, como las de la imposibilidad del acceso a estas infraestructuras ${ }^{154}$ para determinados ciudadanos o la superposición con el uso de ellas de diversas entidades: coches privados, transporte público, caminantes, o gente en bicicleta o la relación con la superficie de aparcamientos subterráneos de la ciudad y la contaminación de la misma.

Los ensamblajes urbanos no constituyen, en ese sentido, realizaciones finales de la ciudad, sino que se hallan entrelazados y concatenados en múltiples niveles, haciendo proliferar los planos y capacidades de acción en la ciudad. Así, la ciudad como entidad múltiple que resulta del entrelazamiento de ensamblajes urbano se caracteriza por la producción de complejidad urbana. ${ }^{155}$

A su vez, las representaciones tradicionales por superposición no infieren en las tensiones sociales producidas por alguna de las entidades estudiadas (red de transporte por ejemplo) Si se cartografían las entidades afectadas y los conflictos generados pueden hacer emerger otro punto de vista sobre otros aspectos diferentes en relación con la capa estudiada. No es una capa más, sino un agregado de situaciones dispersas que se manifiestan por el conflicto. Por ejemplo, en las cartografías críticas de Iconoclasistas o las cartografías semánticas de Teddy Cruz. "Venimos experimentando formas alternativas de cartografiar las situaciones y los escenarios que alteran y desbordan nuestras capacidades de "navegarlos". Ya no se trata de "representar" una realidad allá afuera. Se trata de conectar "indicadores" en diversos marcos. Se trata de que lo representado y la representación no estén separados por una grieta insuperable. “156

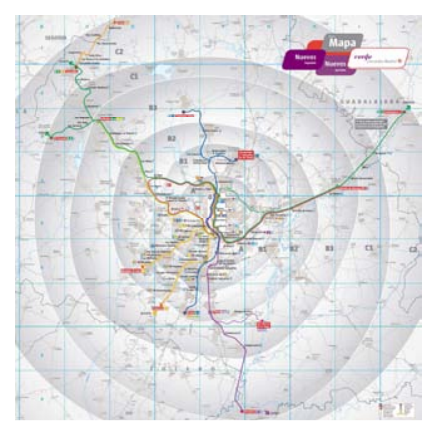

Img. 17

Sistema de la red de tren de cercanías de la ciudad de Madrid. Cercanías RENFE.

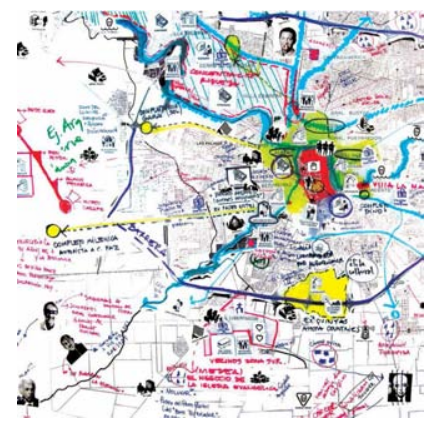

Img.18

Iconoclasistas. Cartografía crítica de la ciudad de Córdoba. Argentina

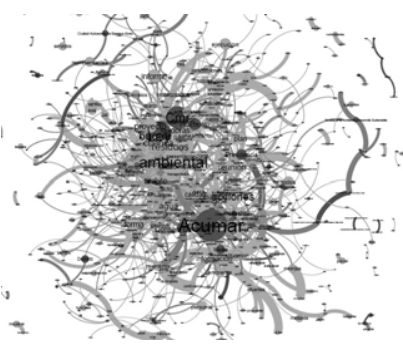

Img.19

Teddy Cruz. Cartografía Semántica. Laboratorio de incertidumbres y ensamblajes.

\footnotetext{
155 Ibid., p. 30.

${ }^{156}$ Cruz, Teddy. Memoria de las cartografías del laboratorio de controversias y ensamblajes. https://laboratoriodecontroversias.wordpress.com/mapas/
} 
Estas cartografías brevemente presentadas, permiten entender el alcance del ensamblaje urbano de la ciudad como objeto múltiple. No son capas operacionales de la ciudad ni experiencias subjetivas de la misma. Sino realizaciones múltiples de la ciudad. Navegar por la ciudad es entender sus múltiples ensamblajes conectados.

\subsubsection{La ciudad objeto múltiple}

Que la ciudad no es un objeto estable lo hemos ido viendo desde diferentes perspectivas epistemológicas. Tampoco de un objeto dinámico que observamos desde diferentes puntos de referencia también en movimiento. No podremos aceptar en su totalidad la idea que expone Manuel Delgado al decir que "Lo urbano es la ciudad menos la arquitectura" ${ }^{157}$ La complejidad del objeto múltiple no permite aislar o exteriorizar unos elementos de otros pues entonces no podremos ver su composición en simultaneidad, tal como interacciona en la realidad.

La ciudad es un objeto múltiple, esto es, compuesto simultáneamente de múltiples maneras. Esta afirmación, no es tan obvia como pueda parecer. Pues la ciudad, en muchos de los estudios críticos urbanos, aparece como un objeto único, coherente y estable.

\footnotetext{
Aún cuando buena parte de la investigación urbana contemporánea ha explorado y revelado aspectos relacionales, transaccionales y procesuales de la vida urbana, en la mayoría de los casos la ciudad se concibe como una entidad que puede ser identificada, observada e investigada como una entidad estable en múltiples contextos de representación y práctica. ${ }^{158}$
}

Que la ciudad sea un objeto múltiple, es pensar que la ciudad es más que un entorno construido. Podemos introducir de una manera simétrica elementos que no se definen cuando se habla de ciudad como los sistemas técnicos, o las naturalezas urbanas ${ }^{159}$. Las teorías de la crítica urbana de los últimos 50 años, según Ignacio Farías, comparten el énfasis en la unidad ontológica del objeto ciudad como un objeto espacial, una entidad económico-política o como formación práctica socio-cultural. La ciudad como objeto múltiple significa que está compuesto simultáneamente de múltiples maneras:

\footnotetext{
${ }^{157}$ Delgado, Manuel. "El espacio urbano como universo derretido" Arquitectura Viva. n.136, 2013. Descargable en su blog: http://manueldelgadoruiz.blogspot.com.es/2015/04/el-espacio-urbano-comouniverso.html

${ }^{158}$ Farías, Ignacio. "Ensamblajes urbanos: la TAR y el examen de la ciudad. Athenea Digitaln.11, v.1, p.24.

${ }^{159}$ Cfr. Fogué, Uriel. Ecología política y economía de la visibilidad de los dispositivos tecnológicos de la escala urbana durante el siglo XX. Abriendo la caja negra. Madrid, UPM, 2015.
} 
No se trata entonces de una multiplicidad epistemológica, que se deriva de las distintas perspectivas desde las que se puede conocer un objeto único, sino de una multiplicidad ontológica. ${ }^{160}$

Una ciudad como Madrid se compone de múltiples maneras. De redes de prácticas expertas y no expertas, o con otros "expertizajes" diferentes, que operan de manera simultánea de una manera no carente de conflictos. Las grandes operaciones urbanísticas como Chamartín o Campamento, las infraestructuras de movilidad y su construcción permanente, la ciudad turística, las olimpiadas como motor urbano, el urbanismo ciudadano, el mercado inmobiliario, los desahucios y sus plataformas, espacios comerciales, controlados y vigilados, cañadas reales, mercados informales, sus redes de residuos líquidos, sólidos y gaseosos, la contaminación del aire, plataformas web, participación, dispositivos digitales urbanos, etc. En esta situación, el objeto es múltiple y simultáneo, informe y conformado en su práctica. No hay estratos, superposiciones de tramas y prácticas. No está una encima de la otra (Bottom-up, top-down) sino que unas conviven con las otras, están entrelazadas, interrelacionadas y forman sistemas de cohabitación simultánea. Es entonces un objeto ontológicamente múltiple y simultáneo. No más un objeto estable, coherente, y localizable.

\subsubsection{Crecimiento simultáneo}

Podemos argumentar que la ciudad como objeto múltiple está producida por prácticas que performan sus espacios, sus objetos, sus cuerpos. Sin práctica no hay ciudad, ni objeto múltiple. Y las prácticas se conforman de cuerpos, objetos, animales, tecnologías, materialidades, textos, individuos, economías, conocimiento que no son a priori prácticas sociales. Si recuperamos la argumentación del punto 1.3 sobre el espacio en la red y las topologías fluidas, sobre la continuidad de las formas en topologías espaciales, y recuperamos el trabajo de J. Law y Mol ${ }^{161}$ sobre los objetos y su enactación en el espacio, llegamos a la conclusión de que los objetos son múltiples en relación a las redes de práctica por las que circula.

Si las prácticas están en primer plano ya no hay un solo objeto pasivo en el medio, a la espera de ser visto desde el punto de vista de la aparentemente interminable serie de perspectivas. En lugar de esto, los objetos entran en juegoy desaparecen -con las prácticas en las que se manipulan. Y desde que el objeto de manipulación tiende a diferir de una práctica a otra, la realidad se multiplica.

\footnotetext{
${ }^{160}$ Farías, Ignacio. Op. Cit., p.29.

${ }^{161}$ Annemarie Mol, compañera de Law en sus investigaciones sobre objetos y espacios enactados, estudió durante cuatro años las prácticas médicas sobre la arterioesclerosis publicadas en el libro El cuerpo múltiple. Mol, Annemarie. The Body Multiple: Ontology in Medical Practice. Durham, NC, and London, United Kingdom, Duke University Press, 2002.
} 
El cuerpo, el paciente, la enfermedad, el médico, el técnico, la tecnología: todos ellos son más que uno. Más que el singular. Esto plantea la cuestión de cómo se relacionan. Porque incluso si los objetos difieren de una práctica a otra, existen relaciones entre éstas prácticas. Así, lejos de caer necesariamente en fragmentos, los objetos múltiples tienden a sostenerse juntos de alguna manera. ${ }^{162}$

Las principales diferencias entre los cuerpos y la ciudad, como sugiere Ignacio Farías, son dos: que la ciudad no es un agregado de redes sino que, como hemos citado antes en redes de expertos y no expertos de la ciudad de Madrid, es la acción simultánea de todas esas redes; y la segunda es que la actualización de la ciudad no depende solo de las redes de prácticas que circulan por ella sino del crecimiento conjunto de todas estas entidades heterogéneas en un proceso continuo y simultáneo ${ }^{163}$.

La ciudad se compone de entidades, asociaciones, unidades potenciales y reales. [...] La acumulación de estas entidades puede producir nuevos deveniresporque se encuentran entre sí de muchas maneras, que pueden ser aprehendidos en muchos sentidos, y debido a que presentan concrescencia. ${ }^{164}$

La ciudad como objeto múltiple también crece en simultaneidad. La concrescencia es un término de la botánica que significa "Crecimiento simultáneo de varios órganos de un vegetal, tan cercanos que se confunden en una sola masa"165. Y esto es algo muy común al hablar de la ciudad como objeto. Las prácticas, las acciones, los sistemas son tan cercanos que es muy difícil separarlos para analizar sus procesos cuando además, está en crecimiento continuo y simultáneo. Luego la ciudad como objeto múltiple también es un proceso, a diferencia de los cuerpos de Mol, en crecimiento. Y este crecimiento se basa en las capacidades de agencia e interacción del objeto potenciales y reales:

La multiplicidad no resulta así solo de las distintas redes de prácticas en las que se actualiza un objeto, sino que resulta de las potencialidades y tendencias virtuales internas al objeto y que implican múltiples posibilidades de devenires conjuntos. ${ }^{166}$

Además, estos devenires conjuntos, ante la imposibilidad de disponer del conocimiento de cada red con sus agentes actualizados, los actores que conciernen

\footnotetext{
${ }^{162} \mathrm{Mol}$, Annemarie. The Body Multiple: Ontology in Medical Practice. Durham, NC, and London, United Kingdom, Duke University Press, 2002, pp.4-5.

${ }^{163}$ No se cumple en todas las ciudades. Pues ciudades como Detroit, paralizan su crecimiento y

"encojen" pero el proceso de redes de prácticas en ella siguen estando aunque con menos intensidad.

${ }^{164}$ Citado por Ignacio Farías. Amin, Ash \& Thrift, Nigel Cities. Reimagining the urban. Cambridge,

Oxford, 2002, p. 27.

${ }^{165}$ Real Diccionario de la academia española. RAE

${ }^{166}$ Farías, Ignacio. "Ensamblajes urbanos: la TAR y el examen de la ciudad." Athenea Digital. n.11, v.1, p.28.
} 
a las prácticas, expertos, afectados, humanos y no humanos, los hechos urbanos, los objetos y procesos, los que son socio-técnicos, los construidos o los naturales, las potencialidades son de una incertidumbre muy elevada, conflictivas y dispersas. Y como explica C. Mc Farlane ${ }^{167}$ en la expansión, indeterminación, emergencia, devenir, procesualidad, turbulencias de los asuntos sociomateriales. ${ }^{168}$

Como argumentación final de este punto, podemos decir siguiendo a Farías, que la noción de ciudad como un todo, identificable, estable y coherente, da paso a la idea de ciudad como objeto múltiple, como una multiplicidad de procesos que se ensamblan en la ciudad de maneras diferentes y simultáneas. Esta noción de ensamblajes simultáneos implica entonces una ausencia de exterioridad.

Estos sistemas de ensamblajes no pueden entenderse en términos de diferencia con un entorno (Parsons, Luhmann) ni eventos que pueden ser vistos como una actualización contingente de patrones o sistemas estructuras socio-culturales más grandes (Geertz, Levi Strauss). Los ensamblajes son procesos self-contained de asociaciones heterogéneas que solicitan una descripción positiva de su devenir, sin explicaciones externas. ${ }^{169}$

Si los ensamblajes son una herramienta de investigación para el objeto múltiple, esta nos permite de nuevo cambiar el foco de estudio de la ciudad no solo desde el espacio, sino investigarla también desde los múltiples ensamblajes urbanos en que las topologías urbanas se hacen y deshacen en continuidad. El espacio aparece entonces como un efecto relacional. De esta manera también las heterotopías, como espacio de realidades espaciales simultáneas, se convierten en politopías. Heterotopías que aparecen como efecto de una relacionaliad híbrida entre humanos, no humanos, tecnologías y naturalezas. El entrelazamiento entonces de las agencias y los crecimientos en simultaneidad de los ensamblajes serán el resultado de pliegues continuos de la exterioridad y la interioridad. Las politopias, pertenecerán entonces a esa clase de entornos donde será imposible delimitar sus exterioridades y sus interioridades pues se basan en ellas, como los ensamblajes se basan en relaciones de exterioridad ${ }^{170}$, y a la vez como acabamos de citar, la

\footnotetext{
${ }^{167}$ McFarlane. Colin "The city as assemblage: dwelling and urban space." Environment and Planning D: society and space. 2011, v.29, pp.649-671.

${ }^{168}$ Esto puede verse en los trabajos desarrollados por el autor y VIC en el seminario y consiguiente publicación. Concepts and critique of production of space. Urbanismo Afectivo Knierbein, Sabine. Krasny, Elke, Viderman Tihomir.(eds.) Raum-Skuor-TUM, 2015.

${ }^{169}$ Farías, Ignacio."The politics of urban assemblages." City: analysis of urban trends, culture, theory, policy, action. n.15, v.3-4, 2011, p.369.

${ }^{170}$ Como acabamos de explicar, sobre la definición de ensamblaje de Manuel de Landa, Los ensamblajes permiten pensar todos constituidos por partes heterogéneas. Pero estos no constituyen totalidades pues las relaciones entre las partes se basan en un principio de exterioridad. Cada componente o entidad que forma parte de un ensamblaje se constituye con independencia de ese ensamblaje.
} 
internalización del afuera hace de estos mismo ensamblajes una entidad que no deja exterior alguno, pues el exterior de un ensamblaje se conecta al interior del otro.

\subsubsection{Temporalidades del ensamblaje}

La performación del ensamblaje, implica una labor del actuar, el espacializar y el temporalizar. Y esta cuestión temporal, también tiene vínculos con la noción de ensamblaje urbano que estamos desarrollando. De esta manera, la forma de realizar los ensamblajes urbanos, desde luego, deberá tener en cuenta la multiplicidad de temporalidades que se dan en un hecho o práctica concreta. Y esta multiplicidad, al igual que lo descrito por Massey sobre el "sense of place", 171 podrá darse también en un "sense of time". Un sentido del tiempo no será un sentido del tiempo propio sino que será la esfera de posibilidades temporales de la multiplicidad en el sentido de la pluralidad contemporánea. Hablaremos de temporalidades para englobar un tiempo donde conviven distintas trayectorias, espacialidades y entidades, y donde la heterogeneidad temporal también puede coexistir.

En la aceleración del proceso urbano actual, que cada vez tiende más a la instantaneidad, usamos el concepto de temporalidades no solo para referirnos a la agregación junto a él de las espacialidades y las acciones, sino también en su cualidad transitoria como algo pasajero, fugaz incluso efímero. No remitirá a acciones secuenciales ni permanentes, sino continuas en su condición de continuidad espacial y temporal incluso en sus discontinuidades.

El ensamblaje urbano, bajo esta condición, no solo remite a una categoría espacial resultante de la acción, la performación o los acontecimientos, la espacialización del ensamblaje resultará de su alineamiento sociomaterial. Este a su vez dependerá de condiciones temporales de diferentes ritmos de actividad diurnos o nocturnos; dependerá de diferentes momentos en el tiempo.

Para algunos estudiosos de Foucault la temporalidad del ensamblaje tiene que ver más con lo efímero que con la larga duración. Para Rabinow el ensamblaje es "una matriz experimental de elementos heterogéneos, técnicas y conceptos" que desaparece en años o décadas en lugar de siglos. ${ }^{172}$

Con esta noción sobre la temporalidad de los ensamblajes urbanos, McFarlane quiere explicar que el ensamblaje no es tan útil para explicar los grandes

\footnotetext{
${ }^{171}$ Cfr. Massey, Doreen Space, Place and Gender. Minneapolis, University of Minnesota Press, 1994.

${ }^{172}$ McFarlane, Colin. "The city as assemblage: dwelling and urban space." Environment and Planning D: society and space. 2011, v.29, p. 655.
} 
problemas, donde tenemos el instrumento del aparato (Foucault) o el dispositivo (Agamben), sino explorar la apertura y la emergencia de nuevas problematizaciones a las que no le asignaremos una temporalidad particular, ni siquiera un nivel necesario de estabilidad.

\section{Ejemplo 05: Domesticidades desahuciadas ${ }^{173}$}

Como hemos argumentado varias veces, no podemos ver las formas de la exterioridad tradicionales, la casa, el espacio público, la ciudad como entidades separadas, pues todas ellas se construyen en simultaneidad. Y no solo eso. Sino que estas se conforman se espacializan y se actualizan en situaciones concretas de múltiples maneras ensambladas con otras entidades heterogéneas.

Un caso específico es la situación de los procesos de construcción y desahucio de la vivienda en Madrid durante estos últimos 15 años. Por un lado, la burbuja inmobiliaria desarrolló en la ciudad de Madrid casi un 50\% de su superficie, mientras que la población aumentó sólo un 3,5\%. Esto fue debido a la liberalización del suelo, los créditos baratos y una "campaña de propiedad" dirigido por las administraciones, los medios de comunicación y la sociedad en general. El ciudadano, debía ser un ciudadano "atado" a la propiedad de la vivienda. Este proceso de construcción masiva de la ciudad ligada a la mercadización de lo urbano ${ }^{174}$ se compone de entidades financieras, inmobiliarias, empresas constructoras, nuevas leyes de edificación, incorporación de inmigrantes al mercado de trabajo, expertos técnicos, arquitectos, ingenieros, nuevos códigos y protocolos de construcción, y multitud de entidades más. Todas ellas conforman un primer ensamblaje del desarrollo urbano en torno a la vivienda. España construyó en esos años más viviendas que Francia, Alemania e Italia juntas.

Tras el colapso del mercado financiero, y consiguiente reducción de las economías locales, las entidades comenzaron a recibir morosidades en sus pagos y se pone en marcha toda una maquinaria para desalojar a los propietarios de sus casas por impagos de hipoteca. Aparecen los primeros desahucios en la capital. Si los interesados en el mercado de la vivienda (stakeholders) representan un estado institucional de la vivienda (color azul) aparecen los afectados en este proceso (shareholders) en forma de plataformas de afectados por la hipoteca (PAH) y multitud de colectivos, iniciativas, plataformas que de manera operativa diferente trabajan por un objetivo común: el derecho a la vivienda.

\footnotetext{
${ }^{173}$ Investigación desarrollada por el autor junto a VIC para la Bauhaus Dessau Foundation. 2015.

${ }^{174}$ Relación estudiada por Harvey, David. “El derecho a la ciudad”. New Left Review, n.53, 2008. Akal, Madrid. pp. 23-39.
}

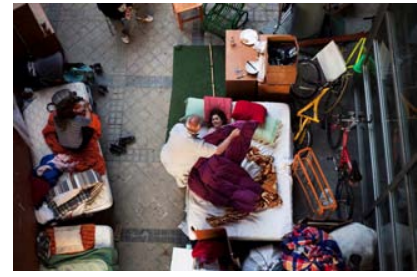

Img 20.

Imagen de una disposición doméstica en el espacio público tras el deshaucio en Madrid de una familia. Imagen Andrés Kudacki/ AP 


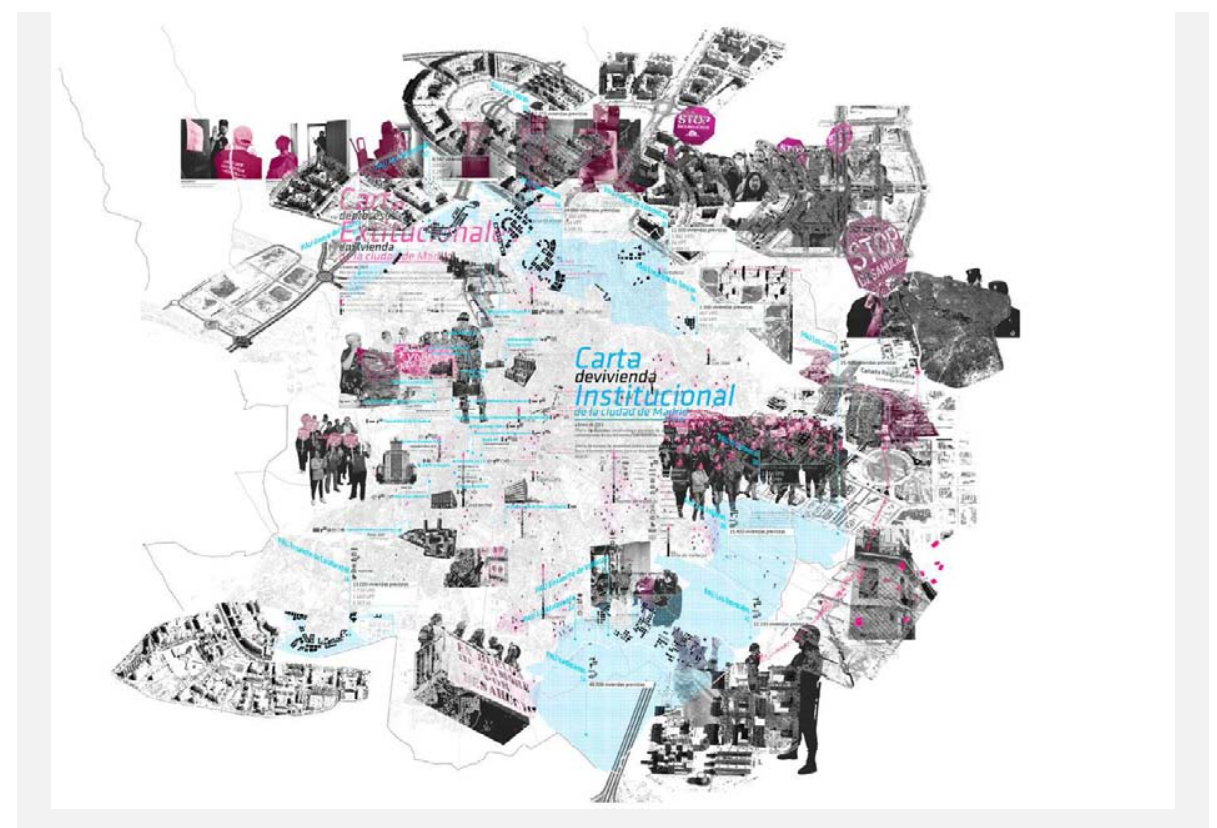

Fig.09 Madrid es un campo de batalla de procesos urbanos en torno a la vivienda. Superposición de la cartografía de vivienda institucional (azul) y la cartografía de procesos y espacialidades extitucionales (rosa)

Madrid se convierte en un campo de batalla, entre ciudadanos y entidades financieras. Este conflicto se visibiliza en multitud de espacialidades de la casa al espacio público y privado. Por un lado oficinas de bancos privados, manifestaciones masivas en espacios públicos, escraches como protestas personalizadas en las calles, discursos parlamentarios, representaciones mediáticas,... todas ellas mediadas por las redes sociales y las tecnologías de comunicación.

La ciudadanía se organiza en un proceso extitucional ${ }^{175}$ para componer un ensamblaje que es parte de un todo. Cada iniciativa, comunidad o plataforma ciudadana forma parte de una red de acciones que son independientes de su participación en su conjunto. Los enlaces se basan en las relaciones entre las partes, los órganos, los individuos, grupos y comunidades, sus objetos, infraestructuras y sus espacialidades, que implican conjuntos de relaciones que no pueden ser explicadas por las partes, a pesar de que dependen de ellos. Estas situaciones tienen a inter-afectarse, sin por ello, constituir mutuamente su propia identidad. Rige el principio de exterioridad que hemos explicado de Manuel de Landa. Pero los desahucios performan en el momento de la ejecución hipotecaria

\footnotetext{
175 Si las instituciones son sistemas organizacionales basados en un esquema dentro-fuera, las extituciones se proponen como superficies en las que pueden ensamblarse, eventualmente, multitud de agentes. De materialidad y temporalidad difusas, la extitución nos sirve para entender las relaciones de poder que toman forma en el capitalismo blando, pero también puede problematizarse y servir como sistema de funcionamiento crítico ante las organizaciones institucionales normativas (hegemónicas y anacrónicas). Por Jara Rocha en el Glosario Abierto de VIC http://viveroiniciativasciudadanas.net/wiki/glosario-abiertos/
} 
un espacializar, un temporalizar y un programa de acción propios. Este performar produce un ensamblaje de domesticidades desahuciadas.

Este ensamblaje urbano se compone de entidades bancarias, fondos buitre, partidos políticos, instituciones de justicia, modificaciones de las leyes de la ejecución hipotecaria, etc. que provoca que un día concreto se presente la policía, el juez, los representantes de los bancos a primera hora de la mañana en una vivienda para desalojar a su propietario. A su vez, ciudadanos organizados bajos las plataformas de derecho a la vivienda forman una entidad de resistencia híbrida. Esta entidad está formada básicamente por:

Cuerpos sólidos y frágiles: La familia desahuciada y unas 10 personas más permanecen dentro de la casa. Otros 50-200 ciudadanos impiden el acceso al cuerpo de policía desde el exterior.

Objetos violentos y de resistencia: los objetos reconfiguran su agencia como objetos de resistencia. Por ejemplo, la nevera se convierte en objeto de resistencia debido a su volumen y peso.

Protocolos múltiples: esta performación tiene sus propios protocolos. Los de la policía por un lado. Los de los medios de comunicación. Los de los servicios sanitarios y asistenciales. Los de los activistas por el otro.

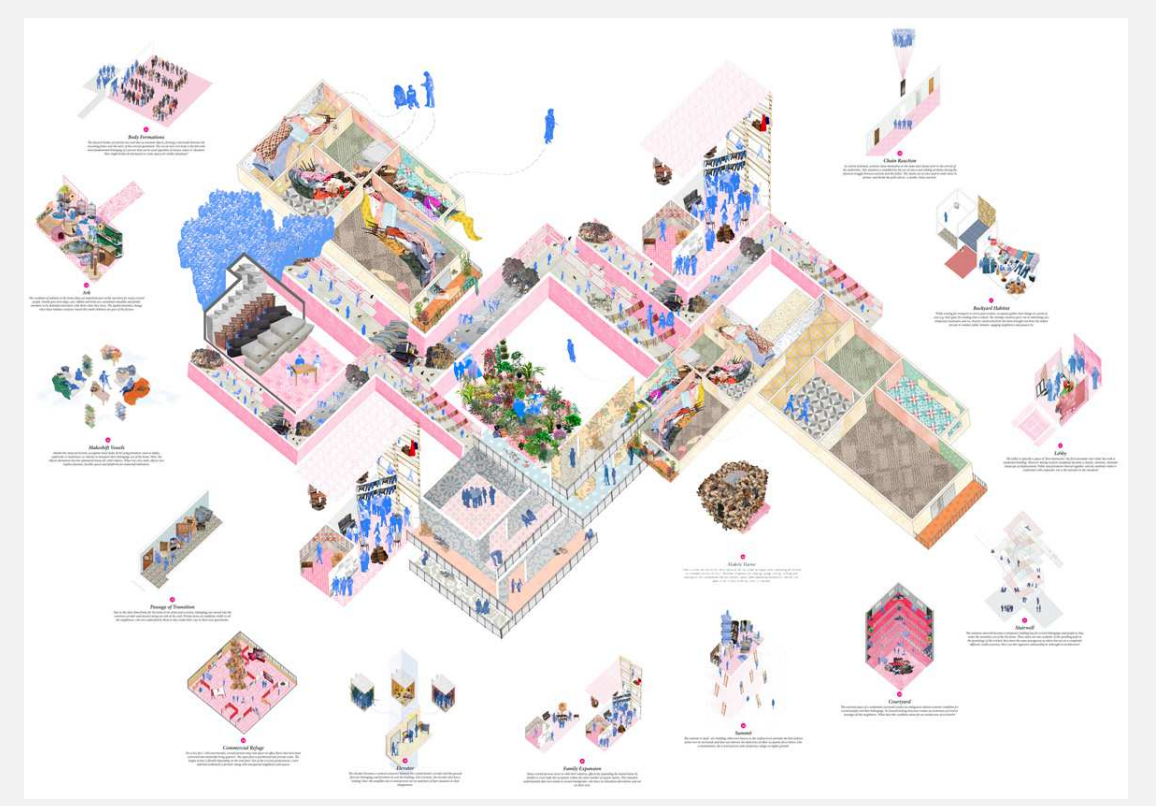

Fig.10 Configuraciones de domesticidades desahuciadas conformadas por cuerpos, objetos, protocolos, materialidades diversas y afectos en una ejecución hipotecaria.

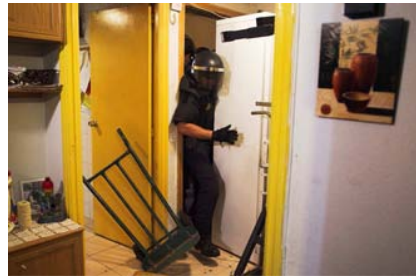

Img.21

La nevera actualiza su agencia en este ensamblaje. Transforma su mediación de mantener en frío los alimentos, a objeto de resistencia. La agencia se actualiza del uso diario a usos contingentes o no previstos.Imagen; Andrés Kudacki/ AP 
Tras la entrada de la policía en la casa, se produce una mudanza instantánea que convoca a los objetos (porras, rompepuertas), animales domésticos (como no humanos familiares), objetos afectivos (cuadros, fotografías), electrodomésticos (neveras, microondas, etc.), para conformarse en situaciones domésticas eventuales, frágiles y precarias. Una mudanza en emergencia que produce múltiples configuraciones de domesticidades desahuciadas.

Cómo hemos dicho, la idea de los ensamblajes urbanos son capaces de articular relaciones entre el plano actual y el virtual. En este ensamblaje particular, la producción del plano virtual: afectos, capacidades, capitales no económicos (como el capital simbólico, el relacional, el conocimiento, la atención, los afectos, el trabajo, el capital de salud, etc.) son imprescindibles para describir este proceso. La propia PAH es una entidad de empoderamiento individual y colectivo a la vez que opera desde la afectividad, el apoyo mutuo y el cuidado. Este proceso está dirigido por mujeres ${ }^{176}$. Esto hace de la PAH una iniciativa ciudadana tan relevante y contemporánea. La PAH desarrolla un conocimiento colectivo para la auto-gestión de talleres, grupos de apoyo en materia de violencia de género, la violencia contra los niños, las personas con diversas funcionalidades, los ancianos, los migrantes y las redes de apoyo mutuo. En ellos intervienen ciudadanos anónimos, psicólogos, abogados, investigadores, etc. Esto feminización del desahucio trae a la luz lo que Kate Miller afirmo: " Lo personal es político". Estas prácticas conectan lo cotidiano, lo personal y lo colectivo, la visibilidad en el ámbito legal e institucional. En definitiva, la conexión de la esfera pública con los cuidados.

Todos estos procesos forman un ensamblaje urbano, que no es posible desarrollar aquí en su totalidad, en torno al proceso de vivienda en Madrid y el posterior desahucio colectivo. Este proceso ensamblaje se performa día a día, de una manera casi instantánea, y que implica toda una existencia urbana. Este proceso diluye todas las separaciones entre las formas de la exterioridad tradicionales pues estas se construyen, como hemos visto, en continuidad, simultaneidad e instantaneidad en el ensamblaje.

${ }^{176}$ Citando a Carolina Pulido de la PAH Madrid "en primer lugar, debido a la feminización de la pobreza y en segundo lugar porque los hombres, incapaces de cumplir con el mandato de ser el titular de las familias de género, dejar lleno de vergüenza y culpa". 


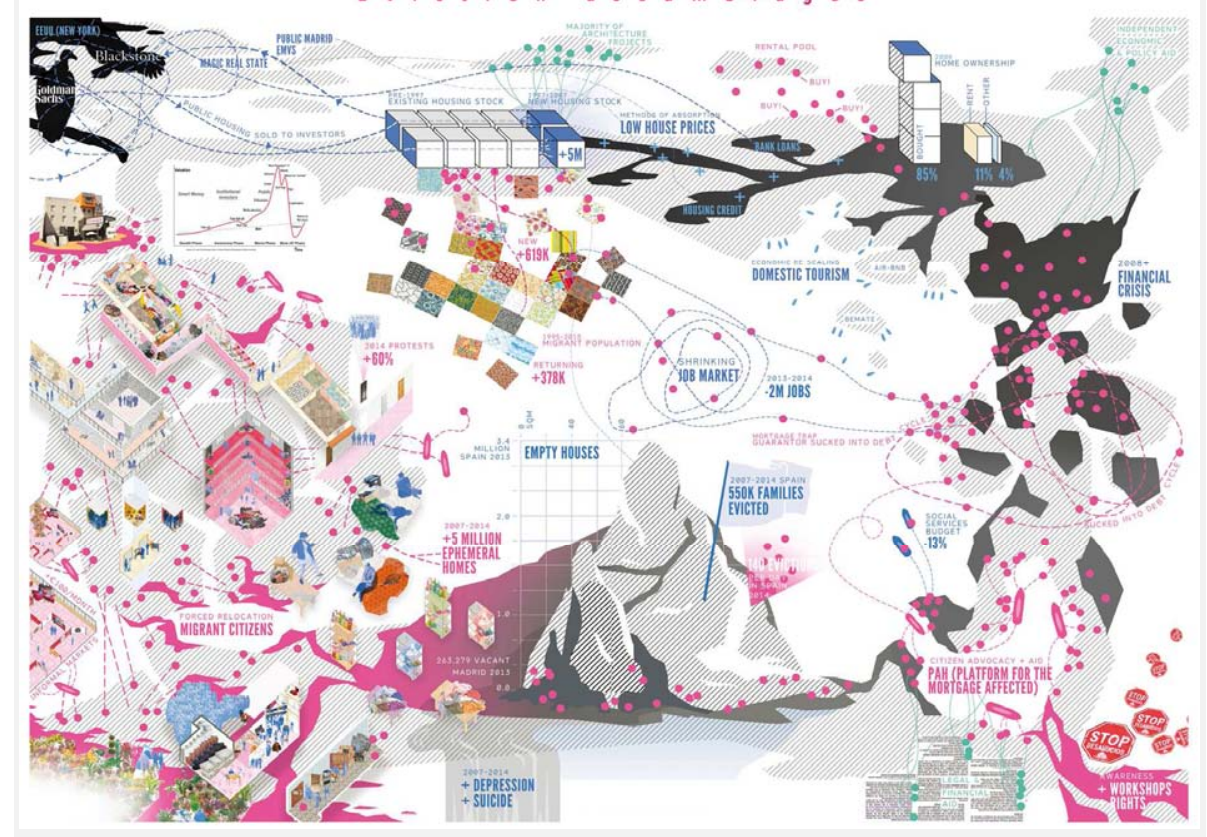

Fig.11 Ensamblaje urbano de domesticidades desahuciadas que opera bajo las operatividades que se proponen en esta tesis como conclusiones. 


\subsection{Problematizando los límites de la ANT}

Como hemos explicado en el primer capítulo sobre la noción de red que hemos utilizado, a su vez, esta se ha visto problematizada en varios sentidos y con ella la teoría de la ANT en sus diversas acepciones y sobre todo en el cuestionamiento de sus límites.

Primero. Si las redes son disposiciones complejas del espacio sin un centro claro ni dependencia en una relación de jerarquías diferentes. ${ }^{177}$ Estas no reorganizan las centralidades. Por ejemplo, en otros muchos casos las redes, como las de concentración del capital, se disponen entorno a nuevas centralidades. ${ }^{178}$ Desde dentro de la ANT, J. Law, uno de sus fundadores, revela una tensión entre la centralidad del actor y la descentralización de la red. Estas tensiones se producen también entre actores "fuertes" y actores "débiles" y sus aliados humanos y no humanos. "Dicha decisión alimenta más que evita que se reproduzca una narrativa en la que sobresalen cuestiones de control y gestión centradas sobre todo en el poder del actor central y en cómo éste consigue crear o asegurar redes cada vez más fuertes." 179

Segundo. Preguntar a la ANT por la condición de enunciación de la dualidad entre humanos y no humanos, cuando es esta misma dualidad y separación la que se pone en cuestión en la teoría. Si la agencia no reconoce distinción humanos y no humanos ¿Por qué siempre se requiere de esta distinción en su naturaleza? En este sentido se ponen en cuestión la problemática entre agencia y estructura. Entre los enfoques microsociales y las estructuras más culturalistas, sociológicas o abstractas para conectar lo local con esas leyes generales. Para Latour esto no así, pues la ANT ha pretendido fundir ambas situaciones "convirtiendo lo social en una trayectoria, un movimiento, una entidad circulante, el actor-red, que aunaba al mismo tiempo interacciones locales y acción socialmente organizada. Actores que son redes y redes que son actores." ${ }^{180}$

\footnotetext{
${ }^{177}$ Hetherington, K.\& Law, J. "After Networks”. Guest editorial en Environment and Planning D: Society and Space. 2000, v.18, p.127.

${ }^{178}$ Fuera de la ANT, pero en un sentido similar, será lo explicado por Saskia Sassen en las nuevas centralidades de los centros financieros urbanos en Sassen, Saskia. Contrageografías de la globalización. Madrid, Traficantes de sueños, 2003.

${ }_{179}$ Rodríguez-Giralt, Israel. "De redes y otros enredos: acerca de la ontología política de la red" en Teoría del Actor Red. Más allá de los estudios de la ciencia y la tecnología. Barcelona, Amentia, 2012, p.365.

${ }^{180}$ Ibid., p.367.
} 
Tercero. La teoría del actor-red en su manifestación misma logra convertir todo lo existente en parte de la misma red: humanos, animales, objetos y cosas, ambientes, producciones, naturalezas forman parte de cada red a estudiar y observar. Entonces si todo forma parte de las agencias ¿Dónde se sitúa un exterior? ¿Cuáles son los límites de la red? ¿Existen esos límites? ¿Tiene sentido definirlos? La cuestión de la exterioridad como alteridad u "otredad" es fundamental al hablar de redes en el sentido de las asociaciones y sus espacialidades. Si todo es capaz de pertenecer a la red y no deja espacio afuera ¿significa esto que todo y todos están contenidos en la red? Por ejemplo, en la definición de la relación de los cuerpos y la tecnología como hemos citado anteriormente

Incluso la forma de los humanos, de nuestro propio cuerpo, está en gran parte compuesta por negociaciones y artefactos sociotécnicos y. Concebir de manera polar a humanidad y la tecnología es desear una humanidad lejana: somos animales sociotécnicos y cada interacción humana es sociotécnica. Nunca nos limitamos a vínculos sociales [...] Como mínimo espero haberte convencido de que, si nuestro desafío va a ser atendido, no lo será considerando a los artefactos como cosas. Merecen algo mejor. Merecen ser alojados en nuestra cultura intelectual como actores sociales hechos y derechos. ¿'Median nuestras acciones? No, ellos son nosotros. ${ }^{181}$

La crítica de Lee y Brown ${ }^{182}$, es que si la ANT es una crítica post-estructuralista a la imposibilidad de los grandes relatos y todo queda dentro de las redes ¿no tiene la ANT una posición colonialista a este respecto? Según ellos su pretensión es la de crear otra gran narrativa sobre los temas de las relaciones y la diferencia - y el coste que esto tiene es la exclusión de la otredad o de la exterioridad y su también importante espacialidad. Esta crítica también se ha realizado desde algunas posiciones feministas como la de Star, Griesemer o Strathern. ${ }^{183}$

Por otro lado, J. Law, se pregunta por la posición de la alteridad en las relaciones dentro de la ANT que nos conciernen. Para mirar a "lo otro" sin establecer una ontología espacial prefijada. Según Law, es cierto, que la metáfora de la red es limitada en las asunciones de las conexiones, guiones, centros de cálculo, nodos. La red como un imaginario espacial trabaja bien cuando las relaciones entre los actores diferentes son buscadas, pero reconocer la exterioridad (otredad) dentro

\footnotetext{
${ }^{181}$ Latour, Bruno. La esperanza de Pandora. Barcelona, Gedisa, 2001, p. 256.

182 Lee, Nick \& Brown, Steve. "Otherness and the Actor Network: The Undiscovered Continent" American Behavioral Scientist, 1994, v.37, n.6, pp.772-790.

${ }^{183}$ También desde las posiciones de Zoe Todd, John Borrows o Val Napoleon explicadas en el artículo "El giro ontológico es una palabra para un colonialismo más". Descargable en https://zoeandthecity.wordpress.com/2014/10/24/an-indigenous-feminists-take-on-the-ontologicalturn-ontology-is-just-another-word-for-colonialism/
} 
más que excluir requiere otra manera de pensar en el espacio. Quizás necesitamos una forma más topológica y menos incuestionable que acerque la otredad.

Las relaciones con la alteridad salen a flote en formas que no son obvias al hablar de relaciones espaciales. Y tendremos que ver qué pasa con este asunto. En su artículo "After Networks" dice Law

Hemos de admitir que con Maurice Blanchot [Foucault] el espacio exterior de la alteridad esta siempre dentro y moviéndose por caminos que son indiferentes a las relaciones de diferencia que nosotros como escritores del espacio relacional siempre tendemos a asumir. ${ }^{184}$

Quinto. Hoy en día la supremacía de la red como figura espacial ha sido puesta en cuestión por la agencialidad ilimitada de los actores-red se sustenta en un ideal liberal de inclusión total de las diferencias, es decir, en la posibilidad de un gobierno total de las diferencias sin necesidad de hacer frente a una exterioridad. Aparece de nuevo la necesidad de pensar "la otredad" a partir de figuras espaciales que no la reduzcan a una totalidad. En términos de sistemas la ANT es una herramienta expansionista o proyecto de colonización de todo el espacio interno y externo. Pero la ANT puede criticar las teorías de sistemas "porque disuelve lo humano y lo no humano en un medio sobre asuntos de polos de fuerzas. Destronando y descentrando lo humano dentro del sistema." ${ }^{185}$ Las investigaciones de Law y Mol de acuerdo con esta problematización harán explicita un aumento de las capacidades de la red, de acuerdo a sus topologías fluidas que enuncia y hemos explicado en su capítulo correspondiente.

Sexto. Para los estudios urbanos, la ANT no dispone de herramientas para describir y desarrollar el papel de los afectos, por ejemplo, en la producción de ciudad. Cómo explica Ignacio Farías, de la mano de Harman, "La ANT carece de herramientas conceptuales para dar cuenta de lo virtual." 186 La ciudad se compone nos solo de hechos científicos, positivos o planificados. Las eventualidades, capacidades o los afectos, sí elaborado por Deleuze en del concepto de agenciamiento, como el plano de lo virtual, queda pendiente en su desarrollo dentro de la ANT.

Séptimo. Tras el gran proceso de internalización de la ANT, donde queda el exterior? ¿Siguen existiendo exterioridades? A esta cuestión Bruno Latour

\footnotetext{
${ }^{184}$ Law citando a Blanchot. (Blanchot 1993, Foucault 1990) Op. Cit., Hetherington, K. \& Law. p.131. 185 Lee \& Brown. Op. Cit., p.774.

${ }^{186}$ Cfr. Harman, Graham Prince of Networks. Bruno Latour and Metaphysics. Melbourne, Re.press, 2009.
} 
responderá que "la exterioridad será un proceso explicito de externalización" 187 de entidades que se envían fuera de la red o de un ensamblaje.

Por otro para Latour el exterior, será lo no enredado, lo que "aún no está formateado, aún no está medido, aún no está socializado, no está comprometido en redes metrológicas, aún no cubierto, investigado, movilizado o subjetivado" 188 Este mundo que está por ser medido y enredado, Latour lo denomina con la noción de "plasma" 189 El plasma es el exterior de la red. "Toma un mapa de Londres e imagina que el mundo social visitado hasta ahora ocupa poco menos que el metro. El plasma sería el resto de Londres" ${ }^{190}$ Lo cual es una débil construcción cuando se ha internalizado todo con la ANT.

Luego los límites de la ANT quedan problematizados en su propio devenir, pero estos no dejan de aportar más matices, más preguntas, más cuestiones que incrementan su capacidad de observar con más precisión y más apertura la realidad contemporánea. La propia ANT será una red de manifestaciones diversas de la caja de herramientas que es la ANT para esta tesis doctoral y muchas otras investigaciones.

${ }^{187}$ Latour, Bruno. Políticas de la naturaleza. Barcelona, RBA, 2013.

${ }^{188}$ Latour, Bruno. Reensamblar lo social. Buenos Aires. Manantial. 2008. pp.244

${ }^{189}$ Un concepto que sin duda añade una nueva latitud a la noción de red Doel, Marcus. A Miserly thinking/excessful geography: from restricted economy to global financial crisis. Environment and Planning D: Society and Space, v.27 n.6 2009. pp.1054-1073.

${ }^{190}$ Op. Cit., Bruno Latour, p.341 
2. Espumas (Sloterdijk)

$\mathrm{El}$ gran interior 
Espumas, elabora una articulación particular para nombrar lo complejo, lo que no es tan sólo autónomo y aislado, sino que también funciona en colectivo, con propiedades singulares, particulares y específicas en un determinado ambiente, lugar o situación. Explicar las Espumas ${ }^{191}$ es explicar las sociedades junto con sus materialidades y espacialidades climáticas. Espumas es una explicación sociomaterial de la condición posthumana, ${ }^{192}$ de la cultura occidental contemporánea.

En esta tesis, hablar de espumas es adentrarse en cada nodo de la red, de cada espacialidad, de cada asociación o ensamblaje particular. Es crear un espacio nuevo allí donde las trayectorias y la relacionalidad híbrida de la red, no nos había permitido hacerlo. Por lo tanto, la espuma no se contrapone a las redes de la ANT descritas en el capítulo anterior, pero de alguna forma, parece que a las redes les cuesta trabajo ofrecer una descripción socio-morfológica del mundo físico contemporáneo formado por complejos residenciales, casas de apartamentos o colonias de casas baratas, gated communities, favelas, etc.

[La idea de la espuma quiere corregir] la confusión producida por la metáforared sobretensionada, de la que demasiados autores esperaban demasiadas cosas, la mayoría de ellos sin darse cuenta de que con el discurso de la redificación se hacían acreedores de un grafismo falso y de una geometría sobremanera reductiva: en lugar de acentuar la dimensionalidad propia de los comunicadores a poner en relación mutua, la imagen de la red sugería la idea de puntos-no expandidos, que, como interfaces, estuvieran unidos por líneas: un universo de pescadores de datos y anoréxicos. ${ }^{193}$

La aproximación que realizamos en esta tesis doctoral es la evaluación de la complementariedad de ambas teorías como modos de describir la condición contemporánea. Ambas teorías tienen una aproximación topológica, pero esta, no es inmediata. $\mathrm{Si}$ como hemos visto en el primer capítulo, la mejor forma de entender un actor-red precisamente no es una red. "La metáfora de la espuma ofrece la ventaja de captar en una imagen la estructura topológica de las producciones de espacio vital." ${ }^{194}$

Para Sloterdijk la metáfora de las espumas explica de una manera topológica y directa la construcción de sociedades como sociedades-espuma. Esto implica que la condición material del espacio protector y confortable es un producto derivado

\footnotetext{
${ }^{191}$ Nombraremos a la Teoría de las multiplicidades-espacio como Espumas y a partir de ahora en minúscula, aunque sea una teoría particular y específica.

${ }_{192}$ Sloterdijk, Peter. "El post-humanismo: sus fuentes teológicas, sus medios técnicos" conferencia en el Aula del Rectorado de la Universidad Internacional de Andalucía, el 9 de mayo de 2003.

${ }^{193}$ Sloterdijk, Peter. Esferas III. Espumas. Esferología plural. Madrid, Siruela, 2006, p.197.

${ }^{194}$ Ibid., p.195.
} 
de la existencia misma. Es el vínculo existencial que Sloterdijk expresa como una coexistencia social y material.

Por eso hablamos de estructuras englobantes y a su vez de unidades vecinas frágiles; es decir, de sistemas co-frágiles y co-aislados. De co-existencia a coinsistencia, como dice Sloterdijk, algo que en ninguna parte se ha articulado más clara y técnicamente que en ciertas concepciones de separación y trabazón de espacio de la arquitectura contemporánea.

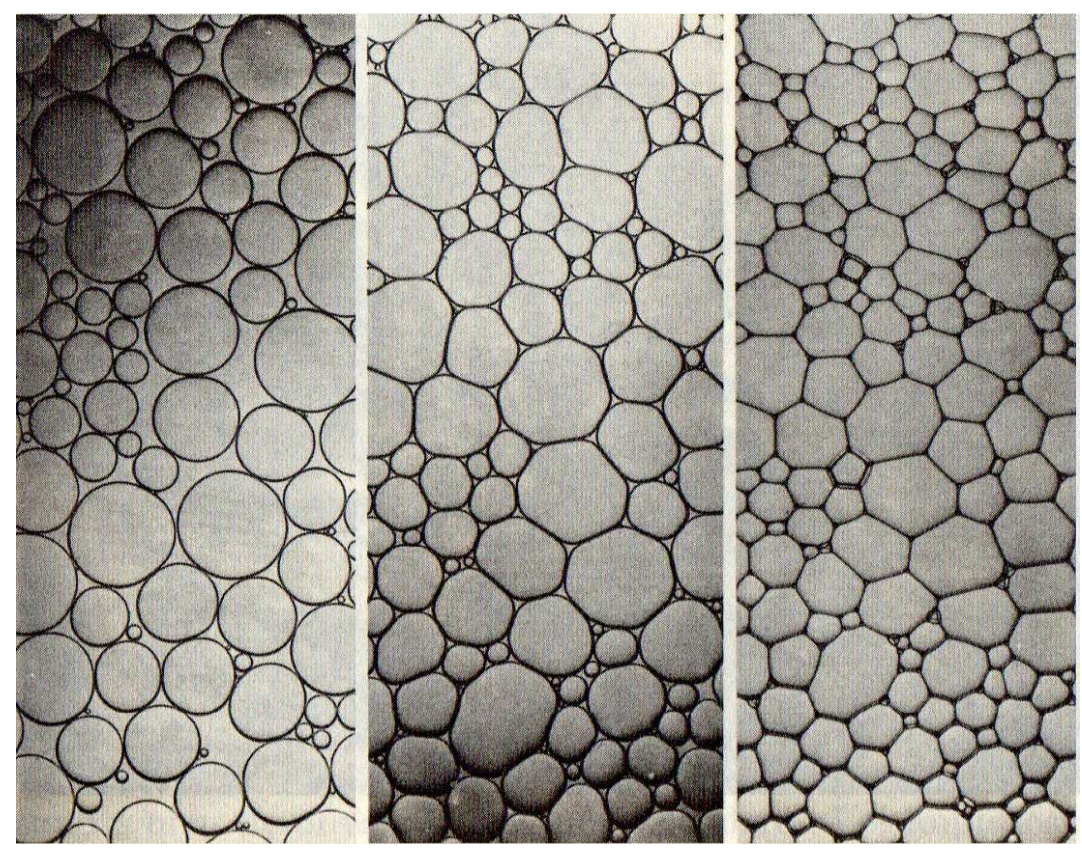

Fig. 12 Transición de una balsa de burbujas a una red poliédrica aplanada según el grupo de estudio de Frei Otto.

¿Cómo situar la espuma? ¿Podemos definir las espumas como una materia sólida? ¿O es quizás un líquido? Técnicamente deberíamos distinguir entre los diferentes tipos de dispersiones. Las líquidas: soles o suspensiones coloidales, emulsiones. Las líquidas: soles sólidos, geles, espumas sólidas y las gaseosas: aerosoles y aerosoles líquidos. Sin ser todas ellas espumas puras, pertenecen a la gran familia de lo que denominaremos espumas. Todas ellas, muchas veces, son tan solo estados volátiles en un instante determinado, que se ven modificados en el tiempo y que adquieren múltiples formatos. Pasaremos de la estabilidad a la liquidez en cuestión de segundos; es decir, formas improbables por su fragilidad. 
Sloterdijk desarrolla dos metáforas inversas. Por un lado la espuma como entidad físico-química y por el otro la arquitectura como el modo de expresar el mensaje de la sociedad, porque formato y mensaje son ya lo mismo. ${ }^{195}$

De las espumas como entidades físico-químicas, no vamos a detenernos en su primer investigador. J.A. Ferdinand Plateau, demostró la existencia de las superficies de área mínima inscrita en unos límites dados. Las leyes de Plateau son las demostraciones matemáticas que elaboran esta condición que se forma en las burbujas y pompas de jabón.

Cómo las espumas son procesos que producen en sus celdas saltos, transformaciones y cambios constantes de formato con el fin de tener una mayor estabilidad e inclusividad. Las espumas, como las sociedades, son sistemas cofrágiles que alcanzan el máximo nivel de interdependencia aglutinadas por paredes, membranas, tabiques peliculares, interfaces de vecindad, que se apropian de ambos lados y crean sistemas inmunes, separaciones, y aislamientos recíprocos. Estas superficies de coaislamiento múltiple podemos describirlas como apertura y cierre al mismo tiempo. Por eso, no podemos hablar del interior de una espuma, por lo tanto tampoco de su exterior, porque se constituyen como sistemas de coburbujas circundantes unas con otras, pared con pared, donde son a la vez separadoras, vecinas e inaccesibles y a su vez están unidas y apartadas.

Para situar las espumas, tenemos que partir de la concepción de Niklas Luhmann sobre la sociedad contemporánea en la que se basa Sloterdijk. La espuma en Luhmann aparece "cuando la estructura social y la semántica social se desmoronan, en ese momento aparece la espuma" ${ }^{196}$. Es interesante para nosotros porque su teoría social de sistemas no se basa en el individuo, forma tradicional del estudio, sino en los sistemas de comunicación y las relaciones que genera. No se trata del hombre o una acción humana, como diría Habermas. Según Luhmann "Los hombres no comunican, solo la comunicación comunica"197. La sociedad, como uno de los sistemas sociales, no comunica fuera de ella. Luhmann establece una diferenciación básica entre sistema y entorno. Acompañando a Luhmann en el recorrido por las espumas, Sloterdijk recurre a autores de pensamiento alemán, como Elias Canetti, Ernest Bloch o el biólogo, etólogo y pionero de la ecología Jakob Von Uexküll.

\footnotetext{
${ }^{195}$ Sloterdijk. Peter. En el mundo interior del capital. Para una teoría filosófica de la globalización. Madrid, Siruela, 2007, p.210.

${ }^{196}$ Niklas Luhmann citado por Peter Sloterdijk en Esferas III, p.197.

${ }^{197}$ Cfr. Luhmann, N. "Sistemas sociales: lineamientos para una teoría general". v.15, Anthropos Editorial, 1988, p.157.
} 
J. Von Uexkül, formuló la idea de que el mundo humano no proporciona un mundo común para todos los seres vivos. Con esta idea y según Sloterdijk dio paso de una metafísica monológica a una ontología plural.

[El universo] no consiste en una única pompa de jabón [...] sino en millones de pompas de jabón estrechamente colindantes, que se cruzan e interfieren por todas partes. ${ }^{198}$

Y este precisamente es el recorrido que desarrolla Sloterdijk en su trilogía esfereológica, o de esferas plurales. Pues, como ya hemos enunciado, la esfera es la entidad constitutiva de la existencia. En esta trilogía, Sloterdijk elabora 3 fases de la historia de la globalización. La primera, Esferas I trata sobre la globalización metafísica. La mejor protección contra un exterior, el mejor aislamiento de un interior, es precisamente integrar el exterior en él. Esta primera globalización desarrolla totalidades, sean estas Dios o el Cosmos, y está liderada por filósofos, geómetras y teólogos; desde los griegos hasta Emanuel Kant. La segunda, esferas II, que se superpone a la primera, trata sobre la globalización terrestre. El mundo, es una sola esfera a descubrir y colonizar hasta agotar el exterior. Como por ejemplo, los procesos colonizadores de los europeos. La tercera, esferas III, es la globalización de la espuma. Donde ser en el exterior de uno mismo, no significa ser, inmediatamente y sin mediación, en el todo. Al mismo tiempo, Sloterdijk afirma que ya no hay espacios por descubrir, no existe ese desconocido exterior tras la globalización terrestre. ${ }^{199}$

La esfera, es un espacio que se comparte con la vida. La evolución de las esferas, son los modos diferentes que el espacio comparte con la existencia. Esta aproximación permite a Sloterdijk pasar de una monología a una redescripción de la individualización en la esferología plural. La esfera, por lo tanto, permite ver una complementariedad entre los estudios postestructuralistas y las posiciones antropo-fenomenológicas de Sloterdijk.

Una esfera es un edificio inmunológico y psico-espacial compartido. Podría ser comparada positivamente con las cadenas del Actor-Red de Latour o con los ensambles deleuzianos. Tiene elementos de los dispositivos foucaultiana en el enredo entre los discursos, las prácticas y los objetos y en el potencial de dar forma a lo humano. Tiene también elementos del sistema social de la teoría sociológica de Luhmann, tanto en su separación de un interior sistémico desde el exterior y en actividades extra-sistémica como su inmunizante potencial y

\footnotetext{
${ }^{198}$ Von Uexküll, Jakob. kompositionslehere der Natur, o.c. p.355. citado por Sloterdijk en Espumas III ${ }^{199}$ Para desarrollar esta cuestión, ver Morin, Marie-Eve. "Cohabiting in the globalised world: Peter Sloterdijk's global foams and Bruno Latour's cosmopolitics" Environmental and planning D: Society and space. v.27, 2009, pp.58-72.
} 
carácter epistemológico perspectivista (aunque [ Sloterdijk ] declina la concepción anti-espacial de Luhmann). ${ }^{200}$

Como acabamos de afirmar, hoy no es posible salir directamente de uno mismo al exterior, para estar en la totalidad, pues ni esa totalidad existe como monología, sino como esfereología plural y ese salir, aún inmediato, no se realiza sin mediación. Hemos de admitir que Sloterdijk, no resulta tan operativo para describir esas mediaciones, como si lo hace la ANT. Si la ANT se mueve en las continuidades y diferencias dentro de un sistema particular, Sloterdijk, se centra en el estudio de los entornos espaciales-materiales dentro de los sistemas. Y esta condición es la que llamará la atención de Latour para incorporarla a sus investigaciones. "Lo que Sloterdijk nos ayuda a todos a descubrir es que incluso la política necesita aire acondicionado"201

Ambas aproximaciones se complementan y hacen énfasis en análisis como los realizados también por Donna Haraway sobre la necesidad de transparencia y especificidad del entorno estudiado. Es importante referir como nuestro análisis y descripción de experiencias se sitúan en un punto donde la pregunta ya no es ¿Quién soy yo? Sino más bien ¿Quiénes somos nosotros? ( Si es que se diera el caso de poder hablar de un nosotros) y ¿Cómo nos relacionamos, interactuamos, comunicamos? y ¿Cómo construimos nuestras espacialidades?

¿Cómo entender, en su totalidad, la ciudad reunida y el mutuo ajuste de los reunidos en multiplicidades humanas, cuando entre los participantes ya no puede presuponerse, con aquella primera obviedad, la coordinación apriórica que aporta el sistema de sangre y casamiento? ¿Cómo interpretar la coexistencia de seres humanos con sus iguales, junto con sus propiedades y allegados, en un colectivo que suponga una relación vinculante del existir unos con otros, unos en otros y frente a otros, ahora que ya no puede derivarse la compacidad de su asociación de las configuraciones de la comunidad de sangre? Es decir, los nosotros y no nosotros y las existencias multinosotros. ${ }^{202}$

Y también representando estas diferenciaciones afirmar, que en la línea trazada por Simmel-Luhmann y Tarde las sociedades son conformadores de seres que están a la vez dentro y fuera de ellas. Los individuos reales no son parte del sistema social, sino que pertenecen a su entorno.

\footnotetext{
${ }^{200}$ Schinkel, Willem \& Noordegraaf-Eelens, Liesbeth. "Peter Sloterdijk’s Spherological Acrobatics: An Exercise in Introduction." en In Medias Res: Peter Sloterdijk's Spherological Poetics of Being Schinkel, Willem \& Noordegraaf-Eelens Liesbeth (Eds.).Amsterdam, Amsterdam University Press, 2011, p.13.

${ }^{201}$ Latour, Bruno. "Atmospheres, atmospheres. Laboratory inside out." Introducción al catálogo de Olafur Eliasson en la exposición de la Tate Modern. London, Tate Modern, 2002, p.15.

${ }^{202}$ Sloterdijk, Peter. Esferas IIIOp.Cit., p.204.
} 
Entonces, es cuando hablando de sociedad no podemos hablar de un receptáculo mono esférico, como si lo hace la idea social de la masa, la estadística, etc. ni de un proceso de comunicación inespacial diversificado en subsistemas. Hablaremos, según Sloterdijk, de parejas, hogares, empresas, asociaciones, organizaciones de formato diferente que limitan unas con otras, se apilan, se juntan, sin ser necesariamente accesibles unas para otras, ni efectivamente separables unas de otras. Es mejor verlo como un medio turbio, que posee "cierta conductibilidad para informaciones y cierta permeabilidad para materiales. Medio transparentes, medio opacas" 203

Las sociedades son hoy muchas espumas que se crean, destruyen y transforman. El sí mismo y el extraño aparecen tan ensamblado a niveles profundos que son estrategias demasiado primitivas de delimitación lo que se provoca y es en efecto contraproducente. ${ }^{204}$ El límite que ponemos a lo ajeno, a lo extraño, a lo extranjero y exterior es un límite propio y determinado por nuestra experiencia. Como ya sabemos, un límite une tanto como desune. Pero ¿Por qué hablamos de espumas para enmarcar como funciona un sistema bajo la ausencia de exterioridad, como un gran interior?

La espuma constituye un interior paradójico, en la que la mayor parte de las coburbujas circundantes son, a la vez, desde mi emplazamiento, vecinas e inaccesibles, y están a la vez unidas y apartadas. ${ }^{205}$

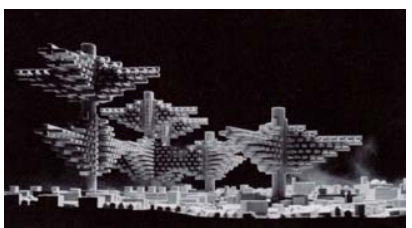

Img.22

Modelo original "Cities in the Air" del arquitecto japonés Arata Isozaki 1960

Y si esto sucede en los espacios- sociedades: "Pertenecen a esa región de objetos el hecho de que el co-aislamiento-múltiple de los hogares-burbujas en sus diversas vecindades pueda describirse como cierre y como apertura al mundo. Según la cita evocativa de E. Bloch 'Muchos aposentos en la casa del mundo' que no tienen puertas, posiblemente solo ventanas ciegas, en las que hay pintada una escena exterior. Las burbujas en la espuma, es decir, las parejas y hogares, los equipos y comunidades de supervivencia, son microcontinentes construidos autoreferencialmente"206 escribe Sloterdijk, sobre Ernst Bloch.

\footnotetext{
${ }^{203}$ Ibid., p. 53 .

${ }^{204}$ Ibid., p.156

${ }^{205}$ Ibid., p.49.

${ }^{206}$ Ibid., p.51.
} 


\subsection{Pompas de jabón}

Las espumas cuando son jóvenes, se muestran como conglomerados muy frágiles de burbujas pequeñas que se unen y des-unen constantemente. Cuando son mayores, las espumas van adquiriendo cierta estabilidad y son grandes y perfectamente ensambladas. Hubo un tiempo donde las burbujas eran grandes pero aún no formaban grandes espumas. Ese momento lo llamamos: cuando las espumas eran pompas de jabón.

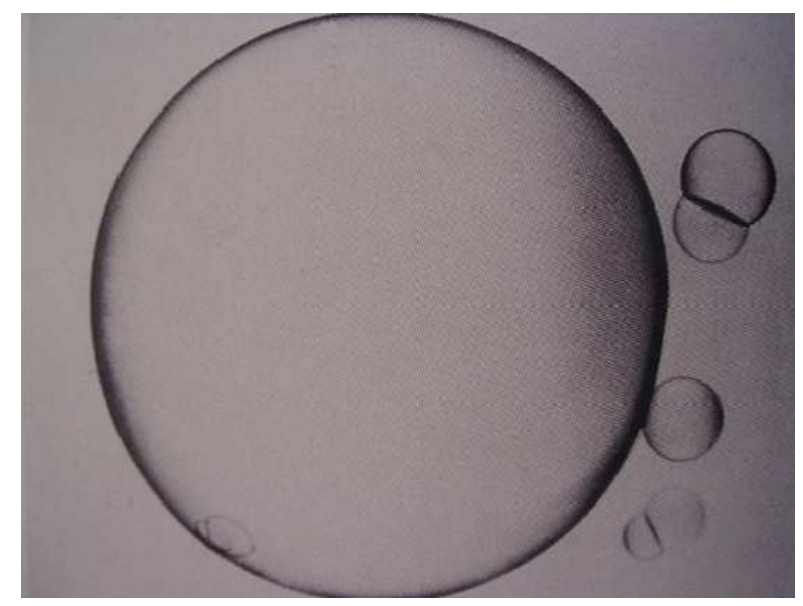

Fig. 13 Burbujas de Jabón. Presión interior y tensión de membranas. Frei Otto.

¿Por qué nos interesan esas primeras burbujas? Porque son las que preceden a la construcción del mundo contemporáneo. Son los primeros síntomas que inmunizan al espacio público categorizándolo y haciéndolo habitable en cualquier momento. Mientras el concepto de espacio público en París se está desarrollando como espacio burgués, lugar de visibilización de las posiciones sociales, de subalternación de la mujer en brazos del hombre, a su vez se está deshaciendo o construyendo, según se mire, en otras burbujas tal vez no conectadas en ese mismo momento. Hablamos entonces de pequeñas pompas de jabón, como los cafés y a su vez de grandes burbujas como los palacios de cristal, invernaderos y galerías. Estos espacios, insulamientos atmosféricos ${ }^{207}$ en palabras de Sloterdijk, construyen una idea fuera de las categorías de exterioridad que ganaron el pulso discursivo.

Walter Benjamin, como precursor del pensamiento moderno, fue pionero en visibilizar una ciudad dentro de la ciudad. Él definió, en su libro sobre los Pasajes y las Arcadas parisinas, conceptos-materialidades donde los límites tradicionales

\footnotetext{
${ }^{207}$ Sloterdijk Peter. Esferas IIIOp. Cit., p.260.
} 


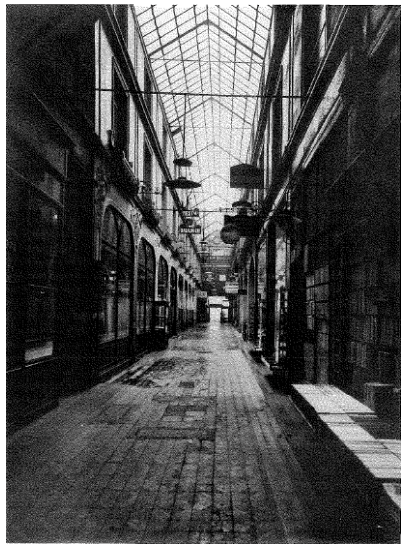

Img.23

Passage de l'Opera, 1822-1823.

Fotógrafo desconocido Musee Camavalet,. En p.39 The Arcades project. W. Benjamin. de la casa, el espacio público o la ciudad, no se podían marcar claramente. La ciudad se trasladaba a los interiores y estos mismos se desplazaban a otros lugares.

Peter Sloterdijk sugiere que no hemos hablado lo suficiente sobre cómo son estas cuestiones, qué dispositivos utilizan, en qué se fundamentan, como operan, qué producen, cómo el espectador/usuario participa de este enunciado, cómo se conforma, cómo se produce, cómo se nos oculta, y cómo se muestra, qué evidencias físicas y arquitectónicas tiene. Cómo son sus suelos, sus estructuras, sus definiciones elementales de arquitectura. Qué significado tiene cada elemento: la puerta, la ventana, los marcos, las carpinterías. La escala, el programa, la forma, la distancia.

Si asumimos con Sloterdijk, que es la modernidad la época en la que se produce en el mundo antiguo la salida del monocentrismo y la primera globalización metafísica, ${ }^{208}$ esto tiene también unas repercusiones urbanas. Como lo explica Sloterdijk: "La sociedad del consumo y del acontecimiento se inventó en el invernadero." ${ }^{209}$ En el París de Benjamin, el hogar se extiende por la capital. Lo doméstico se organiza fuera de los límites de la casa, pero dentro del espacio exterior de la ciudad.

Dos son los principales argumentos por lo que nos interesa fijarnos en las burbujas que nacieron al calor de esta primera modernidad y dos son los lugares en disputa por celebrarse como fundadores de esta nueva modernidad. París y Londres. París descrito con precisión por Walter Benjamin. Londres en disputa por la misma posición, lo observa con agudeza Richard Sennett. De París, pensemos en la construcción de un urbanismo de interiores. De Londres, la incorporación de la velocidad a la moderna vida urbana. Ambos autores describen las ciudades como creación de burbujas independientes que operan como infraestructuras para habitar un mundo sin exterior.

Sobre el París de Benjamin tendríamos que explicar qué significa un urbanismo de interiores en el siglo XIX. Por un lado, la construcción de los pasajes de París. Según Benjamin los pasajes surgen en el decenio y medio posterior a 1822. La primera condición es el florecimiento del comercio textil y la posibilidad de almacenar grandes cantidades de mercancías. Estos pasajes son los predecesores de los grandes almacenes, como Le Bon Marché. La segunda condición es el comienzo de la construcción en hierro y vidrio. Con el hierro aparece en la historia de la arquitectura un material de construcción artificial. Al igual que los pasajes,

\footnotetext{
${ }^{208}$ Cfr. Sloterdijk, Peter. Esferas II. Globos. Macrosferología. Madrid, Siruela, 2004.

${ }^{209}$ Sloterdijk, Peter. Esferas III. Op. Cit., p.142.
} 
Benjamin enumera una serie de construcciones que llama oníricas: "Pasajes, invernaderos, panoramas ${ }^{210}$, fábricas, gabinetes de figuras de cera, museos, casinos y estaciones de tren" Con estas construcciones, según Benjamin, el interior sale afuera.

Es como si el burgués estuviera tan seguro de su sólido bienestar que despreciara la fachada para decir: mi casa, por donde quiera que hagáis el corte, es fachada. ${ }^{211}$

Como por ejemplo las fachadas de las casas berlinesas donde la calle se vuelve cuarto y el cuarto se vuelve calle. Un mirador que no sale hacia fuera sino que se remete dentro. Pero siguiendo con los pasajes, Benjamin habla de ellos como si fueran casas. "Los pasajes son casas o corredores que no tienen ningún lado externo-como los sueños. " $212 \mathrm{Y}$ a su vez la casa es una membrana que protege ese interior desplegado. El interior no es solo el universo del particular, sino también su estuche. Y ahí se establece también "la tendencia a resarcirse de la ausencia de huella privada en la gran ciudad. No dejar huella." ${ }^{213}$ "Pero si la muchedumbre no habita hoy las calles, es porque habita los interiores multitudinarios, esos espacios sin aura que Benjamin descubriría en las construcciones de vidrio y en los interiores sin huellas pues el vidrio no deja huellas" ${ }^{214}$ José Luis Pardo lo resume así citando a Benjamin:

Debido a la reproducción técnica, la arquitectura produce el urbanismo escalofriante de las cuidadas modernas. Las ciudades de cristal [y acondicionadas] los aposentos sin misterios ni densidad ontológica. Las casas sin estatuto estético, la funcionalidad desnuda del vidrio: podemos hablar de una cultura del vidrio, el nuevo ambiente del vidrio transformará al hombre. ${ }^{215}$

Decía Scheebart ${ }^{216}$ en 1904 y citaba Benjamin a propósito de la arquitectura de Loos, Gropius, Le Corbusier. Benjamin observa como las cosas del vidrio no tienen aura. "La nueva arquitectura [moderna] crea, por lo tanto, espacios en los que es imposible dejar o encontrar huellas personales, como sí sucedía en el cuarto del Burgués. ${ }^{217}$ Pero la arquitectura de Loos, Gropius y Le Corbusier, explicitará

\footnotetext{
${ }^{210}$ Sobre la construcción de los "panoramas" como antesala de la fotografía, que recrean una imitación perfecta de la naturaleza, con sus luces, tiempos, y colores que se muestran en las galerías y muestran un nuevo sentimiento vital "El habitante de la ciudad, cuya superioridad política sobre el campo se expresa de múltiples maneras, intenta traer el campo a la ciudad”. Benjamin, Walter. The arcades project. Tiedemman, Rolf. (Ed.) Mass., Harvard University Press, 1999, p.40.

${ }^{211}$ Ibid., p.412.

${ }^{212}$ Ibidem

${ }^{213}$ Ibid., p.56.

${ }^{214}$ Pardo, José Luis. Las formas de la exterioridad. Valencia, Pre-textos, 1992, p.236.

${ }^{215}$ Ibid., p.101.

${ }^{216}$ Scheebart, Paul. Arquitectura de cristal. Valencia, Arquilectura, 1998, [1914].

${ }^{217}$ J.L. Pardo. Op. Cit, p.101.
} 
a través del vidrio otras manifestaciones de la cultura y la sociedad de principios del siglo XX sin la nostalgia de Scheebart.

Walter Benjamin observa como por primera vez en este momento, el espacio de la vida, aparece por primera vez como opuesto al lugar de trabajo. La construcción de la privacidad comienza a operar en esta época donde el varón es el cuerpo del espacio público y laboral, y la mujer el cuerpo frágil del espacio doméstico. "El espacio de la vida, se constituye como un interior. La oficina, en su complemento." ${ }^{218} \mathrm{El}$ particular exige del interior que le mantenga sus ilusiones. El interior entonces representa el universo. Su salón es un palco del teatro del mundo. Por ejemplo, en a la misma vez que se construye el interior, se habilita su crisis. Según Benjamin:

El Art Noveau produce la crisis del interior. El ensalzamiento del alma solitaria produce su ensalzamiento. Moviliza todas las fuerzas de la interioridad. En esta época el verdadero centro del espacio se traslada a la oficina. El desrealizado se procura su lugar en el hogar. ${ }^{219}$

Luego son los pasajes e invernaderos y la construcción de la privacidad en la casa las que ejemplifican un urbanismo de interiores como un continuo públicoprivado en la ciudad de París. En este escenario nuestra buscada ausencia de exterioridad se mostrará aquí en el continuo físico de interiores aclimatados y no como la ausencia de otras exterioridades, como la intimidad. Son estos grandes interiores los que se encargarán de la supratemporal simulación de los espaciosúteros en la ciudad. Aunque más tarde a los shopping malls y a los estadios se les fue exonerando de la tarea de fingir calidad de hogar. Ahora fingen ya la calidad de ciudad o centro urbano. Doble agencia para simular lo ya desposeído, la casa o la calidad de hogar, pero esta es ya otra cuestión.

De estas dos formas de crear un urbanismo de interiores mencionados, José Luis Pardo anota dos cuestiones también importantes representadas por un doble fenómeno:

A nivel funcional, se trata de la reclusión de la multitud de espacios interiores diáfanos, panópticos, bien vigilados y que faciliten la transparencia y la plena visibilidad (espacio diferencial y analítico en contraposición al espacio recargado e hiper-decorado del cuarto burgués); por eso, este proyecto político es el primer plan para vaciar la calle.

\footnotetext{
${ }^{218}$ W. Benjamin. Op. Cit., p.43.

${ }^{219}$ Ibid., p.44.
} 
A nivel artístico, un intento de provocación a la burguesía neo-victoriana a quien van dirigidas las vanguardias. La muchedumbre queda entonces confinada al interior de eso edificios de vidrios, bien ventilados, pero no así el interior de la propia muchedumbre.

De estas dos maneras descritas aparece el primer argumento en París mediante Walter Benjamín para argumentar una primera construcción de interiores como burbujas o pompas de jabón.

La segunda sería la construcción de la ciudad en base a la velocidad que argumenta Richard Sennet en el Londres del XIX. Tanto Benjamin como Sennett explican los procesos de individualización que se crean en las ciudades y por lo tanto en los espacios que configuran las diferentes exterioridades. Este proceso de creación de burbujas, lo entendemos como un estado previo a la posterior configuración de redes y espumas que operan por acumulación de complejidad. El proceso de individualización pasa por pensar en que cada persona se comporta como un extraño respecto al destino de los demás.

Por lo que se refiere a su intercambio con sus conciudadanos, puede mezclarse con ellos, pero no los ve; los toca pero no los siente; existe solo en sí mismo y para sí mismo. Y si sobre esta base sigue existiendo un sentimiento de familia, ya no existe un sentimiento de sociedad. ${ }^{220}$

Coexistencia de personas que se toleran entre sí por indiferencia. Y esto tiene un impacto en el espacio urbano "Si la planificación urbana del siglo XIX intentó crear una masa de individuos que se desplazaran con libertad [y en interiores] y dificultar el movimiento de los grupos organizados por la ciudad, los cuerpos individuales que se desplazaban por el espacio urbano se independizaron del espacio en que se movían” ${ }^{221}$; y si a esto le añadimos la condición de velocidad que se desarrollaba en la época, Sennett saca una primera conclusión: "El individualismo unido a la rapidez tienen un efecto letal sobre el cuerpo moderno. Este carece de conexiones" 222 pero esta cuestión es discutible, pues como hemos visto en el capítulo primero, lo que se modifican son el carácter híbrido de las conexiones y no la propia idea de conexión. Quizás Sennett quiera explicar que los cuerpos interactúan con menor intensidad entre ellos pues en ese momento comparten agencia con dispositivos que comienzan a nacer. El viajero del tren, no será ya un cuerpo aislado, sino una entidad cuerpo-periódico-velocidad al que le corresponde una agencia diferente. Más tarde veremos, como la velocidad de la

\footnotetext{
${ }^{220}$ Sennett, Richard. Carne y Piedra. El cuerpo y la ciudad en la civilización occidental. Madrid, Alianza, 2010, p.344.

${ }^{221}$ Ibidem.

${ }^{222}$ Ibid., p.345.
} 


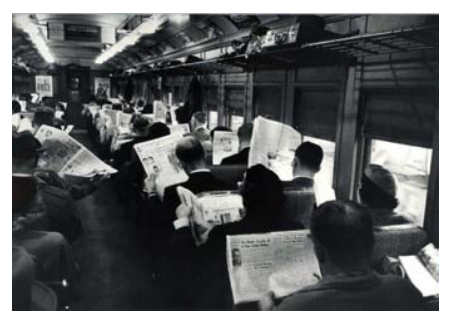

Img.24

Trenes y metros muestran la condición moderna de aislamiento que elabora Richard Sennett en "Carne y Piedra". modernidad, da paso hoy a una aceleración máxima, y esta, a la instantaneidad y la ubicuidad.

La construcción de los límites en el Londres del siglo XIX también se marcaba por la velocidad. Los automóviles trazaban el plano urbano que "distinguían claramente los espacios de lo externo e interno y lo público y lo privado." ${ }^{223}$ Un ejemplo claro de este movimiento era como Londres, que básicamente era una ciudad de casas individuales, juntas de parroquias y consejos de tutelaje, es decir, sin un organismo de gobierno central, desarrolló el Regents park de John Nash como un muro de vehículos en movimiento. Si en París, las galerías de cristal, funcionaban como capilares urbanos, en Londres el Boulevard de Sebastopol, cita Sennett, como espacio vivo también dividía a la multitud urbana y los automóviles " el tráfico quedó divorciado de los edificios, solo importaba la fachada; y la vena urbana convirtió la calle en un medio de escapar del centro urbano, más que de habitar en él." 224

Pero la innovación más importante de Londres como urbanismo de interiores y la velocidad, fue la puesta en Marcha del Metro de Londres. El metro es la infraestructura que permite que la ciudad no se entienda desde la distancia física y comience a articular y diluir los límites tradicionales. Si el automóvil limita y jerarquiza como en el proyecto de Regents park, el metro une. Londres comenzó a fluir hacia el exterior como explica Sennett. "Los trabajadores comienzan a abandonar el centro de la ciudad para vivir en casas adosadas de la periferia o el norte de la ciudad como Candem Town" 225 Entonces, el paisaje geográfico de Londres ya no estaba geográficamente limitado sino que sus límites eran transgredidos indiscriminada y peligrosamente dice Sennett citando a la historiadora Judith Walkopwitz. La segunda de las grandes burbujas tras los pasajes y los invernaderos aparece en movimiento.

En el metro de Londres "había cobrado forma la geografía temporal del centro urbano moderno: congestión y diversidad por el día, descongestión y homogeneidad por la noche. La gente trabajaba y compraba y después regresaba a su casa." 226 Aparecen, entonces, nuevos espacios aislados, esta vez por la velocidad. El metro aísla a las personas del entorno por la velocidad. Conecta y aísla de una misma manera. Pone en situación de silencio a las personas en un mismo habitáculo. Como opina George Simmel "Antes de la aparición del transporte de masas, rara vez se había visto obligada la gente a ir sentada junta en

\footnotetext{
${ }^{223}$ Ibid., p.347.

${ }^{224}$ Ibid., p. 354.

${ }^{225}$ Ibid., p. 356.

${ }^{226}$ Ibid., p.360.
} 
silencio, simplemente mirando durante un tiempo prolongado." ${ }^{227}$ Pero no son solo los vagones de metro y tren los que se aíslan del exterior creando burbujas en movimiento. Los pubs, y los cafés comienzan a ser espacios públicos introvertidos cuando la arquitectura urbana comenzó a estar sellada mecánicamente. Calefacción, aire acondicionado y grandes paños de vidrio son las tecnologías que aparecen en el momento y que rompen el vínculo necesario en las construcciones anteriores entre el exterior y el interior. "El cuerpo pasivo pierde todo contacto físico con el exterior" ${ }^{228}$ pero a la vez se comunica con el exterior a través de los paños de vidrio.

Estas nuevas situaciones que parten del siglo XIX Sloterdijk las llama Islas atmosféricas, lugares que delimitan un aire de alrededor aislándolo de él y estabilizan una diferencia atmosférica permanente entre el espacio interior y el espacio exterior. Islas atmosféricas terrestres las hay desde la aparición del invernadero de cristal. Según Sloterdijk estas constituyen la innovación arquitectónica $^{229}$ más importante desde la antigüedad porque con ellas la construcción de casas se convierte en una explícita construcción climática. ${ }^{230}$ Estos lugares coloniales, se crearon para la aclimatación de plantas tropicales a medios centroeuropeos. Con lo que la pregunta que se hace Sloterdijk es: ¿No podríamos afirmar que la sociedad multicultural fue ensayada ya en los invernaderos?

\subsubsection{El invernadero}

La gran instalación, el palacio de cristal, el espacio interior del mundo, la isla atmosférica, son sinónimos que Sloterdijk utiliza para referirse a la construcción de la sociedad como el gran interior del invernadero.

La pregunta que dejamos en el punto anterior resulta muy pertinente. Pues los invernaderos como "laboratorios casas-calor" fueron una mezcla de especies humanas, animales y vegetales de diferentes procedencias y ensambladas a través de la mediación del acero y el cristal. Paxton, ya estaba utilizando sin darse cuenta el concepto de Sloterdijk de "contorno-contornado" ${ }^{231}$. Para Sloterdijk, la realidad es una superposición de invernaderos o espacialidades climatizadas. El invernadero, se utiliza entonces de dos modos diferentes: como espacialidad física

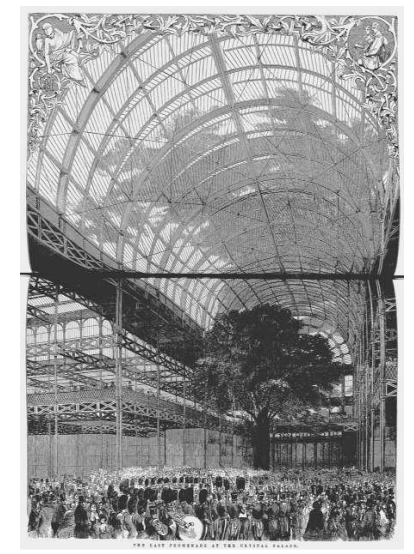

Img. 25

Interior del Palacio de Cristal de Joseph Paxton en su inauguración 1851.

\footnotetext{
${ }^{227}$ George Simmel citado por Sennett Op. Cit., p.367.

${ }^{228}$ Ibid., p.371.

229 Sigfried Giedon inaugura su genealogía de la arquitectura moderna con la construcción del Palacio de Cristal en Giedon, Sigfried. Espacio, tiempo y arquitectura. Barcelona, Reverté, 2009, p.268.

${ }^{230}$ Sloterdijk, Peter. Esferas III. Espumas.Esferología plural. Madrid, Siruela, 2006, p.260,

${ }^{231}$ Un contorno-contornado se refiere a la idea de la inmersión del medio ambiente. El hombre no solo reproduce el medio ambiente sino que lo invierte. Un contorno-contornado sería la alteración de la relación exterior de la naturaleza para invertir no solo esta relación sino los climas que estas naturalezas poseen. Es decir, fenómenos naturales interpretados, repetidos y alterados.
} 


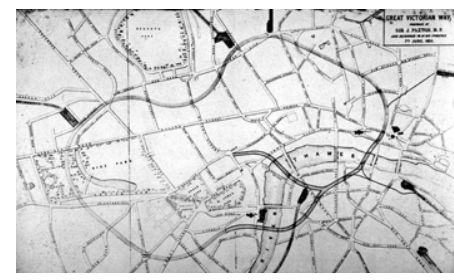

Img.26

Proyecto Great Victorian Way para la ciudad de Londres de Joseph Paxton de 1855

y material, y como metáfora de un concepto de sociedad. Pero, como enuncia Sloterdijk, "formato y mensaje ya no difieren en su significado." 232

Por un lado, la isla atmosférica "delimita un enclave del aire de alrededor, aislándolo en él, y estabiliza una diferencia atmosférica permanente entre el espacio interior y el espacio exterior.” ${ }^{233}$ Esta formulación puede trasladarse desde la idea de la casa, como Insula latina que designaba la casa romana el siglo II. d.C. Para Sloterdijk la isla atmosférica terrestre en el sentido estricto de la palabra, solo puede darse desde la construcción del invernadero de cristal del siglo XIX porque con ellos "la construcción de casas se convierte en una explícita construcción climática." ${ }^{234}$

En el invernadero de cristal de Paxton, se dan los primeros experimentos con implicaciones botánicas, climáticas y culturales de la globalización. Paxton construyó el gran invernadero del 30 de julio de 1850 al 1 de mayo de 1851. Con una longitud de 563 metros, una anchura de 124 metros y una altura de 33 metros. El invernadero de Paxton, se convirtió en el mayor espacio interior edificado del mundo. La condición XXL del manifiesto Bigness de Rem Koolhaas también comienza a operar aquí.

El invernadero enseguida dio paso a ideas urbanas para convertir espacios determinados de la ciudad como calles y plazas en un continuo urbano sin exterior. El proyecto no realizado que culmina este proceso es el Great Victorian Way de Joseph Paxton de 1855 para la Comisión Parlamentaria Metropolitana de Londres. Consiste en un circuito cubierto que rodea parte del centro y el Oeste de Londres. Este circuito construye un urbanismo de interiores que integra ferrocarriles, tiendas, casas. El circuito integra el cruce de tres ríos creando puentes habitados, interiores. Todo ellos cubierto con estructuras de hierro y vidrio con la tecnología desarrollada para el Palacio de Cristal. Una gran burbuja desarrollada como una pompa de jabón lineal en la ciudad de Londres.

No vamos a hacer aquí una explicación histórica de la evolución del concepto de invernadero como construcción material de un aire interior. Esta pasaría por pensar en las patentes de James Anderson en 1803 para la construcción de invernaderos de 2 pisos, la formulación de los fundamentos teóricos para la construcción de formas hemisféricas de Thomas Knight y George Mackenzie en 1811 y 1815 respectivamente; Loudon y el construcctor del gran jardín de invierno

${ }^{232}$ Sloterdijk, Peter. En el mundo interior del capital. Para una teoría filosófica de la globalización. Madrid, Siruela, 2007, p.210.

${ }^{233}$ Sloterdijk, Peter. Esferas III. Op. Cit., p.261.

${ }^{234}$ Ibid., p.262. 
de Laeken, cerca de Bruselas; O los grandes invernaderos del siglo XX como el proyecto Biosfera2 en Oracel, Tucson, Arizona, los proyectos de B. Fuller, o el Eden Project de Grimshaw.

Según Le Corbusier se puede comparar un edificio con una pompa de jabón: "Las pompas de jabón son armónicas. Cuando el aliento está bien regulado desde dentro, el exterior es el resultado de un interior." ${ }^{235}$ A esto contraponemos lo escrito por Federico Soriano en su tesis doctoral "cuando un exterior es ya totalmente independiente de un interior no hay escala ni exterior. Un objeto sin escala se revela como una pieza donde la fachada no manifiesta aquello que ocurre dentro, sino que es independiente de su interior" ${ }^{" 236}$ Los invernaderos como burbujas aisladas han dado paso hoy a las espumas conectadas y coincidentes. En ellos se explicita la condición de doping atmosférico a las que estas infraestructuras someten al aire interior de ellos y forman islas ya conectadas dentro de la espuma de la globalización del siglo XX.

\subsubsection{Europa es un invernadero sin exterior}

Como hemos comentado al principio del capítulo anterior, para Sloterdijk, el invernadero no es solo una infraestructura climática material. Es también un concepto que define nuestra sociedad. Y esto lo hace argumentándolo de dos modos diferentes. Por un lado, como caracterización de la sociedad occidental, y por otro como el receptáculo interior donde se da la condición de aligeramiento ${ }^{237}$ contemporáneo.

Para explicitar el primero, Sloterdijk parte de la narración "Las memorias del subsuelo" de Dostoievski, donde se captan las enormes dimensiones simbólicas y programáticas de esa híbrida construcción arquitectónica a la que Dostoievski llamó: el palacio de cristal. Para Sloterdijk, con el palacio de cristal de Paxton, “comenzó una nueva estética de la inmersión o aislamiento en un edificio inmaterializado y artificialmente climatizado.” 238

Con su erección [el invernadero de Paxton], el principio interior sobrepasó un umbral crítico: desde entonces no significó ya una vivienda burguesa o aristocrática, ni su proyección en la esfera de las arcadas comerciales ciudadanas [de Benjamin]; más bien puso las bases para una transferencia del mundo externo como un todo a una inmanencia mágica, transfigurada por el lujo y el cosmopolitismo. Tras ser transformado en un gran invernadero y centro

\footnotetext{
${ }^{235}$ Ibid., p.55.

236 Soriano, Federico. Sin tesis. Barcelona, Gustavo Gili, 2004, p.30.

${ }^{237}$ Este concepto se desarrolla en el epígrafe 3.5 de las conclusiones operativas.

${ }^{238}$ Sloterdijk. Peter. En el mundo interior del capital. Para una teoría filosófica de la globalización.

Madrid, Siruela, 2007, p.203.
} 
imperial de la cultura reveló la tendencia del tiempo a convertir naturaleza y cultura juntas en asuntos-indoors. ${ }^{239}$

Sloterdijk construye su idea de la sociedad-invernadero basándose en la asociación que hace Dostoievski con las ideas del Palacio de Cultura de la novela de Chernyshevsky ¿Qué Hacer? de 1863 donde un gran interior de acero y cristal estabilizado como arquetipo de las comunas del Este y el Oeste, estaba diseñado como receptáculo de lujo climatizado en el que tendría que reinar una eterna primavera de consenso. A partir de aquí, según Sloterdijk," la biopolítica se instituye como construcción-cercado. Después de la historia combativa de Europa la vida social solo puede desarrollarse en un interior ampliado, un espacio ordenado domésticamente y climatizado artificialmente" 240

¿Quién podría negar que hoy, en sus propiedades esenciales, el mundo occidental-sobre todo la unión europea tras su relativa consumación en mayo y la firma de su constitución en octubre del 2004-encarna exactamente un gran interior así? ${ }^{241}$

Para argumentar la segunda acepción del invernadero como receptáculo del aligeramiento, tenemos que pensar en su condición apaciguada tras las batallas inter-europeas. Para Sloterdijk, la construcción europea tras la II guerra mundial sienta las bases de una construcción basada en los "derechos humanos" como garantía para una sociedad de confort para la auto-realización de los consumidores. Europa se constituye como infraestructura institucional, jurídica y psicodimámica del consumismo. Tras la paz perpetua solo queda el aburrimiento, el aligeramiento. ${ }^{242}$

Desde el giro del bienestar de las "masas" en el interior del gran invernadero se puso en vigor la igualdad entre derechos humanos y derechos de confort. ${ }^{243}$

Visto de esta manera, Europa, como palacio de cristal o gran invernadero configura una ciudad que no deja salir de ella a sus visitantes-habitantes pues los rodea de una red irrompible de ofertas de confort y otros motivos de permanencia en el invernadero del bienestar, por lo tanto según Sloterdijk también del confort, el aburrimiento y el aligeramiento.

\footnotetext{
${ }^{239}$ Ibid., p.204.

${ }^{240}$ Sloterdijk, Peter. En el mundo interior del capital. Op. Cit., p.204.

${ }^{241}$ Ibid., p.205.

${ }^{242}$ Aquí Sloterdijk cita a Heidegger. “¿Es necesario decir todavía que la gran fenomenología de Heidegger del aburrimiento de 1929-1920 solo puede entenderse como un intento de liberación en el palacio de cristal establecido en toda Europa? "Ibid., p.206.

${ }^{243}$ Sloterdijk, Peter. Esferas III. Op. Cit., p.606.
} 
La estancia en el invernadero significa estar incluido en los flujos de repartición de los medios del mimo, animación y levitación. La casa común del lujo es la obra de arte de la vivienda y la producción, climatizada confortablemente, inmunizada por derechos de protección y disfrute, que se ramifica en forma de hogares, empresas, subculturas y colectores, en millones de microinstalaciones de una vida relativamente descargada. En este agregado espumoso. ${ }^{244}$

La explicitación del invernadero como caracterización de la sociedad occidental y como el receptáculo interior donde se da la condición de aligeramiento contemporáneo, se conforma con materialidades y espacialidades concretas que pueden argumentar la existencia de Europa como una ciudad sin exteriores, o donde los exteriores se manifiestan como una imposibilidad de acceso al gran invernadero y se materializan en entidades como la valla de Melilla, los naufragios de los refugiados en el mar Mediterráneo o la tele-vigilancia aérea, por drones y satélites en las fronteras de Brasil o California del Sur.

A partir de la metáfora del Palacio de Cristal, Sloterdijk desarrolla un análisis filosófico-arquitectónico de cómo el capitalismo liberal encarna una particular voluntad de excluir el mundo exterior, de retirarse en un interior absoluto, confortable, decorado, suficientemente grande como para que no se perciba el encierro. La transparencia del Palacio genera la ilusión en los habitantes de los márgenes de poder participar de su confort y seguridad. El palacio se hace desear, se propone como ideal de desarrollo para los "perdedores de la Historia" ocultando las fronteras que los dividen, invisibilizando sus rigurosas medidas de control. ${ }^{245}$

\section{Ejemplo 06. Europa: una ciudad sin exterior}

Sloterdijk, ofrece una lectura de la Unión Europea como un gigantesco invernadero libre de tensiones consagrado al placentero culto al consumismo. Pero también podemos leer la Unión Europea como una ciudad de interiores en continuidad que atraviesan todas las formas de la exterioridad.

Europa es hoy una ciudad sin exterior donde el avión hace las funciones de un metro transnacional. Para defender este argumento podemos recurrir de nuevo a Sloterdijk

\footnotetext{
${ }^{244}$ Ibid., p.614.

${ }^{245}$ Vásquez Roca. Adolfo. "Sloterdijk; psicopolítica, globalización y mundo interior del capital".

Nómadas. Revista Crítica de Ciencias Sociales y Jurídicas, v.28, n.4, 2010, p.1.
}

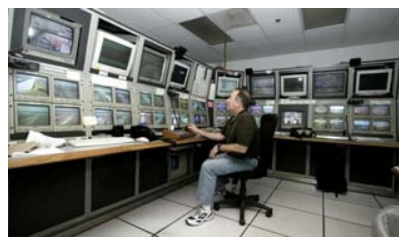

Img. 27

Los límites transparentes del Palacio de Cristal Occidental se actualizan en salas como esta de monitoreo de fronteras en California del Sur. Imagen. Lenny Ignelzi/AP. 2005 
Los visionarios del siglo XIX, al igual que los comunistas del XX, habían advertido ya que, al concluir los combates de la historia, la vida social solo podría desarrollarse en un interior dilatado, en un ámbito ordenado a la manera de una vivienda ¿Quién podría negar que el mundo occidental y muy especialmente la Unión Europea reúne en sí todos los rasgos esenciales de este amplio espacio interior. ${ }^{246}$

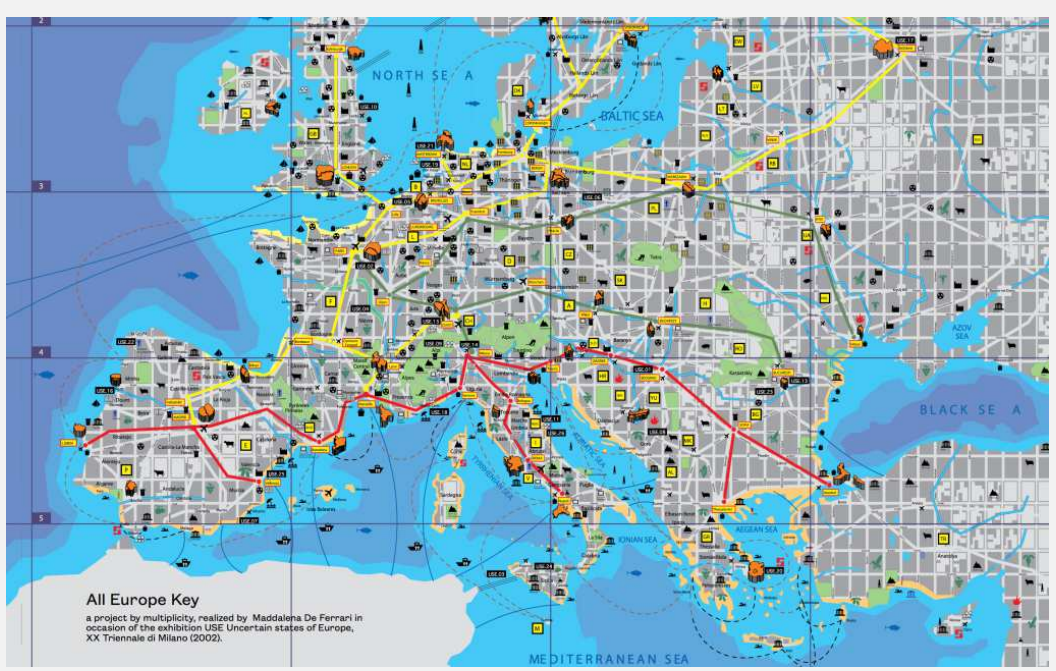

Fig. 14. Uncertain States of Europe. USE Stephano Boeri. Presentado en la Triennale di Milano 2002.

Continuando con el ejemplo, si el avión hace las funciones del metro urbano, los ensamblajes del avión transitan desde el lugar donde compramos el billete por internet, a distancia de un lugar físico, en nuestro espacio doméstico, quizás tumbados en la cama de nuestra habitación, al tránsito urbano que realizamos desde nuestra casa al aeropuerto como infraestructura alejada del centro urbano, en una periferia ubicua, al sistema que nos permitirá un acceso al propio avión. En todo este proceso, se han realizado ya multitud de mediaciones pues como dice B. Latour "Los aviones no vuelan, lo hacen las líneas aéreas" ${ }^{247}$

Este aeropuerto nos ofrecerá un tiempo especial para el consumo y más tarde nos llevará por un espacio aéreo regulado y normativizado que transcurre por la estratosfera, que ya no es ni territorial, ni natural. A una velocidad de casi $1.000 \mathrm{~km} / \mathrm{h}$ nos traslada a otro entorno urbano o metropolitano donde viviremos una experiencia inversa atravesando de nuevo la ciudad, el territorio, la naturaleza como las formas tradicionales de la exterioridad que hemos definido.

\footnotetext{
246 Sloterdijk. Peter. "El palacio de Cristal". Conferencia trascrita de "Traumas urbanos. La ciudad y los desastres". Centro de Cultura Contemporánea de Barcelona , 7-11 julio, 2004, p.1.

${ }^{247}$ Latour, Bruno. "De la mediación técnica: filosofía, sociología y genealogía." en Sociología Simétrica: ensayos sobre ciencia, tecnología y sociedad. Tirado y Montaner. (Eds.). Barcelona, Gedisa, 1998, pp.249-302.
} 
Este proceso podemos hacerlo en un espacio temporal de 3 horas y encontrarnos en el punto opuesto de la Unión Europea. Nuestra experiencia ensambla lo exterior y lo interior en sucesivos pliegues donde participamos mediante nuestra práctica (la de coger un avión) de otras políticas y otras afecciones. La responsabilidad de coger un avión y el gasto de emisiones de co2 tiene también implicaciones ecológicas para el territorio por donde transitamos. Pero este ensamblaje de transporte en el interior del gran invernadero se une a otros en continuidad.

Existe una ciudad sin exteriores. Una ciudad provisional con una población tendente a la mudanza. Construida con cooperación e interiorismo. Ni parís, ni Bruselas, ni Estrasburgo son ya la capital Europea. La capital de la unión Europea está formada por 80 millones de personas que en estos momentos viven en casas compartidas: casas Erasmus, casas patera, casas caras para grupos profesionales caprichosos, pisos tutelados, hogares de mujeres maltratadas. Compartir casa es un fenómeno masivo y diverso, un urbanismo invisible, que desafía la forma en que la vivienda y la ciudad han sido pensadas en las últimas décadas. ${ }^{248}$

Una de las características principales del ejemplo Europeo, como palacio de cristal, es el ensamblaje que se desarrolla entre el avión-líneas aéreas-Unión Europea-casas compartidas. Estos ensamblajes están ligados por canales de continuidad territorial ${ }^{249}$ y estos canales no son solo espaciales, es decir, conformados por aire climatizado en continuidad, que separa un exterior de un interior. También por dispositivos materiales e inmateriales que producen otros ensamblajes complementarios como son las tarjetas de crédito, las transferencias internacionales, las comunicaciones móviles y los dispositivos de tele-presencia. Todos ellos forman un entramado de relaciones heterogéneas, agencias compartidas y mediaciones que en su travesía por el territorio, la ciudad, la casa, etc., redefinen en sus límites los pliegues que confirman su exterioridad y su interioridad. No hay más una Unión Europea de diferentes ciudades nacionales agrupadas y exteriores unas a otras, sino una sola ciudad urbana, transnacional, con sus nodos de mayor y menor densidad de interacción, comunicación, cercanía, con sus Parques Protegidos y naturalezas reservadas, sus territorios hiperurbanizados, sus campos productivos, sus vacas reguladas, normativizadas y controlados y toda una serie de relaciones espacializadas que conforman una gran ciudad europea sin exterior garantizada por los canales de continuidad territorial.

\footnotetext{
${ }^{248}$ Jaque, Andrés. Dulces Arenas Cotidianas. Sevilla, Lugadero, 2013, p.49. 

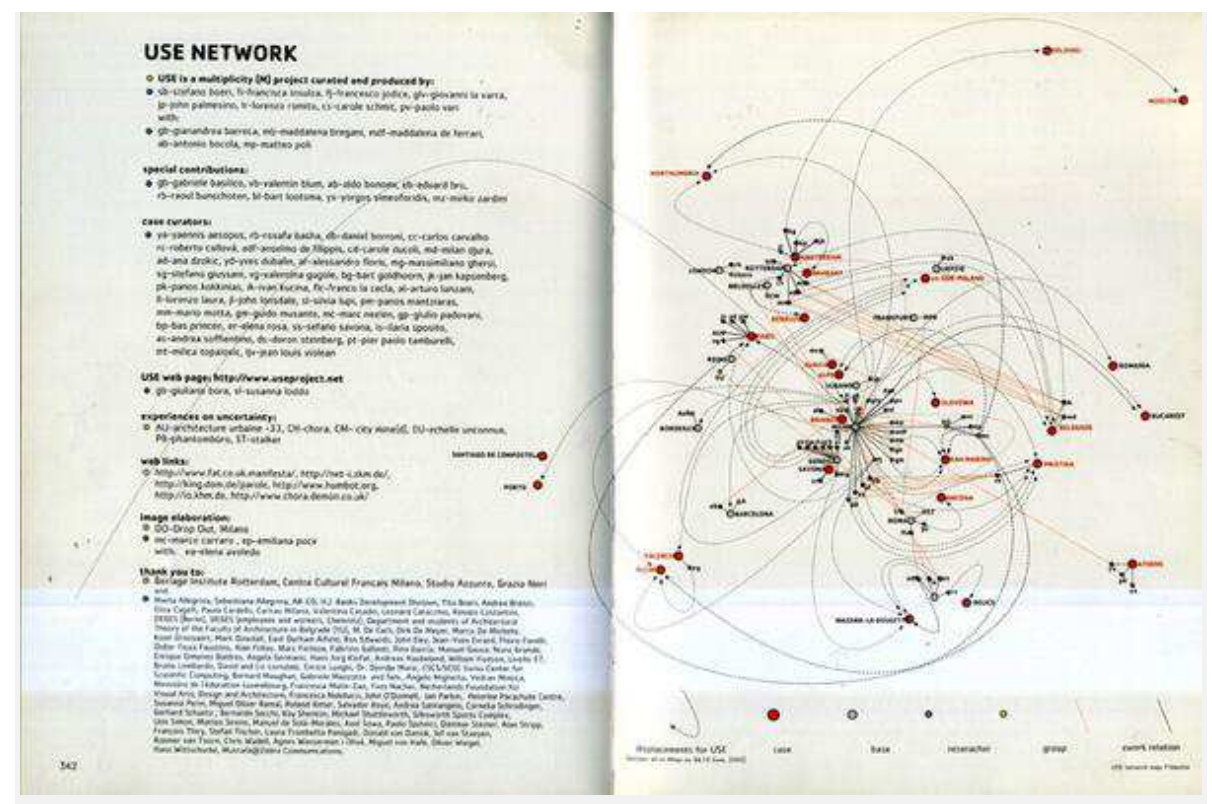

Fig. 15. Uncertain States of Europe. USE Stephano Boeri. Presentado en la Triennale di Milano 2002. A partir de la exposición Mutations, y publicado en el libro Multiplicity, USE, Viaggio nell'Europa che cambia, Skira, Milan, 2003.

Por lo tanto, dentro del gran invernadero se conforman espumas: multiplicidades espacio que Sloterdijk denomina: "Teoría Espacial de las multiplicidades". Antes de acceder a las argumentaciones de esta teoría para entender el alcance de esta para la tesis doctoral, veamos con que herramientas técnicas y operativas se conforma esta posibilidad de la tensionalidad de la espuma para conformar invernaderos, palacios de cristal y sociedades. Esta herramienta técnicoestructural, pero también metafórica es la tensegridad.

\subsubsection{Tensegridad}

Como hemos descrito en el primer punto de este capítulo sobre las espumas, estas en su fragilidad, operan mediante geometrías de covecindad. "La espuma es un sistema cofrágil en el que se ha alcanzado un máximo nivel de interdependencia. ${ }^{250} \mathrm{La}$ espuma, por lo tanto, puede existir gracias a que alcanzan un alto grado de tensión interior o tensegridad.

En la mecánica estructural, la tensegridad se define como "un principio estructural basado en el empleo de componentes aislados comprimidos que se encuentran dentro de una red tensada continua, de tal modo que los miembros comprimidos (generalmente barras) no se tocan entre sí y están unidos únicamente por medio de componentes traccionados (habitualmente cables) que son los que delimitan espacialmente dicho sistema." ${ }^{251}$ Este principio se basa en la continuidad de las

\footnotetext{
${ }^{250}$ Sloterdijk, Peter. Esferas III. Op. Cit., p.44.

${ }^{251}$ Gómez Jáuregui, Valentín. Tensegridad. Estructuras Tensegríticas en Ciencia y Arte. Santander, Servicio de Publicaciones de la Universidad de Cantabria, 2007.
} 
tensiones y la discontinuidad de las compresiones. B. Fuller fue el arquitecto que nombró este fenómeno como Tensegrity, en inglés. Tensegridad es la contracción de las palabras tensional integrity (integridad tensional). La otra denominación de tensegridad como compresión flotante fue usada principalmente por Kenneth Snelson.

La tensegridad para Sloterdik, diluye el principio de pared soporte, como algo estable y fijo, coformador de contendores, para sustituirlo por la coinsistencia de esfuerzos de tracción entre barras unidas por cables. De aquí, la idea de la tensión interna distribuida por diferentes entidades.

También hay para Sloterdijk, un componente rescatable e imaginario para una teoría sociológica en relación a las nociones de estabilidad, sistema y estructura. La idea de una teoría sociológica que no utilice la expresión sistema, sino que se defina por el desarrollo operativo de la construcción de máquinas, casas e instituciones, es una innovación para superar las estructuras sistémicas. Del mismo modo, una teoría que se sustente por la adaptación a lo móvil parece, para Sloterdijk, de mayor interés. Frente a la explicación del edificio mediante la estática, pensar en cómo la palabra estado y estática tienen la misma raíz. Para Sloterdijk la construcción histórica de los edificios es paralela a la construcción de las normas. ${ }^{252} \mathrm{La}$ tensegridad como arquitectura social está compuesta, para Sloterdijk, de "expectativas, apremios y resistencias mutuas, en una palabra: una primera constitución." ${ }^{253}$

Las sociedades son tensegridades de expectativas, es decir, multiplicidades de condiciones de vivienda y acciones reguladas, que se consolidan mediante acciones y amenazas. ${ }^{254}$

La tensegridad para Sloterdijk, resulta como la expresión de las tensiones internas de la convivencia humana. Con la tensegridad, Sloterdijk, quiere anular las teorías sistémicas de lo social en favor de una teoría donde la espuma presenta la multiplicidad de espacialidades como el resultado de una sociedad construida de entidades que aseguran su aislamiento en un entorno permanentemente conectado y comunicado. Si los invernaderos se han construido como ideal de consenso, la tensegridad es la manera de visibilizar las tensiones interiores no resueltas en el palacio de cristal. Con la inclusión de estos dos conceptos por Sloterdijk, la arquitectura se hace sociedad. Si la tensegridad se disipa, se produce el colapso de

\footnotetext{
${ }^{252}$ P. Sloterdijk. Op. Cit., p.361.

${ }^{253}$ Ibid. p. 280 .

${ }^{254}$ Ibid. p.363.
} 
la estructura. Por este motivo, la existencia de tensiones internas puede darse también hoy por la condición de covecindad que inauguran las espumas.

\subsection{Covecindad}

Para argumentar la inexistencia de una exterioridad a la que remitirnos hay dos ideas fundamentales a la hora de buscar modos de pensamiento que permitan entender por qué las espumas y la teoría de las multiplicidades-espacio lo permiten. Para Sloterdijk, a diferencia de Heidegger, el "Ser-en-el-mundo", es descrito por Sloterdijk como un "Ser-en-la-esfera". 255 Pero este "Ser-en" se transforma en un "Ser-con". ${ }^{256}$ La existencia es una existencia "con" y se da en condiciones de covecindad.

La primera idea es la aparente paradoja de construir invernaderos inmunes. Islas de todo tipo que separan a los humanos del exterior y la idea de que no hay un exterior. Esta paradoja podemos ponerla en cuestión pues a más construcción interior, más separación de un exterior. Pero para Sloterdijk, todos son interiores pues incluso el exterior está ya saturado y de él se sostienen otras tecnologías de comunicación, de consumo, etc. El palacio de cristal no tiene paredes visibles, pero existe. El exterior en Sloterdijk es el interior del Palacio de Cristal. Por otro lado, el exterior de un insulamiento, es el interior de otro insulamiento. El exterior de una burbuja de la espuma, es el interior de otra burbuja de la espuma.

La segunda idea es la anulación de la categoría individual como punto de partida para pensar en el hombre. El individuo es un individuo en covecindad interna o en "sociedades de ados"257. Estas sociedades se conforman entre uniones psíquicas de parejas humano-humano, y materiales de humano-tecnología. A esta situación Sloterdijk la llama auto-emparejamientos. La espuma, son múltiples sociedades de individuos de ados. ${ }^{258}$

Pero la idea fundamental para entender un giro en la tradición del pensamiento social no es solo la idea de la espuma como multiplicidad, sino de cómo se compone la unidad inmunológica y su condición de vecindad en el pensamiento de Sloterdijk. La identificación de la autovecindad, es decir el emparejamiento

\footnotetext{
255 Sloterdijk, Peter. Esferas I. Burbujas. Microsferología. Madrid, Siruela, 2003, pp.46-343.

${ }^{256}$ Sobre un análisis más extenso de esta cuestión ver: Vásquez Roca, Adolfo. "Sloterdijk y Heidegger: humanismo, deshumanización y posthumanismo en el parque humano." Nómadas. Revista Crítica de Ciencias Sociales y Jurídicas, v.23, n.3, 2009.

${ }^{257}$ George Simmel en La sociedad de a dos. 1908 desarrolla la disputa de la relación de a dos entre individuo y sociedad. Por otro lado, la filósofa feminista Luce Irigaray para referirse a la construcción del mundo como sociedad de dos (hombre y mujer). La publicación de Espéculo de la otra mujer de 1974 discute la obra de J. Lacan El estadio del espejo como formador de la función del yo de 1949 por la inconsideración de que la sociedad es una sociedad de dos. Esto le llevo a una fuerte disputa con J. Lacan sobre su posición.

${ }^{258}$ P. Sloterdijk. Esferas III. Op. Cit., p.47.
} 
del individuo o la construcción de "sociedades de ados", demuestra que el pensamiento interior basado en el sujeto-individual es para Sloterdijk insuficiente. El giro que produce Sloterdijk es el de pensar que la unidad, es binaria y múltiple, y se produce al construir el individuo como la suma del individuo de a dos y los soportes de vida que necesita. No existe entonces una sola unidad individual humana de la que parte el pensamiento ni que se expone al exterior. En la línea del pensamiento de Simmel o Tarde que analiza la sociedad como "composición de composiciones" Sloterdijk propone un giro que llama "Diadológico"259 Las sociedades-espuma habría que considerarlas como multiplicidades de díadas, "cuyas unidades elementales no constituyen individuos, sino parejas, moléculas simbióticas, hogares, autoreceptáculos."260

La idea de una multiplicidad de auto-receptáculos psíquicos conduce por sí misma a la expresión, espuma. ${ }^{261}$

También la noción de auto-emparejamiento no se reduce solo a un ámbito psíquico del individuo-humano sino a la relación de este con la tecnología y sus soportes de vida. En esta relación no se puede hablar de un exterior o un interior al individuo, pues el individuo en sí, se ha desdoblado en múltiples autoemparejamientos. Ambos, exterior e interior, se coproducen simultáneamente, el humano y la tecnología o el cuerpo y arquitectura no se componen por separado. Argumentamos esta noción en los apartados que continúan.

\subsubsection{Autoemparejamientos humanos}

Al desarrollar la idea de los auto-emparejamientos o las sociedades de ados que propone Sloterdijk, tenemos que recuperar los trabajos sobre la filosofía feminista de Luce Irigaray. Luce defiende una sociedad de dos que nuestra sociedad ha dejado vacía con la unidad. Y esta unidad es siempre de un sujeto único, masculino y que construye una filosofía vertical. Si, en cambio, se entra en la óptica de los dos sujetos, masculino y femenino, diferentes pero en continua relación entre ellos, esta relación cambia ."La humanidad es a dos y necesita divinizar esta condición, cultivar nuestro ser en relación con el prójimo." ${ }^{262}$ Esta noción también tiene la capacidad de cambiar las espacialidades y temporalidades como la que estamos definiendo de la casa. También cada hogar, como espacialidad propia en red, posee enclaves de vecindad y separación recíproca

\footnotetext{
${ }^{259}$ Sloterdijk cita a Béla Grunberger como iniciador del giro diadológico al enunciar el concepto de mónada psíquica cuyos contenidos los proporciona la coexistencia de dos, implicados mutuamente en una interacción psíquica fuerte. Ibid., p.230.

${ }^{260}$ Ibid. p. 230

${ }^{261}$ Ibidem.

${ }^{262}$ Irigaray, Luce. Conferencia en El Festival de Literatura de Mantua. Septiembre de 2006.
} 
Aglomeraciones de burbujas, sistemas agregados de vecindades esféricas donde cada una de ellas construye un contexto o un hogar. Cada hogar es un invernadero de "sociedades de ados". 263

Para Sloterdijk, la idea de un aislamiento o inmunidad individual se argumenta mejor por la idea de una "inmunidad nosotros" ${ }^{264}$

Seres humanos con seres humanos producen un interior hasta ahora poco considerado. A este interior le llamamos microesfera. Es la pareja y no el individuo la que representa la magnitud más auténtica. El ser-ahí lleva implícito la esfera de la posible vecindad; ya originariamente es vecino de... ${ }^{265}$

Podemos decir que con esta noción de espacios-insulamientos, Sloterdijk está provocando un desplazamiento fundamental al inaugurar el espacio de coexistencia que provoca la vecindad, la inmunidad colectiva frente a la comunidad como espacios-espuma. En este sistema sin exterioridad, también desde una visión individual, aparecen diferentes posibilidades espaciales que provocan otro desplazamiento y con ello la aparición de los autoemparejamientos. Esta segunda idea es la de no partir de una unidad individuo sino de la dualidad y autoemparejamientos, lo que sostiene que no hay un exterior porque siempre vamos de la mano de algo-alguien. la covecindad nos permite no seguir pensando la dualidad espacio-individuo sino una valoración de la pareja de ados y el aireentorno que lo rodea da lugar a la teoría espacial de las multiplicidades espacio.

La burbuja individual del siglo XX, como continuación de la burbuja colectiva de los invernaderos del siglo XIX, es la espuma habitacional que constituye las relaciones del habitante consigo mismo en la unidad vivienda. Este es el escenario del autoemparejamiento. Tras el autoemparejamiento inicial, expuesto por Sloterdijk, Matriz/útero Feto/Placenta, el apartamento como invención del siglo $\mathrm{XX}$ aparece como una isla de auto-emparejamientos. Uno es el otro en la vida del apartamento. Ese otro, como exterior, sólo puede ser descubierto como un otro real en una época en la que se han vuelto epidémicos el autodesdoblamiento del uno en sí mismo y la multiplicidad de los otros interiores virtuales."Por lo tanto la existencia de ese otro vinculado a uno mismo es un proceso que anula la exterioridad del individuo. La pareja, en un proceso de autosimbiosis da como resultado una unidad ${ }^{266}$. Uno más uno, es igual a uno.

\footnotetext{
${ }^{263}$ P. Sloterdijk. Esferas III. Op. Cit., p.47.

${ }^{264}$ Ibid., sobre Esferas I p.15.

${ }^{265}$ Ibid., p.16.

${ }^{266}$ Ibid., p.443.
} 


\subsubsection{Autoemparejamientos tecnológicos}

El segundo modo de auto-emparejamientos en la espuma se da en la construción de "sociedades de ados" entre humanos y su tecnología. La aportación de Sloterdijk, varía de la inclusión de los no-humanos de Bruno Latour que hemos desarrollado en el capítulo primero. Por un lado Sloterdijk, dispone una simetría en la condición de la existencia humana debida a los "soportes de vida" 267 que dispone, por otro lado teniendo en cuenta que estos soportes de vida no son solo climáticos y espaciales sino también tecnológicos. De esta manera pueden darse dos situaciones generales.

La primera de ellas puede ejemplarizarse en la idea del apartamento. Este no desarrolla, como la celda de los monjes, la dúplice unicidad (bi-unidad) entre dios y alma. Más bien apoya el autoemparejamiento consigo mismo (uni-binidad).

La segunda situación tendría que ver con los procesos de mediación técnica, como los teléfonos, radio y televisión. Estos, son para Sloterdijk, la contribución técnica más importante para la disolución del aislamiento climático y protector. El teléfono es entonces un dispositivo que anula la exterioridad del ser en la vivienda. "Representa una nueva adquisición ambivalente porque introduce en la vivienda un canal de infecciones provenientes del exterior pero amplia el radio del habitante en el sentido de oportunidades de acción y alianzas concretadas" ${ }^{268}$ Esto puede ejemplarizarse en la afirmación de Andy Warhol sobre su propio autoemparejamiento tecnológico que no solo es actual y operativo sino también virtual y afectivo.

En los años 50 comencé un "affaire" con mi televisión que me llevó al presente [...] pero no me casé hasta 1964 cuando conseguí mi primera grabadora. Mi esposa [mi pareja] Cuando digo "nosotros" quiero decir mi grabadora y yo. Mucha gente no entiende esto. ${ }^{269}$

Sloterdijk, aún en su condición de filósofo-antropólogo que estudia principalmente a los seres humanos y sus construcciones atmosféricas, lejos del guión relacional que postula Bruno Latour y la ANT, no presupone ninguna relación apriori entre los humanos y la tecnología. Para Sloterdijik, las explicaciones deben concernir a las palabras y las cosas simultáneamente. Esto lo hace explícito en la consideración que las culturas de occidente "son países de

\footnotetext{
${ }^{267}$ Soportes de vida: significa exactamente esto: satisfacer la lista de condiciones bajo las cuales un mundo de vida humano puede ser mantenido temporalmente en condiciones de funcionamiento como isla absoluta. Ibid., p.254.

${ }^{268}$ Ibid. p.454.

269 Warhol, Andy. Mi filosofía de $A$ a $B$ y de $B$ a $A$. Barcelona, Tusquets, 2010.
}

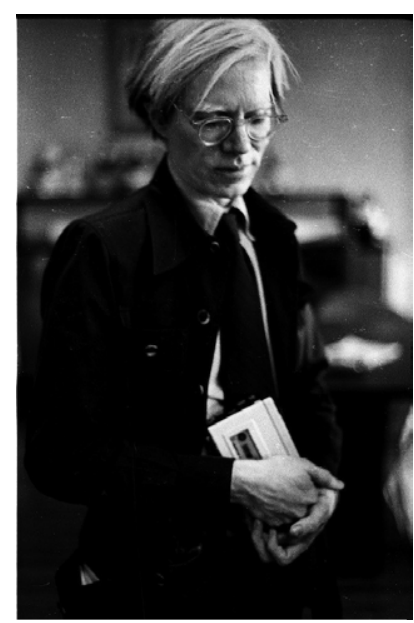

$\operatorname{Img.29}$

“Te presento a mi mujer" o "Ésta es Sony, mi esposa”. El autoemparejamiento tecnológico de Andy Warhol y su Grabadora Sony explicado en su libro De la $A$ a la $B$ y de la B ala $A$. 
inmigración de máquinas" ${ }^{270}$ y con ello de objetos, tecnologías, aparatos, teoremas, entidades y procedimientos. El mundo de los seres humanos y las cosas, ya no está separado, ni es el mismo de antes. Sloterdijk se preocupa de cómo estos objetos, invenciones e innovaciones aparecen en la arena de la realidad y se hace la ingenua pregunta de ¿Dónde estaban antes de su descubrimiento? ¿Dónde estaba el ácido láctico antes de Pasteur? ¿Dónde estaban los microbios antes de su descubrimiento? Para así, finalizar preguntando: ¿Dónde estaban las espumas, los sistemas de inmunidad antes de que los explicáramos?

Para Sloterdijk, existen tres clases de objetos. ${ }^{271}$ Los objetos inventados, como los automóviles o tamagochis. Los objetos descubiertos, como las feromonas o los virus del sida. Los objetos mixtos: como las bacterias recombinables, enzimas transgénicas, o los conejos fosforescentes.

Si los teléfonos y los hornos de microondas hacen su entrada en los hogares de los ciudadanos; si abonos químicos y antibióticos colocan sobre nuevos fundamentos el metabolismo del ser humano con la naturaleza; si el automóvil, en una ola de imitación de apenas 100 años, lleva a una revisión radical de todas las ideas tradicionales de ciudades, calles, hogares y entornos: tras cada una de esas invasiones y de sus propagaciones epidémicas el mundo común de los seres humanos y las cosas ya no es el mismo de antes. ${ }^{272}$

\section{Ejemplo 07: una sociedad híbrida de "más que humanos"}

La sociedad en el contexto de la desaparición de la exterioridad no es una entidad tan solo humana. Pues esta significación, reflejaría una posición única, masculina y heteronormativa o como dice Haraway de un patriarcado capitalista blanco, que dejaría afuera a todas aquellas personas, humanas no incluidas en este ámbito

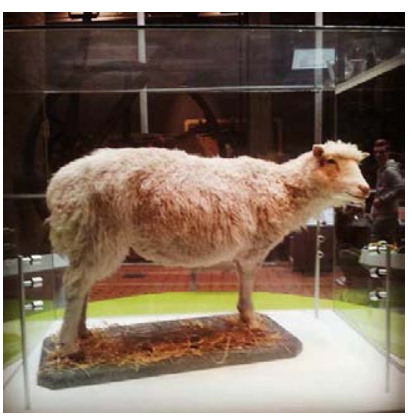

$\operatorname{Img} .30$

La oveja Dolly 1996-2003 clonada por los científicos del Instituto Roslin de Edimburgo (Escocia), Ian Wilmut, Keith Campbell. humanista y a todos los seres no humanos, que también forman parte de la sociedad como colectivo ampliado. Bajo esta perspectiva, el exterior es de nuevo dependiente del sujeto normativizado que mira.

Pero pensar en la sociedad como una sociedad de "más que humanos" es pensar en los auto-emparejamientos y objetos híbridos de otro modo. Incluir en el repertorio de entidades con agencia a todos esos "otros" que no serán más entidades exteriores a nosotros y conformadoras por tanto de nuestra exterioridad, sino por el contrario entidades humanas, más que humanas y de sistemas de cosas que formarán parte de un "nosotros" múltiple, en continuo conflicto e interacción. Y este "nosotros" como sociedad no será un interior común, sino un espacio

\footnotetext{
${ }^{270}$ P. Sloterdijk. Esferas III. Op. Cit., p.164.

${ }^{271}$ Ibid. p.165.

${ }^{272}$ Ibid. p. 165
} 
formado de espacios inmunes donde conviven los conflictos. Aunque Sloterdijk, de una forma expresa, dentro de los autoemparejamientos también estarían los referidos no solo a humanos u objetos-tecnologías sino, como apuntaba M. Callón, al conocimiento y la información.

La naturaleza no podemos considerarla ya un exterior, como algo que observamos ahí afuera. Una sociedad de "más que humanos" remite también a una sociedad donde la información compone entidades diversas.

Desde el anuncio de la clonación de la célula de la oveja Dolly en febrero de 1997 , tampoco los animales forman parte de esa naturaleza exterior, y forman parte del espacio de relaciones socio-materiales. Desde Pasteur hasta el momento presente donde la oveja Dolly se desarrolla un planeta que se compone también desde la ciencia, la naturaleza, la genética y la ética. "La naturaleza, contrariamente a la impresión superficial, no es un objeto por ahí, sino que es sobre todo, un animal político." ${ }^{273}$

La naturaleza como animal político, se convierte a su vez en objeto controversial, y esta condición hace de ella algo ligado a lo social. También en términos del uso que hacemos de la naturaleza, es un uso de ella como recurso. "La naturaleza es sólo la materia prima de la cultura, apropiada, reservada, esclavizada, exaltada o hecha flexible para su utilización por parte de la cultura en la lógica del colonialismo capitalista" 274

La oveja Dolly ¿es entonces un monstruo que hemos asimilado como propio? Un Frankestein de ordenadas proporciones genéticas. Un nuevo agente híbrido producto de nuestro tiempo. ¿Qué proceso natural exterior a nosotros le queda a la oveja Dolly? ¿Qué exterior, si queremos, recibe la oveja Dolly bajo su punto de vista como sujeto de derecho? o es simplemente un nuevo recurso para producir un mercado de ovejas genéticamente modificadas. $\mathrm{O}$ una innovación biogenética que produce otros cuerpos no humanos inscritos de políticas humanas, técnicas y científicas.

Para Sloterdijk, la oveja Dolly, como objeto híbrido, se compone de materia e información. Materia porque su ADN no existe sin una estructura molecular e inteligencia porque la interrelación de la información con otros componentes

\footnotetext{
${ }^{273}$ Latour, Bruno. "Atmospheres, atmospheres. Laboratory inside out”. Introducción al catálogo de Olafur Eliasson en la exposición de la Tate Modern. Susan May editor, London, Tate Modern, 2002, p.341.

${ }^{274}$ Haraway, Dona. Ciencia, cyborgs y mujeres. La reinvención de la naturaleza. Madrid, Cátedra, 1995, p.321.
} 
puede clonar un $\mathrm{ADN} .{ }^{275}$ Es una homeotecnología: una tecnología entre entidades que poseen el mismo status ontológico. ${ }^{276}$

La homeotecnología, al tener que vérselas con información realmente-existente, no hace más que avanzar en el camino de la no violación de los entes; gana en inteligencia inteligentemente, creando así nuevos estadios de inteligencia. ${ }^{277}$

Sin entrar en la controversia de, si la oveja Dolly, es un sujeto de derecho o por el contrario tiene una consideración de objeto sensible como animal, podemos decir que tenemos que disponer de las herramientas de la ANT para otorgarle una entidad ontológica. La oveja Dolly es un actor con capacidad de agencia que está más allá de la dualidad objeto/sujeto.

¿Qué es en efecto un sujeto? Lo que se resiste a la naturalización. ¿Qué es en efecto, un objeto? Lo que se resiste a la subjetivación." 278

La oveja Dolly es un miembro de una asociación, de una sociedad de más que humanos, que es capaz de "modificar a otros actores mediante una serie de transformaciones elementales" 279 ¿Se trata entonces Dolly de un objeto? En absoluto, dirá Latour. Dolly se encuentra asociada a los científicos Ian Wilmut, Keith Campbell y los trabajadores del Instituto Roslin de Edimburgo que señalan con el microscopio los genes, las situaciones, los protocolos, sin que sea posible distinguir quién habla y con qué autoridad lo hace. ¿Se trata entonces de un sujeto? Ya no. Pues en la asociación de más que humanos, de la que Dolly es miembro, hay también laboratorios, lugares, situaciones, efectos que no se reducen a las acciones de un sujeto. Esta presentación de la sociedad como una sociedad de más que humanos, nos permite entender la ampliación o la internalización del "medio ambiente que hasta ahora había considerado como otro mundo" 280

Para Sloterdijk, hay un antes y un después de la clonación de Dolly. El momento Post Dolly Creatam anuncia un apocalipsis biológico, al igual que las bombas atómicas de Hiroshima y Nagasaki en 1945 anunciaron el apocalipsis geopolítico pues "La humanidad no existe bajo los signos de lo divino, sino de lo monstruoso. Lo humano es lo Humano(C "281 y Dolly tiene un próximo devenir humano que aparece desde su nacimiento. "Del mismo modo que Dolly no es una oveja

\footnotetext{
${ }^{275}$ Van Tuinen, Sjoerd. "Transgenous Philosophy": post-humanism, anthropotechnics and the Poetics of natal Difference en In Medias Res: Peter Sloterdijk's Spherological Poetics of Being Schinkel, Willem \& Noordegraaf-Eelens Liesbeth (Eds.).Amsterdam, Amsterdam University Press, 2011, p.53. ${ }^{276}$ Concepto utilizado por Sloterdijk en "El hombre operable. Notas sobre el estado ético de la tecnología génica" conferencia 19 de mayo de 2000, en el Centro de Estudios Europeos (CES) de la Universidad de Harvard, en Estados Unidos.

${ }^{277}$ Van Tuinen, Sjoerd. Op. Cit. p.53.

${ }^{278}$ Latour, Bruno. Politicas de la naturaleza. Barcelona, RBA, 2013, p.124.

279 Ibid. p. 125

${ }^{280}$ Ibid. p.104

${ }^{281}$ Preciado, Paul B. sobre Sloterdijk y Dolly en Testo Yonqui. Madrid, Espasa Calpe, 2008, p.161.
} 
engendrada por su especie, el Homo clonatus no sería tampoco un hombre engendrado por el hombre." 282

Para Sloterdijk el problema no resuelto del pensamiento tradicional es cómo se infiltran estos objetos-innovaciones en el mundo de la espuma. Y dónde estaban antes de su descubrimiento, o en palabras de Sloterdijk. “¿De qué modo estaban disimulados el clima, el aire y la atmósfera para los individuos y los grupos antes de que por sus explicaciones atmoterroristas ${ }^{283}$ y los desarrollos meteorológicos y técnico-climáticos se convirtieran en objetos de preocupación moderna por el medio ambiente?” ${ }^{284}$ En definitiva ¿bajo qué formas y vecindades se asimilan estos objetos-cosas en la comunidad de realidades?

Dos son las aproximaciones que destaca Sloterdjik para superar las fronteras del realismo y el idealismo respecto a esta cuestión. Las aproximaciones de Bruno Latour y la ANT en sus repúblicas de las cosas, y las de Heidegger sobre la "esencia de la verdad" que alude a la incorporación de estas entidades. ${ }^{285}$

El concepto que ya hemos tratado en el capítulo primero sobre la "articulación" de Latour, es el que recoge Sloterdijk para aproximarse a su concepto de explicación o explicitación de los insulamientos. Dolly también es un insulamiento. Es una espuma. Sloterdijk aprueba un "descubrir" basado en las nociones de propuesta de Whitehead y reformulado por Latour como articulación. ${ }^{286}$ Para Sloterdijk, las articulaciones desarrollan nuevas vecindades entre propuestas. Recupera el ejemplo descrito por Latour:

El fermento de ácido láctico existe ahora como unidad discreta porque entre muchas entidades están articuladas ahora en otros tantos entornos activos y artificiales. ${ }^{287}$

Las espumas, en su forma esencial, se forman desde el autoemparejamiento de sociedades de "ados". Este también es múltiple entre humanos y entre humanosobjetos-cosas. Estos autoemparejamientos conforman las celdas, como raíz de la espuma, como multiplicidades-espacio. Las sociedades modernas son por tanto multiplicidades de producción de espacio inmune (aislado) "El descubrimiento de los sistemas de inmunidad y su incorporación a la ecología del saber de la

\footnotetext{
${ }^{282}$ Heinrichs, Hans-Jürgen \& Sloterdijk, Peter. El sol y la muerte. Investigaciones dialógicas. Madrid, Siruela, 2004, p.110

${ }^{283}$ Sobre la explicitación del aire como arma de ataque químico en Sloterdijk, Peter Terror from the

Air. Los Ángeles, Semiotext[e], 2009.

${ }^{284}$ Sloterdijk Peter. Esferas III. Op.Cit., p.168.

${ }^{285}$ Para ver la aproximación a Heidegger, Sloterdijk la desarrolla en Ibid. Esferas III. pp.170-177.

${ }^{286}$ Esta aproximación está desarrollada en el texto de Bruno Latour. ¿Tienen historia los objetos? "El

encuentro de Pasteur y Whitehead en un baño de ácido láctico.”

${ }^{287}$ Ibid., Bruno Latour.
} 
"sociedad" moderna presuponen una situación de cultura global" ${ }^{288}$ y ese universo de cultura global no consiste en "una única pompa de jabón [...] sino de millones de pompas de jabón estrechamente colindantes, que se cruzan e interfieren por todas partes." ${ }^{289}$ Las espumas, dan lugar a la teoría de las multiplicidades espacio.

\subsection{Multiplicidades-espacio}

Como dice Sloterdijk tradicionalmente eran la familia, la tribu, luego también la ciudad, la comunidad de fe, el pueblo, el partido, la empresa, las entidades que se hacían valer como unidad inmunológica operativamente efectiva, es decir, los mecanismos de confort social. Estos sistemas obligaban a sus miembros a modos de comportamiento correspondientes al estándar de inmunidad conseguida en común sin una capacidad de "tensegridad".

Pero es ahora con el escándalo del modelo moderno, que consiste en dirigirse a las necesidades de aislamiento y relación de individuos flexibilizados y sus compañeros de vida, que no buscan su optimum inmunitario en colectivos imaginarios y reales o en totalidades cósmicas casa, pueblo, clases y estado. ${ }^{290}$

Los tradicionales sistemas de confort, se sustituyen según Sloterdijk en sistemas de aislamiento que parten de la construcción del hogar-burbuja como explicitación de la isla o celda personal. Se sustituyen de esta manera los sistemas como la casa, el pueblo, las clases y el estado por sus propias estancias materiales desde las que se desarrolla el humano.

Pero es hoy, quien apoyado por los medios habita una casa en la modernidad, ha sustituido los vagos sistemas de inmunidad por sus propias células habitáculo, altamente aisladas desde un punto de vista jurídico y climático. La vivienda moderna es un lugar donde no acceden nunca huéspedes ni invitados. La vivienda se consolida así como máquina de ignorancia o como mecanismo integral de defensa. En ella se encuentra su apoyo arquitectónico el derecho fundamental a no prestar atención al mundo exterior. ${ }^{291}$

Img. 31

Isolator de Hugo Gernsback 'El autor trabajando en su estudio particular con la ayuda del Isolator. Con los ruidos exteriores eliminados, el trabajador se puede concentrar fácilmente en el objeto que le atañe ".Revista "Science and Invention” en 1925.

Es decir, aunque nuestros insulamientos físicos o la construcción de invernaderosespacio donde alojarnos individual y colectivamente, sean islas cada vez más independientes climáticamente, se hacen interdependientes virtual y relacionalmente. También el excesivo aislamiento de un exterior sin condiciones de vida, como por ejemplo, la estación espacial, hace del exterior un lugar

\footnotetext{
${ }^{288}$ P. Sloterdijik. Esferas III. Op.Ct., p.189.

${ }^{289}$ Uexhküll, Jakob von, "kompositionslehere der Natur. p.335 citado por Sloterdijk Ibid. p.191

${ }^{290}$ Ibidem.

${ }^{291}$ Ibid. p.412.
} 
impracticable para la vida por lo tanto inaccesible y no transitable. Por lo tanto las multiplicidades espacio son la materialización de "las sociedades como multiplicidades compuestas de espacialidades propias." ${ }^{292}$

La indivisión entre el individuo y sus "soportes de vida" queda patente en la complejidad para precisar las esferas humanas con sus propiedades específicas como multiplicidades pompas de jabón de las formas de vida en los entornos propios. Estos entornos se cruzan e interfieren por todas partes y Sloterdijk los sitúa "en una dimensión ontológica más allá de los espacios y las formas de vida interpretados biológicamente." ${ }^{293}$

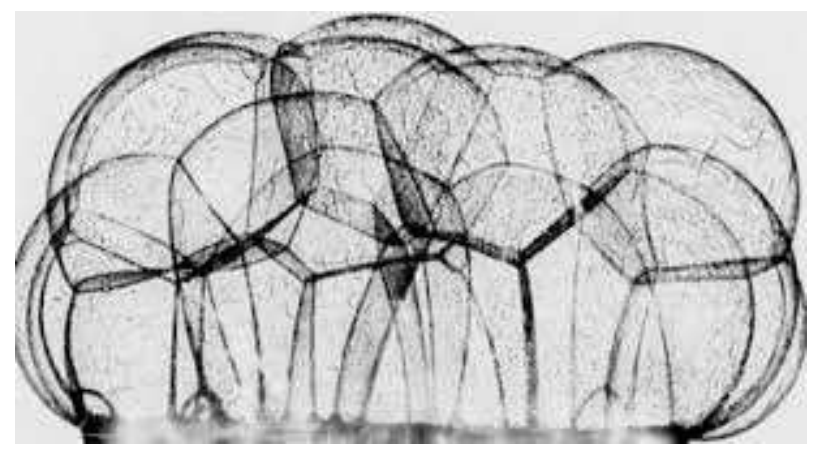

Fig. 15 Aglomerado de espumas y burbujas por adhesión neumática de Jabón. Frei Otto.

Ante la volatilidad ${ }^{294}$ de la civilización contemporánea, la estabilidad de las multiplicidades espacio se da por la condición de covecindad de la espuma. La estabilidad pasa, para Sloterdijk, por cambiarla por liquidez. La liquidez de la espuma también se basa en lo argumentado por la covecindad de las burbujas. Como hemos explicado en la introducción de este capítulo, la liquidez o la estabilidad de las mismas, se basa en el principio de co-aislamiento según el cual "una y la misma pared de separación, sirve de límite en cada caso para dos o más esferas. [...] El coaislamiento de los hogares-burbuja en sus diversas vecindades puede describirse como [...] un interior donde desde mi emplazamiento, las coburbujas circundantes son vecinas e inaccesibles, y están a la vez unidas y apartadas" 295

Para tratar de extraer conceptos "útiles" a esta tesis de las multiplicidades espacio analizamos los conceptos de aislamientos conectados, sistemas coincidentes y arquitecturas de la cohabitación como las tres líneas que nos permitirán argumentar la desaparición de la exterioridad para Sloterdijk mientras se

\footnotetext{
292 Ibid. p.232.

${ }^{293}$ Ibid. p. 192

${ }^{294}$ Concepto desarrollado en el epígrafe 3.6 de las conclusiones operativas.

${ }^{295}$ P. Sloterdijk. Esferas III. Op. Cit., pp.48-49.
} 
construye lo que él denomina "el gran interior" basado en la saturación de las espumas.

\subsubsection{Aislamientos conectados}

El concepto de aislamiento conectado sitúa la simultaneidad de nuestras formas de existir hoy en el mundo. Entender que la sociedad y por ende, sus espacios, tiempos y formas construidas, lo hacen de manera aislada y a la vez conectada implica modificar la noción de exterior e interior de estas mismas esferas construidas como lo público y lo íntimo. Esto se base en la idea de que tampoco podemos constituir esferas duales entre el individuo y la multitud pues ambas se construyen simultáneamente.

Entendemos bajo sociedad un agregado de microesferas (parejas, hogares, empresas, asociaciones) de formato diferente, que, como las burbujas aisladas en un montón de espuma, limitan unas con otras, se apilan unas sobre y bajo otras, sin ser realmente accesibles unas para otras, ni efectivamente separables unas de otras. ${ }^{296}$

Para Sloterdijk el enlace entre vecindad y separación hay que considerarlo como dos caras de un mismo hecho. El principio de co-aislamiento según el cual un límite une lo mismo que separa, el límite se convierte en interfaz de ambas esferas. La espuma, físicamente, limita con una pluralidad de burbujas vecinas que condicionan la repartición de su espacio. Del mismo modo, la interpretación de las sociedades se da en forma de vecindades, separaciones y aislamientos recíprocos y de multiplicidades que componen espacialidades propias con capacidad psíquica de coexistencia.

El co-aislamiento múltiple de los hogares-burbuja en sus diversas vecindades pueda describirse como cierre y apertura al mundo. Por eso la espuma constituye un interior paradójico, en el que la mayor parte de las co-burbujas circundantes son, a la vez, desde mi emplazamiento, vecinas e inaccesibles y están a la vez unidas y apartadas. ${ }^{297}$

Sloterdijk define las islas en donde se producen estos sistemas coincidentes de coaislamiento como múltiples formas de entender los topos construidos. La vida como los lugares del calor (termotopo), del sonido (fonotopo), de los uteroscavenas (Uterotopo) de la creación a mano (quirotopo), de las comunidades e imperios (ergotopo), del deseo (erototopo), del saber (alethtopo), de la muerte y lo divino (thanatotopo) o lo originario (nomotopo). Todas estas islas de la antropo-

\footnotetext{
${ }^{296}$ Ibid., p.50.
}

${ }^{297}$ Ibid., p.49. 
esfera como lugares, cápsulas o invernaderos son los lugares aislados en proceso de permanente conexión. El concepto de aislamiento conectado referidos a las espumas lo toma Sloterdijk de la arquitectura contemporánea donde más explícitamente se ha articulado la separación y la trabazón. El proyecto del grupo Morhposis (Tom Mayne y Michel Rotondi, fundado en 1974) propone la fórmula de Connected isolation que Sloterdijk explicita.

\subsubsection{Sistemas coincidentes}

Bajo este primer punto de aislamientos conectados aparece el segundo de los conceptos "útiles". El espacio de la espuma no pensado como coexistencia sino como coinsistencia, es decir como un sistema coincidente.

Es de interés en este punto explorar las condiciones en las que se forman esas relaciones simultáneas, de cohabitación entre sistemas de cosas y seres humanos. Espacios que a la vez separan y permiten un acceso. Colocados uno al lado del otro, donde de manera simultánea los contactos, las paredes, puertas, ventanas, corredores, calles, cercados, instalaciones fronterizas, dominios de tránsito, etc. permiten el flujo o intercambio de información, energía, datos, y a la vez lo cierran. Estos espacios, ya los hemos nombrado en esta tesis como espumas y existen debido a la simultaneidad de formar conjuntos y a la vez de estar aislados unos de otros. Y estas espumas, son el agregado de las multiplicidades-espacioshumanos y no humanos que van desde las unidades habitáculos, que hemos descrito como células, celdas o celdillas, siguiendo a Sloterdijk, al entrelazamiento de las redes que circulan por ellas, o la producción de macro-esferas como imagencubierta-del mundo definida por sus usuarios. Estas espumas forman lo que llamamos sistemas coincidentes, entendiendo la coincidencia como la acción de concurrir simultáneamente en un mismo tiempo o lugar.

El concepto de sistemas coincidentes pone de relieve la simultaneidad de vecindad y separación: un hecho sin cuya intelección resultan incomprensibles las grandes sociedades modernas. ${ }^{298}$

$\mathrm{Y}$ es en esa simultaneidad, en esta "coinsistencia", en la que de nuevo, como veíamos en el capítulo de redes sobre el espacio, en el Sloterdijk, define su idea de espacio en las espumas.

Para Sloterdijk, la condición apriorística del espacio de E. Kant, donde las cosas solo "llenan" el espacio existente debe verse sustituida por su reverso. En vez de pensar como Kant en el espacio como posibilidad del "estar juntos", pensar en el "estar juntos" como posibilitador del espacio. El espacio socio-esférico a la

\footnotetext{
${ }^{298}$ Sloterdijk, Peter. Esferas III. Madrid, Siruela, 2009, p.197.
} 


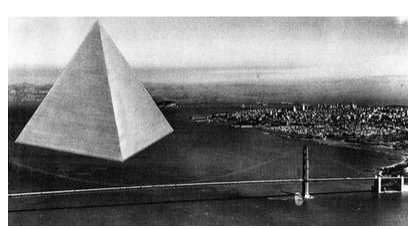

Img.32

Tetra City proyecto de B. Fuller para una ciudad flotante. manera de Sloterdijk, los que se reúnen, los que "están juntos" conforman ellos mismos espacio. "Están ensamblados unos en otros y configuran un lugar psicosocial [y socio-esférico] de tipo propio, a modo de cobijo mutuo y evocación recíproca." 299

Tras la "revolución del espacio" de Carl Schmitt, tras la neutralización de las distancias. El espacio, como distancia y barrera, se convirtió para Sloterdijk en una magnitud ignorable. "se desacreditó como dimensión señorial, como soporte de tráfico y comunicación" como sede de cosificación desde un punto de vista crítico-ideológico" 300 El espacio tras la demanda de rapidez e instantaneidad deja de ser para Sloterdijk "lo que estable vecindades discretas, dispersa partículas, separa cuerpos, posiciona agentes, propone límites de lo extenso, dificulta aglomeraciones, amortigua explosiones, reduce pluralidades a la unidad." 301 Para Sloterdijk, lo que permanece de las definiciones clásicas del espacio es su conductibilidad, conectabilidad y medialidad. "Al espacio de distancia, separación y posicionamiento, que se llamaba naturaleza, aparece el espacio de reunión, vinculación y concentración que nos rodea como entorno técnico." ${ }^{302}$

De esta manera las sociedades, como sistemas coincidentes en un entorno técnico, son multiplicidades compuestas de espacialidades propias con una capacidad de coexistencia, que será de coinsistencia. Esta configuración del espacio coinsistente basado en la noción de aislamiento conectado y los sistemas coincidentes dará lugar también a sus propias arquitecturas.

\subsubsection{Arquitecturas de la cohabitación}

Si la cohabitación en la espuma viene definida por el sistema de distribución y aparición en la espuma de humanos, cosas y espacios propios. Estos al estar juntos producen sus propias arquitecturas.

El hábitat en el mundo, será para Sloterdijk "La cultura de los sentimientos en el espacio cerrado" 303 habitar es insularse, aislarse, separarse, fabricar islas ${ }^{304}$ y "Las islas son prototipos del mundo en el mundo" 305 Las arquitecturas en la espuma, se dan en régimen de cohabitación, definido como la agregación de las características ya enunciadas de covecindad y coaislamiento en sistemas coincidentes. Para

\footnotetext{
${ }^{299}$ Ibid. p.235.

300 Sloterdijk. Peter. En el mundo interior del capital. Para una teoría filosófica de la globalización. Madrid, Siruela, 2007, p.298.

301 Ibidem.

${ }^{302}$ Ibidem.

${ }^{303}$ Peter Sloterdijk. Esferas III. Op. Cit., p.241.

${ }^{304}$ Sloterdijk define y clasifica los distintos tipos de islas en el capítulo Insulamientos de Esferas III.

305 Ibid., p.238.
} 
Sloterdijk, la arquitectura son islas, conectadas y coincidentes, pero islas. La arquitectura es la explicitación de esta condición insular.

Las tres formas técnicas que define Sloterdijk para la cohabitación son:

1. Las construidas de manera separada o absoluta a la manera de los barcos, aviones y estaciones espaciales. En ellas el mar como aislante se sustituye por otros medios como el aire.

2. La construcción de islas climáticas donde, se explicita la imitación del efecto invernadero.

3. La construcción de islas antropógenas ${ }^{306}$, como las coexistencia de seres humanos y herramientas para la construcción de incubadoras.

Si bien, Sloterdijk define la arquitectura de la modernidad como " el medio en el que se articula procesualmente la explicitación de la estancia humana en interiores construidos por el ser humano." ${ }^{307}$ Este remite a un interior que diseña el clima, planifica el medio ambiente y explora las relaciones de vecindad con dos estructuras inhumanas antepuestas y asociadas a la humana. La cósmica como isla absoluta y la virtual. De hecho, la formulación de la arquitectura en un futuro próximo pasará, según Sloterdijk, por explicitarse como si fueran parientes próximos de la cápsula espacial.

Para desarrollar la idea de la arquitectura de la cohabitación vamos a argumentar la condición de las islas absolutas como emergencias de la arquitectura en la espuma, para rastrear las arquitecturas terrestres como explicitación de las condiciones de co-aislamiento y coincidencia.

\subsubsection{Islas Absolutas}

Las arquitecturas absolutas, tienen varios atributos que nos serán útiles para comprender la posible incorporación de estas a la esfera terrestre y sus arquitecturas. Todas ellas según Sloterdijk.

La primera condición será la de prescindir de una fijación de lugar. Las islas absolutas son islas móviles. Como el Nautilus, el hotel submarino de Julio Verne, o los aviones que modifican el elemento del entorno agua por el aire, o las naves espaciales que lo modifican por el vacío.

La segunda condición será la dependencia de sistemas técnicos de abastecimiento de aire. En el interior de estas islas la respiración se vuelve dependiente de estos sistemas. Su clima solo es posible como interior absoluto, sellado y cerrado

\footnotetext{
${ }^{306}$ Ibid en Sloterdijk. Esferas III. Islas antropógenas, pp.275-373

307 Ibid., p.385.
} 


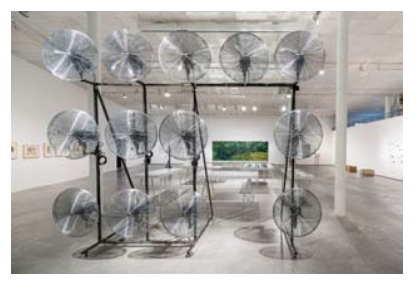

Img.33

Olafur Eliasson. Your windless arrangement. 1997

herméticamente. El diseño aero-técnico de la superficie habitable describe a los habitantes de la isla, por ejemplo los astronautas, como consumidores de oxígeno y productores de $\mathrm{CO} 2$.

La tercera es la creación de "contornos contornados" para establecer un mundo de vida en el mundo de la no-vida es preciso invertir el ambiente. No se trata de colocar un edificio en un medio ambiente, sino instalar un medio ambiente en un edificio. Envolver lo envolvente, sustentar lo que sustenta. La inversión del ambiente para la creación de "soportes de vida" desde la cápsula espacial interior a los trajes para los viajes espaciales al exterior. Es una prótesis en un mundo de vida.

La cuarta es la organización ontológicamente híbrida. Los humanos, coexisten con seres, cosas, plantas, microbios, paneles solares, que generan un espacio común. Cohabitan en esta arquitectura los sistemas de cosas con seres humanos.

Este resumen de condiciones, explicitan su simétrico contemporáneo en muchas arquitecturas que ya hemos mencionado, como el protocolo desarrollado por B. Fuller “Operating Manual for Spaceship earth" de 1969, donde se presentaba la gestión global de la tierra de estos presupuestos, o su proyecto para una cúpula sobre Manhattan. Otro ejemplo que podemos dar es como tras el desarrollo del proyecto de los arquitectos italianos de Superestudio del "Monumento continuo" y "Supersurface" como una extensión continua y saturada del planeta tierra su proyecto "Interplanetary architecture"

Si el "monumento continuo" y "supersurface" 308 es un proyecto donde la malla se entiende de manera infinita, este carácter infinito implica la inexistencia de un afuera pues todo pertenece a la superficie-malla: la vida, los cuerpos, los objetos o la ausencia de ellos, la naturaleza, lo doméstico, las relaciones sin trabajo, sin mercado. Si no hay afuera, el interior de la superficie en sus pliegues se convierte en un interior auto-referencial y esto hace que sea a su vez un exterior.

\footnotetext{
${ }^{308}$ Para un contexto ampliado sobre el proyecto ver: Quesada, Fernando. "From the World without Objects to the Universal Grid" Delft Architecture Theory Journal. n.8, 2011, pp.23-34.
} 


\section{Ejemplo 08: Superstudio "Interplanetary architecture" 1972}

Cuando esta superficie es interplanetaria, el proyecto convierte al planeta en una superficie sin afuera. Luego el interior auto-referencial planetario también se convierte en un exterior. El proyecto "Arquitectura Interplanetaria" 309 de Superstudio, problematiza la hipótesis de la liberación del ser humano del sistema represivo y racional de las ciudades ilustradas y modernas. Cuando la ciudad ha sido pensada como la ciudad de la masa, del ciudadano medio, objeto y sujeto del sistema capitalista no hay territorio para la producción de arquitectura, según Superestudio.

\footnotetext{
El aumento de la conciencia de la frustración de la arquitectura terrestre y la última posibilidad de la mano de obra en una zona libre de la lógica racional de la arquitectura como la producción de bienes. ${ }^{310}$
}

El proyecto ante la imposibilidad de que la arquitectura pueda liberarse de sí misma, escapa del espacio terrestre para encontrar un lugar donde autocolonizarse en el espacio exterior. El proyecto, de nuevo cinematográfico ${ }^{311}$, tiene 6 partes. 1. La formación de la tierra y la luna, 2.La llegada del ser humano a la luna, 3.Los primeros intercambios y canales de comunicación física entre la luna y la tierra, 4.La captura de meteoritos, 5.El sistema habitacional, y 6. La extensión del territorio, incluyendo otros planetas interconectados.

El proyecto explora la extensión de la superficie terrestre a otros espacios exteriores. Y esos espacios son, por ejemplo, la imagen de la luna como espacio público. El acercamiento de la luna a la tierra a una distancia aproximada de $40.000 \mathrm{~km}$ que es su diámetro: la tierra y la luna forman un solo cuerpo. Dos anillos en circunvalación rodean la tierra y la luna respectivamente. Los asteroides se agregan al nuevo cuerpo terrestre-lunar.

Lo importante para nosotros, es como el proyecto está materializando relaciones que se dan en ese momento y se continúan desarrollando hoy en día con otros planetas en acercamientos físicos como en Marte o en las nuevas y recientes imágenes públicas como las de Plutón. Lo que estaba lejos, se vuelve cercano y más conocido. Las distancias lejanas como medida en una relación de exterioridad se convierten en cercanas, anulando esa relación. El exterior se repliega en un interior que se modifica, se tecnologiza, se agrega al ideario colectivo y se

\footnotetext{
309 “Architettura interplanetaria”. Casabella, n.364, 1972.

310 Ibidem.

${ }^{311}$ El proyecto cinematográfico puede verse aquí: Supersurface an Alternative Model for Life on the Earth. https://www.youtube.com/watch?v=vd4SjQB2TeM
}

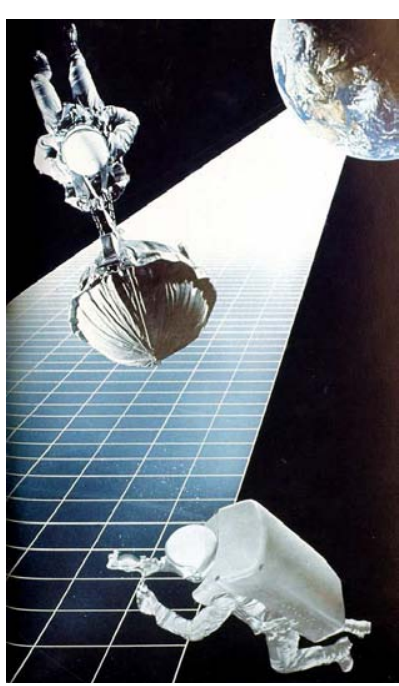

Img.34

Superstudio "Interplanetary architecture”. 1972

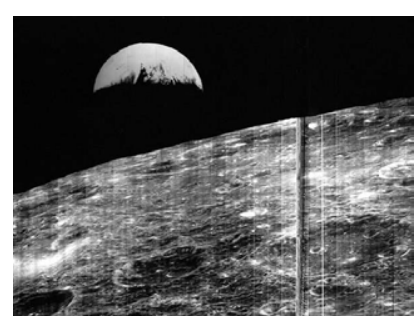

Img.35

Primera Fotografía de la tierra desde la Luna. La fotografía cambia la consciencia del mundo y promociona la noción de una unidad y un solo sistema. Las teorías cibernéticas y tecnológicas coinciden en este nuevo icono. Es el año 1966 y vemos la tierra desde la luna. Una imagen en blanco y negro que determina nuevos horizontes. Explicado en The Whole Earth catalog. California and the dissapearance of the outside. Exposición en HKW, Berlín. 2013. Fotografía cortesía de la NASA/Lunar Orbiter 


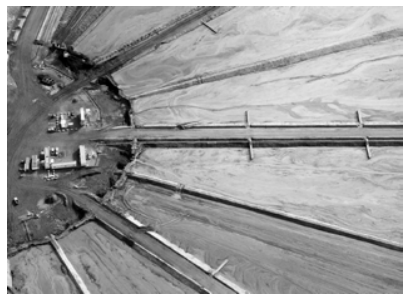

$\operatorname{Img.36}$

Las arenas de petróleo o de alquitrán de Athabasca en Alberta, Canada. Es el mayor depósito de bitumen crudo en el mundo. Su urbanización explicita el "urbanismo planetario" que desarrolla Neil Brenenn en sus investigaciones. interviene en él. La arquitectura se propaga más allá de sus límites y fronteras que no son más las físicas y gravitacionales como las relacionales y colonizadoras.

Pero no solo se trata de encontrar en la continuidad por extensión un argumento para la desaparición de la exterioridad, sino también en la densidad de los espacios extendidos. Ambos proyectos de Superstudio, como Islas Absolutas, son hoy una realidad en el mundo contemporáneo con otras materialidades y tecnologías.

Que el planeta tierra está saturado en la espuma, es una constatación desde diversos frentes. Sloterdijk anuncia una emergencia actual en las nuevas consideraciones de lo colonial, y las islas absolutas en una doble condición. Como la emergencia de las islas absolutas o arquitecturas espaciales cada vez más alejadas de la tierra y la condición de un planeta finito donde cada vez es más difícil acceder a los soportes de vida.

El urbanista teórico Neil Brennen centra sus estudios urbanos en Harvard en lo que llama la "Urbanización Planetaria" como un proceso de reconversión urbana de todo el territorio planetario. Brenner y Christian Schmid están desarrollando un marco de estudios para implementar una "Teoría de la urbanización extendida" en un marco teórico que se presenta en el espacio de las teorías urbanas postmarxistas con herramientas para el análisis de la omnipresencia mundial del proceso de urbanización. ${ }^{312}$

Asociado a la idea del Antropoceno, el mundo es hoy un todo urbano. Si señalábamos en el primer capítulo el nacimiento del telégrafo como uno de los hitos que destruyen las ideas kantianas del tiempo y el espacio. El mundo es hoy, para N. Brenenn, un sistema de sistemas que operan de forma simultánea y de manera interconectada. El campo de los estudios urbanos, sigue basándose en un pensamiento del siglo XIX donde podíamos diferenciar entre asentamientos urbanos o lugares naturales. La distinción campo-ciudad establecía una exterioridad de una respecto a la otra. Desde que el siglo XX se caracteriza por un desarrollo industrial de gran escala y ciudades-región, la antigua noción de campo,

\footnotetext{
312 Para la ANT esta posición es problemática desde las nociones de los ensamblajes urbanos. La posición de I. Farías y C. McFarlane (ANT) difiere en los puntos básicos de la posición de Brenenn (postmarxista). En el marco comparado de ambas posiciones sobre lo urbano se trata de definir qué se hace (investigación o crítica), la diferencia en la definición del objeto de estudio (la ciudad o el capitalismo) la concepción de lo social (ensamblajes o estructuras) o el proyecto político que hay detrás (democracia o revolución) e incluso de que figura se trata (herramienta o teoría) Existe una disputa abierta entre las teorías del ensamblaje urbano de Ignacio Farías, Mc Farlane y la ANT abierta por Neil Brenen et all en su artículo "Assemblage urbanism and the challenges of critical urban theory" City v.15, n.2, pp.225-240. y respondida por Farías en Farías, Ignacio. "The politics of Urban Assemblages” City: analysis of urban trends, culture, theory, policy, action. 2011, v.15, n.3-4, pp.365-374.
} 
se ve ocupada por asentamientos suburbanos acompañados de cambios demográficos y sociales. Y continuamos describiendo el territorio como lo urbano y lo no-urbano generalmente clasificado como rural. Las etiquetas para definir entonces el territorio se generan con la misma velocidad que este se modifica. El planeta es hoy un continuo urbano-rural terrestre, acuático, aéreo.

\subsubsection{Islas Atmosféricas}

Si las islas absolutas explicitan al máximo la condición de aislamiento, las islas atmosféricas son también demostrativas de la condición de aislamiento en otros medios que no son el vacío, como la superficie terrestre o el mar, como por ejemplo las plataformas de sondeo marinas.

Si el mundo es un mundo de islas atmosféricas que saturan la espuma, como hemos mencionado en el punto anterior, esta también se hace explícita por la urbanización planetaria del mismo. Las condiciones de esta saturación urbanizadora que conforman el estado de la cuestión para evaluar la forma de operar de la arquitectura, debe pasar obligatoriamente por estas características. Continuando con Neil Brennen en su texto "Teoría urbana sin exterior", y mostrando su posición Lefevbriana respecto a cómo se produce el espacio.

En cuanto a la naturaleza precisa de la ciudad y lo urbano, el ámbito de estudios urbanos presupone la existencia de un reino relativamente estable no urbano como exterior constitutivo en el aparato operacional epistemológico y empírico. $^{313}$

Para Neil Brennen el exterior constitutivo se repliega en su interior debido a cuatro razones principales ${ }^{314}$.

1. La creación de nuevas escalas de urbanización. Como las desarrolladas en la Megalópolis Gottmannian de "BosWash" (Boston-Washington DC) y el "azul banana " de Europa Occidental. Procesos emergentes como "San San" (San Francisco-San Diego), en California, o la Perla Delta del río en el sur de China, o la conurbación litoral centrada en Lagos, en África occidental.

2. La disolución y la rearticulación de los territorios urbanos. Sobre todo por la redistribución de las funciones urbanas anteriormente en los centros de ciudades ahora dispersas fuera de ellas.

\footnotetext{
${ }^{313}$ Brenenn, Neil. "Urban Theory without an outside" en Implosions/Explosions: Towards a Study of Planetary Urbanization. Brenenn, Neil. (Ed.). Berlin, Jovis Berlag, 2014, p.12.

${ }^{314}$ Ibid., pp.12-13.
} 


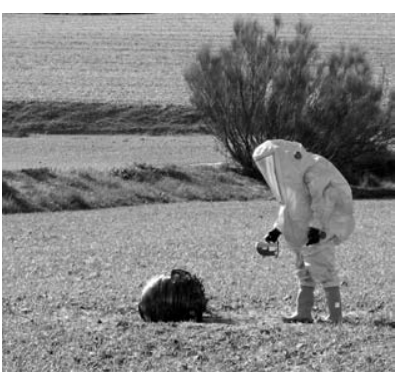

Img. 37

Los residuos explicitan la ausencia de exterior volviendo siempre al mismo lugar. Sean estas las islas de plástico marinas que, como el mensaje en una botella, siempre aparece en otra orilla o como en la imagen: basura espacial caída en los campos de Mula y Barrancadas en Murcia. Noviembre 2015. Imagen Ministerio del interior. España.
3. La desintegración de la "zona de influencia". Los antiguas centralidades urbanas se reconfigura en función de nuevos programas planetarios que tienen que ver con sistemas de uso de la tierra agroindustriales, zonas recreativas, la generación de energía, las áreas de extracción de recursos, los grandes depósitos de combustible, áreas de eliminación de desechos, o los corredores de conectividad para facilitar la continua expansión de la urbanización industrial y sus redes asociadas.

4. El fin de la "tierra salvaje" en todas las regiones del mundo, los antiguos espacios salvajes o naturales son transformados y degradados a través de las consecuencias socio-ecológicas acumuladas de la urbanización sin restricciones en todo el mundo. Los océanos del mundo, las regiones alpinas, las selvas ecuatoriales, los grandes desiertos, las zonas árticas y polares, e incluso la atmósfera, se interconectan cada vez más con los ritmos de la urbanización planetaria a todas las escalas geográficas desde lo local a lo global.

Estos cuatro puntos resumen los modos en que la acción humana, industrial, tecnológica, social y política interviene en un proceso de urbanización que no conoce límites y que ha convertido el planeta en un "monumento continuo" de captación de recursos y expansión de las comunicaciones. Superstudio anticipaba un futuro real, pero con otras coordenadas. La urbanización total del planeta es una realidad que todo lo incluye y lo repliega una y otra vez en un ciclo continuo de consumo y deshecho. $\mathrm{Y}$ son los residuos, los que lanzamos al exterior, los que hacen muy visible la ausencia de exterioridad, pues siempre vuelven y permanecen en el mismo planeta. La basura espacial, también permanece.

Por lo tanto, la urbanización extensiva, continua y total ya no puede definirse por las formas de la exterioridad que hemos venido utilizando. Las ciudades, regiones, metrópolis o megalópolis no nos sirven como "tipos" para definir el territorio.

En consecuencia, a pesar de su continua omnipresencia en el discurso académico y político, la categoría de la "ciudad" se ha convertido hoy obsoleta como herramienta analítica de las ciencias sociales. Ya no es plausible caracterizar las diferencias entre las zonas densamente y menos densamente pobladas de una región, de un territorio nacional, un continente o el mundo a través de la herencia de la dualidad urbana / rural. Hoy en día, lo urbano representa cada vez más una condición planetaria donde están inmersas las relaciones político-económicas. ${ }^{315}$ 
Para pensar la situación de un urbanismo planetario sin exterioridad tendremos que observar espacios en continuidad topológica y en relaciones heterogéneas como pueden ser: los procedentes del transporte marítimo transoceánico, redes de carreteras suburbanas y ferrocarriles transcontinentales, las infraestructuras de comunicación, los enclaves turísticos, las zonas y costeras, parques, centros financieros extraterritoriales, zonas de captación agroindustriales y antiguos espacios "naturales", como los océanos del mundo, desiertos, selvas, cordilleras y la atmósfera como indica Brennen. Pero también deberemos atender a los mercados financieros, los algoritmos, los centros de cálculo, los ordenadores cuánticos, Facebook, y muchas otras entidades que transformar lo urbano a donde llegaremos mejor desde herramientas como los ensamblajes urbanos. La malla del monumento continuo de Superestudio se ha convertido hoy en parte integral de la trama urbana planetaria. Por lo tanto las arquitecturas o islas atmosféricas se dan hoy también bajo esta situación de saturación global.

Si los invernaderos fueron la principal innovación arquitectónica del siglo XIX, como islas atmosféricas terrestres, según Sloterdijk. Hoy son multitud de entidades las que constituyen estas arquitecturas aisladas en un entorno de urbanización planetaria.

Las islas atmosféricas en la definición de Sloterdijk, delimitan un enclave de aire alrededor, aislándolo de él y estabilizando la diferencia atmosférica entre el espacio físico exterior e interior. $\mathrm{Y}$ a su vez estas Islas están conectadas con otras islas, a diferentes escalas y entornos de movilidad que pueden ofrecer una imagen de la construcción del gran interior que sitúa Sloterdijk. En este punto, lo mejor vuelve a ser un ejemplo. 


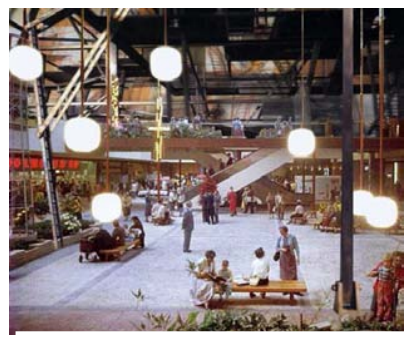

Img.38

El interior del SouthDale Center como Arquitectura Atmosférica. EEUU. 1952

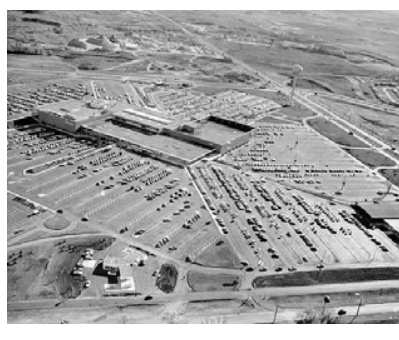

Img.39

La creación del gran interior del invernadero interior como "soporte de vida" implica un gran uso de recursos del exterior. Aparcamiento del SouthDale Center.
Ejemplo 09: Islas Atmosféricas: Southdale Center, Victor Gruen, 1952, y West Edmonton Mall, (WEM) Maurice Sunderland $1981^{316}$

Si como ya hemos argumentado, la sociedad de consumo se inventó en el invernadero ${ }^{317}$, su desarrollo introdujo innovaciones arquitectónicas como nuevos invernaderos conectados. Estos invernaderos funcionan como islas atmosféricas dentro de las arquitecturas de la cohabitación.

El desplazamiento de lo considerado el centro urbano de las ciudades a otros nuevos centros situados en las periferias americanas a mediados del siglo XX estableció un modelo de transitar por lo urbano que enlazaba la casa, el coche y el trabajo. El arquitecto Victor Gruen ${ }^{318}$ fue el gran planeador de un nuevo modo de vivir lo urbano queriendo sacar a los ciudadanos del coche creando espacios para formar comunidades urbanas asociados a los espacios de venta y retail. Estos nuevos espacios urbanos, invernaderos atmosféricos, están ligados a innovaciones tecnológicas como el aire acondicionado, el marketing ligado a la expansión de los suburbios y a las formas de ventas y el mercado de masas donde el producto pierde su valor de uso en favor de un valor de intercambio. Los nuevos espacios en venta e individuos. Todo un urbanismo sin exterior opera en este territorio que ha llegado a nuestros días haciéndose ubicuo por doquier.

El desarrollo de estos invernaderos atmosféricos asociados a lo comercial, puede verse de maneras extrema hoy en el West Edmonton Mall (WEM) situado en Alberta, Canadá. El WEM es más que un invernadero, es una máquina para consumir ciudad ${ }^{319}$ que es el máximo exponente de este urbanismo de interiores donde cada individuo customiza su experiencia urbana.

La abundancia de imágenes y el bombardeo de posibilidades es una ficción para homogeneizar y controlar los espacios pre-producidos. Como un nuevo entorno construido donde no son solo objetos arquitectónicos sino que debemos considerarlo como un ensamblaje urbano, es decir, objetos construidos de políticas, discursos y herramientas de seducción que son producidos por la máquina tecno-estética que lo soporta. Esta máquina traspasa las fronteras establecidas para incorporar los conceptos ambiguos y generar de esta forma las

\footnotetext{
316 Conferencia presentada por el autor en el Congreso Equi-ciudad, San Sebastián, 2012.

317 Argumentado en el epígrafe 2.1.1

318 Victor Gruen (1903-1980) Fue un arquitecto Vienés. Trabajo con Peter Behrens tras la salida de Le Corbusier y Mies Van de Rohe de su despacho. Al llegar a EEUU diseñó escaparates y arquitectura comercial. El SouthDale Center fue el primer proyecto de escala urbana que desarrollaba la idea de la continuidad espacial entre la casa, el trabajo, el coche y el centro comercial.

${ }^{319}$ Gil-Fournier, Mauro. "WEM, una máquina para consumir ciudad." Sevilla. Revista digital. La ciudad viva. 2013. Descargable. http://www.laciudadviva.org/blogs/?p=16346
} 
diferentes simulaciones ${ }^{320}$ : el lugar simula un centro urbano, lo privado simula ser público, el deseo simula necesidad, cada quien simula ser alguien más, el consumo simula esparcimiento, la soledad simula compañía, lo nacional simula ser extranjero, lo local simula ser global, un grupo social fragmentado simula comunidad, etc... las simulaciones están construidas por las mediaciones que se producen.

Estas ambigüedades, están construidas con unos patrones también claros respecto al uso del espacio arquitectónico que se construye en base a un patrón preproducido sobre lo que es masculino-femenino, lo público-privado (doméstico y subjetivo) el trabajo-ocio, los ingresos-gastos, producción-consumo, empoderados-desempoderadas y define en sus métodos una reacción sobre estas categorías alterándolas por completo. La máquina define un espacio colectivo y privado. Ocio y negocio para conducir hacia un tiempo instantáneo y prolongado. El mayor tiempo en el espacio, el mayor tiempo para el negocio. Los entornos urbanos clásicos como calles y fachadas, se modifican, copian y tematizan para provocar una mayor dependencia del recuerdo. Lo lejano ya está cerca, y es superficial. Venecia y los barcos de Colón, al alcance de tu mano y en un solo lugar. ¿Quien no quiere poseer un quirotopo o el mundo en su propia mano? dice el promotor del WEM ${ }^{321}$.

La pre-producción del espacio homogéneo, como isla atmosférica. pasa por inferir las siguientes relaciones de mediación entre las materialidades de su arquitectura y el comportamiento de los ciudadanos que lo practican.

1. Formadora de espacios que funcionan en condiciones no hegemónicas.

2. Experimentadora de la realidad a través de la ayuda de otro en tanto que ese otro es algo ajeno a mí mismo pues construye una realidad a través de las mediaciones que se producen.

3. Los dispositivos de mediación son sus bóvedas, sus escenografías, la localización controlada de las circulaciones como motores de deslocalización ${ }^{322}$. También los grandes espacios para la contemplación y la multiplicidad de niveles.

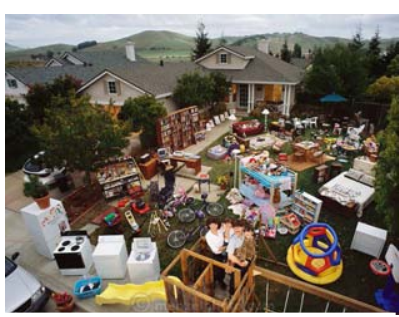

Img.40

La expansión de los suburbios americanos van ligados a las nuevas centralidades de los malls como islas atmosféricas.

Imagen del fotógrafo Peter Menzel que muestra la familia Caven, en con todas sus posesiones materiales en su casa de California. La fotografía forma parte de su trabajo de investigación : Material World: A Global Family Portrait. 1994

\footnotetext{
${ }^{320}$ Simulaciones en el sentido de J. Baudrillard en Cultura y simulacro. Barcelona, Kairós, 1995.

${ }^{321} \mathrm{La}$ familia promotora son los Ghermezian quienes contratan al arquitecto Maurice Sunderland su construcción.

${ }^{322}$ Lo que se llama "Gruen Effect" también conocido como el "Gruen Transfer" que consiste en un conjunto de mediaciones materiales y técnicas de diseño que hace que los consumidores que entran en un centro comercial y, rodeado de un diseño intencionalmente confuso, pierdan la pista de sus intenciones originales rodeados de un diseño intencionalmente confuso. Se denomina así por el arquitecto ya citado Victor Gruen, fue al final de su vida muy crítico con estas técnicas manipulativas.
} 


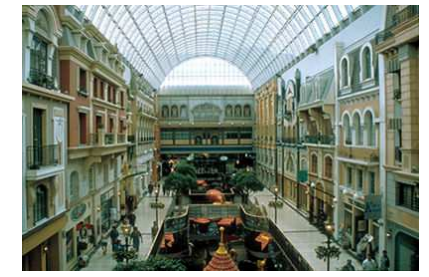

Img.41

Europa Boulevard en el interior del WEM, en Alberta, Canada.
4. Las superficies que hacen que lo lejano se confunda con lo cercano.

5. Aislamiento del exterior para incluir un nuevo interior energéticamente controlado y acústicamente provisto de un ruido blanco. ${ }^{323}$

6. Un lugar de levedades, aligerado en palabras de Sloterdijk, sustancializado y homogeneizado por las mercancías que posee para construir el entorno que satisfaga a la sociedad del aburrimiento y del confort del palacio de cristal.

Y es esta última relación de mediaciones la que no nos permite hacer una lectura tradicional del WEM.

La organización física del espacio de esta máquina es un reflejo de la disyuntiva provocada por la lógica económica objetiva y la subjetividad inestable de los mensajes cruzados entre consumidores y mercancías. Es esta disyuntiva la que no ha permitido a la crítica arquitectónica convencional, cuyo discurso se basa en manifestaciones visibles del orden, no ha sido capaz de penetrar en su sistema. ${ }^{324}$

Pero el WEM, sigue desarrollando su propio urbanismo, creando sus propias formas de consumir el territorio. Este año 2015 comienza la construcción del nuevo WEM en New Jersey. Una nueva isla atmosférica terrestre esta vez con vistas a Manhattan. El mundo unificado de los tiempos pre-modernos puede volver a través del consumo eliminando el conflicto, su negociación y la diversidad. El palacio de cristal escenifica el consenso. ${ }^{325}$

\footnotetext{
${ }^{323} \mathrm{El}$ ruido blanco es un tipo de sonido que aplicado a los centros comerciales proporciona un cambio de conducta en el consumidor. La corporación Muzak empezó a comercializar bandas sonoras para tiendas y ambientes de trabajo en 1928, cuando el general de los Estados Unidos George Squire, fundador de la compañía, descubrió cómo transmitir música a través de la línea telefónica. Se estima que los clientes de las tiendas que hacen sonar música Muzak por el hilo musical dedican un $18 \%$ más de tiempo a las compras y realizan un $17 \%$ más de adquisiciones.

${ }^{324}$ Crawford Margaret. "The world in a shopping mall." en Variations on a Theme Park: The New American City and the End of Public Space, Michael Sorkin (Ed.). Hill and Wang, New York, 1992, pp.3-30.

${ }^{325}$ Sloterdijk, Peter. "El Palacio de Cristal". Op. Cit., p.204.
} 


\subsection{Entidades sin exterior}

Tratar de argumentar de nuevo, tras haberlo hecho en el capítulo de redes, la existencia de entidades sin exterior, es tratar de visualizar, desde otro punto de vista, otra aproximación a esta problemática. Desde la teoría de las espacialidades múltiples o las espumas, argumentar la desaparición de la exterioridad esta vez situada en entidades como el apartamento o el cuerpo humano acondicionado.

"Si la proposición "Cada uno es una isla" casi se ha hecho verdadera en las metrópolis modernas para la mayoría de la población ¿Cómo es posible, entonces, seguir pensando en la "sociedad"? nos pregunta Sloterdijk. Si bien no solo existen las viviendas como espacios de aislamiento, pues estos son coincidentes con otras espumas. Las islas no son solo autónomas, sino que están co-aisladas y conectadas a redes contiguas y estructuras más grandes y sofisticadas. Los ejemplos que pone Sloterdijk son pertinentes. La vivienda o el apartamento se conecta con, por ejemplo, una convención nacional, una love parade, un club, una logia masónica, un colectivo de empresa, una reunión de accionistas en un público en una sala de conciertos, un vecindario suburbano, una clase escolar, una comunidad religiosa, una multitud de automovilista en caravana, una asamblea deliberante de contribuyentes, y son estos conglomerados los que describimos como espumas. Cada práctica genera un ensamblaje urbano que conecta todas estas situaciones. Así que es el momento de volver a definir lo que es una espuma:

Para formular un enunciado sobre la relativa compacidad de conglomerados de vida coaislados o alianzas: una compacidad que siempre será mayor que la de los archipiélagos (que ofrecen una metáfora concluyente de multiplicidades insuladas) pero menor que la de las masas (en las que entran en juego asociaciones engañosas de agrupaciones de unidades que se rozan físicamente como pasta, arena y sacos de patatas). [...] Las espumas co-aisladas de la sociedad individualistamente condicionada no son meras aglomeraciones de cuerpo vecinos (que comparten separaciones),[...] sino multiplicidades de células que se rozan unas con otras sin aperturas, a cada una de las cuales, por su propia amplitud, corresponde la dignidad del universo. La metáfora de la espuma hace observar que no hay propiedad privada total de los medios de aislamiento; al menos una pared de separación es posesión común con una célula-mundo colindante. ${ }^{326}$

Esta situación de covecindad en las arquitecturas de la espuma genera la multiplicidad de relaciones heterogéneas que se dan en la espuma. Por lo tanto, las entidades urbanas modifican su relación interior-exterior debido a la continuidad

${ }^{326}$ P. Sloterdijk. Esferas III. Op. Cit., p.461. 
de las paredes de las celdas o espumas y la simultaneidad de la condición de coaislamiento.

Veamos ahora como la entidad apartamento y la entidad cuerpo-humanoacondicionado reaccionan a la presión de los límites exteriores e interiores en su definición tradicional para argumentar su desaparición desde la aproximación de Peter Sloterdijk en el contexto de las espumas.

\subsubsection{El apartamento}

Si la vivienda, en una definición dinámica, es un "sistema espacial de inmunidad" 327 podemos entender el apartamento, como la expresión radical de esta situación. Si la vivienda, era vivienda para una familia, o una comunidad real afectiva, el apartamento es la estancia del habitar para el individuo. Revisar la conexión entre comunidad e inmunidad, es la tarea que también realiza el apartamento como entidad espacial. El que se sale de la comunidad, pasa a un estado de inmunidad o aislamiento de esa comunidad. El proceso de individualización que se materializa en el apartamento ya estaba anunciado en los años ochenta del siglo XIX "El ser humano civilizado de hoy aspira propiamente a la posibilidad de renunciar al apoyo humano" 328 y se manifestaba claramente en mitad del siglo XX con la idea de Playboy de crear un apartamento como "el imperio del soltero en la ciudad" 329

El apartamento, para Sloterdijk, es una de las principales innovaciones arquitectónicas del Siglo XX por varios motivos. En él se explicita la condición de isla atmosférica pues también son instalaciones climáticas. Aparece como el lugar del autoemparejamiento. Es la unidad elemental, celda, de la espuma como sistema de inmunidad (aislamiento) pero desarrollado en un campo contaminado por sus conexiones.

La definición de apartamento que propone Sloterdijk pasa por definirlo como "una forma elemental, como burbuja celular del mundo, de cuya repetición masiva surgen las espumas individualistas" ${ }^{\text {330 }}$ De esta definición podemos extraer una idea clave de la relación en la extensión y proliferación de las celdas como espuma, pues se da en base al concepto material de la estandarización mediante la cual se produce "una fabricación descentralizada de elementos constructivos y una centralización en su montaje." 331

\footnotetext{
${ }^{327}$ Ibid., p.408.

${ }^{228}$ Tarde, Gabriel. Las leyes de la imitación y La Sociología. Madrid, Centro de investigaciones sociológicas, 2011.

${ }^{329} \mathrm{Cfr}$. La idea misma del apartamento individual está fuertemente desarrollada en torno a los patrones de género como explica el libro: Preciado, Paul B. Pornotopía. Barcelona, Anagrama, 2010.

330 P. Sloterdijk. Op. Cit. p.433.

331 Ibidem
} 
Para argumentar la idea del apartamento como una entidad sin exterior tenemos que remitirnos a los conceptos enunciados en puntos anteriores. La idea del apartamento como contenedor de relaciones consigo mismo de su habitante, es decir de su autoemparejamiento y de sus relaciones de coaislamiento y coincidencia en la espuma, es decir de covecindades. Por ello, el apartamento representa una entidad de máxima relevancia en las arquitecturas de la cohabitación.

Si el apartamento, es el lugar de aislamiento de las comunidades antiguamente establecidas como la familia, esta queda superada por la entidad híbrida que se crea entre individuo (humano) y objeto (apartamento). En términos de una unidad (biunidad) que enunciábamos con los autoemparejamiento humanos, la entidad híbrida humano-celda se explicita con mayor intensidad en el apartamento.

Se podría hablar de las crisis de las segundas personas, que ahora se instalan en las primeras. [en las teorías éticas recientes] el "otro" solo puede ser descubierto por un otro real [...] en una época en la que se han vuelto epidérmicos el autodesdoblamiento del uno en sí mismo y la multiplicidad de los otros interiores virtuales. ${ }^{332}$

El soltero del apartamento Playboy se entendería mal como un vivir solo sin compañero o complementación de otro humano. La simbiosis entre miembros de una comunidad, se puede entender en el apartamento como una autosimbiosis donde la forma de la pareja la cumple el propio individuo. Según Sloterdijk, esto se produce en situaciones como:

- Los soportes mediadores de la autocomplementación, como el espejo.

- Las ideas del autocuidado, autocomplementación, o automodelación.

- La elección del auto-proyecto o como el habitar se convierte en tarea de diseño personal.

- La autoalimentación que se hace explícita como automedicación.

- El antisilencio como forma de estar en el apartamento. Dispositivos tecnológicos que dejan entran lo exterior en él. Periódicos, radios, teléfonos, internet.

La idea del apartamento como entidad coaislada se hace patente en la paradoja de que la celda de aislamiento, nunca puede ser físicamente de aislamiento total, aunque cumpla bien estas funciones. A su vez se incita constantemente la apertura al mundo de sonidos, informaciones, imágenes, mediante el acceso de partículas

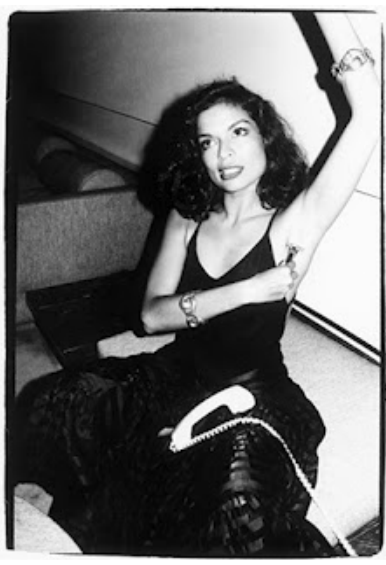

Img. 42

El cuerpo junto al apartamento se convierten en una tarea de diseño personal. Imagen: Bianca Jagger en el apartamento de Halton en New York. Fotografía de Andy Warhol.1979.

\footnotetext{
332 Ibidem.
} 


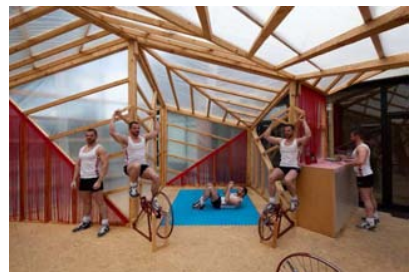

$\operatorname{Img} .43$

La JF-Kit House de los arquitectos madrileños de Elii “virtualiza la visión de un futuro posible donde los

ciudadanos producirán parte de los requerimientos energéticos de sus espacios domésticos mediante sus propias actividades físicas." (De la memoria del proyecto). El individuo en el apartamento, como explicita Sloterdijk, se disocia en su autoemparejamiento en entrenador y entrenado. Pero cabría preguntarse como hace Elii, ¿¿Qué otros cuerpos quedan excluidos de este que hacer diario? ¿Qué tecnologías, también hegemónicas, median en estos procesos? de realidad, compras, ruidos, experiencias, llamadas. El apartamento pasa a formar parte de una red de vecindades que componen su día a día.

Es entonces, según Sloterdijk, cuando el aislamiento no se experimenta en soledad. El apartamento, lejos de ser una celda monacal, "pasa de desarrollar una unidad dúplice (Dios y alma) a una emparejamiento del individuo consigo mismo (uni-binidad). " ${ }^{333} \mathrm{El}$ apartamento se constituye entonces como entidad para acceder a un "entorno propio" de uno consigo mismo pero conectado a los "otros" que son objetos y humanos.

De alguna forma, la autorrealización, se ejercita mediante prácticas de diseño. La decoración interior de los apartamentos se realiza por el individuo como autoficción. Esta ficción, donde se aparece con más claridad, es en la dimensión sexual del régimen individualista. "El apartamento como investigación en el espacio de posibilidad interior erótico" 334 El proceso de autoemparejamiento remite a la ficción de parecerse a una estrella de la cultura de masas. De esta manera el apartamento es una "celda de ensayo" un laboratorio del individuo. La relación entre el diseño interior, la autoficción y la celda de ensayo podemos verla en esta situación que describe Beatriz Preciado sobre el artículo "la vida moderna" publicado en el Daily News en 1953:

Hefner hace visible, el interior de su propia casa a través de su construcción teatral de una autoficción doméstica heterosexual americana. Pero no se trata de un desvelamiento de una verdad escondida, sino de un proceso de construcción teatral en el que cada detalle ha estado orquestado. [El artículo explicita la estrategia] de la producción de una autoficción teatralizada y pública del interior doméstico y privado. 335

El apartamento entonces es el lugar donde se realizan las autoficciones dentro de un alojamiento propio. En la cultura del cuerpo y lo doméstico también aparece la idea del apartamento como emplazamientos donde ejercer lo que antes eran prácticas exteriores del "culto al cuerpo". Los aparatos de entrenamiento median en estas prácticas de autorrealización y modelización del cuerpo, para convertirse en ejemplo del autoemparejamiento. El individuo del apartamento "se disocia entre entrenador y entrenado". 336

\footnotetext{
333 Ibid., p.447.

${ }^{334}$ Ibid., p.456

335 Citado por Preciado, Paul B. Pornotopía. Op. Cit., p.83.

${ }^{336}$ P. Sloterdijk Esferas III. Op. Cit., p.458.
} 
$\mathrm{Si}$ desde el punto de las teorías de género, el apartamento ha formando la emancipación doméstica del sujeto masculino, ${ }^{337}$ las versiones femeninas del insulamiento o la celda, deberíamos encontrarlas en las habitaciones o cuartos propios. Desde comienzos del siglo XX, la habitación propia ha sido el lugar de la emancipación feminista acompañado de una cantidad económica anual según Virginia Woolf. ${ }^{338}$

A comienzos del siglo XX este cuarto propio, aislado ya estaba conectado con otras esferas públicas donde se desarrollaba también la emancipación y manifestaciones feministas. Es interesante observar algunas otras prácticas que sucedían en los grandes almacenes del siglo XIX como Le Bon Marché en París. Estos propiciaron ir de compras, no por pura necesidad, sino como una forma de entender lo urbano. En 1854, estos grandes almacenes disuelven la figura del dependiente masculino tras el mostrador, para generar un espacio libre de obstáculos entre el cliente (preferiblemente femenina) y el objeto de seducción. Este hecho provocó que según algunos autores, como Sally Aitken hablen de la emancipación femenina como un suceso coyuntural. Por ejemplo, las mujeres parisinas se quitaban los guantes para tocar los objetos de Le Bon Marché y descubrían así el cuerpo que se mantenía oculto en el espacio público. Un espacio público, eminentemente masculino, al que no tenían acceso las mujeres en el Paris del XIX. También, el ejemplo del apoyo que recibían "las sufragistas" de los grandes almacenes para sus campañas.

El principio de aislamiento conectado de Sloterdijk, ya operaba un siglo antes en la relación entre el cuarto propio, como apartamento femenino, y el espacio público masculino. De alguna forma, estos ya se construían en simultaneidad.

Las versiones contemporáneas más radicales del apartamento como espacio femenino las podemos encontrar en las situaciones desarrolladas por Remedios Zafra en el concepto de "Cuarto propio conectado". 339 La idea de que el cuarto ya no existe en su estabilidad física sino en un espacio relacionalidad heterogénea.

El cuarto propio conectado sería, en este sentido, un potencial escenario de creación, juego y versatilidad donde surgen nuevas oportunidades respecto a los sistemas disciplinares de producción y difusión creativa. De forma que el tándem sujeto-máquina-online en un espacio de concentración privado se

\footnotetext{
337 Ver capítulo "A room of his own. Una Habitación propia ... para él” en Preciado, Paul B. Op. Cit. pp.41-55.

${ }^{338}$ Cfr. Woolf, Virginia. Un cuarto propio. Buenos Aires, Lumen, 2013, [1929].

${ }^{339}$ Cfr. Zafra, Remedios. Un cuarto propio conectado. Madrid, Fórcola, 2010.
} 


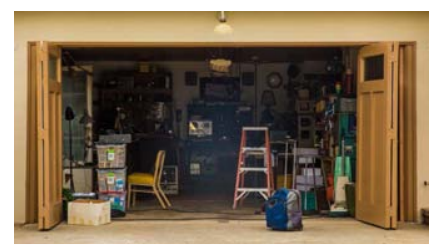

Img.44

Podemos pensar, siguiendo a Remedios Zafra, que la existencia del garaje como cuarto propio también es un potencial escenario de creación e imaginación. Imagen garaje de la casa familiar de Steve Jobs en Palo Alto.

EEUU. posiciona como uno de los más contemporáneos territorios de experimentación digital. ${ }^{340}$

Por otro lado, el cuarto propio como versión femenina del apartamento, tendría un simétrico masculino que no es el propio apartamento sino el garaje de la casa suburbana como la habitación del coche y a la vez taller de autorrealización masculina dentro de la comunidad familiar. ${ }^{341}$ Por último, en el caso de los adolescentes contemporáneos la idea del cuarto propio como espacio de privacidad e intimidad se ha instalado actualmente en el teléfono móvil. Si quizás antes fuera el coche como objeto emancipador de la unidad familiar, como conector a otras realidades, es hoy, y cada vez a una edad menor, el teléfono móvil. Dicha tecnología permite al adolescente operar con él como si de su cuarto propio se tratara, pero este, aunque aislado, se conecta con otros mundos cercanos y lejanos al mismo tiempo. La intimidad del adolescente se comparte y opera en condiciones de extimidad. ${ }^{342}$ Luego el concepto de apartamento como entidad o celda de insulamiento vemos que puede tener ramificaciones en varios sentidos.

Nadie como Le Corbusier para argumentar esta tendencia moderna. La casa de apartamentos o la unité d'habitacion es para Sloterdijk una espuma materializada en hormigón, donde los apartamentos se apilan y amontonan. En ella podemos encontrar lo que decíamos al principio de este punto, el apartamento es un aire interior climatizado donde se explicita la condición de isla atmosférica pues también son instalaciones climáticas. Así Le Corbusier defendía como la ventana deja de cumplir su condición de elemento de ventilación. Esta cuestión se vuelve relevante en el momento en el que es el "aire exacto" que se produce en el interior de la casa controlado por las tecnologías de calefacción, ventilación y acondicionamiento. Esto hace de la casa, del apartamento "Un artificio entre el ocupante y el mundo exterior, [...] una máquina para respirar. El mundo exterior se hace artificio; como el aire, ha sido acondicionado, convertido en paisaje" ${ }^{343} \mathrm{La}$ función de la ventana es para Le Corbusier la de "mirar a través, ver el exterior, asomarse." ${ }^{344}$ Conectarse desde su aislamiento al mundo exterior desde un cuarto también con aire propio y climatizado. ${ }^{345}$

\footnotetext{
${ }^{340}$ Ibid., pp.2-3,

341 Ibidem.

342 Concepto desarrollado en el capítulo 3.3 de las conclusiones operativas.

${ }^{343}$ Colomina, Beatriz. Publicidad y privacidad. Murcia, CDEAAC, 2010, p.209.

${ }^{344}$ Le Corbusier Twenty century living and twenty century living. en Ibid., p.21.

345 Sloterdijk recurre al concepto de ventilación psíquica de Le Corbusier para argumentar la "calidad" de la obra de la unidad de habitación, frente por ejemplo a los desarrollos posteriores a la II guerra mundial como el de Pruitt Ignoe en Sant-Loius en 1972 "Le Corbusier proporcionó la fórmula que hizo notar que lo que importa en un edificio es la "ventilación psíquica". Una unidad de vivienda arquitectónicamente lograda no sólo representa un trozo de aire cercado, sino más bien un sistema psíco-social de inmunidad, que es capaz de regular [...] el grado de su impermeabilización hacia fuera."
} 


\subsubsection{El cuerpo acondicionado}

La entidad del apartamento como una entidad sin exterior, es decir, que está en relación de intercambio con él permanentemente, podíamos definirla como una entidad híbrida que se compone de apartamento-ciudadano-tecnología en autoemparejamientos múltiples. El cuerpo acondicionado que participa de esta situación es un cuerpo atmosférico, porque él se conforma en una situación de permanente aclimatación. Es una unidad doble que podíamos entenderla como cuerpo-aire-acondicionado. Según Sloterdijk, "los seres humanos que se encuentren momentáneamente o habitualmente en situaciones indoors tienen que ser conectados a un "sistema de abastecimiento de aire" auxiliar." 346

Esto sucede de una manera muy evidente en la situación de las islas absolutas o naves espaciales, y en particular en la entidad que se conforma entre el astronauta y el traje acondicionado que permite su respiración en el viaje espacial. Este cuerpo será una unidad de cuerpo aclimatado en gravedad cero. El cuerpo acondicionado, posee un devenir cyborg. Es decir, se compone de manera situacional en determinadas localizaciones. Si bien es cierto, que cada vez con más frecuencia esta situacionalidad se estabiliza, por ejemplo, con el habitar en los canales de continuidad territorial o el urbanismo de interiores constante. El cuerpo acondicionado es el cuerpo contemporáneo que ya no suda, y esto actualiza y da forma a los cuerpos occidentales y refrigerados de hoy.

En las islas atmosféricas, que son las que nos ocupan en mayor grado, la situación de lo que hemos llamado en esta tesis, el cuerpo acondicionado, se dará de múltiples formas en la espuma. Por un lado el entorno, como un entorno meteorológico, instituye prácticas de aprendizaje sobre el clima sobre en el común de sus ciudadanos.

La moderna información meteorología modela poblaciones nacionales como espectadores de un teatro climático. [...] En tanto que describen el tiempo como una representación escénica de la naturaleza ante la sociedad, los meteorólogos reúnen a los seres humanos convirtiéndolos en un público de expertos bajo el cielo común; hacen de cada individuo un crítico climatológico. ${ }^{347}$

Pero en este aspecto, el tiempo o los fenómenos "naturales" climáticos hacen del ser humano un cliente y co-causante meteorológico, se implican el uno al otro. Es decir, la meteorología no es una propiedad de la naturaleza exterior. ${ }^{348}$ En este aspecto de la coproducción de fenómenos climáticos cabe destacar los trabajos de la arquitecta Lindsay Bremner, y sus investigaciones actuales sobre los

\footnotetext{
${ }^{446}$ P. Sloterdijk. esferas III. p.134.

347 Sloterdijk, Esferas III. Op. Cit., p.136.

${ }^{348}$ Estos aspectos los hemos explicado en el epígrafe 1.4.1 El mundo es un laboratorio.
}

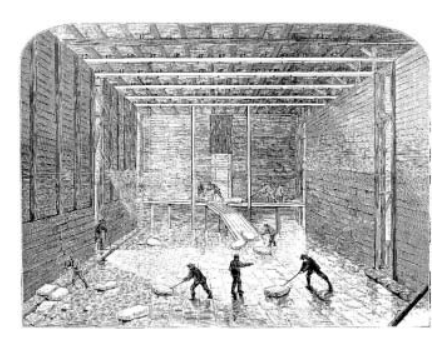

Img. 45

Las Industrias del hielo desarrolladas en el siglo XIX son la primera puesta en marcha global del desarrollo de tecnologías para la creación del cuerpo-acondicionado. La imagen un almacén de Hielo en BarryTown en el rio Hudson. EEUU en el siglo XIX. 
“ensamblajes del monzón” ${ }^{349}$ Para L. Bremner el monzón es una coproducción de dinámicas físicas y sociales, diseños urbanos y políticas climáticas que desarrollan la aparición e intensidad de estos monzones. Para L. Bremner, no podemos seguir pensando en los monzones como un sistema meteorológico natural, una amenaza externa. Su propuesta trata a los monzones como principio organizador de la vida urbana para evaluar desde su ensamblaje el impacto potencial en la política urbana, la planificación y la inversión en infraestructura, los nuevos programas políticos, teóricos y estéticos de disciplinas como el diseño o las humanidades ambientes. Al igual que en el capítulo de "Ciudades sin afuera". El proyecto de Bremner da un paso adelante para comprometerse con la idea de la coproducción climática urbana en un momento donde como hemos explicado, el mundo es un laboratorio.

Por otro lado, el diseño de las condiciones del aire para los humanos se coproduce con una diversidad de instituciones tales como los shopping malls, las clínicas, las tiendas de perfumes, centros de convenciones, hoteles, wellnes o cabinas de pasajeros donde se configuran en palabras de Sloterdijk "entornos respiratorios mediante aire psicoactivo de diseño" ${ }^{350}$. El cuerpo humano no solo es dependiente de los sistemas de aire sino que es afectado de manera sugestiva por estos entornos para mediar en sus acciones y prácticas o estados de ánimo. Estas prácticas también se producen en el espacio público. El olor el espacio público occidental, no es un residuo de una acción, sino que se convierte como hemos dicho en una técnica psicoactiva que detona el consumo. Los restaurantes se hacen oler desde la calle para favorecer la entrada de clientes. Las tiendas de muebles favorecen un olor a leña de encina o algunas tiendas de moda dispersan su perfume con micropartículas que aclimatan olfativamente el aire. Una apropiación invisible del espacio público.

Otra condición del cuerpo acondicionado es la de la conformación de entidades particulares para esta condición. Si el primer aire acondicionado se instala en el comedor del hotel de nueva york en 1880, y su uso desde ese momento es eminentemente colectivo, teatros, salas de cine, etc. permite que se puedan congregar multitudes de espectadores en espacios cerrados, desde el año 1928, Carrier comienza a instalar dispositivos de aire acondicionado en las casas americanas. Tras la ubicuidad de estas tecnologías en grandes lugares públicos, como el Southdale Center antes mencionado, y en las viviendas y hogares de todo el mundo, el cuerpo humano, es ya un cuerpo permanentemente acondicionado. Los ciclos urbanos de V. Gruen ejemplifican la circularidad del proceso de la casa,

\footnotetext{
349 https://geoarchitecture.wordpress.com/2015/10/15/monsoon-assemblages/

${ }^{350}$ P. Sloterdijk. Op. Cit., p.142.
} 
al coche, al trabajo y al centro comercial, de un cuerpo permanentemente acondicionado en todas las espacialidades por las que transita. El aire se homogeniza en un sensibilidad térmica de unos 24-26 grados Celsius. El ciudadano promedio, tiene un aire promedio.

Pero esta condición climática también genera cuerpos no acondicionados. Cuerpos excluidos dentro del palacio de cristal del confort. En Austin (Texas) y el sur-este de EEUU existen albergues climáticos. Estos "condensadores del frio" permiten el acceso a otros cuerpos que no pueden acondicionarse por sus propios medios. Estos refrigeradores colectivos forman parte de la red de infraestructuras y tecnologías urbanas para consolidar el cuerpo acondicionado. También existen programas sociales para proveer a personas sin recursos de aparatos individuales de aire acondicionado como el programa del estado de Nueva York de "Asistencia de Energía para el Hogar HEAP.”

En la actualidad aparece una variante interesante. Una vez que el diseño de edificios no se da solamente para entidades humanas. El Salk Institute de Louis Khan, destina la misma superficie para entidades humanas ( en el suelo) que para máquinas acondicionadoras ( en el falso techo) para que sean estas máquinas (no humanas) las que acondicionen el aire para (humanos) y otras entidades como bacterias, virus, etc.) en el laboratorio. Hoy se produce una agencia diferente cuando el aire acondicionado se utiliza para acondicionar los "datos" en las granjas de servidores de google, por ejemplo. Estas infraestructuras son diseñadas ya para otros cuerpos,(no-humanos) acondicionados por máquinas ( no-humanas) En términos de la ANT el proceso que se da hoy, va más allá de un cuerpo humano climatizado para componer situaciones donde no-humanos intercambian sus propiedades térmicas en infraestructuras específicas para este desarrollo.

Por último, desde que en el 22 de abril de 1915, se utilizaran gases de cloro en la primera guerra mundial, y con ello, la explicitación de que el aire, no era una propiedad dada sino, tratada. Su ausencia podría convertir espacios terrestres en situaciones irrespirables. La guerra química es la visibilización del cuerpo acondicionado. Este como hemos visto en este punto puede verse afectado por este mecanismo de acondicionamiento de manera vital (como sobrevivir a más de $5^{\circ}$ grados de temperatura) o de manera mortal (como las guerras químicas). Que el cuerpo humano es hoy un cuerpo acondicionado también podemos demostrarlo por la diversidad de situaciones en las que este condicionamiento mortal se da, como en cámaras de gas (individuales o colectivas), o en la contaminación nuclear de entornos terrestres. A esta situación Peter Sloterdijk la denomina

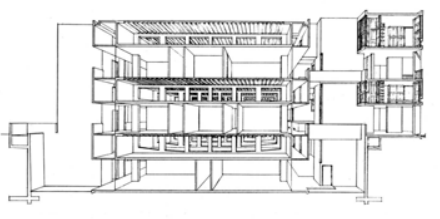

Img.46

El edificio no solo se diseña para humanos. El 50\% de la superficie en planta del edificio se diseña para alojar a las máquinas climáticas y de purificación de aire. Sección del Salk Institute en la Joya, California diseñado por Louis Kahn. en 1965.

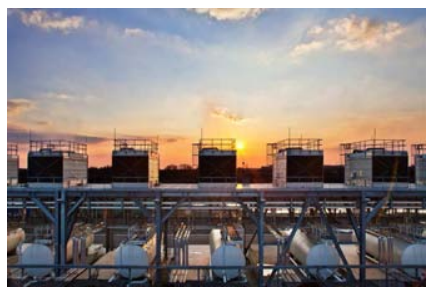

Img.47

El cuerpo acondicionado ya no es solamente humano. Las "granjas de servidores" de las compañías de internet como Google o Facebook, son infraestructuras de acondicionamiento para máquinas-servidores de datos. 
atmoterrorismo. ${ }^{351} \mathrm{El}$ atmosterrorismo entonces, hace explícita la existencia de un cuerpo permanentemente acondicionado.

\subsection{Coinsistencia}

Una vez hemos situado la teoría de las multiplicidades espacio, la pregunta que nos queda por situar es ¿Dónde queda la idea de lugar en la espuma? En un momento donde las espumas son específicas y están localizadas pero a la vez se distribuyen de manera ubicua por el globo, se hace necesario situar la idea de lugar para entender como bajo la composición de entidades en entornos de coaislamiento y coincidentes, el lugar se conforma como coinsistencia de estas espacialidades múltiples. La coinsistencia, entendiéndola como coincidencia, como la acción de concurrir simultáneamente en un mismo tiempo o lugar, y no desde la coexistencia. Situaciones donde las entidades operan en vecindad y separación al mismo tiempo. La simultaneidad de sociedades, espacios y tecnologías ofrecen una situación de coinsistencia. No se trata de la formación de comunidades para Sloterdijk, sino de procesos de inmunidad. Por lo que no es solo la coexistencia, sino la simultaneidad de la vecindad y la separación como coaislamiento. Las sociedades, como sus espacialidades, operan en sistemas coincidentes como ya hemos argumentado.

Para Sloterdijk un lugar es: "una porción de aire cercada y acondicionada, un local de atmósfera transmitida y actualizada, un nudo de relaciones de hospedaje, un cruce en una red de flujos de datos, una dirección para iniciativas empresariales, un nicho para auto-relaciones, un campamento base para expediciones al entorno de trabajo y vivencias, un emplazamiento para negocios, una zona regenerativa, un garante de la noche subjetiva”. ${ }^{352}$

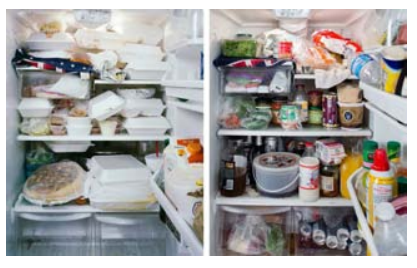

Img.48

La nevera doméstica como lugar privilegiado donde entender la coinsistencia del lugar urbano.

\section{Ejemplo 10: La nevera doméstica. ${ }^{353}$}

Según la definición de lugar de Sloterdijk que acabamos de ofrecer, la nevera doméstica, cumple las condiciones de un lugar urbano. Pues esta es una porción de aire cercada y acondicionada. Es un local de atmósfera transmitida y actualizada, un nudo de relaciones de hospedaje (de no-humanos), un cruce de flujo de datos. Y además posee también las condiciones afectivas y virtuales de lo urbano. La nevera es un objeto donde se despliegan nuestros afectos. Los

\footnotetext{
${ }^{351}$ Desarrollado en el Capitulo primero Aerimotos de Sloterdijk, Peter. Esferas III. pp.75-123.

352 P. Sloterdijk. Esferas III. Op. Cit., p.385.

353 Presentado por el autor en el Congreso de sociología ordinaria III. Mad. 2015
} 
personales (fotos familiares, calendarios de menús, etc.) y los políticos (qué comemos, cómo consumismos, etc.)

La nevera es un objeto localizado, ubicuo, que contiene productos de múltiples localizaciones, ubicuos también, aislados, envueltos o en tuppers. Podemos entender la nevera como un electrodoméstico que ensambla las trayectorias que pasan por él en el día a día. Los urbanismos de la nevera revelarían por ejemplo múltiples posiciones en conflicto que podrían leerse al abrir una nevera cualquiera. Esta desvelaría cuestiones en términos de producción alimentaria, conservacionismo, antiespecismo, veganismo, salud, cuidados y afectos. La nevera se enacta como entidad aglutinadora de estas controversias y de esta manera podríamos entenderla como un espacio público de discusión y de conflicto. La nevera define un ensamblaje asociado a cada entidad micro (un individuo o unidad familiar diversa) y sus entidades macro (sus sistemas de consumo, procedencias, etc.) e incluso la virtualidad de su entidad múltiple (política, afectiva, etc.)

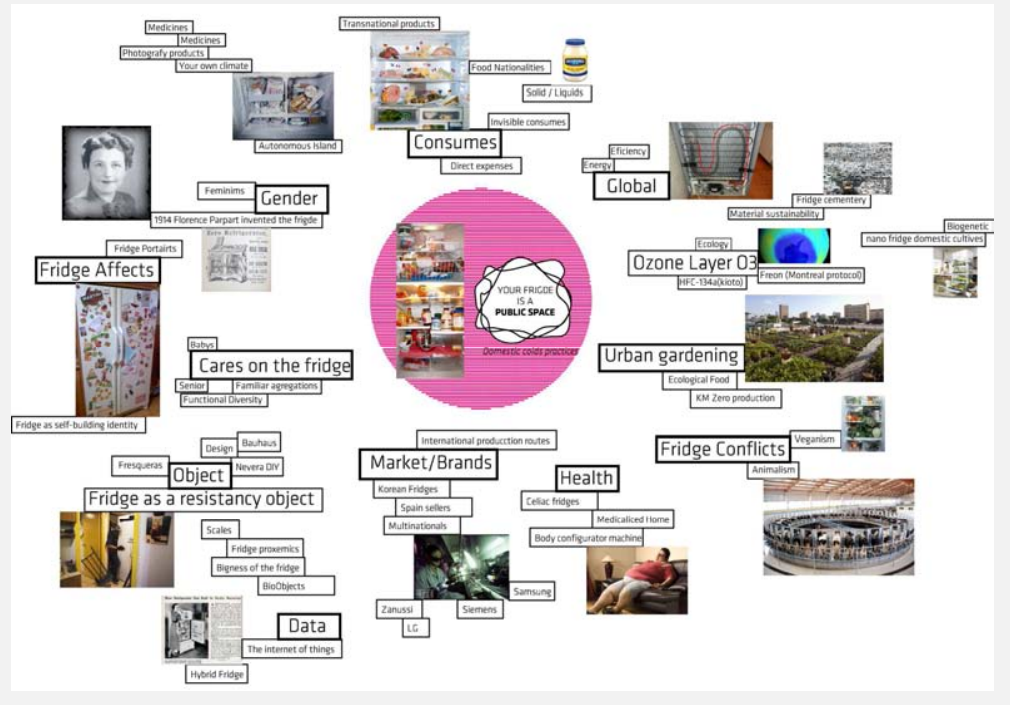

Fig 17. Diagrama del autor sobre los ensamblajes de la nevera doméstica.

Podríamos observar como la nevera es punto de paso obligado de las producciones industrializadas de la carne situadas a cientos de kilómetros de la ciudad, o de su interferencia en la capa de ozono por sus líquidos refrigerantes, o su deshecho en los cementerios de residuos de neveras que se acumulan en el norte de Inglaterra, o los conflictos de género que están inmersos en ella, o los afectos que se acumulan en su puerta. Visualizar también a través de una nevera particular, la vinculación ciudadana y urbana de su propietario con, por ejemplo, los huertos urbanos. O su uso como objeto de resistencia frente a la policía en un 
desahucio, etc. La nevera tiene capacidad de agencia y esta se despliega en múltiples espacialidades y temporalidades. La nevera colocaliza diversas redes diferentes que operan desde la coinsistencia. Es por ello, un buen lugar para extender los estudios urbanos.

Esta ambigua definición de lugar de Sloterdijk, podemos desarrollarla en torno a la idea de lo que significa tener una posición en la espuma y pensar que esa posición no se da solo en condiciones de covecindad, como hemos argumentado, sino también de co-insistencia, es decir, en situaciones donde se simultanean las presencias y el aislamiento. Para Foucault, al igual que para M. Serres, la condición de la coexistencia se da en un mundo que solo puede expresarse de manera topológica. Para la pertinencia de este concepto en esta tesis podemos extraer la afirmación de Foucault sobre el espacio y lo simultáneo.

La época actual quizá sea sobre todo la época del espacio. Estamos en la época de lo simultáneo, estamos en la época de la yuxtaposición, en la época de lo próximo y lo lejano, de lo uno al lado de lo otro, de lo disperso. Estamos en un momento en que el mundo se experimenta, creo, menos como una gran vida, que se desarrolla a través del tiempo, que como una red que une puntos y se entreteje. ${ }^{354}$

Si experimentamos lo urbano como redes en continuidad o como espumas coincidentes, tenemos que encontrar el modo de cómo los espacios que se performan junto a las cosas que lo hacen posible, son simultáneos y se conforman de manera múltiple. Si tradicionalmente los espacios pudieron distinguirse entre espacios jerarquizados, espacios sagrados y profanos, lugares urbanos y rurales, protegidos y abiertos. Estas dicotomías permitían diferenciar ámbitos exteriores o interiores unos a otros. Para definir un espacio de localización, Foucault establece un cambio a partir de Galileo, donde la localización da paso a un punto en movimiento. A partir de Galileo, la localización da paso a la extensión en un campo infinito e extensivamente abierto. Foucault define que el espacio de hoy en día no está en la localización sino en el emplazamiento definido como relaciones de proximidad entre puntos o elementos en una red. Foucault se interesa en este contexto por una forma particular de emplazamientos que tienen la propiedad de estar en relación con los otros. Lo llamará Heterotopías: espacios que operan

\footnotetext{
${ }^{354}$ Foucault, Michael. De los espacios otros "Des espaces autres”, y El cuerpo utópico Le Corps utopique." Conferencias dicada en el Cercle des études architecturals, 14 de marzo de 1967, publicada en Architecture, Mouvement, Continuité, n 5, octubre de 1984. Traducida por Pablo Blitstein y Tadeo Lima.
} 
como espacios otros: "Un lugar real en el que se yuxtaponen diferentes espacios incompatibles." 355

Si Gaston Bachelar y los fenomenólogos establecieron relaciones con los espacios otros desde la interioridad, señalando que el espacio nunca es un espacio homogéneo y vacío, sino un espacio cargado de cualidades derivadas de nuestras primeras percepciones sobre él.

Asociada a esta idea aparece la necesidad de situar cómo se conforman lo que Rem koolhaas denomina espacios genéricos y como se constituyen en términos de presencias ubicuas y localizaciones en copresencias y en base a qué tecnologías se desarrollan. Para ello tenemos que desarrollar la idea de ubicuidad en relación a la coinsistencia de entidades en presencias simultáneas y las consideraciones de esta situación.

\subsubsection{Ubicuidad}

Para llegar a enunciar como se produce hoy una simultaneidad de presencias, acciones, procesos o arquitecturas en ubicuidad, tenemos que desglosar las maneras en que los modos de estar presente en la distancia se han venido sucediendo. Las tecnologías de la telecomunicación y de la telepresencia se asocian a las nuevas tecnologías digitales de comunicación. Queremos explicar en este punto, que estos fenómenos son diversos y anteriores a estas tecnologías contemporáneas. Lo único que las une es que todas estas simultaneidades están construidas mediante mediaciones materiales y nunca son directas. La telecomunicación, la multipresencia y la tele-acción son un proceso de agencias distribuidas entre humanos, tecnologías, protocolos, acuerdos internacionales y redes inmateriales que siempre están formadas por dispositivos materiales sean estos terrestres, acuáticos o aéreos.

Los procesos de telecomunicación, que ya apuntamos en el capítulo anterior, hablando sobre la extensión del apartamento o los protocolos de diseño de Martha Stewart no son estrictamente novedosos. Lo que es innovador, es la forma y las modos de hacerlo, la tecnología que utiliza y las consecuencias que esta tiene. Pero la telecomunicación de alguna forma existe hace mucho tiempo. Basta con pensar en los modos de representación que han desarrollado los humanos para con otros humanos.

Es soberano quien puede hacerse representar como si él estuviera presente en su representante. Por eso las grandes esferas en-globantes se conciben como

\footnotetext{
${ }^{355}$ Ibidem
} 
imperios políticos , como espacios de irradiación de verdad que según el modelo de ekklesia o academia- necesitan desarrollar la posibilidad de la representación. Representación es el caso crítico y el caso normal de telecomunicación del poder. 356

La telecomunicación en estos casos se ha dado en forma de presencias reales de representantes, de imágenes, sean estas talladas en piedra, pintadas en lienzos de cuadros o paredes de murales, tejidas en tapices, estandartes o banderas o impresas en papel. El centro del poder, o en palabras de Sloterdijk, el centro de las cúpulas y esferas, actúa siempre en la lejanía. La telecomunicación del poder se ejerce siempre desde la distancia ${ }^{357}$. Este ejercicio de poder, se consumaba históricamente en la ocupación terrestre de territorios otros. Los procesos de ocupación y colonización expandían esta representación del poder a territorios aún más lejanos. Hoy en día, una vez que los territorios terrestres están saturados, se disuelven las ocupaciones de otros territorios acuáticos o aéreos.

Cubiertas virtuales han sustituido al imaginado cielo de éter de otros tiempos, mediante sistemas de transmisión la eliminación de la lejanía se ha implementado técnicamente por doquier desde los centros de poder y consumo. 358

Las innovaciones tecnológicas del siglo XIX, con la invención del telégrafo y el teléfono produjeron la primera crisis del espacio y el tiempo y con ella la aparición de la globalización como una esfera terrestre sin exterioridad.

Al igual que la telecomunicación, la tele-presencia no es algo nuevo del mundo contemporáneo. La virtualidad del espacio de la presencia en la lejanía, de alguna manera siempre ha estado con nosotros. Pero antes, se situaba en el conocimiento de lo lejano, de lo expandido, de lo que estaba afuera, pero que podía alcanzarse.

La singularidad de nuestro siglo, las redes de comunicación hacen realidad los espacios virtuales que en otros tiempos estuvieron reservados a los sueños y a las representaciones: mundo en construcción en el que, deslocalizados, localizamos y desplazamos, espacio menos alejado de lo que se piensa del antiguo territorio, ya que no hace mucho tiempo, los que permanecían apegados a tierra permanecían en lo virtual tanto como nosotros, aunque sin tecnologías adaptadas. 359

\footnotetext{
356 P. Sloterdijk. Esferas II. Op. Cit., p.581.

${ }^{357}$ Esta noción es fundamental para entender más tarde el concepto operativo que proponemos en las conclusiones como "proxicuidad".

${ }^{358}$ P. Sloterdijk. Esferas II. Op. Cit., p.582

${ }^{359}$ En Serres, Michael. Atlas. Madrid, Cátedra, 1995.
} 
Son estas tecnologías, que M. Serres denomina adaptadas, las que nos permiten disolver la dualidad entre lo real y lo virtual. Ambas esferas pertenecen hoy simultáneamente a nuestra realidad. Lo real es absorbido por lo virtual. Lo geográfico y lo relacional es ya indisoluble. Y esta categoría de lo real ya no se mide en distancias sino en un espacio topológico de vecindarios, de coaislamientos y en un régimen permanente de coinsistencia.

La habilitación de dispositivos de tele-presencia, sistemas de comunicación, pantallas, redes sociales y digitales, significa que estés donde estés, también estarás a la vez en otros lugares. La presencia del individuo, de las marcas comerciales, de los regímenes financieros o de las instituciones es simultánea y, a la vez, ubicua.

Hemos pasado entonces de la representación, a la tele-presencia, y de ella a la teleacción, como capacidad de acción en la distancia. Y esto modifica por completo las relaciones de todas las formas tradicionales de la exterioridad como la naturaleza, la ciudad, la casa y el cuerpo.

Las relaciones entre ellas, bajo la condición de la tele-acción se ven modificadas por el ensamblaje de múltiples agentes y tecnologías. Desde los dispositivos móviles y la irrupción en la intimidad doméstica, (ampliamente estudiadas por Amparo Lasén), a las transformaciones urbanas debido a una geografía de la centralización y sus contra-geografías (desarrolladas por Saskia Sassen), a la posibilidad de tener un cuarto propio conectado (desarrolladas por Remedios Zafra), o una nueva tele-sociedad (narradas por Javier Echeverría en Telépolis).

La posibilidad primera de la tele-visión a dado paso a la de la tele-presencia. Textos, imágenes y videos, se distribuyen en redes P2P que superan la centralidad que tenía la televisión o la radio. Ya no hay solamente emisores y receptores, sino que todos, al igual que la contribución en torno al mundo como laboratorio de Latour, todos participamos activamente del incremento de información en el mundo. Esa producción masiva de información, nos hace hoy ser "prosumidores" 360 . Productores y consumidores de la sociedad de la información ya que nuestras prácticas no se reflejan, sino se crean como información. Y nuestra información se genera por la posibilidad de la acción a distancia. El teletrabajo, la tele-compra, etc. son la forma en la que ejercemos nuestras acciones cotidianas. Estas y otras acciones también poseen sus dispositivos específicos, la tarjeta de crédito, las APPS, los algoritmos o las tecnologías móviles.

\footnotetext{
${ }^{360}$ Glosario abierto de VIC. Prosumidor: Productor + consumidor $=$ Prosumirdor $=$ Profesional + consumidor en http://viveroiniciativasciudadanas.net/wiki/glosario-abiertos/
} 
Lo interesante para nosotros como arquitectos es cómo esta configuración relacional influye en las espacialidades que conformamos. ¿Cómo son las materialidades de la red? ¿Qué espacios producen y como se redistribuyen las agencias de los mismos? Los procesos de ubicuidad y tele-acción producen un efecto directo en las espumas.

La estructura espacial, topológica y métrica sobre la que se asienta la ciudad a distancia es distinta al recinto cerrado de la ciudad tradicional o a los cinturones industriales o las ciudades-dormitorio que dieron lugar a las áreas metropolitanas abiertas. Se instituyó un primer principio de distanciación espacial entre unos y otros ciudadanos; pero no alteró el concepto de circunscripción territorial. ${ }^{361}$

Este primer fenómeno de la dispersión ${ }^{362}$ de las metrópolis ha cambiado la forma de coexistencia de la sociedad que pasa de la urbanidad de concentración en comunidad a una urbanidad de la dispersión en inmunidad. Como hemos explicado en puntos anteriores. A esta dispersión se le han implementado dispositivos como los canales de continuidad territorial, que junto con la multipresencia, forman la infraestructura necesaria para que se desarrolle la simultaneidad ubicua en la espuma.

\subsubsection{Espumas genéricas.}

La multipresencia no se da solamente en los sujetos humanos o los objetos. Se da en multitud de protocolos, inscritos como mutables inmóviles ${ }^{363}$. También en los espacios urbanos, arquitecturas, etc. que se desarrollan en el marco del actual sistema capitalista de producción y representación. La circulación económica y el sistema financiero global, desarrollan las ciudades que conocemos hoy ${ }^{364}$. Fenómenos como la dispersión, la interescalaridad, la contingencia o la volatilidad $^{365}$, resultan más evidentes desde la lógica tardocapitalista de los sistemas de producción de ciudad.

Autores primeramente como H. Lefevbre y más tarde como F. Jameson, E. W. Soja, D. Harvey, M. Davis, S. Sassen, N. Brenenn y toda la rama de los estudios críticos de la teoría urbana, han desarrollado el soporte teórico para explicar los desarrollos urbanos contemporáneos de la ciudad global, los procesos de

\footnotetext{
${ }^{361}$ Echevarría, Javier. Telépolis. Barcelona, Destino, 1994. Descargable en http://textosenlinea.blogspot.com.es/2008/05/javier-echevarra-telpolis.html

362 Este término se desarrolla en el epigrafe 3.7 como disper(x)ión. Como una dispersión que se da en condiciones de conexión.

${ }^{363}$ Recordemos la continuidad de la información que se da en los mutables inmóviles explicados en el punto 1.3.3.

364 Por ejemplo en el texto "El Derecho a la ciudad" de David Harvey en Harvey, David. Ciudades rebeldes. Del derecho de la ciudad a la revolución urbana. Salamanca, Akal, 2013.

${ }^{365}$ Este término se desarrolla en el epígrafe 3.6 de las conclusiones operativas.
} 
desarrollo postcapitalista y las consecuencias de estos para el territorio planetario. Aunque como hemos mencionado antes, en la crítica de I. Farías a los estudios de la teoría urbana como sistema estructurado, quizás el objeto de estudio del capitalismo avanzado sean antes los algoritmos que la investigación de la ciudad.

No es Peter Sloterdijk quien habla del espacio genérico, pero podemos entender que muchos de los insulamientos dentro de las espumas poseen esta condición aparente. Las consecuencias de estos fenómenos urbanos ubicuos han cristalizado también en la idea del espacio basura y la ciudad genérica de Rem Koolhaas. Una de las principales consecuencias que estudiamos aquí es que la simultaneidad ubicua se da también en las espacialidades urbanas, debido a la aplicación de las tecnologías de la información y la tele-acción en los desarrollos urbanos como motor principal de la expansión urbana.

Las tecnologías de la información no han eliminado la importancia de las concentraciones masivas de recursos materiales, sino que más bien han reconfigurado la interacción entre rigidez e hipermovilidad del capital. La vasta topografía económica está siendo implementada a través del espacio electrónico es un momento, un fragmento, de una cadena económica que está, en buena medida, establecida sobre espacios no electrónicos. ${ }^{366}$

Dichos espacios no electrónicos tienden a aparecer rápidamente, casi de manera instantánea, sobre nuestros espacios geográficos y terrestres. Se multiplican como espumas conectadas en todo el territorio global, dando lugar a una ciudad globalmente dispersa pero saturada, de consecuencias interescalares, simultáneas y ubicuas. La ciudad genérica ${ }^{367}$ es el entorno privilegiado de la simultaneidad y la ubicuidad espacial contemporánea. De esta ciudad, que Koolhaas no define sino que sitúa sus atributos, es la que genera el concepto que koolhaas sí define, que es el de espacio basura. Esta ciudad genera espacio basura, a la vez que se construye. No hay una secuencia concatenada de producción y residuos, sino que la construcción de la misma se compone como un desecho urbano al mismo tiempo. Así podemos definir la ciudad genérica como la ciudad que produce y consume espacio basura.

\subsubsection{Tecnologías urbanas ubicuas}

La aparición de la ciudad genérica como productora de espacios basura, se compone como el producto construido de la modernización durante el siglo XX y lo que llevamos del XXI. Como apuntaba Peter Sloterdijk, con la aparición y

\footnotetext{
${ }^{366}$ Sassen, Saskia. Contrageografías de la globalización. Madrid, Traficantes de sueños, 2003, p.28.

${ }^{367}$ Cfr. Koolhaas, Rem. La Ciudad Genérica. Barcelona, GG, 2008.
} 
extensión del apartamento, como unidad de celda en la espuma, esta se produce por la estandarización de los procesos y la dispersión de la fabricación y la concentración del ensamblaje. Estos procesos no se dan solo por la estandarización, sino por una mezcla de conocimientos, tecnologías, empresas multinacionales y técnicas cada vez más blandas de construcción. Todas ellas permiten la aparición de islas o arquitecturas de manera cada vez más rápida e instantánea y en cualquier localidad del globo.

En el siglo XIX fueron las pompas de jabón, las arquitecturas de los pasajes parisinos exploradas por Walter Benjamin, las que desvelaban la continuidad interior de la vida urbana. W. Benjamin era ya un explorador de los espacios basura. Más que los grandes hombres y celebres eventos de la historiografía tradicional, Benjamin desarrolló su descripción "en busca de los rastros de la basura y los detritus de la vida cotidiana de lo colectivo."368 Al igual que Benjamin, Koolhaas explora los espacios basura desarrollados desde el momento que la modernidad parisina comienza a construir los pasajes. Ese momento originario de la modernidad es el que se extiende hasta hoy sin posibilidad de interferencia. El espacio basura es un virus, y como tal, una entidad de expansión total que garantiza la ubicuidad de su alcance.

El virus adscrito al espacio basura es, de hecho, el virus de la compra en sí, que, al igual que la disneyficación, se extiende poco a poco como un musgo tóxico a través del universo conocido. ${ }^{369}$

Para garantizar el alcance total, es decir multilocal y global, al espacio basura le hacen falta herramientas, dispositivos, protocolos, es decir, tecnologías que garanticen la continuidad del mismo, y por lo tanto la presencia simultánea en cualquier localización. Tecnologías que puedan formar lo que queremos llamar Tecnologías urbanas ubicuas.

La continuidad es la esencia del espacio basura. Este aprovecha cualquier invento que permita la expansión, despliega una infraestructura de la no interrupción: escaleras mecánicas, aire acondicionado, aspersores, barreras contra incendios, cortinas de aire caliente... Es siempre interior, y tan extenso que raramente se perciben sus límites. Forma la desorientación (los espejos, los

${ }^{368}$ Sobre esto, leer la introducción de los traductores de la versión inglesa Rolf Tiedemman, The arcades Project. de Walter Benjamin.

${ }^{369}$ Jameson, Fredric. "Future City". New Left Review, n.21, May-June 2003 , Descargable en http://newleftreview.org/II/21/fredric-jameson-future-city 
pulidos, el eco)... El espacio basura está sellado, se mantiene unido no por la estructura, sino por la piel, como una burbuja. ${ }^{370}$

Koolhaas habla del espacio basura como una burbuja. Es cierto que este espacio está sellado, pero no como una isla absoluta, sino más bien como una isla atmosférica, con lo cual también posee la propiedad de la permeabilidad.

Quizás el más importante de los programas ubicuos es el de la garantía de un espacio climático universal, homogéneo y continuo. Al igual que en el capítulo primero hablábamos de los canales de continuidad espacial, como el avión o la tarjeta de crédito, para que estos canales funcionen, estos deben estar soportados por las tecnologías urbanas ubicuas. El aire acondicionado, es entonces el programa moderno y contemporáneo que puede garantizar la aparición de arquitecturas genéricas y por ende del espacio basura asociado. El aire acondicionado garantiza un espacio climático universal e interior.

La cultura moderna de la construcción ha conseguido que el contenido físico casi inobjetivo de todos los edificios, el aire encerrado, haya podido convertirse en un tema sui generis. El aire constituye el último aspecto de la cultural habitacional explicitada de la Modernidad. ${ }^{371}$

Si los pasajes de Benjamin representaban la incipiente explicación atmosféricourbanística, el espacio basura es la planetarización del interior como estancia respirable explícita en máximas coordenadas de confort. El aire acondicionado garantiza la construcción del espacio interior basura.

El aire acondicionado ha lanzado el edificio sin fin. Si la arquitectura separa los edificios, el aire acondicionado los une. El aire acondicionado ha impuesto regímenes mutantes de organización y coexistencia que la arquitectura ya no puede seguir. [...] Como cuesta dinero y ya no es gratis, el espacio acondicionado se convierte inevitablemente en un espacio condicional; antes o después, todo el espacio condicional se convierte en espacio basura. ${ }^{372}$

Las consecuencias que se derivan del programa moderno y contemporáneo de la climatología universal interior también apoyan su principal valor: la deslocalización y desorientación en el espacio basura. Uno no podrá orientarse en la diferencia de espacios ni lugares debido a las condiciones de humedad o temperatura en el espacio basura. La globalización comienza en las condiciones del aire que respiramos. A su vez, el aire climático del espacio basura, produce una

\footnotetext{
${ }^{370}$ Koolhaas, Rem. "Espacio Basura". en la edición en castellano de Lo Ordinario. Walker, Enrique. (Eds.). Barcelona, GG, 2010, p.120.

${ }^{371}$ P. Sloterdijk Esferas III. Op. Cit., p.429.

${ }^{372}$ R. Koolhaas. Op. Cit., p.120.
} 
cantidad de calor, emisiones y efecto invernadero que "la contaminación producida por los coches, motos, camiones, y autobuses del tercer mundo parece una nimiedad." 373

Otra de las tecnologías urbanas ubicuas es la derivada del contenedor y contenido material de estos espacios climatizados. Toda una suerte de materiales de construcción, ligeros, producidos y transportables rápidamente, editables y conformadores de atmósferas de la basura que son la materia prima de la ciudad genérica productora de espacio basura.

Esta producción en serie de elementos unitarios, manejables y de rápido y sencillo ensamblaje, desarrollan una arquitectura de lo aditivo, estratificado y lo ligero. Esta arquitectura no funciona por articulación o composición, sino por acumulación y por adición. No es jerárquica sino heterárquica ${ }^{374}$. Tabiques, pladures, juntas de sellado, siliconas, vidrios, vinilos, fluorescentes, cartonespiedra, pvc, tabiques de acero inoxidable, resinas, gomas, aislamientos, estructuras modulares de acero, conductos metálicos, de amianto, etc. Forman un contraprograma con la evolución cultural. "En el mismo momento que nuestra cultura ha abandonado la repetición y la regularidad como algo represivo, los materiales de construcción se han vuelto más modulares, unitarios y estandarizados. La materia viene pre-digitalizada." 375

Y es esta condición de digitalización de los procesos de producción la que permite la ubicuidad espacial de la materia. La centralización de la producción del vidrio, por ejemplo, en 5 multinacionales, permite un abastecimiento permanente e instantáneo de la producción. No hay ubicuidad sin una codificación de la materialidad. La transformación de esta información es el interface para la nueva producción en otro lugar. Esta tarea de inscripción material ${ }^{376}$ permite la simultaneidad de técnicas innovadoras en cualquier parte del planeta.

Dentro de la misma tecnología material de los procesos urbanos de ubicuidad tendríamos que incluir las prácticas y los métodos constructivos que se hacen más sencillos, ligeros y rápidos. Casi cualquiera en el espacio basura puede construir su propio sistema de inmunidad. La junta seca, es efectivamente una junta rápida.

\footnotetext{
373 Ibidem. R. Koolhaas. p.123.

${ }^{374}$ En la heterarquía todos los componentes son independientes. Se cambia el concepto de ordenar, por el de influir. En vez de orden se habla de relación y esta es bidireccional por su interacción y horizontal. ${ }^{375}$ R. Koolhaas. Op. Cit., p.123.

${ }^{376}$ Hemos definido inscripción material en el epígrafe 1.3.3 con la noción de la ANT de los móviles inmutables.
} 
Toda materialización es provisional; cortar, doblar, rasgar, recubrir; la construcción ha adquirido una nueva tersura, como la sastrería a medida. [...] una superficie ininterrumpida, grapar, pegar, plegar, verter, encolar, disparar, duplicar, fundir, se han vuelto indispensables. 377

$\mathrm{Y}$ es que estas materialidades tienen la capacidad de ser reconfiguradas rápidamente. "Restaurar, recolocar, reagrupar, reformar, renovar, revisar, recuperar, rediseñar, retornar, rehacer, respetar: los verbos que empiezan por 're' producen «espacio basura»" ${ }^{378}$ Es interesante citar aquí el trabajo del artista plástico Tomas Hirschhorn por espacializar mediante la acumulación de estos sistemas constructivos, sellantes, membranas, pegamentos, cintas adhesivas, composites, pinturas donde se visibiliza una téctónica de lo dúctil, lo rápido, lo genérico, repensando las posibilidades expresivas y culturales de estas tecnologías de la construcción basura.

Por último tendríamos que pensar en las materialidades de las naturalezas de plástico, de la limpieza de las calles, de la desnaturalización y la hiperecología. También de los objetos desde pantallas, leds, cajeros automáticos, árboles de navidad, productos, toboganes, balancines, columpios, piscinas, acuosas,...todo un mundo contenido en el espacio basura en un loop permanente y continuo con presencia simultánea en todas las realidades. Desde el interior de lo doméstico hasta lo que R. Koolhaas llama los espacios de la biobasura o ecoespacios ${ }^{379}$, como lugares donde el hiperdesarrollo urbaniza la naturaleza, desde los campos de golf ubicuos o la protección de la selva de Costa Rica.

No podemos en un solo punto desarrollar la cantidad inmensa de tecnologías urbanas ubicuas que produce la ciudad genérica. Pero, si hemos podido hacer notar que la construcción del espacio genérico no se produce sin la mediación de todo un sistema múltiple conectado que es capaz de responder con agilidad a las demandas de ingentes producciones materiales con el consecuente consumo de recursos globales para la producción del espacio basura. Todas estas tecnologías de ubicuidad urbana lo que producen es un agotamiento y saturación del espacio de la espuma. Como hemos dicho en varios puntos, la urbanización es un proceso planetario saturado. Pero por otro lado, el espacio basura detona la idea del planeta como un gran espacio público ${ }^{380}$.

\footnotetext{
377 R. Koolhaas. "Espacio basura”. Op. Cit., p.124.

${ }^{378}$ Ibid., p.132.

379 Ibid., p.138.

${ }^{380}$ Aquí la noción de espacio público es general e indeterminada como espacio de la calle, del exterior convencional.
}

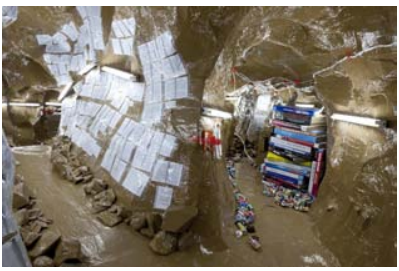

Img.50

The Momentary Monument. Tomas Hirschhorn. Una espacialidad construida de materiales ubicuos.

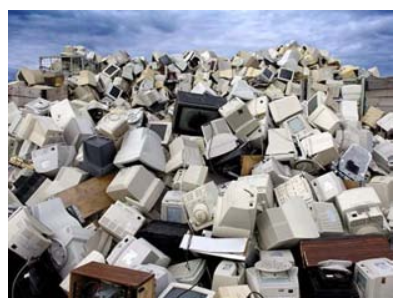

Img. 51

Playas en Gana (África) de residuos tecnológicos contaminantes del "Primer mundo". 
Pensado para el interior, el espacio basura puede engullir fácilmente toda una ciudad. Primero se escapa de sus contenedores, y luego el propio exterior se transforma: la calle se pavimenta con más lujo, el tráfico se aligera, la delincuencia se elimina. Y entonces el espacio basura se extiende... ${ }^{381}$

Hoy es el espacio basura que Koolhaas introduce, el fenómeno más expandido de la ubicuidad espacial y que genera simultáneamente la construcción global de la ciudad genérica. El espacio basura es una de las heterotopías del presente. No está localizado, no tiene un emplazamiento, pero muestra todas las realidades al mismo tiempo.

No seríamos rigurosos en esta tesis si a la introducción de la ciudad genérica y el desarrollo de espacialidades ubicuas descritas por R. Koolhaas, no pudiéramos problematizarlo en el estudio a nivel local. Las infraestructuras y las arquitecturas genéricas se apropian en los contextos locales adoptando formas no directamente genéricas o formas de disenso o contra-genéricas que aumentan la singularidad de cada situación. En relación con lo genérico repliegan por ello la exterioridad e interioridad de lo establecido en el texto. Estas singularidades se producen en las especificidades de cada localidad. Tendríamos que replantearnos la idea de "nolugar" 382 , no existe una construcción de identidad local ni universal. Las identidades son híbridas y se componen de múltiples vectores simultáneamente.

R. Koolhaas reniega de la localidad y la singularidad. Solo es mencionada en ambos textos cuando dice: "Cuanto más indeterminada es la ciudad, más específico es su espacio basura." ${ }^{383}$ Para Koolhaas la globalización no permite el desarrollo de lo local. O dicho de otra manera, sin exterioridad no hay localidad. ${ }^{384}$

Por supuesto que Koolhaas reconoce la singularidad y la localidad de la arquitectura durante el siglo XX aunque no se haga explicito en sus textos sobre la ciudad genérica y el espacio basura. En la última Bienal de Arquitectura de Venecia así lo expone en los temas de los diferentes pabellones nacionales. ${ }^{385}$ Pero

\footnotetext{
${ }^{381}$ Ibidem. p.142.

382 Desarrollamos esta crítica en el capitulo 3.

383 Ibid., p.134.

${ }^{384}$ En la presentación de la Bienal de Arquitectura de Venecia 2014 Fundamentals dice Rem Koolhaas:

"En 1914, tenía sentido hablar de una arquitectura China, la arquitectura Suiza, la arquitectura

India,...Cien años más tarde, bajo la influencia de las guerras, los diversos regímenes políticos, diferentes estados de desarrollo, movimientos arquitectónicos nacionales e internacionales, los talentos individuales, las amistades, las trayectorias personales aleatorias y desarrollos tecnológicos, arquitecturas que antes eran específicas y locales se han vuelto intercambiables"

${ }^{385}$ Del mismo extracto de la presentación de R. Koolhaas para la Bienal de Venecia 2014. "En un momento donde la investigación con google es ubicua y el aplanamiento de la diversidad cultural y la memoria para el futuro de la arquitectura, es crucial para resucitar y exponer estas narrativas ". "Al contar la historia de los últimos 100 años acumulativamente, las exposiciones en los Pabellones Nacionales generarán una visión global de la evolución de la arquitectura en una única estética moderna y al mismo tiempo descubrir dentro de la globalización de la supervivencia de características nacionales únicos y mentalidades que siguen existiendo y prosperar incluso como la colaboración y el
} 
lo que estamos intentando explicar aquí es que los espacios globalizados, genéricos o basura también poseen singularidades propias que anulan la idea de lo genérico como separado de lo no genérico, o de lo particular o lo apolítico dentro del proceso global. Al igual que no podemos separar la sociedad real de la espectacular, no podemos dividir la línea de lo genérico o lo singular dentro de lo genérico. Es decir, lo genérico no sobrevive sin actualizar su localidad o adaptarse a una nueva localidad. Lo hemos visto en el capítulo de Móviles Inmutables y su capacidad de adaptación con el ejemplo de la implantación de los restaurantes de Mc Donals. La simultaneidad ubicua también tiene singularidades.

\subsubsection{Puntos de paso}

Podríamos añadir multitud de ejemplos como los restaurantes de Mc Donals, pero todo ellos nos llevarían a la idea de que "lo genérico" en la espuma es una forma de nombrar de una manera específica los atributos particulares en una homogeneidad de localizaciones habitadas por las marcas comerciales y las tecnologías urbanas ubicuas. La ausencia de identidad de la que habla R. Koolhaas ${ }^{386}$ en relación a la ciudad genérica, es también la ausencia de interés que muestra Marc Auge, en la investigación del concepto de no-lugar. ${ }^{387}$ "El no lugar es un espacio sin identidad"

Si la práctica urbana de los ciudadanos es una continuidad entre espumas diferentes en entornos diferentes en continuidad y simultaneidad, como venimos argumentando a lo largo de esta tesis, ¿Es esta práctica, que confirma los lugares como puntos de paso, una concatenación de lugares (Locales) con no-lugares (genéricos) en la espuma? No parece muy probable esta aproximación. Así que vamos a ver como se conforman las continuidades en la espuma, para definir el concepto de punto de paso y ver como este se muestra importante en definir la coexistencia-coincidencia en la espuma.

El territorio, la ciudad, el espacio público, la casa, están transitados por mujeres y hombres, objetos semi-nómadas que viven en una continuidad interescalar e interespacial en la espuma. Como dice Sloterdijk: "las casas son lugares de parada; con mayor exactitud: salas de espera, en las que se pasa el tiempo hasta la llegada de un acontecimiento exactamente previsto" ${ }^{388}$. La vida cotidiana es hoy, en el mundo occidental, un atravesar espumas y explorar la permeabilidad y la posibilidad de acceso a las mismas.

intercambio internacional intensificará ... " Puede leerse aquí http://www.domusweb.it/en/news/2013/01/25/fundamentals-rem-koolhaas-presents-his-biennale.html ${ }^{386}$ Cfr. Koolhaas, Rem. La Ciudad Genérica. Barcelona, GG, 2008.

${ }^{387}$ Cfr. Auge, Marc. Los no-lugares espacios del anonimato. Antropología sobre la modernidad. Barcelona, Gedisa, 1993

${ }^{388}$ P. Sloterdijk. Op. Cit., p.387. 
Tendríamos que matizar que no solo es la casa una espacialidad que se ha convertido en punto de paso. El arquitecto Toyo Ito ya emplazaba a encontrar el sentido del lugar en un momento donde los tradicionales lugares, como entidades del estar, del reposo o del encuentro se habitaban en lugares en permanencia y separados unos de otros. Bajo esta consideración el espacio público es también un lugar de paso.

El destino, se convierte en punto de paso, y el desplazamiento viene a desempeñar el papel protagonista. Los edificios se han convertido en puntos de paso, en lugar de ser destino como habían sido hasta ahora. Así pues, cuando los lugares de reunión de los habitantes de la ciudad, o el lugar de comunicación para la familia, se convierten en puntos de paso, no hay más remedio que sustituir el concepto espacial tanto de los edificios públicos como de la vivienda, por otro diferente del que se tenía hasta ahora. ${ }^{389}$

Por lo que puntos de paso, como cuerpos, lugares, movimientos, y objetos componen el marco de estudio para las continuidades urbanas contemporáneas. Si tomamos el relato de Guy de Maupassant en Horla, citado por M. Serres en su libro "Atlas", sobre la percepción de las formas de la exterioridad del sujeto que comienza la explicación de su entorno desde el espacio de la cama, podemos ver hoy que esa descripción de la exterioridad no es más una secuencia concatenada de espacios concretos y mitificados, sino un despliegue de la dispersión que habitamos con nuestras prácticas.

El relato contemporáneo del habitar en la ciudad europea contemporánea altera estas reglas de contigüidad entre hechos domésticos, públicos y naturaleza desde la objetividad individual algo que se parece más a una acumulación de acontecimientos aparentemente fraccionados que nuestra práctica sin exterioridad une, enlaza y conforma en continuidad. Haciendo un ejercicio rápido de visualización de un núcleo urbano europeo cualquiera, de una periferia cualquiera, podernos encontrar esta secuencia de lugares que definen más nuestra experiencia urbana en continuidad.

Chalé, chalé, pequeño edificio de viviendas, lavado de coches, galpón, chalé, cobertizo, hotel, chalé, cancha deportiva, pequeño edificio de viviendas, iglesia, chalé, centro comercial, salida de autopista, pequeño edificio de viviendas, 
pequeño edificio de viviendas, terrain vague, lavado de coches, discoteca, chalé, supermercado, chalé, gasolinera, chalé, ... ${ }^{390}$

Las espumas, como ya argumentaba Sloterdijk, son todas ellas aislamientos conectados en simultaneidad. Pero también son continuos en un "atravesar" las espumas que se nos muestran en un tránsito urbano cualquiera como el pasaje citado.

Luego si las vidas humanas no habitan ahora un espacio estable, fijo y localizado, sino que habitan unas trayectorias, debemos atender a rastrear las continuidades de esas trayectorias. Y es ahí donde la ANT nos ofrece herramientas poderosas. Ideas como la escala pierden vigencia si no se convierten en conceptos que se utilizan en continuidad. Lo mismo sucede con el lugar. Podemos estudiar el lugar como concepto en tránsito, y atender a las continuidades del lugar para entrever sus relaciones de exterioridad e interioridad en los diferentes puntos de paso entre las formas que transitamos. El lugar será entonces un lugar en coinsistencia con otros lugares y punto de paso en una trayectoria particular.

Cabe destacar aquí, que no solo es el destino y el trayecto, (la relación entre nuestro estado sedentario o nómada) lo que define la continuidad en términos de los cuerpos, el movimiento y los lugares; son también los objetos que median en estas relaciones. Puntos de paso obligados en estos ensamblajes de las espumas. Si atendemos a la definición de punto de paso obligado que hace Andrés Jaque, retomando los conceptos de B. Latour y el ejemplo de las llaves de hotel con el concepto de anti-programa ${ }^{391}$, podemos comprender como es todo un dispositivo complejo de relaciones el que compone nuestras prácticas y con ello nuestro habitar en el mundo urbano contemporáneo.

Punto de paso obligado: objetos tecnológicos que, sin unificar ni fijar consensos, establecen alianzas más o menos duraderas entre actores con ideologías, expectativas, intereses, deseos, tiempos de evolución y códigos estéticos diferentes, contradictorios e incluso contrapuestos. Los objetos tecnológicos punto-de-paso-obligado son parlamentos en los que estos actores están políticamente representados, y se convierten en mediadores privilegiados, necesariamente presentes en la puesta en práctica de la asociación. ${ }^{392}$

\footnotetext{
${ }^{390}$ Boeri, Stefan. Multiplicity: Uncertain States of Europe. en Walker, Enrique. "Lo Ordinario". Barcelona, GG, 2010, p.195.

${ }^{391}$ Ver epígrafe 3.4 de las conclusiones operativas.

392 Jaque, Andrés. Arquitectura Parlamento: Primer sello de calidad democrática para acciones arquitectónicas. Web de la Oficina de Innovación Política. 29 de Enero de 2007. Disponible en Web: $<$ http://oficinadeinnovacionpolitica.blogspot.com.es/2007/01/arquitectura-parlamento-el-primersello.html>
} 
Esta noción de punto de paso, también es relevante para las multiplicidades espacio de la espuma. Si bien, los objetos son para Sloterdijk, parte del sistema de la espuma, su agencia es detonadora del "estar con" y ese estar se produce en situaciones de movimiento permanente. El apartamento, los invernaderos, los estadios, hoteles, etc. se conforman por las mediaciones de estos puntos de paso obligados. La espuma se transita en su permeabilidad también por estas mediaciones y la tensegridad o tensiones interiores que se hacen visibles con estos objetos. La coinsistencia se conforma entonces como la agregación de lugares, seres humanos, prácticas de insulamiento, objetos y entornos climatizados. En Sloterdijk todo "ser" (being) es un "ser con" (Being with). Como hemos argumentado en el punto de autoemparejamientos, no existe un "yo" sin un "nosotros" y con ello un ser-con-en-el-mundo. (Being-with-in-a-world) La coexistencia en Sloterdijik, es coinsistencia también entre entidades diversas en puntos de paso localizados.

Aunque Sloterdijjk, interpela a la sociedad contemporánea al insulamiento, la cercanía y el "Ser-con" ${ }^{393}$, la noción de puntos de paso bajo la ANT, toma una dirección diferente. Hemos decidido incluir esta definición en este capítulo aquí, para manifestar las dos posturas complementarias, pues para las esferas se cruzan y transitan por los canales de continuidad territorial pero también se sitúan y localizan aunque sea de manera frágil.

Decir que algo es una red es equivalente a decir que residimos entre pasillos de aeropuerto: bueno para viajar, distribuir, realizar conexiones pero no para vivir. Vivir requiere, a su entender, de mejores muros de protección. De políticas de climatización más complejas. De ajustes mucho más locales, frágiles y atmosféricos de los que proporciona la red. Vivir requiere de espacios y burbujas más cerradas y habitables, más íntimas. Lo que él [Sloterdijk]1 denomina esferas. Éstas son nuestro verdadero estar-en-el-mundo. ${ }^{394}$

De esta manera, esta última noción de los puntos de paso en relación a las espumas y la coinsistencia nos hace pensar en una primera problematización de las espumas, donde parecen escasas las explicaciones para ver cómo se desplazan hoy los cuerpos, las cosas y los objetos a través de ellas. Para Sloterdijk, las espumas no son fijas sino inestables o líquidas por naturaleza. El "Ser-en” es un "Ser-con" en movimiento y este movimiento es cada vez más acelerado, casi instantáneo. La coinsistencia es frágil, porque no podemos garantizar la permanencia de las

\footnotetext{
${ }^{393}$ Cfr. Elden, Stuart \& Mendieta, Eduardo. "Being-with as making worlds : the 'second coming' of Peter Sloterdijk.”, Environment and planning D : society and space., v.27, n.1, 2009, pp.1-11.

${ }^{394}$ Rodríguez-Giralt, Israel. "De redes y otros enredos: acerca de la ontología política de la red" en Teoría del Actor Red. Más allá de los estudios de la ciencia y la tecnología. Barcelona, Amentia, 2012, p.347.
} 
espumas contiguas. Estas aparecen y desaparecen con mayor facilidad que antes: son más volátiles que las esferas, las cúpulas (macroesferas) y las burbujas (microesferas). 


\subsection{Problematizando los límites en la Espuma}

La teoría de las multiplicidades-espacio o espumas, como hemos visto en el desarrollo de este segundo capítulo, también nos interpela para tratar de situar sus límites y problematizar algunas cuestiones inherentes a ella.

Primero. Tratar de situar la posición desde la que se forman las espumas es explicitar su situación eurocentrista y occidental. ${ }^{395}$ Las espumas definen un interior global que no significa que sea para toda la humanidad. Primero, porque la propia acepción del término de globalidad, es una cuestión occidental. Como dice el propio Sloterdijk "Creo que todo se reduce a hecho de que las personas en Occidente son los únicos que hablan de la globalización, para todos los demás el tema no existe. La globalización es un tema en el monólogo del mundo rico." 396 Luego la crítica a Sloterdijk debe ser relativa pues es plenamente consciente de la misma. Su acepción del término globalización se explica siempre desde un punto de vista europeo y occidental. Aunque tendríamos que preguntarnos por el significado de "lo occidental" en el mundo capitalista donde países como China participan de esta situación. Pero, la explicitación de esta posición por parte de Sloterdijk marca los límites del conocimiento situado ${ }^{397}$ en el que establece su discurso.

Po otro lado la supuesta colonialidad de las espumas, por lo tanto se debe a la consideración espacial que hace del lenguaje occidental. No en vano, su ánimo en la trilogía de esferas es reconstruir la historia de la Humanidad desde un punto occidental y eurocentrista. De las esferas (griegas) a las atmo-esferas (universales). ${ }^{398}$ En este sentido la imagen del Palacio de Cristal como un vasto interior está concebida para situar la globalidad como un todo aunque, por otro lado, las espumas se conciben como plurales y múltiples de ese interior globalizado.

${ }^{395}$ Cfr. Thrift. Nigel. "Different atmospheres: of Sloterdijk, China and site" Environment and planning D: Society and space. 2009, v.27, pp.119-138.

396 Sloterdijk, Peter en entrevista con Schinkel, Willem \& Noordegraaf-Eelens, Liesbeth en "The Space of Global Capitalism and its Imaginary Imperialism: An Interview with Peter Sloterdijk" en In Medias Res: Peter Sloterdijk's Spherological Poetics of Being Schinkel, Willem \& Noordegraaf-Eelens Liesbeth (Eds.). Amsterdam, Amsterdam University Press, 2011, p.188.

${ }^{397}$ En los términos de Donna Haraway

${ }^{398}$ Thrift. Nigel. Op. Cit., 
Segundo. Si bien su posición antropocentrista, relativa a la historia antropo-técnica de la existencia humana, como una construcción de microesferas (esferas I) macroesferas (esferas II) o espumas (esferasIII), es relativa, pues desde la posición de la covecindad en díadas humanas, también establece las relaciones de los autoemparejamientos entre humanos y tecnologías. 399 "¿Cómo sostener una teoría antropocentrista después del desafío biopolítico del Übermensch de Nietzsche, de la actualización ontológica del Humanitas de Heidegger, del estructuralismo de Foucault en el descentramiento del hombre, de la deconstrucción del discurso antropocentrista en Derrida, y el constructivismo mecánico anti-humanista de Deleuze y Guattari? ¿Cuál son las ideas biopolíticas de la antro-fenomenología de Sloterdijk que comienza no con la clásica pregunta de ¿Qué es un hombre? sino ¿Dónde está el hombre?” ${ }^{400}$ Sloterdijk, en su definición posthumanista atribuye un papel importante a la agencia de entidades "naturales" como el petróleo o el aire. El "ser-con" no está restringido solo a humanos. Con otras palabras, como Latour, Sloterdijk hace del mundo algo con más rango de actores que los que normalmente se identifican como nuevas formas de vida.

Tercero. La globalización interior tiene un exterior para Sloterdijk que es "lo que permanece ignorado, lo no conectado, no afectado por un movimiento particular o tensión en la espuma“401 Si para Latour era un problema de composición del colectivo ampliado a la que el exterior se remite con la noción de "plasma", para Sloterdijk es un problema de hacerse explicito. Aunque en sus últimas intervenciones Sloterdijk construye la noción del interior y el exterior como un proceso simultáneo. "No hay para Sloterdijk, un "afuera", sólo existen los topoi del hombre, y estos son siempre dentro y fuera al mismo tiempo. No sólo es el hombre moderno se caracteriza por el hecho de que su "interior" está totalmente "fuera" [...] pero ser-en-le-esfera siempre significa estar entre el interior y el exterior: estamos en un exterior que lleva interno mundos." ${ }^{402}$

Cuarto. Los límites de la espuma son transparentes y cada vez más invisibles. Pero estos límites a veces se materializan. En el caso del mundo occidental, como la construcción de un palacio de cristal, en el caso de Europa. Los límites de la espuma o palacio de cristal a veces devienen materiales, como en la frontera de México con EEUU, la valla de melilla o la presencia de refugiados en el

\footnotetext{
${ }^{399}$ Ver el punto en el epígrafe 2.2.2. Autoemparejamientos tecnológicos.

${ }^{400}$ Van Tuinen, Sjoerd. "Transgenous Philosophy”: Post-humanism, Anthropotechnics and the Poetics of Natal Difference" en In Medias Res: Peter Sloterdijk's Spherological Poetics of Being Schinkel, Willem \& Noordegraaf-Eelens Liesbeth (Eds.). Amsterdam, Amsterdam University Press, 2011, pp.20-21.

${ }^{401}$ Morin, Marie-Eve. "Cohabiting in the globalised world: Peter Sloterdijk's global foams and Bruno Latour's cosmopolitics”. Environmental and planning D: Society and space. v.27, 2009, p.68.

${ }^{402}$ Schinkel, Willem \& Noordegraaf-Eelens, Liesbeth Op. Cit., p.44.
} 
Mediterráneo como frontera. A veces están sin ser visibles, como la frontera de Brasil controlada por drones y satélites. Pero la ausencia de un exterior no requiere que sus límites sean transparentes. Incluso en la condición de estar fuera de las primeras burbujas del palacio de Cristal en el siglo XIX, China, hasta el umbral de nuestro siglo, hizo un ejercicio constructivo gigante para "existir en un espacio sin afuera debido al auto-emparedado de sus límites. ${ }^{403} \mathrm{Y}$ estos límites estaban cargados de materialidad. Estos muros y fronteras, visibles o invisibles, transparentes u opacos, conforman hoy la materialidad de los límites de la espuma.

Quinto. Estos límites separan entidades diferentes. No son espumas de otro orden pues para Sloterdijk solo hay un mundo y este está saturado por la espuma. ${ }^{404} \mathrm{La}$ finitud del mundo es cuestión primordial para hablar de los límites aunque ya hoy las espumas o islas absolutas también se encuentren fuera de la atmosfera terrestre o en exploraciones espaciales lejanas tripuladas por humanos y no humanos. Frente a esta idea, Bruno Latour ofrece las nociones cosmopolíticas, donde afirma que no hay un mundo global de entidades diferentes, sino muchos y diferentes cosmos. ${ }^{405}$

Sexto. La espuma tiene límites definidos y estos se normalizan y se hacen visibles por la exclusividad del Palacio de Cristal. "La exclusividad es inherente al proyecto del palacio de cristal. Su existencia presupone un exterior ignorable [..] pero la reacción de las dimensiones externalizadas solo puede ser aplazada no descartada de modo permanente. Por ejemplo, las islas flotantes de basura que se encuentran en los océanos con una dimensión aproximada al tamaño de España o la caída de basura espacial en el territorio. Esta condición garantiza, como también explica Latour sobre Sloterdijk, la redondez del globo. ${ }^{406}$ Y para Sloterdijk la condición interior y la minusvaloración del exterior.

Séptimo. La espumas tienen un límite en su exclusividad. Cómo no son totalidades, a pesar de la saturación global del planeta, tienen un reparto diferencial en el globo terrestre. Tal vez, una cuarta parte de la humanidad en un sentido numérico, se encuentra dentro del Palacio de Cristal de las espumas. En consecuencia el gran interior excluye a las tres cuartas partes. Quien se encuentra en el exterior tiene un problema. ${ }^{407} \mathrm{Y}$ esto genera una pregunta ¿Qué tipo de espacio constituye ese exterior? ¿En qué tipo de esfera residen los excluidos? A esta pregunta Sloterdijk responderá diciendo que "Uno puede vivir fuera del

\footnotetext{
${ }^{403}$ Cfr. Sloterdijk, Peter Terror from the Air. Los Angeles, Semiotext[e], 2009.

${ }^{404}$ Eve Morin Op. Cit., p.69.

${ }^{405}$ Cfr, Latour, Bruno. “¿El cosmos de quién? ¿Qué cosmopolítica?" Pléyade. 2014, n.14, pp.119-142.

${ }^{406}$ Van Tuinen, Sjoerd. Op. Cit.,

${ }^{407}$ Esta condición se explicita en las páginas de Sloterdijk. Peter. En el mundo interior del capital. Para una teoría filosófica de la globalización. Madrid, Siruela, 2007, pp.231-232.
} 
espacio interior del capitalismo global, y por lo tanto también una vida auténtica, pero será en diferentes recipientes, diferentes formas, diferentes culturas, diferentes contenedores culturales en el que esta vida tiene lugar." ${ }^{408}$ Finalmente y sobre esta condición, Sloterdijk afirma: "que hay un afuera, esto es enteramente cierto, pero aquellos que viven en el exterior de esta esfera no se limitan simplemente a vivir afuera, pues ellos viven en otra esfera." ${ }^{409} \mathrm{Al}$ igual que en los ensamblajes urbanos o los cosmos de Bruno Latour, una entidad no habita en un exterior, pues el exterior de una esfera, una espuma, un ensamblaje o un cosmos, es el interior de otra esfera, otra espuma, otro ensamblaje u otro cosmos. 


\section{Conclusiones: \\ Principios y operatividades}


Se desarrollan unas conclusiones operativas y abiertas. En un proceso como el de la operatividad de la ANT y las Espumas, que está actualmente en desarrollo ${ }^{1}$. No tendría sentido un cierre de ambas, sino la explicitación de su presencia y su complementariedad. Es por esto que no tratamos de cerrar ningún concepto o aproximación, sino todo lo contrario, abrirlo para permitir su discusión, su evaluación operativa y su controversia si fuera necesario. Las conclusiones son, de esta manera, una herramienta para la cultura del proyecto arquitectónico; que en base los desarrollos de los capítulos anteriores permitirán confrontar su actualidad y sus repercusiones. Este capítulo de conclusiones explicita la operatividad de esta tesis doctoral.

Hemos desarrollado ambas aproximaciones desde las Redes de B. Latour y el resto de autores de la ANT, y las Espumas de P. Sloterdijk. Enunciaremos los principios que expresan la complementariedad de ambas teorías y sus confluencias. Esta confluencia, también posee sus propios conflictos que permiten encontrar sus aproximaciones y diferencias en el diagrama topológico que la tesis elabora como un "set de operaciones".

Los principios que enunciaremos a continuación nos ayudan a construir la disolución de la separación de los conceptos duales, la acción única, y las formas de la exterioridad ${ }^{2}$, según la ANT y Sloterdijk. Estos principios aparecen enunciados como el principio de continuidad, el principio de simultaneidad y el principio de instantaneidad. Como tales, no están definidos por ningún autor específico, ni desarrollado en un marco teórico completo sobre su definición; pero sí aparecen como entornos repetidos por muchos autores como principios existentes en la realidad contemporánea. Principios axiomáticos ${ }^{3}$ que permiten describir la contemporaneidad y su operatividad arquitectónica.

Los principios, como la creación de un marco conclusivo, permiten englobar una serie de conceptos o características que, puestas en marcha, funcionan como operatividades que se despliegan a modo de pequeños casos u ejemplos donde esta condición operativa se desarrolla; bien en un fenómeno urbano, bien en una situación cotidiana, o bien en un proyecto de arquitectura que explicita una condición determinada.

\footnotetext{
${ }^{1}$ Ver el estado de la cuestión de esta tesis doctoral en el capítulo Introducción.

${ }^{2}$ Como las citó J.L. Pardo en Las formas de la exterioridad. Valencia, Pre-textos, 1992.

${ }^{3}$ Como por ejemplo, la globalización terrestre que Sloterdijk considera un axioma. Una considerarse evidente, que aceptamos sin demostración, como punto de partida para demostrar otros conceptos.

Tradicionalmente los axiomas se eligen de las consideradas "afirmaciones evidentes".
} 
La desaparición de la exterioridad, por lo tanto, según Bruno Latour y la Teoría del Actor-Red y las Espumas de Peter Sloterdijk, no remitirá a una ausencia, sino a una inclusión de todo lo previamente no conectado. En esta situación seguirán quedando entidades desconectadas. La internalización del exterior de la ANT se convertirá en un proceso explícito de externalización de nuevas exterioridades. ${ }^{4} \mathrm{El}$ gran interior transparente de Sloterdijk, se materializará en ciertos lugares como construcciones de nuevos exteriores. ${ }^{5}$ Así que, lo importante no será si la exterioridad desaparece y con ella la interioridad o no; sino cómo hemos desarrollado en esta tesis, cómo se conforman, cómo operan, cómo se pliegan y despliegan o cómo se reensamblan en proceso de continuidad, simultaneidad e instantaneidad. La hipótesis ha funcionado como un poderoso detonante, que ha retornado al origen. Pero ese retorno se ha producido por una mediación. La tesis ha operado como mediadora. $\mathrm{Y}$ todo proceso de mediación, es un proceso de transformación. ${ }^{6}$ La tesis, como una máquina conceptual, sin exterior ni interior, ${ }^{7}$ está lista para ser utilizada, prototipada ${ }^{8}$ y reconfigurada.

\footnotetext{
${ }^{4}$ Latour, Bruno. Políticas de la naturaleza. Barcelona, RBA, 2013, p.191.

${ }^{5}$ Cfr. Sloterdijk. Peter. En el mundo interior del capital. Para una teoría filosófica de la globalización. Madrid, Siruela, 2007.

${ }^{6}$ Latour, Bruno. "De la mediación técnica: filosofía, sociología y genealogía." Revista Oeste. 2003,

n.16, p.130.

${ }^{7}$ Deleuze y Guattari El libro como una entidad-máquina sin exterior ni interior, ni objeto ni sujeto. En Deleuze, Gilles \& Guattari , Felix. Mil mesetas, capitalismo y esquizofrenia Valencia, Pre-textos, 1980, pp.9-29.

${ }^{8}$ Nos referimos aquí al camino para aplicar el reto operativo propuesto en esta tesis como máquina conceptual. Una máquina en pruebas o un objeto diseñado para una demostración de cualquier tipo en base a pruebas y errores que mejoran su operatividad.
} 


\subsection{Continuidades, simultaneidades e instantaneidades}

Sin establecer un análisis comparado de ambas teorías, Redes y Espumas y sus principales autores B. Latour y P. Sloterdijk, desarrollamos aquí, la complementariedad de ambas como una caja herramientas 9 para la arquitectura. Y no como sistemas cerrados en sí mismos, pues estas no lo son. ${ }^{10}$

Desde el punto de vista de su operatividad, la ANT ofrece herramientas más precisas desde sus estudios empíricos, que no por ello generalizables ni sistemáticos. La esfereología de Sloterdijk dispone herramientas más conceptuales, una posición desde la que pensar abierta a la multiplicidad.

Es por ello que nos resulta igualmente interesante para "completar" algunas situaciones de carencia que no se desarrollan con tanto énfasis en la ANT y sí lo hacen las espumas de Sloterdijk, y viceversa. Frente a la "anorexia espacial" de la ANT, Sloterdijk provee de espacio para situarse. ${ }^{11}$ Frente al más escaso proceso de relacionalidad heterogénea de las espumas, la ANT ofrece más herramientas para establecer las continuidades, relaciones y mediaciones entre entidades.

Antes de enunciar los principios conclusivos y abiertos de esta tesis doctoral, podemos situar un punto de partida en el pensamiento que no se ha hecho explícita en la tesis y que permite enmarcar los principios que vamos a desarrollar. Esta condición es la condición de simetría que enuncia Bruno Latour en su principio de simetría generalizada. ${ }^{12} \mathrm{~A}$ este principio, que sitúa desde qué posición partimos en el pensamiento; se enfrenta otro de Peter Sloterdijk, que no es desde la posición, sino desde la descripción de la realidad como un principio de la extensión asimétrica. ${ }^{13}$ Estos dos principios pueden situar el enclave, tras los desarrollos de los capítulos 1 y 2 para enmarcar nuestros principios conclusivos como el de continuidad, simultaneidad e instantaneidad, y los conceptos operativos.

\footnotetext{
${ }^{9}$ Foucault, M. (1980). Microfísica del poder (2 ${ }^{\mathrm{a}}$ ed.). Madrid, La Piqueta, p.79.

${ }^{10}$ Las controversias en torno a este aspecto se han explicado en el punto 1.6 sobre los límites de la ANT.

${ }^{11}$ Ibid., p.197.

${ }^{12}$ Latour, Bruno. Nunca Fuimos modernos. Ensayo de antropología simétrica. Buenos Aires, Siglo XXI, 2007, p.141.

${ }^{13}$ Sloterdijk. Peter. En el mundo interior del capital. Para una teoría filosófica de la globalización.

Madrid, Siruela, 2007, p.309.
} 


\subsubsection{Simetría (ANT) y asimetría (Sloterdijk)}

$\mathrm{Si}$, como hemos visto, podemos aceptar que el pensamiento moderno se estructura desde los binarismos, dualismos, y las tensiones que produce la separación de la sociedad y la naturaleza, lo micro y lo macro, etc. La ANT elabora un principio de simetría que argumenta la disolución de estas separaciones. El principio de simetría generalizada ${ }^{14}$ argumenta de un modo básico dos conceptos. El primero, la afirmación que el pensamiento moderno realiza la función de separar, de dualizar, de posicionar y de encapsular los significados, conceptos o situaciones como entidades separadas, interiores o exteriores respectivamente. El segundo, tendría que ver en el modo de enfrentarse a estas separaciones. La ANT asume tales distinciones pero trata de dotarles de procesualidad y movimiento. Es decir, las posiciones duales y antagónicas, serán solo un estado de muchos posibles. Lo que no hace la ANT es abordarlos como a prioris esenciales del conocimiento. En lugar de esto, los aborda como productos, no estructurados ni estructurantes, sino como efectos relacionales: resultados que emergen en el interior de redes complejas en las que actúan diferentes actores-actantes heterogéneos. Conocimiento y significado no son una propiedad exclusiva de los seres humanos. En estas intervienen como hemos desarrollado, diferentes actores, materialidades diversas y multitud de relaciones. De esta relacionalidad híbrida emerge la riqueza de la red. ${ }^{15}$

Dicha separación, para Latour, se produce en la modernidad. La enunciación del principio de simetría generalizado quiere abordar una situación que denomina pre-moderna, para desarrollar la no-separación de la naturaleza y sociedad, o los dualismos modernos.

Son las dos nociones de naturaleza y de sociedad las que hay que abandonar como principio de explicación [...] Es una socio-naturaleza lo que se produce, ligando humanos a no humanos, fabricando nuevas redes de asociaciones. ${ }^{16}$

En este sentido, y como decíamos antes, se asume que tanto sociedad como naturaleza, antes que causas, son consecuencias de las alianzas y negociaciones de la actividad de los científicos y las redes de entidades que las conforman. La fabricación de estas redes como procesos de "ligado" de entidades híbridas, mediaciones y planes de acción, nos ofrece la posibilidad de preguntarnos por las "continuidades" de estas entidades, mediaciones y acciones.

\footnotetext{
${ }^{14}$ Bruno Latour. Op. Cit., p.141.

${ }^{15} \mathrm{~A}$ tal proceso se le denomina lógica semiótica-material. Es decir, con personas, palabras y cosas hacemos más personas, palabras y cosas.

${ }^{16}$ Callon, Michel \& Latour, Bruno, Dir. La science telle qu'elle se fait. Anthologie de la sociologie des sciences de langue anglaise. Paris, La Découverte, 1991, [1990]. p.35.
} 
En otras esferas separadas, como arquitectura y sociedad, ${ }^{17}$ tampoco podemos considerarlas a prioris, porque como hemos demostrado con Sloterdijk, ${ }^{18}$ ambas esferas se conforman al mismo tiempo.

La cuestión es, si es posible abrir la definición de la disciplina al impacto de las fuerzas del mercado y los avances técnicos como una forma de dirigir la evolución de sus códigos y simultáneamente involucrar en su práctica mientras opera como un agente político. ¿Está la arquitectura socialmente construida o por el contrario es una fiel representación de la realidad? O quizás ¿es el enlace perdido entre la comunidad de humanos y la comunidad de $\operatorname{cosas}^{19}$ como entidades políticas?"20

Nada entonces es evidente, y se hace necesaria la descripción, entre distinciones tan aparentemente fundamentales como lo humano y lo no-humano. El principio de simetría generalizado, será entonces un principio básico para la ANT y nos permite situar nuestras conclusiones en un marco de relaciones simétricas.

Para Latour, desde que los occidentales inventaron la ciencia, la gran división interior, explica la gran división exterior.

Nosotros [occidentales] somos los únicos que hacemos una diferencia absoluta entre naturaleza y cultura, ciencia y sociedad mientras los otros, ya sean chinos o amerindios, no pueden separar realmente ese conocimiento de lo que es sociedad. ${ }^{21}$

The First Great Divide: Internal

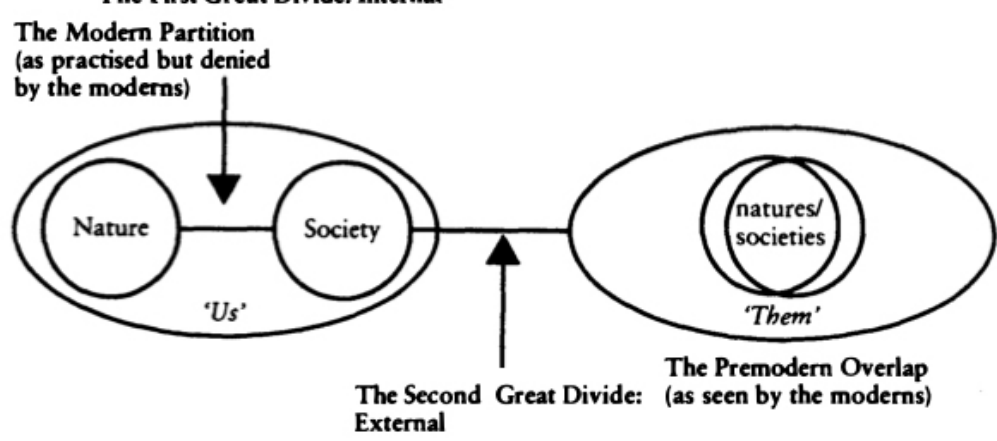

Fig. 18. Diagrama de las dos grandes separaciones. Naturaleza-Sociedad I Ellos-Nosotros.

En Bruno Latour Nunca fuimos modernos. p.147

\footnotetext{
${ }^{17}$ Zaera-Polo. Alejandro. The Politics of the envelope. Volume, n,17, 2008, p.79.

${ }^{18}$ Cfr. P. Sloterdijk en Trilogía Esferas I, II, II.

${ }^{19}$ Traducción del autor de Thing en inglés. Como explica Bruno Latour, la palabra thing, que procede del inglés y el alemán antiguos, no denota tanto un objeto como un caso, una controversia, e incluso un conflicto. Thing implica fricción y negociación. En Latour Bruno, "Athmospheres.” y Eliasson, Olafur. Leer es respirar, es devenir. Barcelona, GG, 2012, p.83.

${ }^{20}$ Zaera-Polo, Alejandro. Op. Cit., p.79.

${ }^{21}$ B. Latour en Nunca Fuimos modernos. Op. Cit., p.148.
} 
A esta necesidad de simetría, Sloterdijk responde ${ }^{22}$ con su principio de extensión asimétrica. Para Latour, existe un import-export de las grandes divisiones modernas entre el nosotros(los occidentales) y el resto del mundo (de China a Yucatán) ${ }^{23}$ que ejerce una división totalmente asimétrica: el exterior (ellos) y el interior (nosotros). Latour quiere por medio de la anulación de la división de humanos y no-humanos, diluir también esta división moderna.

Entonces, al principio de simetría generalizado, como forma de explicar la realidad sin divisiones, sino en continuidades y simultaneidades, Sloterdijk nos enfrenta una visión de la realidad que se compone siempre de manera asimétrica y de esta manera nos enfrenta también a un deseo particular de simetría. ${ }^{24}$

El principio de la extensión asimétrica [...] atraviesa el ámbito nuclear de la esfera política, comenzando con el derecho a la ciudadanía, que divide a la muchedumbre en bípedos vivos, [...] los miembros y no miembros de una nación, la diferencia ellos-nosotros." ${ }^{25}$

Para Sloterdijk, la asimetría puede medirse en quien participa y quien no del Palacio de Cristal o del confort, quien está "aligerado" y qué otras entidades asumen las cargas en un planeta globalizado. ${ }^{26} \mathrm{La}$ asimetría existe. Está por todos los lados, pero una posición más simétrica, no solo es más deseable, sino que favorece el establecimiento de nuevas relaciones heterogéneas. La posición simétrica entonces, no separa entre humanos y no humanos, busca en sus continuidades. No divide entre los conceptos duales, sino que los hace simultáneos. No establece condiciones permanentes, sino que favorece la descripción de lo cambiante e instantáneo. Lo cierto, es que ambas posiciones conviven hoy. Lo simétrico y lo asimétrico también pueden desarrollarse de una manera continua, simultánea e instantánea.

En particular, como resultado de la confluencia de las Redes (ANT) y las Espumas (Sloterdijk) para la arquitectura, se hacen evidentes en la disolución de las categorías de las formas de la exterioridad, como son el cuerpo, la casa, el espacio público, la ciudad, el territorio y la naturaleza, por conformarse desde la modernidad como esferas estables que se separan arquitectura y sociedad. Por lo tanto, bajo el principio de simetría enunciado, pueden modificar su estatus por otro más dinámico, incluyente y premoderno, en los términos de Latour. No serán

\footnotetext{
${ }^{22}$ No hay una relación entre Latour y Sloterdijk que ellos hayan hecho explícita, pero nos parece oportuno superponer sus dos relaciones pues enfrentan un deseo, y una realidad.

${ }^{23}$ Latour, Bruno. Op. Cit., p.144. en "el import-export de las grandes divisiones."

${ }^{24}$ Cfr. Morin, M.-Eve. "Cohabiting in the globalised world: Peter Sloterdijk's global foams and Bruno

Latour's cosmopolitics”. Environmental and planning D: Society and space. v.27, 2009, pp.58-72

${ }^{25}$ Sloterdijk. Peter. En el mundo interior del capital. Para una teoría filosófica de la globalización. Madrid, Siruela, 2007, p.309.

${ }^{26}$ Explicaremos el concepto de aligeramiento en Sloterdijk en el epígrafe 3.5 de las conclusiones operativas.
} 
consideraciones a priori ninguna de estas formas, sino que se explicitaran en el desarrollo de una descripción. Tampoco serán productos establecidos, ni estructurantes. Más bien, como indica I. Farías, un efecto colateral de la formación de redes y ensamblajes, no anterior ni estructurante.

\subsubsection{Principio de continuidad}

Tal como hemos introducido en el capítulo 1.2.1, la hipótesis de continuidad de Latour y Boltanksi ${ }^{27}$ está dirigida a superar los dualismos fundantes individualcolectivo, micro- macro, adentro- afuera, sujeto- objeto, entre otros, que se diluyen por el establecimiento de la continuidad de la acción. ${ }^{28} \mathrm{Y}$ esto sucede por la continuidad de los rastros de las asociaciones ${ }^{29}$, por la continuidad en las escalas que se dan, por la continuidad en las formas de la exterioridad, por la continuidad que puede darse en un estado de simetría.

La ANT como herramienta nos ofrece la posibilidad de encontrar esas continuidades por medio de rastrear y describir las entidades, las agencias, las mediaciones, las traducciones, las inscripciones de todas las entidades que participan de una situación concreta.

Las espumas, como herramienta conceptual, nos permiten encontrar las continuidades que se dan entre las formaciones espaciales en aislamiento conectados. La conexión produce las continuidades que diluyen las relaciones de interioridad o exterioridad de las entidades, espumas o insulamientos.

Pensar en continuidades desde la ANT y las Espumas es pensar en la continuidad de la acción, en topologías formales y espaciales, en canales de continuidad territorial, en puntos de paso, en superficies extensivas y en urbanismos planetarios..$^{30}$ De esta manera, establecemos el principio de continuidad como primera conclusión:

"Las formas de la exterioridad como el cuerpo, la casa, el espacio público, la ciudad o la naturaleza, más que entidades nominativas separadas, son procesos que se forman en continuidad a través de redes de mediaciones socio-técnicas y aislamientos conectados."

\footnotetext{
${ }^{27}$ Cfr. Latour, Bruno. Reensamblar lo social. Buenos Aires, Manantial, 2008, p.102.

${ }^{28}$ Marmisolle, Gaston. "La sociología pragmática de Bruno Latour" Jornadas de Sociología de la UNLP, 2012.

${ }^{29}$ Latour, Bruno. Op. Cit. p.103.

${ }^{30}$ Todos ellos desarrollados en el capítulo primero y segundo.
} 


\subsubsection{Principio de Simultaneidad}

La modulación que podemos hacer de los límites de las dualidades actor-red, humano-no-humano, comunidad-inmunidad, aislamiento-conexión, genera un amplio estado de posibilidades donde poder desarrollar nuevos acontecimientos. La realidad será siempre dual, pues operará por la simultaneidad de las dualidades: intimidad-publicidad, material y virtual, geográfica y relacional. ${ }^{31}$. La simetría aparece en la conformación de estas realidades y dualidades no como entidades separadas, sino como procesos en simultaneidad. Estos procesos simultáneos alteran las nociones de topos, el lugar o la localidad. El objeto deviene ontológicamente múltiple. Las categorías tradicionales como ciudad, espacio público, lo doméstico o el cuerpo pasan a ser procesos dinámicos y no entidades nominales fijas y estables.

Para la ANT el Actor-red no será ni un actor, ni una red. Y esta tampoco será ni humana ni no humana. ${ }^{32}$ Un actor-red será una entidad híbrida cuya actividad se despliega en diferentes prácticas, distancias, programas, situaciones, localizaciones y escalas simultáneamente. Al igual que el principio de simetría generalizado, las formas de la exterioridad ligadas al espacio son producto y no causa, de la conjunción simultánea de entidades híbridas, agencias distribuidas que en su devenir, conforman un "espacializar", un "temporalizar" y un" agencializar" que performan o enactan cada una de estas formas en diferentes situaciones.

Para las Espumas, la simultaneidad se hace operativa en el concepto de los sistemas coincidentes. Ha sido Sloterdijk quien con insistencia ha tratado de describir por qué las sociedades, los espacios, las tecnologías operan hoy en simultaneidad. Esta condición se da desde la coinsistencia, entendiendo la coinsistencia como la acción de concurrir simultáneamente en un mismo tiempo o lugar desde el aislamiento y no desde la coexistencia ni la integración. Situaciones donde las entidades operan en vecindad y separación al mismo tiempo. Las sociedades, como sus espacialidades, operan en sistemas coincidentes.

Pensar en simultaneidad, desde la ANT y las espumas, es pensar la construcción de entidades híbridas o actantes, pensar en las agencias distribuidas y compartidas. En el autoemparejamiento humano-psicológico y humano-tecnológico. En la ciudad como objeto múltiple y con capacidad de concrescencia o crecimiento simultáneo. En los ensamblajes urbanos como entidades múltiples y simultáneas. En la sociedad, la tecnología y sus arquitecturas y soportes de vida como sistemas

\footnotetext{
${ }^{31}$ AAVV. Diccionario Metápolis de arquitectura avanzada. Barcelona, Actar, 2001, p.530.

${ }^{32}$ Callon, Michel. "Techno-economic networks and irreversibility" en A sociology of Monsters: Essays on power, technology and Domination. John Law (Ed.) London. Routledge Sociological Review. Monograph. 1992, v.38, p.156.
} 
coincidentes. ${ }^{33}$ De esta manera, establecemos el principio de simultaneidad como segunda conclusión:

"Las formas de la exterioridad como el cuerpo, la casa, el espacio público, la ciudad o la naturaleza son procesos que se construyen simultáneamente a través de entidades híbridas y en agencias compartidas, que operan como sistemas coincidentes."

\subsubsection{Principio de Instantaneidad}

Los ensayos sobre la velocidad de Paul Virilio o los trabajos de Byung-Chul ${ }^{34}$ sobre la transparencia y la aceleración, explicitan la construcción de la instantaneidad como unidad de valor del tiempo, donde el pasado y el futuro tienen como única medida: el presente instantáneo. La ANT y las Espumas también tienen herramientas para desarrollar las nociones temporales (instantáneas) y procesuales de las formas de la exterioridad.

La ANT nos ofrece herramientas para pensar en esta condición desde la misma definición de "lo social" que hemos venido dando. Lo social como una asociación momentánea de agrupación de actores bajo nuevas formas. ${ }^{35}$ La propia idea de Actor-Red remite a una condición de instantaneidad en la agregación de actores diversos con capacidad de agencia que puede delegarse (de forma temporal), traducirse (en un determinado momento), o mediar (en un proceso de duración limitada). Estos procesos operan con una temporalidad muy limitada y cada vez más acelerada e instantánea. Por ello el ensamblaje urbano como herramienta, opera mejor desde temporalidades cortas. ${ }^{36}$

Las espumas nos ofrecen herramientas para pensar en la instantaneidad desde la propia definición de las espumas, como entidades volátiles y sujetas permanentemente a cambios rápidos y fugaces. Las sociedades, como sus arquitecturas, aparecen y desparecen en distintas localizaciones espaciales y temporales. La posthistoria ${ }^{37}$ de Sloterdijk, es la historia instantánea. Las espumas de Sloterdijk son en sí mismas un desarrollo de la fragilidad, fugacidad, aligeramiento e instantaneidad de las sociedades. De esta manera, establecemos el principio de instantaneidad como tercera conclusión:

\footnotetext{
${ }^{33}$ Todos ellos desarrollados en el capítulo primero y segundo.

${ }^{34}$ Cfr. Byung-Chul Han. La sociedad de la transparencia. Raúl Gabas (trad.). Barcelona, Herder, 2013.

${ }^{35}$ Bruno Latour. Reensamblar lo social. Op. cit. p.232.

${ }^{36}$ Ver epígrafe 1.5.3.3. "La temporalidad del ensamblaje".

${ }^{37}$ Sloterdijk Peter. "Posthistorie" En el mundo interior del capital. Para una teoría filosófica de la

globalización. Madrid, Siruela, 2007, pp.198-203.
} 
"Las formas de la exterioridad son entidades procesuales que se forman cada vez de manera más instantánea desde la conjunción de entidades híbridas diversas y con agencias temporales, que aparecen y desaparecen con mayor inmediatez en el mundo contemporáneo."

\subsubsection{Operatividades}

Estos tres principios, y los procedimientos operativos asociados a ellos, se interrelacionan también de manera continua, simultánea o instantánea. Esto no hace más que expresar la constante formación múltiple de los procesos urbanos. En ellos, estas condiciones se hacen cada día más presentes y se hace, por lo tanto, necesario abordar estos temas para intervenir en un mundo cada día más complejo y donde la arquitectura no puede separarse del ámbito social y tecnológico. Estos conceptos tratan también de graduar las dualidades tradicionales subyacentes para ser pensados como conceptos en continuidad, simultaneidad o instantaneidad. Los conceptos que hemos desarrollado, como la conjunción de sus significados para las redes (ANT) y para las espumas (Sloterdijk), son los siguientes:

La Proxicuidad: como la simultaneidad de lo próximo y lo ubicuo, lo cercano y lo lejano. La Extimidad: como la simultaneidad de lo público y lo íntimo. La Contingencia, como sustitución instantánea a la idea de programa, acontecimiento y fenómeno. El Aligeramiento como proceso en continuidad de un proceso de carga y descarga. La Volatilidad como proceso continuo de cambios sucesivos y repentinos o la Dispersión como separación y conexión simultánea. La Interescalaridad como el proceso de continuidad espacial y temporal en escalas simultáneas. La Transparencia no solo la percepción simultánea o superpuesta de distintas localizaciones espaciales en continuidad sino también como el grado de acceso al conocimiento de un objeto. O la Colocalidad como una situación englobante de localidades simultáneas y/o continuas. Estas características se ejemplifican como procesos operativos que son también procedimientos de proyecto y resultan de la extracción de conceptos útiles para la tesis.

Redes (ANT) y Esferas (Sloterdijk), como hemos visto, también funcionan bajo estos conceptos y desde su operatividad. De hecho, la propia ANT y los estudios de la ciencia y la tecnología STS, se desarrollan no desde el pensamiento sistémico, sino desde la operatividad de los estudios de caso empíricos. La ANT desvela la propia operatividad de la ciencia frente a las nociones sistémicas y universales de la misma. "La ciencia no se rige por normas abstractas, sino por una operatividad concreta y acotada inseparable de las dimensiones que acompañan a toda la 
operatividad humana, y en general orgánica, los intereses, las alianzas." ${ }^{38} \mathrm{El}$ mérito de la aproximación de la ANT, es precisamente la descripción basada en la operatividad concreta y del día a día de la producción de los hechos científicos y sus controversias. La ANT, como sistema abierto, no cierra ni clausura las controversias sobre lo social, ni sobre la propia ANT. "Todo lo contrario, las deja expresarse y fluir, las mantiene abiertas, como incertidumbres, como un terreno movedizo que amenaza constantemente con tragarse cualquier certidumbre que el analista crea que ha alcanzado. "39

Del mismo modo, esta tesis doctoral expresa en este tercer capítulo de conclusiones, su capacidad operativa como una máquina conceptual capaz de hacer evolucionar los conceptos que propone como conclusiones desde lógicas abiertas, incluyentes y permeables a los cambios. La operatividad también sufre de volatilidad.

\footnotetext{
${ }^{38}$ Loredo, J.Carlos. ¿Sujetos o actantes? El constructivismo de Latour y la psicología constructivista. AIBR. Revista de Antropología Iberoamericana, 2009, v.4, n.1, pp.113-136.

${ }^{39}$ Tirado, Francisco. Recensión crítica sobre el libro de Latour "Reensamblando lo social" Madrid. Publicado en AIBR. Revista de Antropología Iberoamericana, Ed. Electrónica Núm. Especial. Noviembre-Diciembre, 2005.
} 


\subsection{Proxicuidad}

Los límites de las formas de la exterioridad, el cuerpo, la casa, el espacio público, la ciudad y la naturaleza se han dispuesto por su proximidad o su lejanía. En base al individuo-hombre-europeo-humanista ${ }^{40}$ la naturaleza ha sido algo lejano y de lo que protegerse; así como la casa era algo próximo. Esta noción de la distancia donde las cosas están lejos o cerca entre entidades independientes y separadas se ha tornado poco operativa ${ }^{41}$. Pues ¿Qué sucede cuando hoy en día las cosas, los objetos, los afectos, la propia casa está lejos y cerca al mismo tiempo? ¿Cómo operar cuando las cosas son ubicuas y cercanas a la vez? La condición de simultaneidad aplicada a la distancia, nos hace proponer, en base a las experiencias de las redes (ANT) y las espumas, la noción de "proxicuidad" ${ }^{2}$ para determinar su operatividad en el campo de la arquitectura.

\section{Aproximaciones / Descripciones}

La RAE no define el término proxicuidad. Es por lo tanto un neologismo. La RAE define lo próximo como lo "cercano, que dista poco en el espacio o en el tiempo" ${ }^{43}$. También como lo inmediato, lo siguiente, lo inmediatamente posterior. Por el otro lado, define lo ubicuo como "Dicho principalmente de Dios: Que está presente a un mismo tiempo en todas partes." ${ }^{44}$ También "Dicho de una persona: que todo lo quiere presenciar y vive en continuo movimiento." ${ }^{45}$ La proxicuidad remitirá entonces a la simultaneidad de la proximidad y la ubicuidad.

\section{Distancias pragmáticas}

Si para David Harvey, como ya hemos explicado en el capítulo 1, las relaciones de distancia, cercanía o lejanía son distancias pragmáticas, es decir, que dependen de los modos de hacer de una época, sus discursos y tecnologías. ${ }^{46}$ Nos enmarcamos en esta consideración para establecer el concepto de proxicuidad que proponemos directamente relacionado con las distancias pragmáticas del medio contemporáneo. "Hoy la lejanía no está lejos. Está cerca. Es transitable, doméstica. De hecho está en las casas, en el monitor del ordenador, en la pantalla de los teléfonos móviles. Porque la técnica de nuestro tiempo es la técnica de lo lejano: el antiguo adverbio griego tele -lejano- forma parte de los elementos y de los instrumentos de la técnica contemporánea. Todo lo que está lejos -islas, desiertos

\footnotetext{
${ }^{40}$ Cfr. Braidotti, R. The Posthuman. Cambridge, Polity Press, 2013.

${ }^{41}$ Cfr. VV.AA. Ontología de la distancia. Filosofías de la comunicación en la era telemática.

Editorial Abada, Madrid, 2010, p.393.

${ }^{42}$ Enunciado por primera vez en el Glosario Abierto de VIC por Ramón Insa Alba.

${ }^{43}$ Diccionario RAE. sobre Próximo.

${ }^{44}$ Ibid., Ubicuo.

${ }^{45}$ Ibid,. Ubicuo.

${ }^{46}$ Cfr. Harvey, David. Explanation in geography. Londres, E. Arnold, 1969.
} 
acontecimientos, costumbres- viene hacia nosotros, se convierte en superficie, pantalla, sonido." ${ }^{47}$

Distancias relacionales heterogéneas

Desde la aproximación de autores ya mencionados como M. Serres B. Latour o J. Law podemos entender que el concepto de distancia se ha vuelto un concepto más topológico, es decir, relacional. Que no es medible en términos solo tradicionales $^{48}$, sino que bajo diferentes situaciones puede ofrecernos un amplio abanico de posibilidades. "La primera ventaja de pensar en términos de red es que dejamos fuera la "tiranía de la distancia" o la proximidad. Elementos que están cerca cuando están desconectados están infinitamente lejos si analizamos sus conexiones; por el contrario elementos que parecen estar a una distancia infinita pueden estar cerca cuando traemos sus conexiones a la red. "49

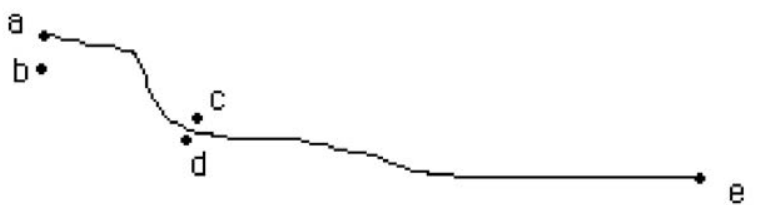

$\mathrm{a}$ is further from $\mathrm{b}$ than from e once connections are taken into account; the proximity of $\mathrm{a}$ and $\mathrm{b}$ or of $\mathrm{c}$ and $\mathrm{d}$ is due to the connections established by the grid system and the work of geographers; grid layering and map making is another network and not what in which networks are situated

Fig. 19. Diagrama de las dos grandes separaciones. Naturaleza-Sociedad I Ellos-Nosotros. En Bruno Latour "On actor-network theory. A few clarifications plus more than a few complications" p.373

\section{Desde la continuidad de la acción}

Por un lado la mirada cercana (micro) de las cosas que propone la ANT nos lleva a cubrir grandes distancias ${ }^{50}$. La continuidad de la acción, el seguimiento, nos ofrece una primera aproximación al concepto de distancia como el resultante de hacer un rastreo desde lo pequeño y lo micro que alcanza distancias lejanas. Lo cercano, nos ofrece una situación de lo lejano.

\section{Desde la Agencia compartida}

Si como hemos argumentado la agencia compartida construye nuevas entidades (como el humano-teléfono móvil), esta produce unas relaciones de distancias donde lo cercano se simultánea con lo lejano (como en una llamada de teléfono).

\footnotetext{
${ }^{47}$ Antonio Petre en la introducción de su libro Tratado de la lejanía. Valencia, Pre-textos, 2011.

${ }^{48}$ Michel Serres, citado ya en epígrafe 1.3

${ }^{49}$ Latour, Bruno. "On actor-network theory. A few clarifications plus more than a few complications" Soziale Welt. v.47, 1996, [1990], p.373.

${ }^{50}$ Farías, Ignacio. "de los rastros que dejan los actores con una mirada micro, casi corta de vista, pero que lleva a cubrir grandes distancias"
} 


\section{Ensamblajes}

Las distintas redes de objetos y prácticas que sustentan la operación de la ciudad y que producen representaciones de la misma, conectan múltiples espacios dispersos geográficamente. Estos pueden incluso estar situados a miles de kilómetros de distancia de las ciudades y que performan haciendo cercano, algo que se transporta desde la lejanía.

\section{Inmediatez}

Lo inmediato es lo que sucede enseguida, algo también muy contiguo o muy cercano. Lo inmediato implica una idea de proximidad. Con lo cual lo inmediato, también es lo que no está separado. Lo que es vecino, lo que fricciona, lo que es permeable y a la vez impermeable a lo otro. Temporalidades permeables e impermeables, pues el tiempo también se produce de co-aislamientos de esferas aisladas, inmunizadas y de esferas concatenadas y más permeables. El tiempo se produce entonces desde la cohabitación y la coinsistencia. El tiempo también es espumoso. "Con una creciente conexión con los demás, o como un sentimiento predominante de urgencia y, tal vez, de la compulsión y la impulsividad en nuestras preocupaciones. ${ }^{"}{ }^{1}$ En la fabricación de esta inmediatez, los medios, las tecnologías de comunicación y transmisión toman un papel revelador. Son los mediadores de todo el proceso. La inmediatez es entonces un principio sociotécnico y cultural donde los nuevos medios están reemplazando cada vez más los industriales. Pasamos de la velocidad de la época de la máquina de Virilio, a los fundamentos de instantaneidad de los algoritmos. La inmediatez reemplaza a la velocidad con la proximidad, la ubicuidad y la instantaneidad. Amazon afirma que queremos la información cerca, en un click de 8 segundos, y en cualquier lugar.

\section{Distancia y conocimiento público}

Lo que estaba lejos, se vuelve cercano y más conocido. Las distancias lejanas como medida en una relación de exterioridad se convierten en cercanas. La foto del Blue Marble de la NASA en 1972 o la actual imagen de Plutón, acercan algo desconocido o distante. Los proyectos de Superstudio como Interplanetary Architecture trabajan con las grandes distancias interplanetarias que hoy se dan también bajo una forma de relacionalidad híbrida.

Distancias sociales alteradas: proxémica

Si la proxémica ${ }^{52}$ es la ciencia que describe las distancias medibles entre las personas mientras éstas interactúan entre sí. Lo próximo, bajo esta perspectiva, pasa por describir las distancias como próximas o distancia íntima: como la

\footnotetext{
${ }^{51}$ Tomlinson John. The Culture of Speed. The Coming of Immediacy. London, Sage, 2007, pp.74-75.

${ }^{52}$ Concepto desarrollado por el antropólogo Eduard T. Hall en The Hidden dimension. NY, Random House, 1966. Y acuñado por el psicólogo animal H. Hediger.
} 
distancia que se da entre 15 y 45 centímetros (6 a 18 pulgadas) entre dos individuos. Para que se dé esta cercanía, las personas tienen que tener mucha confianza, y en algunos casos, estarán emocionalmente unidos, pues la comunicación se realizará a través de la mirada, el tacto y el sonido. Por otro lado la distancia lejana o Distancia pública: se da a más de 360 centímetros (12 pies) y no tiene límite. Es la distancia idónea para dirigirse a un grupo de personas. El tono de voz es alto y esta distancia es la que se utiliza en las conferencias, coloquios o charlas. Y así sucesivamente:

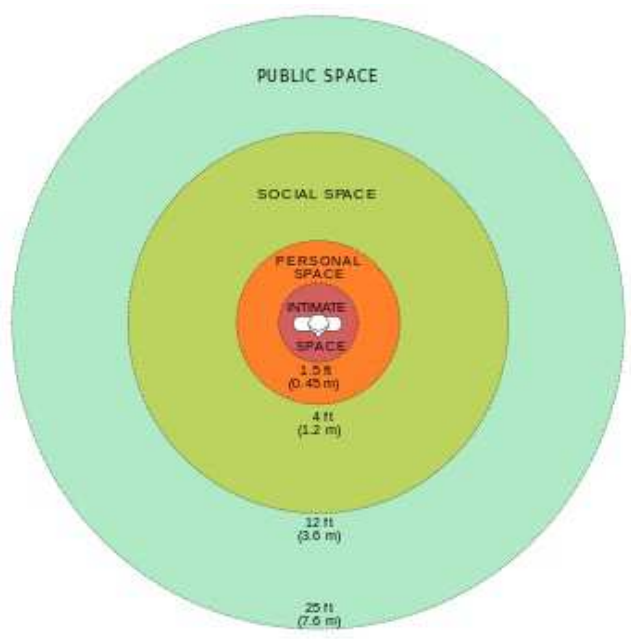

Fig. 20. Diagrama centrado en el individuo moderno que elabora la proxémica de Eduard T. Hall en The Hidden dimension. mostrando las distancias como burbujas concéntricas, con medidas de los radios en pies y metros.

La proxémica enuncia las distancias íntimas, personales, sociales y públicas junto con los espacios comunicacionales que configuran. Por ejemplo, los ascensores americanos difieren mucho en tamaño y medidas de los ascensores de Arabia Saudí. Estos últimos son más anchos y grandes para no provocar cercanía entre sus ocupantes. ${ }^{53}$ Estas relaciones de distancias físicas y medibles se alteran bajo las condiciones contemporáneas que genera la proxicuidad, donde ya no son solo las entidades humanas las que configuran las relaciones de distancias interpersonales, sino las entidades híbridas que las relacionan, tecnologías, objetos, redes. Como decíamos en la aproximación de distancias relacionales, lo social es un "colectivo ampliado" que incluye a tecnologías, objetos, estados de cosas y planes de acción. Las distancias sociales tendremos que estudiarlas también desde la proxicuidad.

\footnotetext{
${ }^{53}$ Sobre la próxemica de los ascensores ver: OMA, Elevator. en Elements of architecture. Bienal de Venecia, 2014, p.65.
} 


\section{Distancias en el aislamiento}

Lo geográfico y lo relacional siempre han estado vinculados, pero hoy forman una unión indisoluble. Lo virtual es lo real sin ser actual, según Deleuze. Y lo real se mide ya en vecindarios, co-aislamientos y en un régimen permanente de coexistencia ${ }^{54}$. Sloterdijk define la distancia por cuestiones como el aislamiento y conexión. En la vecindad, lo que da acceso a la distancia, es la permeabilidad que produce la condición de coaislamiento. Las membranas de separación de la espuma son válvulas de regulación de intercambios y de distancias. "Está claro que la intención de una regulación voluntaria por parte del habitante pasa por descartar las opciones extremas de siempre conectado o siempre desconectado. El potencial reside en la variación y en la adaptabilidad, justo entre los márgenes entre el conectado al $100 \%$ y el totalmente desconectado. Justo en los puntos intermedios y en las posibilidades de variación es donde la regulación de intercambios tiene su mayor potencial." ${ }^{55} \mathrm{Y}$ estos gradientes de permeabilidad decidirán también las diferentes distancias. En la espuma, unas son próximas a otras al igual que otras espumas son lejanas, pero estas están conectadas por multitud de otras espumas mediante procesos, ya explicados en el capítulo de ubicuidad como la representación, la telepresencia o la teleacción, como modos de operar en proxicuidad. ${ }^{56}$

\section{Ubicuidad}

La ubicuidad es un concepto que se ha transferido. De ser una propiedad divina ${ }^{57}$ ha pasado a ser una propiedad de los humanos, de las cosas, objetos, etc. La acepción de ubicuidad de la RAE para los humanos como "Que todo lo quiere presenciar y vive en continuo movimiento." 58 También ha sido superada pues ya no son solo los humanos, junto con los objetos, etc. los que han adquirido las propiedades divinas de "estar presente a un mismo tiempo en todas partes"59 $\mathrm{o}$, por lo menos, en muchas partes.

\footnotetext{
${ }^{54}$ P. Sloterdijk. Esferas III, Op. Cit., pp.121-122.

${ }^{5}$ Santacana, Amadeu. "El acontecimiento como un mundo en yuxtaposición" Tesis doctoral. UPC, Barcelona, 2013, p.271.

${ }^{56}$ Ver en el punto de ubicuidad en el epígrafe 2.5.1

${ }^{57} \mathrm{RAE}$, ubicuidad.

${ }^{58}$ Ibid., Ubicuo.

${ }^{59} \mathrm{RAE}$, Ubicuidad divina.
} 


\section{Proxicuidad}

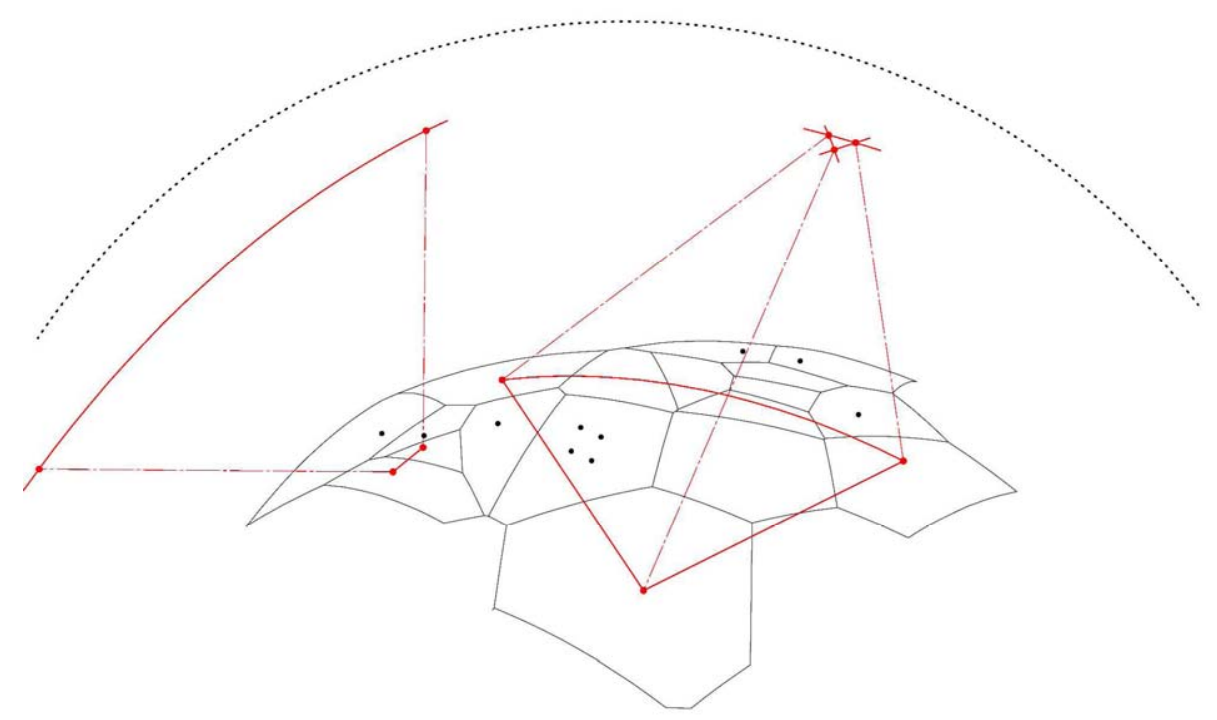

"Dos lógicas complementarias, la proximidad y la ubicuidad. Dos realidades, lo global y lo local, que obligan a mantener un equilibrio entre el contacto de cercanía y la demanda de dispersión. Las distancias, conformadas como relaciones de entidades heterogéneas, se modulan entre el determinismo territorial y la abstracción relacional, y requieren de modelos que permitan repensar los conceptos de cercanía y ubicuidad.” 


\section{Operatividades}

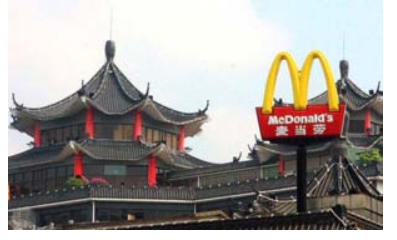

Mc Donalización ${ }^{60}$

\section{Ya hemos}

explicado como los Mc Donals son un ejemplo que va de la tele-presencia o la

representación de la presencia a distancia a la ubicuidad. El logotipo es el medio de inscripción de su representación y sus edificios la infraestructura que posibilita la ubicuidad de sus productos alimenticios. El McDonals siempre se encuentra cerca de casi cualquier lugar. Pero esta condición de proxicuidad no significa como hemos visto una condición de homogeneidad, cada cual se adapta a la localidad donde se inserta. Localidad y globalidad se unen en un producto que según Ritzer, tiene la característica de disponerse como un "producto garantizado": 1. Eficacia, relación directa entre apetito y satisfacción. 2. Rentabilidad. Un producto aparentemente bueno y más barato. 3 . Previsibilidad. Una imagen identificable, reconocida y familiar (próxima) y 4 . Control, orden repetición y su convincente asepticismo. Su ubicuidad y cercanía remite según Ritzer a "patrones comerciales [que son] lugares comunes de vocación universal, como la nostalgia de lo rural, la caricatura del bienestar, la evocación de lo atemporal. Lo proxícuo, en este caso, funciona como conexión a lo arraigado, estable y permanente en el imaginario colectivo." ${ }^{61}$

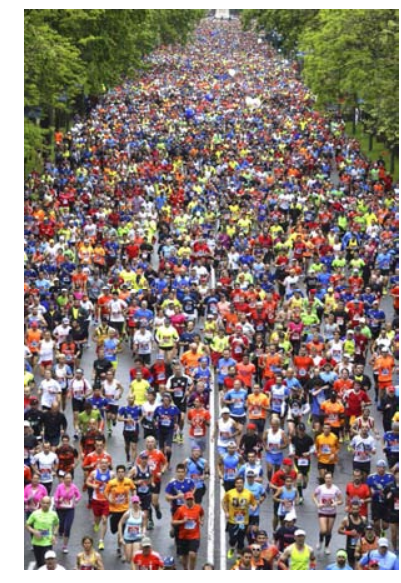

\section{Acontecimientos proxicuos.}

Desde que en 1974 la primera maratón multinacional de Berlín sucediera, Nueva York, Londres y actualmente un número cada vez más creciente de ciudades hacen del maratón un fenómeno urbano hace de él un acontecimiento proxícuo. La ubicuidad del acontecimiento en muchas de las ciudades y territorios globales acercan la posibilidad de que muchos ciudadanos puedan experimentar una carrera cerca de sus residencias a la vez que muchos se desplazan para realizarlo en otras. $^{62}$

\footnotetext{
${ }^{60}$ Termino descrito por Ritzer, George en La McDonalización de la sociedad. Barcelona, Ariel, 1996.

${ }^{61}$ Ibid. and small. Notes on urban studies ANT and geographical scale" en Farías, Ignacio. Urban Assemblages. NY, Routledge, 2009.
}

${ }^{62}$ El Maratón desde los ensamblajes urbanos ver Latham, Alan \& McCormack, Derek P. "Globalizations big

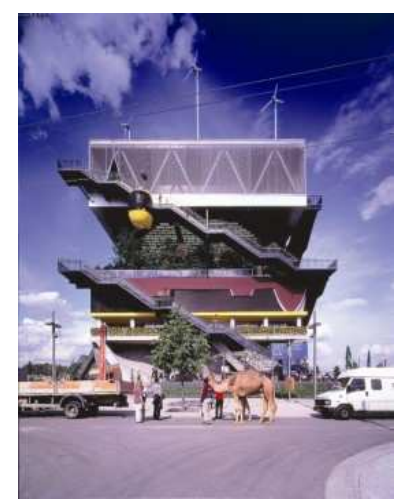

\section{Pabellón Holandés en expo} Hannover. MVRDV-2000. Podemos definir el pabellón como una apilación de paisajes holandeses. Lo lejano (los diferentes paisajes) se hacen cercanos al estar apilados y a un golpe de ascensor. Por otro lado la plantación de "cascaras de mejillón" en la cubierta hacen próxima la distancia a la que se encuentra el mar que se ve desde la cubierta. Según Sloterdijk, de él se deduce que "las naturalezas se encontrarán menos fuera que en los grandes invernaderos" los biotopos diversos estarán cerca y en un interior.

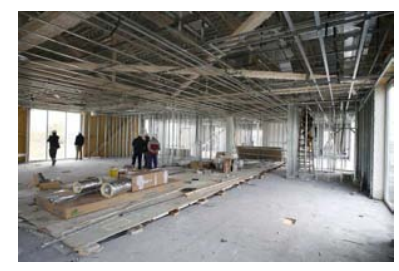

Tecnologías urbanas proxicuas. Hemos definido las tecnologías urbanas ubicuas como las mediaciones constructivas que generan el espacio basura y definen la ciudad ${ }^{63}$ genérica. Estas tecnologías que se propagan en redes de conocimiento, permiten construir con rapidez a la vez que están siempre disponibles o son cercanas a cualquier proceso constructivo occidental. 


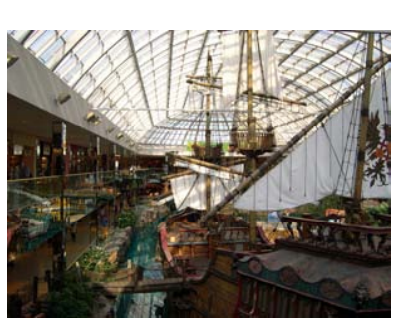

Proxicuidad temporal. La reproducción de los barcos de Colón, los submarinos auténticos, las rocas de cartón Piedra. Todas ellas hacen del "Palacio de cristal" del centro comercial West Edmonton Mall WEM en Alberta, Canadá. Un dispositivo donde las diferentes "esferas" temporales y geográficas lejanas se hacen cercanas. "El mundo en la palma de mi mano"64 decía su propietario.

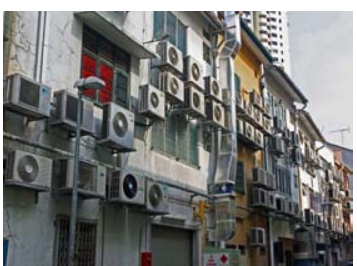

Aire Acondicionado. Hay imágenes que podrían y de hecho lo están en todas partes que se hacen muy cercanas y próximas. El aire

acondici0nado es una máquina que no solo hace ubicuo el aparato y la acumulación de ellos en configuraciones urbanas sino también el propio clima o micro-atmósfera que generan. Esta situación alimenta una proxicuidad atmosférica que sucede en nuestras ciudades y casas hoy en día.

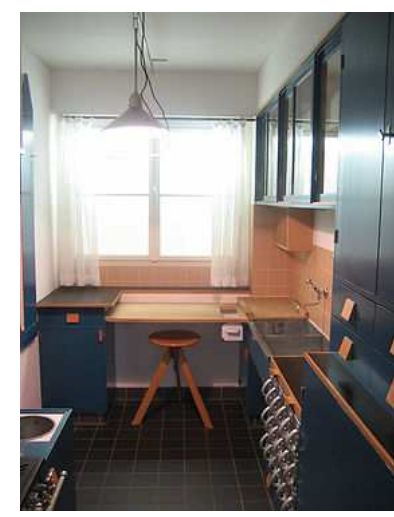

La cocina de Frankfurt

Margarete Schütte-Lihotzky. 1926 fue un prototipo de cocina diseñada tras la primera guerra mundial para permitir el trabajo eficiente y para ser construida a bajo costo. Más allá de las consideraciones de género implícita en ella, la cocina paso a ser un ejemplo de infraestructura doméstica proxicua. Al igual que hoy es Ikea el motor de la ubicuidad doméstica, la cocina de Frankfurt estandarizó hábitos, tecnologías y objetos haciendo de estos un proceso de ubicuidad y proximidad.

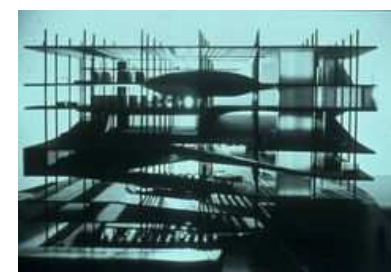

\section{Bibliotecas Jussieu.}

OMA.1992 Ublicuidad. De

Ubicuidad y Oblicuo. [La

liberación del] suelo de su implacable condición

horizontal multiplicando sus condiciones de plano activo y trastocando hasta la misma lectura y representación del espacio con la abolición del concepto de la planta y la evidencia ión de lo superfluo de las fachadas como elementos conformadores de la

verticalidad. La ubicuidad de estas soluciones se prodiga constituyendo un orden urbano oblicuo que, en principio, debería leerse como la superación del sistema vertical, verticalidad del muro, de frontera, de apilamiento, de jerarquía, de falta de igualitarismo.

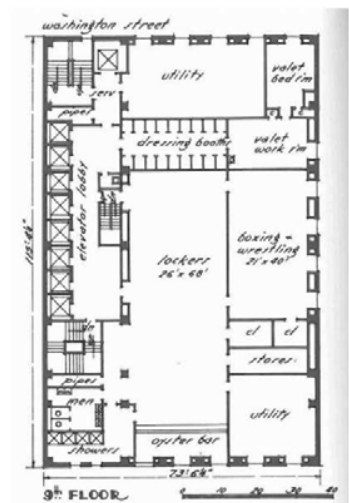

Dowtown Athlectic Club. Manhattan. Starrett \& van Vleck.1926 El DAC y su batería de 13 ascensores harán posible una lejanía espaciotemporal en proximidad, es decir, una proxicuidad. Cada planta del edificio se compone como un programa que hace que los cuerpos masculinos de la ciudad no tengan que salir afuera en busca de naturalezas u otras experiencias. Apilación es la herramienta que como en el pabellón de Holanda de MVRDV permitirá tener relaciones próximas e inmediatas con lo antes lejano. El ascensor, y más tarde, las rampas mecánicas, más tarde la cibernética o los fenómenos informacionales, serán infraestructuras arquitectónicas de la aceleración donde la condición de proxicuidad se hará cada vez más inmediata.
${ }^{64}$ Crawford, Margaret. "The world in a shopping mall." en Variations on a Theme Park: The New American City and the End of Public Space, Michael Sorkin (Ed.). New York, Hill and Wang, 1992, pp.3-30. 


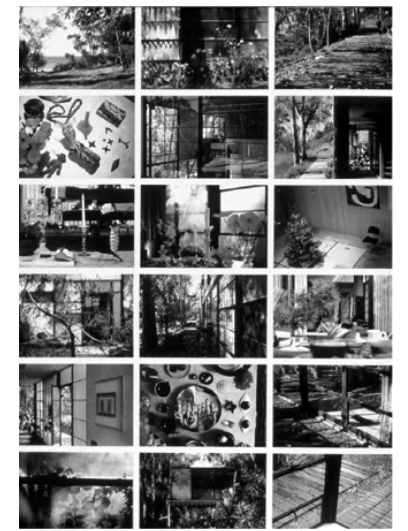

Domesticidad proxicua. Los

Eames como pioneros de una

domesticidad ubicua y cercana.

En su caso una domesticidad ampliada a las revistas, el cine, los libros y la arquitectura. Una domesticidad ampliada a todas partes que hace cercana su práctica arquitectónica y doméstica simultáneamente. Este hecho convertía su trabajo en la constante disposición de lo doméstico y al revés. Su casa, era un escaparate y lo doméstico el airel con el que esparcir sus diseños junto con las revistas, los videos, la televisión, etc. "Los Eames fueron pioneros en esa forma [multipantalla] de ver y hacer cercano sus diseños a un espectador televisivo "a un ojo que mira simultáneamente una multiplicidad de pantallas." ${ }^{65}$

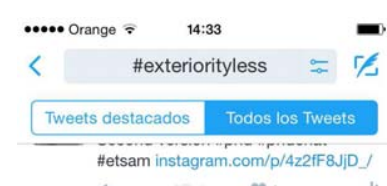

$$
\text { ↔ }
$$

Arantzazu Luzarraga otr... $\$ \frac{02 / 06 / 15}{}$ Stay cool! @mgilfour about air conditioning assemblages \#exteriorityless \#agentsurbanity
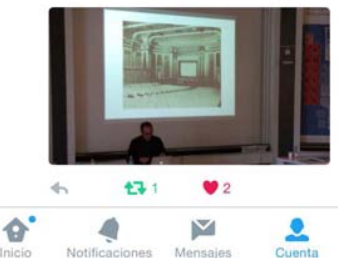

\section{Tecnologías ubicuas y}

próximas. No por resultar más obvias y literales las tecnologías de comunicación e interacción móviles son menos interesantes $\mathrm{y}$ median en nuestras acciones individuales y colectivas. $\mathrm{La}$ presencia de este hastag \#exteriorityless (sin exterioridad) hacen de esta tesis algo cercano y ubicuo en diferentes redes sociales como una condición proxicua de estas a la vez que estas interacciones se expanden y publicitan en otras redes. Otros fenómenos urbanos como las flashmobs que ya hemos explicado, son espacializaciones masivas de estas interacciones entre tecnología, diversión, y espacio urbano. . Imagen: Perfil de tuiter del autor de esta Tesis doctoral.

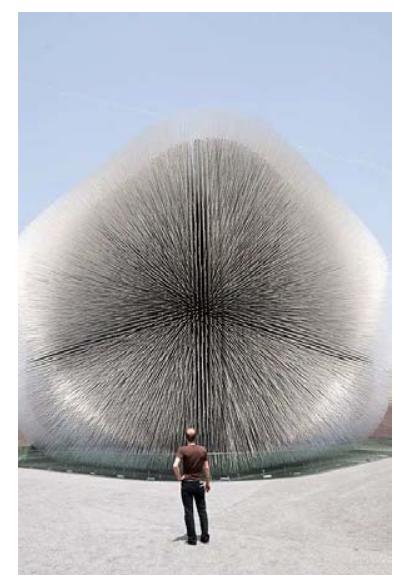

Catedral de Semillas. ExpoShanghái. Thomas

Heatherwick-2010. Si las

semillas es un bien preciado y cada vez más escaso. El pabellón inglés en Shanghái propone una relación directa con ellas. Las semillas componen junto con las varillas de fibra óptica la relación de proxicuidad entre las semillas y el espectador. El pabellón acerca y concentra diferentes semillas del plantea y las exhibe al exterior. Lo lejano se ha hecho cercano y con la imagen del pabellón en todos los medios, algo ubicuo.

Un "invernadero" que al contrario que el del siglo XIX de Hyde Park, no inmuniza a las plantas tropicales del exterior sino que se desplegado precisamente al exterior apareciendo como una especia de invernadero invertido.

${ }^{65}$ Colomina. Beatriz. Reflexiones sobre la casa Eames. RA9. Revista de Arquitectura. Madrid, Junio, 2007, p.16. 


\subsection{Extimidad}

Los límites tradicionales del interior han estado asociados a la casa y al cuerpo. Ambas categorías han funcionado como entidades asociadas. La casa guarda los cuerpos. La casa se guarda así misma. La casa como lugar de protección, calor y seguridad, garantizaba la permanencia del cuerpo como entidad independiente. La intimidad era un concepto que, en la modernidad, estaba confrontado con lo público. ${ }^{66}$ Parecía que uno podía decidir su intimidad, sus espacios, sus tiempos y las personas con las que la compartía. Pero lo íntimo y lo público no son categorías opuestas. Tampoco categorías independientes y enfrentadas. Sino procesos que se construyen simultáneamente.

\section{Aproximaciones / Descripciones}

La RAE no define el término "extimidad" ${ }^{7}$. Es, por lo tanto, un neologismo. Pero la RAE si define lo íntimo como lo "Amistad íntima" 68 o bien como "Zona espiritual íntima y reservada de una persona o de un grupo, especialmente de una familia." ${ }^{69}$

El origen del término (en francés extimité, en inglés, extimacy) se lo debemos a Jacques Lacan que define extimidad: "es lo más íntimo justamente es lo que estoy constreñido a no poder reconocer más que fuera" ${ }^{70}$ o bien lo éxtimo es lo que está más próximo, lo más interior, sin dejar de ser exterior. Su disposición paradójica abre un mundo de interpretaciones y posibles descripciones que queremos explorar. Expresa la manera en que el psicoanálisis problematiza las aparentes oposiciones entre lo interno y lo externo, entre el contenedor y el contenido, etc. Por ejemplo, lo real está tanto "dentro" como "fuera". Para Lacan, el inconsciente no es un sistema psíquico puramente interior, sino una estructura intersubjetiva "el inconsciente está fuera" núcleo"72

\section{Lo íntimo se encuentra en lo exterior}

Es preciso establecer una estructura de lo éxtimo que intente demostrar que es pensable, construible como lo más próximo, lo más interior, sin dejar de ser exterior. Esto llevó a Lacan, en la época en que hacía del inconsciente el discurso del Otro, a plantear el Otro como éxtimo. "Éxtimo es, en primer lugar, el Otro del

\footnotetext{
${ }^{66}$ J.L. Pardo. Políticas de la Intimidad. Op. Cit.,

${ }^{67}$ Apareció por primera vez en el seminario de J. Lacan La ética del psicoanálisis (1958). Es un neologismo cuya brillantez corre pareja con la dificultad para definirlo.

${ }^{68} \mathrm{RAE}$, intimidad.

${ }^{69}$ ibid, intimidad.

${ }^{70}$ Op. Cit., J. Lacan.

${ }^{71}$ Ibid.

${ }^{72}$ Cfr. Pavón-Cuéllar, D. 'Extimacy’, in Thomas Teo (Ed.), Encyclopedia of Critical

Psychology. New York, Springer, 2014.
} 
significante, éxtimo al sujeto, aunque más no sea porque la lengua mía, en la que expreso mi intimidad, es la del Otro. Pero también hay otro éxtimo que es el objeto." ${ }^{\prime 3}$

Jacques-Alain Miller, discípulo y sobrino de Lacan, expresa como el concepto de extimidad ya se va encontrando en el lenguaje cuasi cotidiano, de los mass media, como aquello que, siendo muy íntimo y familiar, se convierte en algo radicalmente extraño. Pareciera encajar en tanto cualidad del sujeto de nuestro tiempo, un sujeto siempre exiliado de sí mismo, que sólo parece encontrar su ser más íntimo en lo más lejano y deslocalizado.

Si lo definiéramos como el opuesto a intimidad, perderíamos muchas posibilidades. Aún así, en el 200, el psiquiatra Serge Tisseron, le da un nuevo significado al concepto. La extimidad es lo contrario a la intimidad en el sentido de que si la intimidad se construye desde la exposición de los aspectos íntimos de la persona (cuerpo, pensamientos, etc.) "el individuo no se muestra para compartir algo con los demás, sino que usa a los otros como un espejo para reafirmarse. ${ }^{" 74} \mathrm{La}$ intimidad personal se construye entonces desde otros colectivos.

\section{El "yo íntimo es público"}

En la extimidad, las fronteras se confunden entre lo real y lo ficcional. "El flujo es doble: una esfera contamina a la otra, y la nitidez de ambas definiciones queda comprometida. Por los mismos motivos se ha vuelto habitual recurrir a los imaginarios ficcionales para tejer las narraciones de la vida cotidiana, lo cual genera una colección de relatos que confluyen en la primera persona del singular "yo"." 75 El "yo éxtimo" transforma las vidas, no tan privadas ya, en realidades ficcionales con la mediación tecnológica.

La extimidad como fenómeno cotidiano se muestra en la modificación de la intimidad cuando esta va a ser publicitada con recursos mediáticos. Bien sea por la acepción de S. Tisseron de una construcción desde lo otro, o por la de P. Sibilia como una modificación de la misma porque esta va a ser publicitada mediáticamente.

\footnotetext{
${ }^{73} \mathrm{http}: / /$ www.pagina12.com.ar/diario/psicologia/subnotas/143452-46125-2010-04-08.html

${ }^{74} \mathrm{http}: / /$ miextimidad.blogspot.com.es/p/concepto_199.html

${ }^{75}$ Sibilia, Paula. La intimidad como espectáculo. Buenos Aires, Fondo de Cultura Económica Argentina, 2008, p.223.
} 


\section{Autoemparejamientos éxtimos}

En el contexto de redes y espumas que estamos desarrollando, la intimidad siempre se dará también en covecindad y coaislamiento, luego no será algo solamente personal, ni individual, ni privado. La intimidad, por lo tanto, no será aquella que sucedía sin ojos ni cámaras, a puerta cerrada, en un interior; sino que esta misma se modifica frente a la "ventana abierta permanentemente" de la multipantalla.

Los autoemparejamientos entre humanos y, a su vez, entre humanos y tecnologías que hemos explicado en el capítulo 2, nos hacen ver que las entidades que se unen en díadas psicológicas de individuos o en relaciones híbridas humano-tecnológicas aparecen bajo este punto de vista como intimidades éxtimas. Por otro lado, la intimidad en la espuma, es limitada y se conforma por esa imposibilidad de la isla absoluta, en favor de una permeabilidad ocasional, sea esta sonora, física o sensible, de la pared-membrana que une las espumas y a la vez las separa. La condición de aislamiento se modifica en la propia conexión de las espumas pues estas operan en aislamientos conectados. La covecindad asimétrica ${ }^{76}$ de Sloterdijk, entre invernaderos de intimidad y mundos propios, es una cohabitación en condiciones de extimidad.

\section{Intimidad en conectividad}

Si la red, no se conforma por ninguna condición espacial sino asociativa y conectiva de heterogéneas entidades, la intimidad es atravesada por múltiples flujos, asociaciones y mediaciones que activan la condición éxtima de la misma. Rastrear bajo que entidades, agencias o ensamblajes, se produce la intimidad, es visibilizar las condiciones amplificadas del "colectivo"77 para describir su operatividad en procesos de extimidad. Por ejemplo, la agencia compartida entre humanos y tecnologías como los teléfonos móviles con su actual gama de aplicaciones, "contribuyen a dar forma a la comunicación, la generación y el mantenimiento de las expectativas y obligaciones, así como ayudar a obtener experiencias express y gestionar un complejo conjunto de sentimientos y emociones modulando la intimidad fuera de la esfera privada." ${ }^{78}$ La capacidad de las inscripciones digitales facilitan estas formas de intimidad pública. Y como hemos desarrollado en el capítulo primero cómo lo íntimo y la ciudad se construyen simultáneamente. Esto sucede también a nivel material, espacial y se dan manifestaciones de este hecho constantemente en la ciudad y también en la arquitectura.

\footnotetext{
${ }^{76}$ P. Sloterdijk, Esferas III. Op. Cit., p.53.

${ }^{77}$ En términos de B. Latour. "La sociedad es el colectivo ampliado"

${ }^{78}$ Lasén, Amparo. "Mobile sentimental education: Attachment, recognition and modulations of intimacy." Gerard Goggin and Larissa Hjorth (Eds.). The Routledge Companion to Mobile Media. NY, Routledge, 2014, p.397.
} 


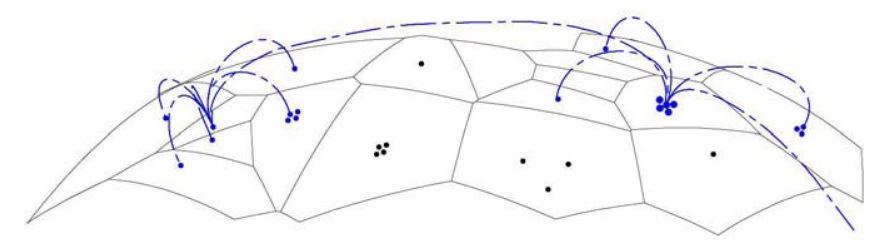

"El concepto transforma su origen lacaniano en dos vías simétricas. Una, como la modificación de la intimidad cuando se sabe de su publicidad expandida. Es decir, cómo transformamos nuestros lugares, tiempos, objetos y personas íntimas cuando actuamos movidos por la necesidad de dar publicidad a esos momentos. Otra, como la construcción de la intimidad desde la reafirmación en base a otros colectivos. La condición de extimidad es aplicable a personas, objetos, tiempos y espacios." 


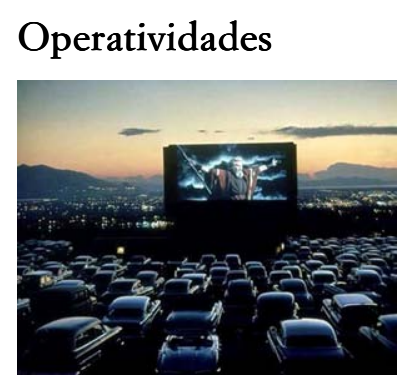

Los cinema drive-in son espacios donde las relaciones cercanas (íntimas) y lejanas (públicas) se hacen simultáneas. Proxicuidad y extimidad convergen como dos conceptos que conforman este "espacializar" urbano. ${ }^{79}$

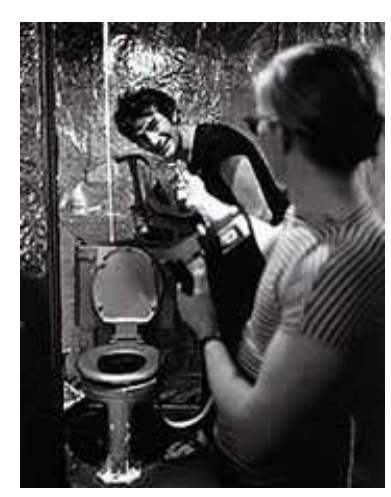

Andy Warhol y la factory. El autoemparejamiento tecnológico de Warhol con su grabadora o con el teléfono muestran la condición de extimidad híbrido humanotecnológica sobre cómo se modula la intimidad al exterior. En su máxima acepción "La Factory" era un espacio de extimidad. "Era casi como si la Factory se hubiese convertido en una gran cámara estenopeica: entrabas, te exponías y te revelabas." ${ }^{80} \mathrm{~A}$. Warhol ya predijo, que todos tendríamos 15 minutos de fama. Lo que no dijo es que esa fama estaría ligada a la exposición pública de nuestra intimidad.

${ }^{79}$ Podemos observar esto en la película de George Lucas American graffiti. 1973 ${ }^{80}$ Catalogo "De la Factory al mundo: Fotografía y la comunidad de Warhol "La fabrica. Madrid. Comisariada por Catherine Zuromskis. 2012

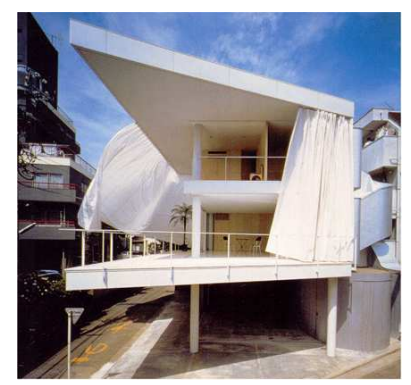

Espacialidades éxtimas. $\mathrm{La}$ Casa Cortina de Sigueru Ban en Tokio 1995 es un ejemplo de cómo el pensamiento sobre la condición de extimidad puede desarrollar una vivienda cuando ya los muros se han diluido y el vidrio ha desaparecido. La casa no solo expone a sus habitantes, sino que les permite explorar nuevas posibilidades domésticas en el uso de su espacio interior, la terraza, etc. ${ }^{81}$

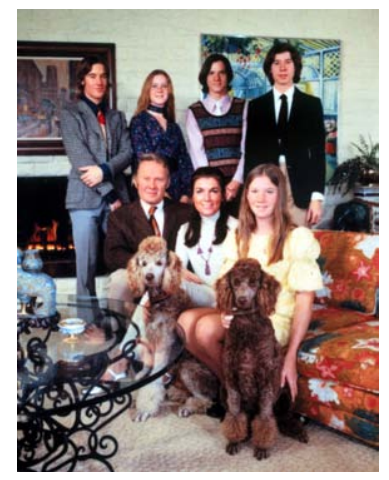

An American Family . Es considerado el primer "reality" de la televisión. Los 15 minutos de fama de Warhol se convirtieron en 300 horas de rodaje mayo a diciembre de 1971 de la vida íntima y familiar de los Louds. En el PBS (Public Broadcasting Service) de EEUU la intimidad de la familia se exponía. Esta serie es el prototipo de los programas de Gran hermano que se dan ubicuamente en otras naciones. Lo familiar como comunidad ha dado paso a los procesos de inmunidad y aislamiento. Y esto puede verse en la propio plató de grabación doméstico que, como una espuma, en la condición que se da entre los participantescompetidores de los realitys.

${ }^{81}$ Riley, Terence. The UnPrivate House. Catálogo NY, MOMA, 2002.

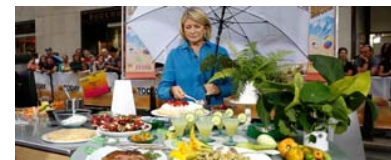

Marta Stewart. Cómo ya hemos explicado, la construcción de lo íntimodoméstico, del hogar se produce hoy también en condiciones de extimidad asociadas a la proxicuidad. Desde los diferentes platós de Marta Stewart se compone la vida interior de los

espectadores que la siguen. Koolhaas y Colomina la entrevistaron para entender la capacidad de la TV, revistas y redes como mediaciones en la construcción de lo doméstico. ${ }^{82}$

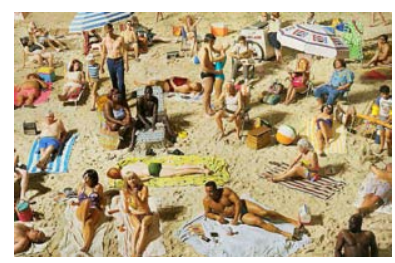

Playas. Las playas occidentales son uno de los espacios urbanos por excelencia. Lugares de confluencia de espumas y redes, que se instauran en un híbrido natural, infraestructural, que despliega de forma instantánea lo doméstico y lo íntimo haciendo de esta manera aparecer lo público simultáneamente. Las playas como los lugares donde los cuerpos y prácticas se exhiben o como los lugares donde el sexo, se comparte con los voyeurs en nocturnidad.

Todo un despliegue arquitectónico que compone ciudades instantáneas con sus multiplicidades y sus conflictos.
${ }^{82}$ Koolhaas, Rem \& Colomina, Beatriz. Content. Op. Cit., 


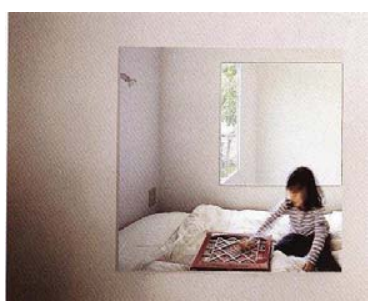

Lo éxtimo en el interior de la Casa de Ciruelos. K.Sejima.

2003 La vivienda en un campo de ciruelos se estructura espacial y materialmente- con planchas de acero macizo de 2 centímetros de espesor que constituyen delimitación espacial y cerramiento en vertical y horizontal. En la casa conviven una pareja con dos niños y la madre de uno de ellos en una organización espacial matricial sin puertas ni aislamiento. El aislamiento de las burbujas de Sloterdijk, se vuelve totalmente permeable a la exposición interior entre los habitantes de la vivienda. La extimidad también se produce entre las paredes finas de la casa.

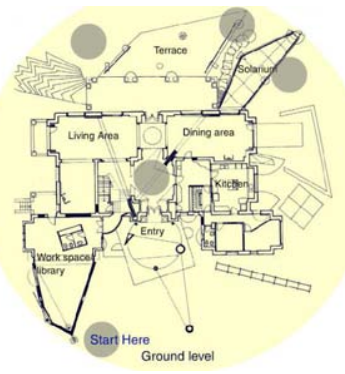

Trabajo en extimidad. La planta de la Ghirardo-Cohen House de Clorindo testa en Buenos AIres 1994 nos habla de la expresión del trabajo masculino y público desde la intimidad y lo doméstico. Los programas relacionados con el placer y el trabajo se

"externalizan" de la casa para hacerse públicos y componer la imagen de la casa.

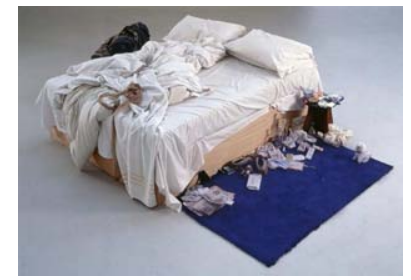

Mi cama. 1998. Tate Gallery

Si como decía Sloterdijk, la cama es el centro del mundo, para la artista Tracey Emin. Un autorretrato a través de los objetos que conviven en su intimidad y si proceso del día a día. La cama como objeto íntimo extremo, es la exposición y viceversa. $\mathrm{La}$ extimidad no es una cuestión de humanos solamente sino de la agencia compartida de estos con los objetos que los conforman.

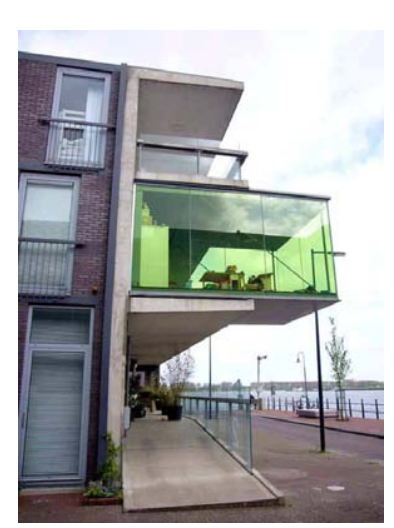

Domesticidades éxtimas.

Borneo Houses. Amsterdam. MVRDV. 1999 "Si escucho la conversación privada de una persona con su novia mientras camino por un paso de cebra y cuando llego a casa veo la intimidad de la protagonista del reality en la tv. ¿Por qué esto no puede suceder en la arquitectura?" Dice Winy Maas. Las condiciones de publicidad

y privacidad me resultan irrelevantes hoy en día." 83

${ }^{83}$ Op. Cit. Riley. Maas, Winy. En el catálogo de Un-private.

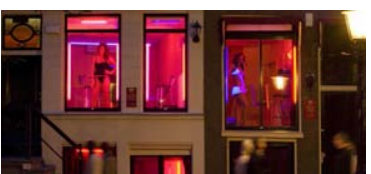

La ventana discreta. El barrio rojo de Ámsterdam se compone de fachadas de cuerpos. De ventanas discretas, porque se componen de partes separadas, con sus especificidades, circunstancias e intensidades. Las casas del barrio rojo son domesticidades al desnudo. Lo contrario de las casas pario miesianas. Sus muros son transparentes y la intimidad es solo aparente. El despliegue de cuerpos semidesnudos, se refiere tan solo a la intimidad del cuerpo. Espumas y redes deben ser construidas para explicitar la extimidad de este lugar.

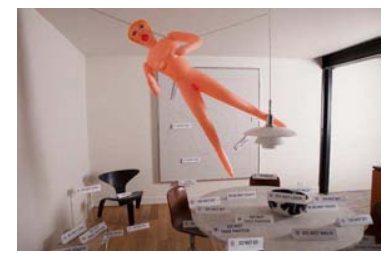

Mi casa es tu museo. Torres Nadal. 2013-14. Las políticas de la intimidad se encuentran en este proyecto en la capacidad de como decía Warhol o Gramsci que "cualquier persona puede ser un intelectual o cualquier persona puede ser un artista" ${ }^{84}$ luego, el proyecto afirma que toda casa puede ser un museo La exploración de lo ordinario en un entorno

doméstico se explora en su capacidad de modificar las concepciones públicas de lo que es un museo o lo que es una casa. La extimidad aparece aquí como motor del proyecto performativo de Torres Nadal.
${ }^{84}$ De la memoria del proyecto de J.M. Torres Nadal. 


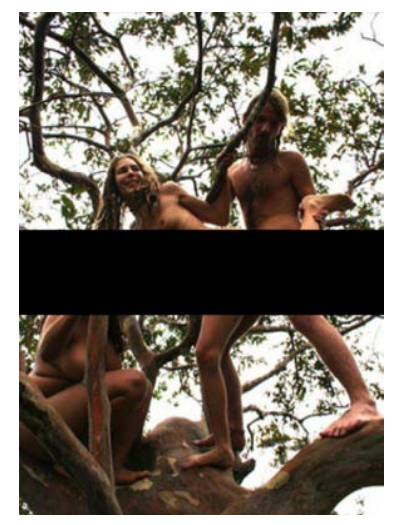

Prácticas éxtimas. A parte de las ya mencionadas se dan en el mundo contemporáneo multitud de prácticas que en base a una "intimidad en grupo" desarrollan otras relaciones que llegan hasta la protección de los bosques como el "Fuck for forest" una ONG que consigue fondos para la protección de los bosques con sexo colectivo en los mismos. También el dogging o el cruising extreman la relación íntima y doméstica del cuerpo creando lugares en el espacio libre donde practicar sexo entre comunidades abiertas. La repercusión de los masajes orientales en determinadas plazas de Madrid, nos ofrece imágenes de relaciones cuerpo a cuerpo en el espacio público de la ciudad, creando zonas temporalmente domésticas en el entorno común del espacio público. $^{85}$

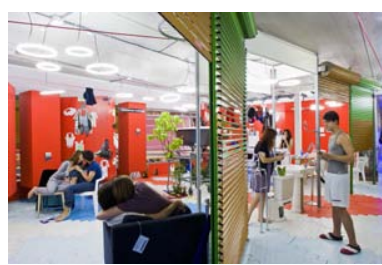

La intimidad en casas compartidas. Si hoy un número de ciudadanos viven en casas compartidas o en agregados de unidades no familiares, en estas la construcción de la intimidad no es algo cerrado y personal. El proyecto de la "Rolling House" de A. Jaque "La casa no es el refugio de intimidad pacificado ante una urbanidad en disputa" $" 86$

Tampoco la distinción del salón como lugar social o la habitación como lugar íntimo. Bajo una condición de extimidad, el proyecto propone: Asignar a cada participante una cápsula de intimidad compuesta por una cama o un biombo desplegable.
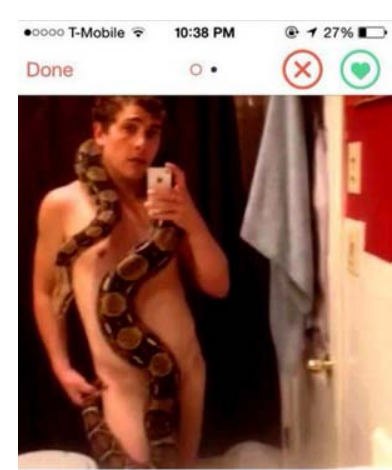

Philip, 22

$\cdots$

Tinder y Grindr. Son dos plataformas para gestionar las citas íntimas que muchas veces se dan en el espacio público. La casa es un Photocall desde el que autoretratarse para exhibir el cuerpo. La construcción de la esfera pública como el ejemplo ya citado en la tesis, se da desde la esfera íntima. La ciudad es entonces el lugar que hace explícita la

extimidad.

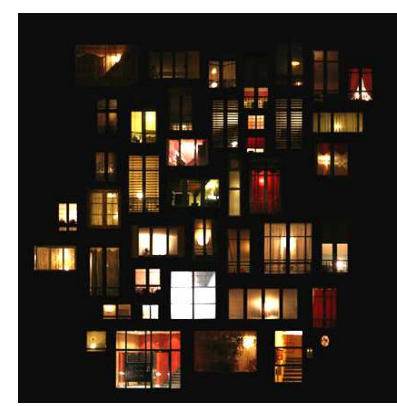

$\mathrm{La}$ intimidad es una espuma. Los trabajos de la artista francesa Ane Laure Maison, explicitan cómo bajo la luz de la intimidad, está en cada celda, en cada burbuja, conforma una espuma determinada. La intimidad en una situación de co-aislamiento podemos verla como un proceso de extimidad. No solo por la agregación de ventanas discretas en la ciudad sino, por las relaciones y conexiones que entre ellas se dan constantemente. Por supuesto que esta condición se da en espacios climáticamente controlados.
${ }^{85}$ Para saber más. Gil-Fournier, Mauro. "Procesos de domesticación urbana" Artículo en la plataforma La ciudad viva. descargable en http://www.laciudadviva.org/bl ogs $/$ ?author $=67$
${ }^{86}$ Jaque, Andrés. Dulces arenas cotidianas. Sevilla, Lugadero, 2013. 


\subsection{Contingencia}

La construcción de las categorías de la exterioridad se ha formado a partir del conocimiento de lo necesario. Los espacios públicos se hacen partiendo de una necesidad y tratando de dar una respuesta concreta a esa necesidad. El programa, como afirmación del valor de la función, se quiebra constantemente por su valor de uso. La función, como entidad determinista ligada a la necesidad, muestra sus debilidades en el día a día. La contingencia detona la apertura de nuevas posibilidades abiertas, variables, flexibles e interpretativas a la red de acontecimientos humanos y no humanos. La lógica contingente tendría que ver con la lógica de la informalidad. ${ }^{87}$ Es contingente porque depende de las condiciones iniciales y específicas de cada espacio-tiempo.

\section{Aproximaciones / descripciones}

Contingencia es para la RAE es "la posibilidad de que algo suceda o no suceda." 88 Pero esta definición se nos queda corta en la ambigüedad que maneja.

\section{Espumas contingentes}

Podemos entender la aproximación de Sloterdijk y las espumas sobre la contingencia de la idea de Luhmann, como "la acepción semántica convencional en inglés de contingencia (contingent) que implica una "dependencia de" (contingent on)." ${ }^{89}$ La espuma es, entonces, co-dependiente de lo que haga otra espuma y viceversa. En segundo lugar, como "la exclusión de toda necesidad e imposibilidad." $"{ }^{90}$ Los sistemas de covecindad son contingentes también en la noción de emergencia. Estos suceden por relación con los otros en formas de no causalidad directa. Las burbujas aparecen y desaparecen en su instantaneidad por estados de contingencia, sin poderlo valorar en términos de necesitad ni de posibilidad.

\section{La contingencia de los estudios científicos}

Los estudios de la ANT se definen por su constructivismo y su relativismo respecto a los hechos científicos. Puede decirse que los hacen depender "de la existencia de los hechos científicos de las condiciones sociales-contexto del laboratorio, legislación, intereses de los financiadores, etc., en los que se fabrica el conocimiento" 91 También se sostiene que todos los productos de la ciencia son contingentes y se defiende el lema de que "todo podría haber sido de otro

\footnotetext{
${ }^{87}$ Soriano, Federico. Sin Tesis. Op. Cit., p.49.

${ }^{88} \mathrm{RAE}$ definición de contingencia.

${ }^{89}$ Lewkow. Lionel. Niklas Luhmann como crítico de la fenomenología de la intencionalidad: intersubjetividad y doble contingencia.

${ }^{90}$ Ibidem

${ }^{91}$ García D., Paloma. Bruno Latour y los límites de la descripción en el estudio de la ciencia. Tesis

Doctoral. Departamento de Filosofía I. Universidad de Granada, 2007, p.15.
} 
modo" 92 Pero la solidez aparente de la ciencia, según B. Latour, "encubre la composición heterogénea y las relaciones contingentes gracias a las cuales se ha fabricado una realidad." 93

\section{$\underline{\text { Programa / antiprograma }}$}

Nos interesa especialmente la noción de anti-programa que plantea Latour, no como contingencia, sino como posibilidad de alteración de la necesidad de un programa dado. Si el programa, aún siendo contingente, establece una necesidad de acción controlada y, esta siempre es contingente, también es posible que no suceda. Quedaría reflejado en el ejemplo que pone Latour sobre los llaveros de madera grandes para las llaves de Hotel. El programa del dueño del hotel dice "Deja las llaves antes de salir" y los hospedados por su despiste u otra razón se llevan las llaves al salir. Pero a la introducción del llavero grande de madera los huéspedes responden con las posibilidades del antiprograma. De esta manera el programa se vuelve más predecible. "La mayoría de los clientes dejan ahora la llave" se ha producido una traducción del programa del dueño del hotel al llavero. El dueño del hotel ya no es el mismo, los clientes tampoco y la llave tampoco. El programa ha sido delegado a otras entidades no-humanas. El programa de acción se ha hibridado y el antiprograma (como posibilidades contingentes, se ha reducido).

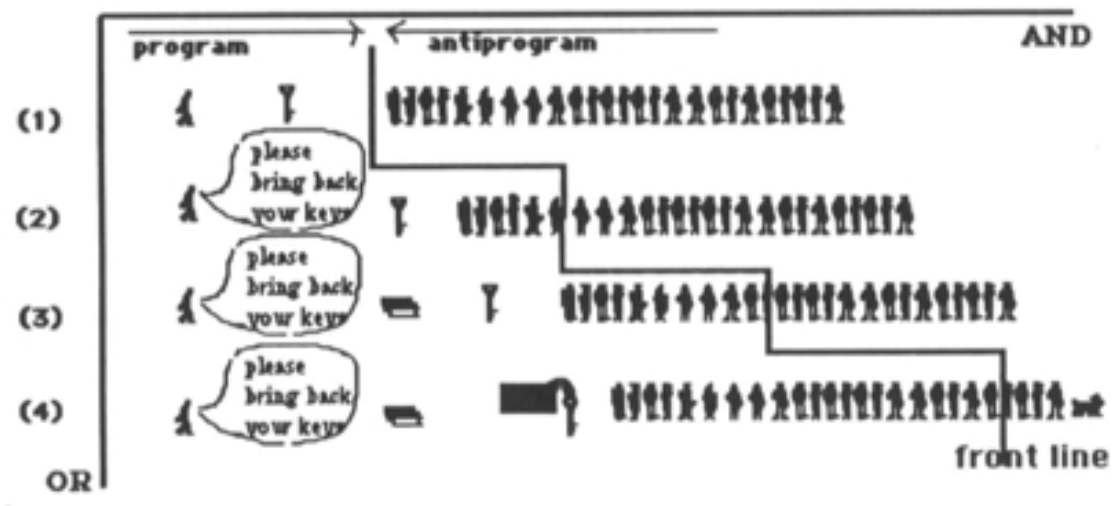

Fig. 21. Diagrama sobre las relaciones programa/antiprograma de Bruno Latour en "La tecnología es la sociedad hecha durable"p.107

En este ejemplo, vemos como la mediación técnica que se produce gracias a la introducción de un llavero grande y pesado (incómodo para los clientes del hotel) permite reducir el anti-programa al programa de acción que recordemos era (No salir con las llaves)

\footnotetext{
92 Ibidem.

${ }^{93}$ Citando a Latour "Contingente o necesario significan la misma cosa, es decir nada." Contingent ou nécessaire veleunt dire la même chose. c’est á dire rien. en Pasteur: guerre et paix des microbes suivi de irreductions. Paris, La Découverte, 2001, [1984], p.247.
} 
La cuestión de los hechos es cómo la contingencia es una propiedad de las sociedades (Luhmnan) o espumas (Sloterdijk), y de las redes (ANT). En arquitectura la contingencia siempre se produce pero no se incluye como herramienta en el diseño. La noción de programa, es determinista y no "aguanta" la producción de otros programas o necesidades emergentes. Por un lado la creación de redes ayuda a garantizar una interdependencia con la otredad y, por lo tanto, una disolución como exterioridad. Por el otro, las redes conforman programas de acción que van más allá del emisor-receptor o de lo posible o necesario.

\section{Transformación Incorporal}

La contingencia no siempre tiene unas transformaciones corpóreas o materiales. La construcción de la acción y el cambio de condición de las entidades también sucede, según lo denomina Deleuze, como una la transformación incorporal. "La transformación incorporal se reconoce en su instantaneidad, en su inmediatez, en la simultaneidad del enunciado que la expresa y del efecto que ella produce; por eso las consignas están estrictamente fechadas, hora, minutos y segundos, y son válidas a partir de ese momento." ${ }^{4}$

Para ser conscientes de este tipo de transformación instantánea contingente Deleuze pone el ejemplo del paso de pasajeros a rehenes y de cuerpo-avión a cuerpo-cárcel en un secuestro aéreo. Esta acción es una transformación corporal instantánea una mutación de la condición de los cuerpos debido a un speech-act o un mass-media act. Esta acción se produce en condiciones de instantaneidad y transforma las relaciones intro-exo, por ejemplo, en el caso citado del avión y sus pasajeros.

\section{Performatividad cibernética: participación y control.}

La contingencia no se tiene que entender como un factor de predicción, ni siquiera de anticipación, sino de posibilidad y participación. La modificación de la idea de programa a la idea de acontecimiento, fugaz, espontáneo, interdependiente, está enlazada con el desarrollo de las infraestructuras arquitectónicas de la aceleración, como ascensores, plataformas, cintas transformadoras, etc. La arquitectura del Fun Palace del arquitecto Cedric Price, Joan Littlewood, veterana del teatro radical inglés y Gordon Pask, experto en "máquinas para enseñar", aventura la contingencia performativa entre humanos y máquinas cibernéticas para explorar nuevas interacciones. La crítica al proyecto se realiza desde la relación entre

\footnotetext{
${ }^{94}$ Deleuze, Gilles \& Guattari Felix. Mil mesetas, capitalismo y esquizofrenia. Valencia, Pre-textos, 1980, p.86.
} 
contingencia, participación, predicción y control..$^{95}$ El Fun Palace se convirtió en un sistema que mediante las máquinas cibernéticas y el estudio de patrones de comportamiento, tenía capacidad de predecir una nueva relación entre la participación abierta y el control. La evaluación de la contingencia, por lo tanto, también puede ser una herramienta de control. ${ }^{96}$

\section{Eventualidad / emergencia}

No solo son la eventualidad o la emergencia posibles sinónimos de la contingencia sino que se hace necesario incluirlos. De la emergencia de otros actores-red, otras burbujas o espumas, saldrá enriquecido el proyecto arquitectónico. La emergencia, vista como una eventualidad no predicha, también forma parte de lo contingente. Así que, más allá de lo probable, de lo multi, del vale para todo, la contingencia también es específica, localizada y, por lo tanto, material de trabajo en cada situación para los arquitectos. Existe toda una arquitectura de lo contingente, de la emergencia que trata de paliar la falta de cobijo y confort mediante efímeros palacios de plástico para dar una repuesta de inmunidad y aislamiento, por ejemplo en los campos de refugiados. Ciudades instantáneas y contingentes que se transforman, en muchos casos, en permanentes Así podemos definir contingencia como

\footnotetext{
${ }^{95}$ Cfr. Lobsinger, Marye Luise. "Cybernetic Theory and the Architecture of Performance: Cedric Price's Fun Palace" en Anxious Modernisms. Experimentation in Postwar Architectural Culture. Montreal \& London, Canadian Center for Architecture \& MIT Press, 2000.

${ }^{96}$ Deleuze hablaba entonces del paso de las sociedades disciplinarias foucaltianas a las sociedades de control. Deleuze, Gilles. "Postscript on the Societies of Control" October. v.59, 1992, pp.3-7.
} 


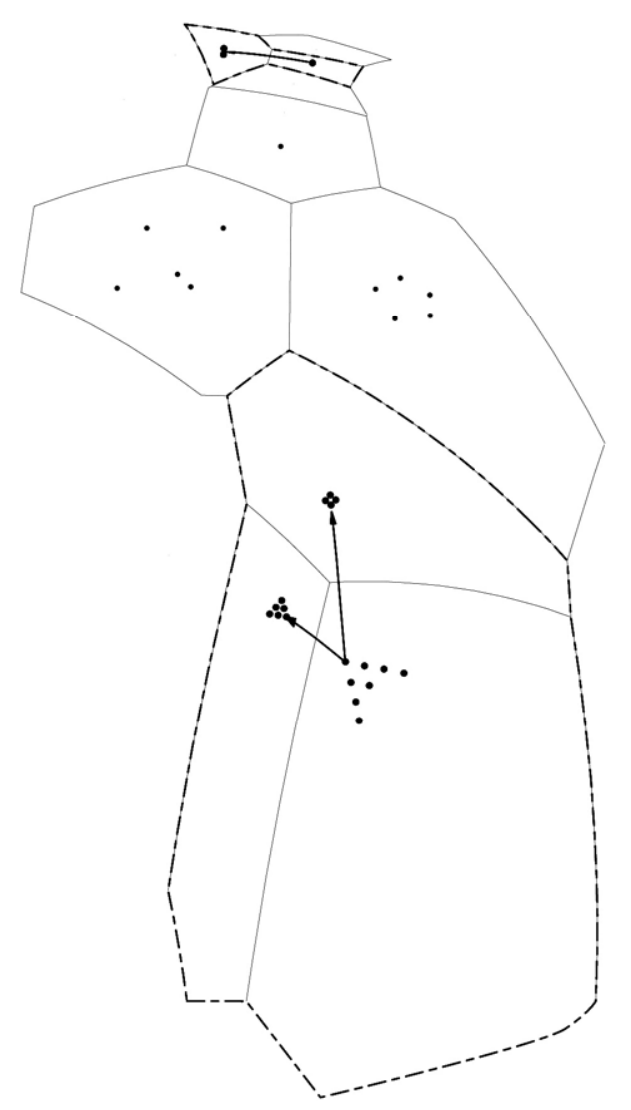

"El modo de ser de lo que no es necesario ni imposible, sino de lo que puede ser o no ser. La contingencia depende de la composición de entidades híbridas y diversas que tienen la capacidad de hacer transformaciones eventuales, incorpóreas o materiales. De este modo, ampliar las relaciones de lo contingente es también tarea del proyecto de arquitectura." 


\section{Operatividades}

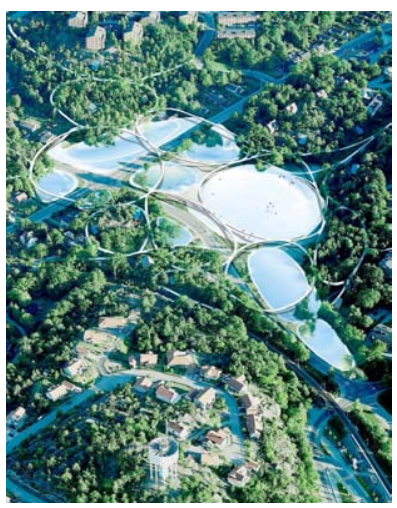

Performar la contingencia

Non solid Landscape. Dj

Architecture. 2011. El proyecto plantea una red de caminos

elevados que conforman

sombra o hacen de puente

durante los periodos

inundables del lugar. El

proyecto performa un rol en la

coexistencia de los procesos

naturales, los de urbanización

facilitando la conectividad y el

uso del valle como espacio

público. De esta manera lo

contingente entra a formar

parte del proyecto.

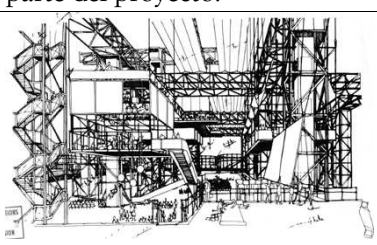

Cibercontingencia. ${ }^{97}$ Fun

Palace. Cedric Price\& Joan

Littlewood\& Gordon Pask. En

1963 formaron el "Comité para

el Teatro Cibernético del Fun

Palace. El proyecto propone

una infraestructura capaz de

agenciar todas las

subjetividades individuales y la

tecnología a su alcance para

generar un proyecto que

permita salirse de las rutinas,

ritmos y convencionalismos del

día a día para ejercer una

práctica de disfrute en libertad.

Frente a la ciudad sincrónica y

representada de la

modernidad, su proyecto para

el Fun Palace propone un

centro de entretenimiento

infinitamente flexible, en un

entorno $24 / 7$ junto con las

tecnologías cibernéticas, y la

construcción mediante

elementos industriales para

producir una máquina

adaptativa y resiliente a las

contingencia de sus actividades.

${ }^{97}$ Op.Cit., Lobsinger, M.Luise

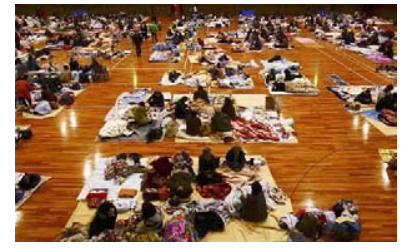

Emergencias. Los

Polideportivos podemos considerarlos como el tipo arquitectónico de la contingencia. En el caso de Japón, tras el tsumani y Fukushima, los polideportivos fueron en tan solo unos días dormitorios colectivos, hospitales improvisados o lugares de higiene químiconuclear. Su lógica permitió reconfigurar estos edificios en programas emergentes no predecibles pero operativos en mayor o menor grado. También en el caso explicado sobre chile, y como los oceanógrafos forman parte ahora de las redes de conocimiento que planean la ciudad.

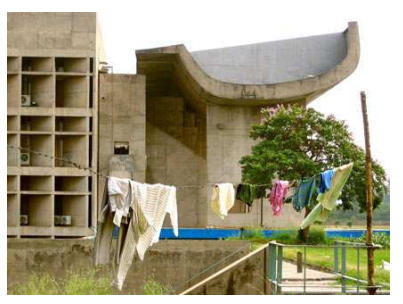

Cotidianidad. Chandigart. Le

Corbusier. 2010. La

cotidianidad actualiza la

realidad. La arquitectura moderna, que suprime los cuerpos, la piel, el día a día o lo contingente se actualiza constantemente, reflejando como lo necesario se hace presente también como contingente. La imagen más famosa de Chandigart hoy es esta que refleja la ausencia de lo que también es cotidiano como actual, frente a la imagen construida y fotografiada que aparecerá como virtual. ${ }^{98}$

\footnotetext{
${ }^{98}$ Fotografía tomada en 2010 por Vinayak Bharne.
}

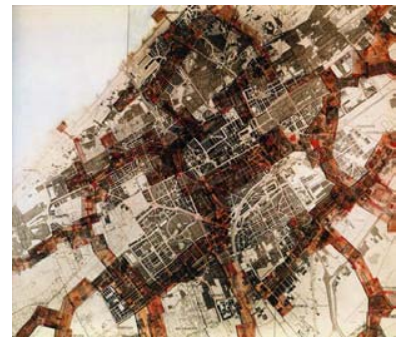

Ciudad contingente. New

Babylon. Constant

Es el humo ludens y el homo faber que proclama Constant una posibilidad para una ciudad permanentemente contingente. Si la sociedad "crea y recrea" y no es más una ciudad funcional. ¿Cabe extraer del manifiesto de Constant como una infraestructura para la contingencia?

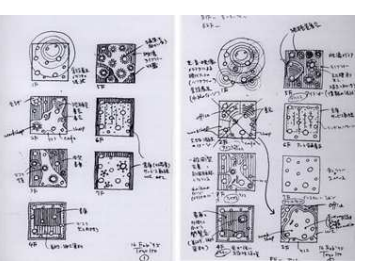

Mueble /Inmueble. Mediateca de Sendai. Toyo Ito. 2001. La capacidad de asumir la contingencia en el proceso de diseño, no limita las capacidades de interacción entre diferentes actores del proyecto. Sendai propone un proceso de participación ${ }^{99}$ abierto que configure la condición de variabilidad de sus salas. El mobiliario como orden variable de configuración permite que los usuarios reconfiguren la "planta" y la actividad de una manera contingente. La mediateca es un "espacializar" constante y diferente en cada ocasión.

${ }^{99}$ Ito, Toyo. Escritos. Op. Cit., "Informe sobre el proceso de construcción de la Mediateca de Sendai. 


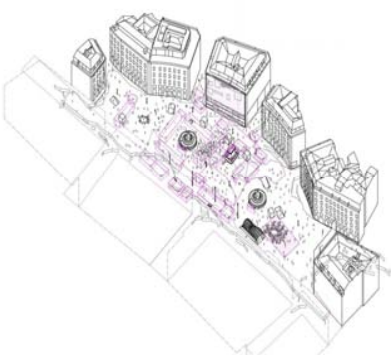

15M Madrid. 2011 El espacio público ya no es contingente. $\mathrm{Su}$ actividad diaria es el tránsito, el movimiento, la seducción,... El 15M reterritorializa el espacio público explicitando la posibilidad para la contingencia. Una" espuma democrática" aparece durante un mes en la puerta del sol de Madrid habilitando un nuevo espacio para la propuesta. Esta también es material y aparece como arquitecturas precarias que posibilitan la restitución de la contingencia como posibilidad en el espacio público. Tecnologías digitales, afectos como la indignación, comunidades de práctica y ciudadanos confluyen en una posibilidad no dada hasta el momento en la puerta del sol. 100

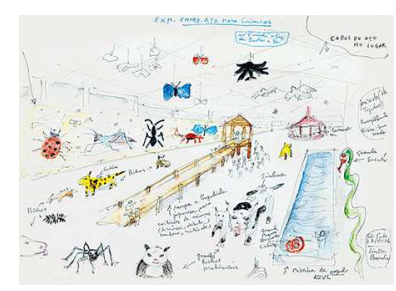

Lina Bo Bardi. La

espontaneidad es una

posibilidad a menudo anulada.

Los dibujos de Lina Bo Bardi explicitan la posibilidad de la emergencia de situaciones no previstas. La diversidad de actores que presentan sus dibujos, objetos, animales, infraestructuras ofrecen la posibilidad de que más allá del "programa de acción" y el antiprograma, la arquitectura aloje en su interior la contingencia necesaria para la vitalidad y la espontaneidad.

${ }^{100}$ Investigación en VIC. Vivero de Iniciativas Ciudadanas. Paisajes Apropiados. 2011.

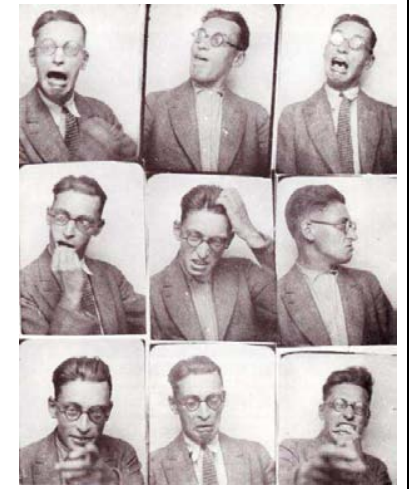

\section{La restricción como}

contingencia. En el ejemplo

dado por Amadeu Santacana ${ }^{101}$,

el libro de Ejercicios de estilo

de Raymond Queneau," la

restricción se convierte en una

fecunda contingencia. La

membrana mínima

como potencial de

interconexiones, capaz

de mantener un estado de

inestabilidad permanente.

Una inestabilidad operativa, de

la acción, que no congela las

situaciones sino que las

posibilita y las adapta

temporalmente. Una

inestabilidad que se enlaza de

una forma muy directa e

inmediata con la propia

inestabilidad de las voluntades

de los seres humanos. Una

inestabilidad permanente que

posibilita

posibles estados estables

temporales."

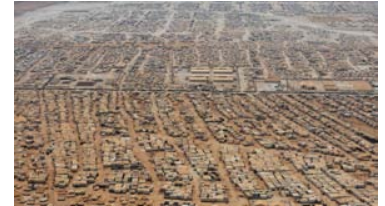

Anticipación. Los llamados "Planes de contingencia" son una herramienta operativa para anticiparse a una contingencia más previsible. "La

planificación de contingencia reduce el tiempo de

producción necesario para poner en marcha una respuesta efectiva y resulta un instrumento fundamental para desarrollar una mayor capacidad de respuesta." 102 Los planes de contingencia componen ciudades instantáneas de miles de habitantes donde el estado habitual de la misma es un permanente estado de contingencia pese a la anticipación sobre la misma.

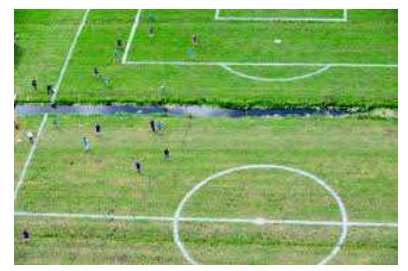

Contingencias provocadas. $\mathrm{La}$ artista Vasca Maider López, trabaja sobre el

cuestionamiento de los programas a priori para desarrollar ciertas actividades. Una contingencia provocada desde la que desarrollar un programa inverso. En el proyecto Polder Cup en Ottoland, 2010. Maider invierte la relación de contingencia al establecer los límites de un campo de futbol en un terreno agrícola irrigado.
${ }^{101}$ Santacana, Amadeu. "El acontecimiento como un mundo en yuxtaposición" Tesis doctoral. UPC, Barcelona, 2013, p.271.
${ }^{102}$ Manual para situaciones de emergencia. ACNUR. $2^{\circ} \mathrm{ED}$. 


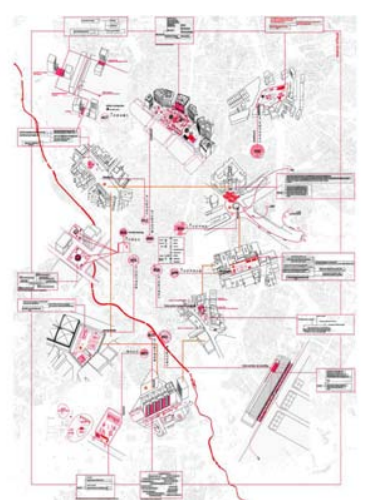

Madrid 2013. La contingencia se ha apoderado de Madrid. Y se ha vuelto productiva.

Cientos de prácticas ciudadanas coproducen espacios contingentes donde lo abierto, lo no autónomo tiene cabida y hacen de la ciudad un espacio híbrido donde redes de infraestructuras materiales, comunidades, protocolos de apropiación, etc. posibilitan el "todo puede suceder" sin ser previsto, ni predicho, ni siquiera anticipado. La posibilidad de la contingencia es productiva para la arquitectura y la ciudad. Madrid es una espuma y no solo un palacio de cristal. ${ }^{103}$

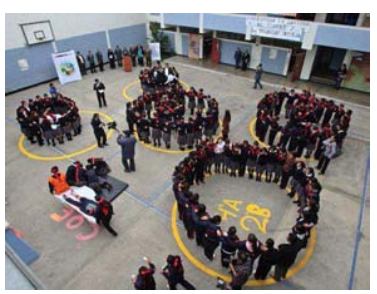

Simulacro ${ }^{104}$. La necesidad de la aproximación a estados contingentes genera en nuestros espacios urbanos, prácticas constantes de contingencia. Estos simulacros, espumas provisionales crean un espacializar, temporalizar y un programa de acción propio entre entidades diversas que se hacen recurrentes y necesarios, por lo tanto no son contingentes, en nuestras ciudades y espacios urbanos. En la imagen, los niños se disponen según las normas que dicta el plan de contingencia contra una inundación.

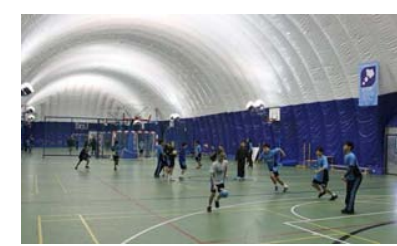

¿Es la contaminación atmosférica una contingencia? La imagen muestra un polideportivo hinchable instalado ya de forma permanente en el Colegio Británico de Pekín. La infraestructura, como membrana, permite acondicionar la calidad del aire en su interior para practicar deporte debido al alto número de contaminantes del aire de Pekín. Nuevas infraestructuras atmosféricas se instalan en el colegio junto a esclusas de aire para no salir al exterior. Bajo esta condición de airpocalypse las prácticas deportivas de los cuerpos al exterior se hacen indoor. La infraestructura junto con programas de comunicación, tecnologías de medición, etc. componen un ensamblaje de contingencia. Pero tendríamos que preguntarnos si los estados de cosas que hoy son muy evidentes, los seguimos denominando contingencias.

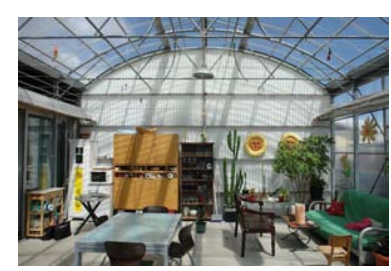

Segundas vidas contingentes. $\mathrm{La}$ arquitectura de Lacaton \& Vassal no construye invernaderos sino que desactiva su función climática para hacer emerger otras posibilidades habitables. Las restricciones económicas y materiales, que ya no son renuncias sino nuevos grados de libertad, posibilitan un nuevo entorno organizativo que cambia flexibilidad por contingencia. Esto permite pasar de un uso actual a un futuro incierto. La contingencia permite a la arquitectura otras segundas vidas posibles. ${ }^{105}$
${ }^{103}$ Op. Cit. VIC

${ }^{104}$ Cfr. Baudrillard, Jean.

Cultura y simulacro. Barcelona, Kairós, 1995.
${ }^{105}$ Sobre esto ver Herreros,

Juan en "Nada excepcional" EI Croquis. n.177-178, p.364.

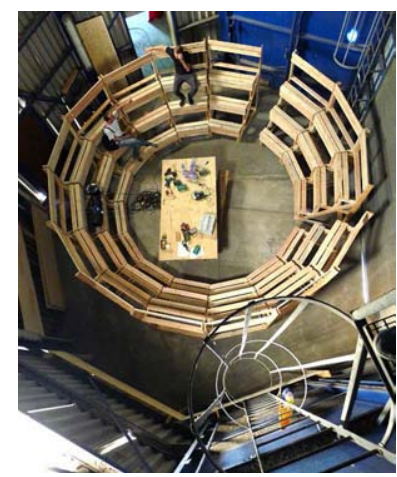

Foros Híbridos. ${ }^{106} \mathrm{Si}$ la sociedad es contingente y las situaciones son siempre cambiantes. Se detecta la necesidad de establecer foros donde discutir las asimetrías para permitir un diálogo democrático. En términos de M. Callón (ANT) se necesitan foros híbridos donde tanto expertos como no expertos puedan discutir. En la manera de I. Stengers la cosmopolítica necesita la discusión tanto de los Stakeholders (agentes promotores) como de los Shareholders (agentes afectados). ${ }^{107}$ Para Latour hace falta instaurar el parlamento de las cosas. Para Sloterdijk la necesidad de repensar de democracia no en términos de eficacia sino de simultaneidad de situaciones diversas. ${ }^{108}$

${ }^{106}$ Esta noción está explicada por M. Callón en Hybrid Forums.

${ }^{107}$ Cfr. Stengers. Isabelle. "La propuesta cosmopolítica." Pléyade. n.14, 2014, pp.17-41. ${ }^{108}$ Imagen.Raumlabour.Perform ing Politics, Berlin, 2012. 


\subsection{Aligeramiento}

Si las categorías tradicionales han podido subsistir hasta nuestros días, es debido al peso y su relación con la materia (pesada) Los objetos arquitectónicos, las infraestructuras, han sido constructos pesados, inmutables, inamovibles y relativamente estables que han condicionado la estabilidad, por ejemplo, de las instituciones. ${ }^{109}$ Estas condiciones podemos aplicarlas también a las sociedades. Ellas han sido tan pesadas, inmutables en el tiempo como el mundo de la materia. Si pensamos en la sociedad actual como una sociedad en aligeramiento, como explican autores como P. Sloterdijk o G. Lipovestski, podremos detectar también sus infraestructuras, materialidades y espacialidades de lo leve, lo ligero, que aquí conectamos con lo frágil, lo dúctil, lo instantáneo, lo efímero, la levedad, la ligereza pero no por ello menos carga.

\section{Aproximaciones /descripciones}

Pensar el aligeramiento de las sociedades-espuma es pensar en el invernadero de confort o el palacio de Cristal. ${ }^{110}$ Para Sloterdijk, la sociedad del estado de bienestar es una sociedad del aburrimiento ${ }^{111}$. "El concepto de civilización tiene hoy como premisa la antigravitación que implica la inmunización frente a la gravedad." 112 En ese aislamiento individual, el aburrimiento es "la dilatación del tiempo interior, [...] porque no se llena de acciones significativas." ${ }^{113}$ No es de extrañar, que la arquitectura de lo ligero esté muchas veces ligada al divertimento, la fiesta, lo efímero, lo ordinario y lo celebrativo.

\section{Descarga}

Para Sloterdijk, la sociedad de confort se ha descargado. El "download” requiere menos esfuerzo que el "upload". Por eso lo ligero y lo pesado, también remiten al esfuerzo, la carga, la concentración, o la seriedad. Pero quizás podamos cambiar, según Sloterdijk, el punto de vista pues "la dispersión es más amplia que la concentración, la ligereza más rica que la seriedad, la indecisión que la decisión o la falta de compromiso abarca un campo más complejo que el compromiso." ${ }^{114} \mathrm{La}$ anti-gravedad, puede ser la forma de pensar de nuestro tiempo, desde las islas absolutas y sus astronautas, a las islas atmosféricas y sus perspectivas, en ausencia de gravedad, es decir en levitación.

\footnotetext{
${ }^{109}$ Sobre la estabilidad de las instituciones. Cfr. Foucault. Microfísica del poder. Madrid, La Piqueta, 1980.

${ }^{110}$ Estas nociones se han explicado en el capítulo segundo.

${ }^{111}$ P. Sloterdijk. Esferas III. Op. Cit., p.539.

${ }^{112}$ Ibid., P. Sloterdijk, p.546.

${ }^{113}$ Ibidem.

${ }^{114}$ Ibidem.
} 


\section{Flotar en caída libre}

La artista Hito Steyer, tiene una respuesta para explicar esta ausencia de perspectiva, de estabilidad y de gravedad. La sensación de estar en caída libre permanentemente nos hace preguntarnos por la estabilidad del horizonte y el sentido de desorientación de cuerpos, objetos y sociedades. ${ }^{115} \mathrm{La}$ forma de mirar ha cambiado. Las imágenes aéreas de google, las vistas-satélite antes reservadas para Dios, al igual que la ubicuidad, se han generalizado. La orientación espacial y temporal ha cambiado y, con ella, pierde relevancia la visualidad que dominó nuestro tiempo: la perspectiva lineal. La estabilidad, mediante la línea del horizonte y su unidad, se complementa hoy con múltiples perspectivas, ventanas, pantallas, líneas de vuelo y puntos de vista divergentes y superpuestos. Bajo estas dimensiones desde arriba, el cuerpo deja de ser un cuerpo observador para pasar a ser un cuerpo flotante imaginario que se mueve entre perspectivas de visión general, sobre un terreno imaginario aparentemente estable en movimiento ascendente/descendente. Bajo la ausencia de gravedad.

\section{Ligero}

En la arquitectura la descarga también se ha materializado. La construcción ha devenido en un ejercicio de lo leve, lo inmaterial, y lo espumoso. El palacio de cristal es hoy un invernadero plástico, que se deforma y se altera por la contingencia. Los muros son ahora paredes finas que están hechas de espuma y aislamientos que forman nuestras sociedades y sus espacialidades. Esta construcción de descarga, paradójicamente es una carga para el planeta.

\section{$\underline{\text { Simetría }}$}

$\mathrm{El}$ aligeramiento es siempre un aligeramiento en aire acondicionado, en un aire "a presión" que sostiene una membrana que lo rodea. El aligeramiento en el modo de estar, flotar en el palacio de cristal. Sucede como acabamos de decir, con otros sujetos, entidades o el mismo planeta que son los que aguantan la carga que lleva el aligeramiento. No es solo el aire acondicionado, es una red de actores que sostienen "en la distancia" la membrana del invernadero de confort occidental. Sloterdijk cita al filósofo Heinz von Foersters. En un plano conceptual, "los objetos se hacen pesados cuando se colocan en el plato de la balanza de la prueba de la realidad sin el contrapeso de lo subjetivo, [...] con un sujeto sin peso. El peso de las cosas es un constructo que se forma en el trato con ellas, y es tácticamente modificable. "Gravedad y ligereza no puede ser otra cosa que un efecto de equilibramiento o no-equilibramiento de pesos y contrapesos." ${ }^{116} \mathrm{La}$ balanza de

\footnotetext{
${ }^{115}$ Cfr. Steyerl, Hito. "In Free Fall: A Thought Experiment on Vertical Perspective”. E-flux. n.24, Abril, 2011.

${ }^{116}$ P Sloterdijk. Esferas III. Op. Cit., p. 557.
} 
pesado debe ser simétrica. Según Foersters "Quien se incorpora a este camino no tiene por qué soportar ninguna externalización; no concederá autoridad alguna a afirmaciones que remitan a un exterior objetivo." ${ }^{117} \mathrm{El}$ aligeramiento siempre será entonces una llamada al desequilibrio, a la asimetría, a la otredad.

\section{Ductilidad}

También la ductilidad es aplicable a los "conceptos en aligeramiento" La adolescencia, como una etapa de lo ligero, nos dice Sloterdijk" representa la categoría de descarga como ductilidad. Frente a lo duro, lo estable, lo que es fijo, aparece lo moldeable, lo posible, lo que genera apertura. "La ductilidad de los conceptos y la necesidad de la reinterpretación de las normas [...] la astucia frente al trabajo pesado [...] el ardid frente al método" 118

Por otro lado, las infraestructuras también son dúctiles. Estas han sufrido un proceso de aligeramiento y se han desarrollado en redes que requieren otra complejidad para establecerse. Por un lado las infraestructuras urbanas que operaban como cajas negras desde el siglo XIX se han hecho visibles en la ciudad desde los años $70 .{ }^{119}$ Pero también otras infraestructuras materiales aparecen y desaparecen a cada instante para promover actividades urbanas efímeras que se establecen desde estas infraestructuras dúctiles, como los conos de los patinadores, las vallas de terciopelo de acceso a las discotecas, o las boyas de las playas que delimitan el espacio a utilizar por humanos y no humanos.

\footnotetext{
${ }^{117}$ Ibid., p.558.

${ }^{118}$ Ibidem.

${ }^{119}$ Cfr. Tesis doctoral Uriel Fogué.
} 


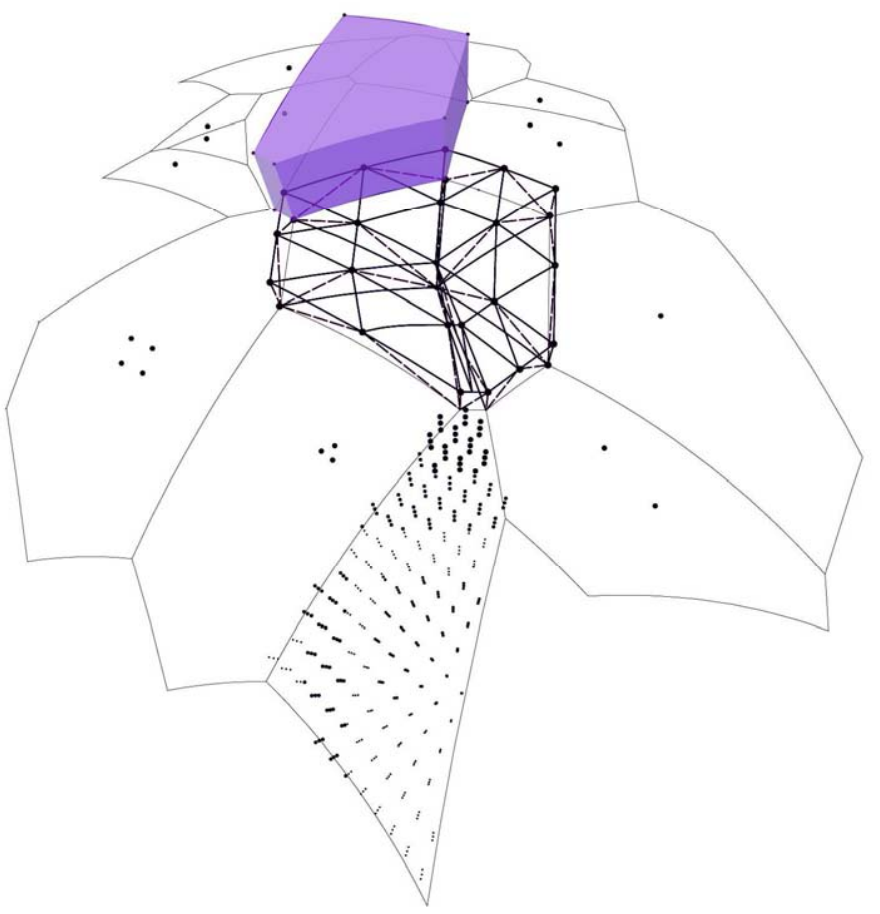

"La ruptura de la relación entre fuerzas gravitatorias, tensionales, sociales y culturales cargantes y descargantes. El aligeramiento es también lo espontáneo, lo frívolo o la distensión de la subjetividad. Toda una cultura material y arquitectónica está desarrollada no solo como ligera, sino dentro de una sociedad en aligeramiento." 


\section{Operatividades}

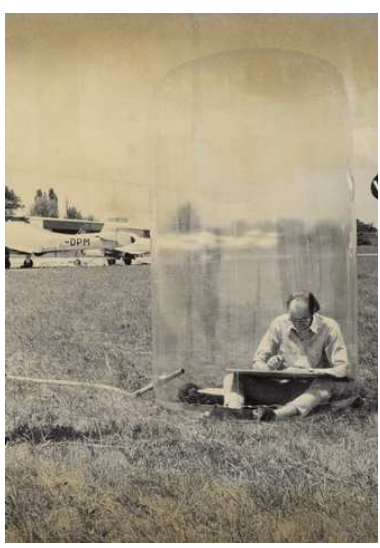

Trabajo aligerado. Oficina Móvil. Hans Hollein. Viena. 1969. Desde que años antes se comenzará a desarrollar la comunicación a distancia $\mathrm{H}$. Hollein propone un espacio de trabajo pop-up a base de un teléfono, un cuaderno de dibujo y un aire encerrado en una cápsula plástica. Un sistema en coaislamiento. Para Sloterdijk el trabajo en occidente también se ha aligerado. "Las oficinas de trabajo deberían llamarse oficinas de simulación de trabajo. Simulan servir a los fines "sólidos y pesados" del trabajo. "120

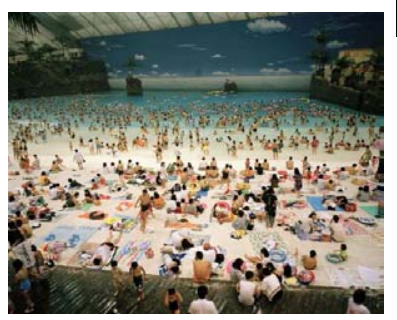

Flotar en la playa. Los invernaderos del confort, son espacios abovedados que garantizan una sensación de ligereza, de flotar. El agua de esta playa artificial Ocean

Dome en Japón, garantiza ese consenso. Pero la asimetría de esta situación con todos las redes y actores que forman parte de ellas está por construir. Fotografía de Martin Parr.

${ }^{120}$ P.Sloterdijk. Esferas III. Op. Cit., p.548

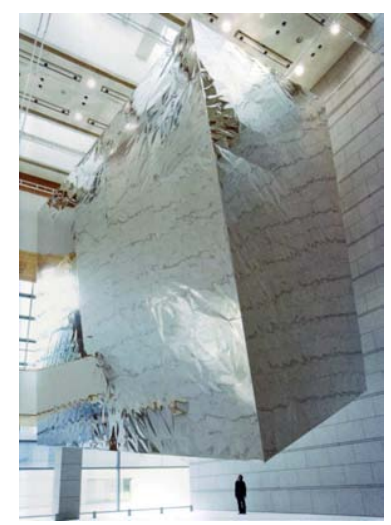

Materia flotante. El "flotar" de Hito Steyerl, no solo es una propiedad de los humanos. Las cosas, los objetos también flotan hoy independientes de su magnitud. La agencia que se produce entre el Helio, la estructura interior de acero, el film de aluminio y el Hall del Museo de Tokio, permiten a Junga Hishigami expresar el aligeramiento como una propiedad de la materia. Si los globos son generalmente redondeados, y su forma esférica encarna individualidad, el globo "material" de Hishigami expresa las relaciones de tensegridad entre la estructura interior que lo conforma y su levitación.

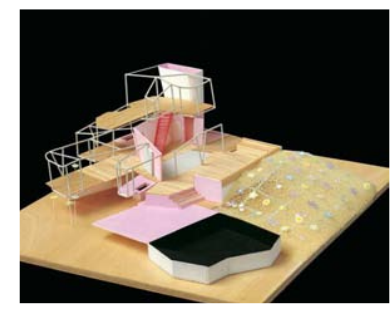

\section{Hospedería de los}

Divertimentos flotantes.

A.Jaque.2011 Una arquitectura de objetos frágiles y ligeros en red en el interior de la casa existente. "El proyecto refleja el deseo de ensayo el papel de la arquitectura en la preservación de los frágiles y marginales. $\mathrm{Al}$ igual que el verdadero papel de la democracia según Peter Sloterdijk es "espacializar y dotar a los momentos fugaces y marginales con presencia, la casa anhela convertirse en un punto de tránsito para algunos de los placeres que hacen valiosa verano." 121

${ }^{121}$ De la memoria del proyecto.

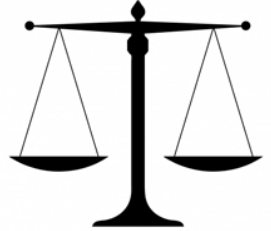

Simetría. El aligeramiento es parte de una ecuación de carga y descarga, de gravedad y antigravedad, de posibilidades o de imposiciones. La simetría de descarga es una utopía de las sociedades modernas, pero necesaria para la equidad gravitacional de las sociedades y las cosas.

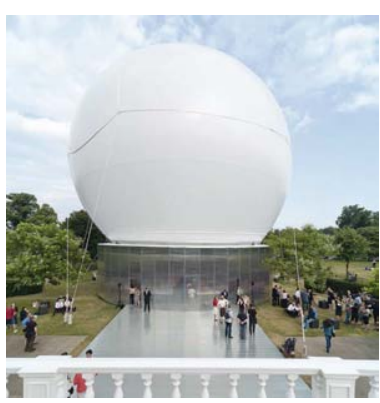

\section{Parlamento global.}

El globo, como membrana insuflada es ligero. El proyecto de Oma/R.Koolhaas/ C. Balmond / H.U.Olbrich. 2006para el pabellón de la Serpetine Gallery está

aligerado. Pero en su base, este pabellón refleja su simetría. Un pequeño parlamento, lugar de reunión, donde se discuten las controversias contemporáneas en actividades diarias. El "peso" del pabellón, diría Koolhaas está en sus conversaciones, en sus actividades, en sus discusiones El globo de Koolhaas no vuela, pero está en un "impulso hacia arriba" pues es un globo dentro de invernadero del confort europeo. Del mismo modo, este globo conforma un cielo propio y privado. "que conforma un confort material y emocional en el invernadero de cristal. Un Cristal Palace contemporáneo en Hyde Park. 


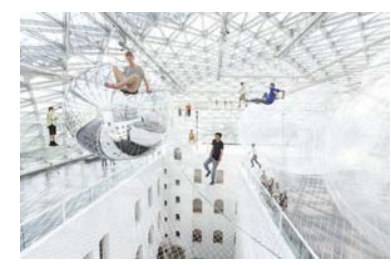

En Órbita. Tras la instalación "On Spacetime Foam." y "Cloud Cities"el artista Tomás Sarraceno produce en 2013 In Orbit.

El proyecto conforma una serie de relaciones

espaciotemporales entre las membranas ligeras dentro de espacios museísticos. Las membranas producen un entorno "sin forma" la distorsión de lo ligero bajo la presión de los cuerpos flotantes, produciendo en cada instante relaciones nuevas entre los plásticos, las mallas, el aire y los cuerpos. Para B. Latour es un ecosistema con las mismas propiedades del actual antropoceno donde no podemos decir si estamos dentro o fuera pues estamos en un continuo. Cuando uno se desplaza, todo un "mundo" se desplaza con él. Este trabajo reúne y complementa en su materialidad las dos teorías que tratamos en esta tesis doctoral.

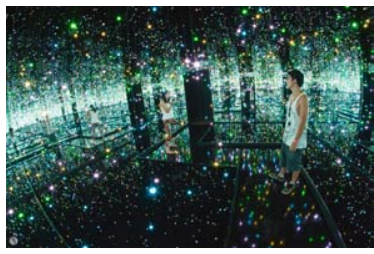

En otra órbita. La artista japonesa Yayoi Kusama invierte el proceso en la performación de espacialidades infinitas donde uno aún situándose de forma estable en un suelo, tiene la sensación de flotar intensamente en un mundo hecho de luces, espejos y partículas en suspensión.

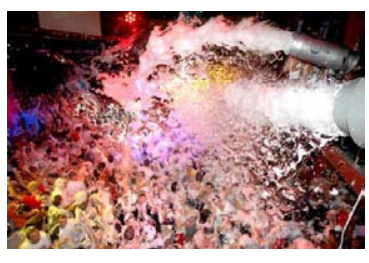

\section{Lo atmosférico. Esta}

condición deviene siempre en lo ligero. No solo en términos de aligeramiento como noción cultural de Sloterdijk sino como la atmósfera particular como un "espacializar" propio. Las fiestas de las discotecas de Ibiza se performan en base a materiales como el aire, el humo, el agua o la espuma. Los materiales ligeros devienen en elementos de configuración de atmósferas interiores particulares de relajación o sobre-excitación colectiva.

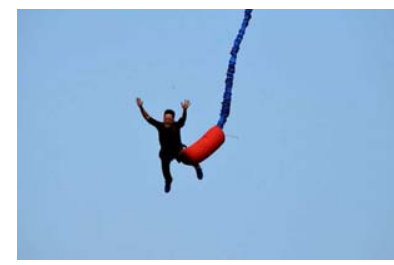

Experiencias aligeradas. A la situación cargante de la vida diaria se le superpone los instantes en caída libre que supone vivir el aligeramiento en el Palacio de Cristal. El Puenting, no es solo una experiencia de riesgo. Es una interacción instantánea con la gravedad que hace explicitito lo descrito por

Hito Steyerl sobre la

estabilidad de nuestros cuerpos en caída libre.

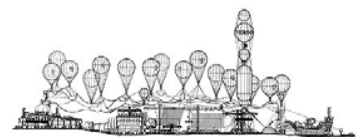

Instant City. Archigram.

1969. Propone un dirigible aéreo que contiene los recursos culturales y educativos de una metrópoli que podría aterrizar en áreas rurales y remotas dando a sus habitantes un sabor de vida de la ciudad. Instant City puede leerse como un dispositivo móvil y ligero de aceleración de territorios no acelerados. Una entidad compuesta de globos de aire caliente que lleva consigo "dispositivos audiovisuales, equipamientos de ocio, exposiciones, todo ello transportados en gigantes, lúdicos y divertidos agentes transmisores; dirigibles que al posarse sobre inocentes "ciudades durmientes", transformaban

irreversiblemente su fisonomía incluyéndolas en un sistema metropolitano activo; la ciudad instantánea. 'Lo ligero llama a lo ligero.Fiesta, diversión y aceleración suceden en el aligeramiento de la sociedad contemporánea.

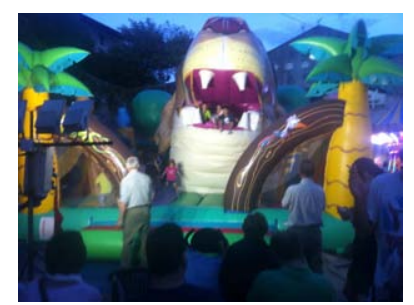

\section{Aligeramiento temprano.} Desde muy pequeños el aligeramiento se introduce en nuestros cuerpos a través de las ferias y sus materialidades hinchables que nos permiten experimentar fantasías y sensaciones de aligeramiento en edades muy tempranas junto son los cuerpos plásticos de personajes como Mickey Mouse o Bob Esponja. 


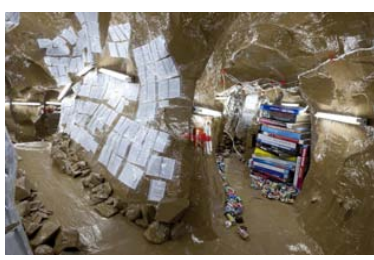

The Momentary Monument. Tomas Hirschhorn. 2011.

Toda una suerte de materiales de construcción, ligeros, producidos y transportables rápidamente, editables y conformadores de atmósferas de la basura son la materia prima de la ciudad genérica productora de espacio basura. Los materiales ligeros como tabiques, pladures, juntas de sellado, siliconas, vidrios, vinilos, fluorescentes, cartonespiedra, pvc, tabiques de acero inoxidable, resinas, gomas, aislamientos generan una materialización procedimental también ligera materialización es provisional; cortar, doblar, rasgar, recubrir; la construcción ha adquirido una nueva tersura, como la sastrería a medida. [...] una superficie ininterrumpida, grapar, pegar, plegar, verter, encolar, disparar, duplicar, fundir.

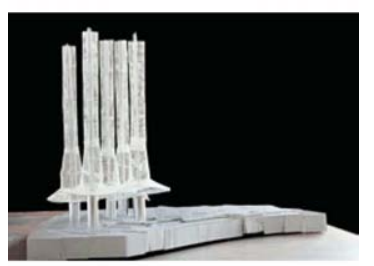

Infraestructuras ligeras. Las infraestructuras urbanas también se han hecho ligeras en un proceso de visibilización y transparencia de las mismas en la ciudad. Las Chimeneas del proyecto de S\&Aa de la central de cogeneración en el ecobarrio de Vallecas en Madrid. 2011

Estas ecochimeneas se muestran no ya como las pesadas chimeneas de ladrillo de la era industrial sino como ligeras cubriciones que dan sombra y elevan los gases productos de la biocombustión en un nuevo espacio público generado desde el

aligeramiento de las

infraestructuras urbanas.

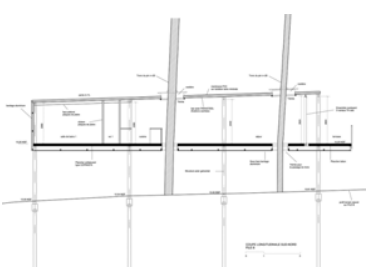

Aligerar no es desplumar. " $\mathrm{La}$ arquitectura ligera no se produce aligerando de su pesado lastre a la más compleja [arquitectura] hasta dejarla desplumada; se produce construyéndola con otros ingredientes materiales, técnicos e intelectuales del contexto en el que se opera." ${ }^{22}$ La casa en Lege de Lacaton \& Vassal, 1998, se aligera conservando la duna existente y los árboles del bosque. Su interior "desdensificado" muestra también el aligeramiento de la propia vida. La casa de vacaciones destartalada se transfiere a todos sus proyectos de vivienda para una vida contingente en un ocio permanente.

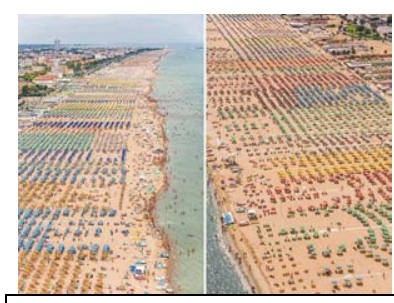

\section{Infraestructuras dúctiles.}

Muchas son las infraestructuras dúctiles con las que convivimos día a día. Quizás las que tengan una presencia más acusada y visible son las generadas en las playas. Estos espacios públicos imperfectos ${ }^{123}$ se generan desde la implantación de toallas, sombrillas, neveras, cuerdas delimitadoras de propiedad, boyas flotantes y todo un sistema de "acotación" de la superficie tanto de arena como de agua salada donde se instalan las prácticas de cuerpos semidesnudos que experimentan un aligeramiento y un descanso de nuevo dentro del Palacio de Cristal que es el mundo occidental o sus proxicuas playas éxoticas para sus turistas como agentes colonizadores efímeros.

${ }^{122}$ Herreros, Juan. Op. Cit., p.364.

${ }^{123}$ Sobre las playas ver Gil-

Fournier, Mauro en La ciudad viva. Descargable en:

http://www.laciudadviva.org/bl ogs $/$ p $=24575$

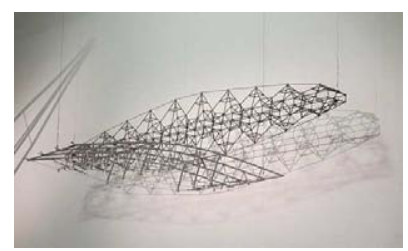

Tensegridades. Robert Le Ricolais. Double Parabolic

Trihex Bridge for the Skyrail.

La tensegridad como hemos

explicado en el capítulo 2 puedes ser social o tensionalestuctural. La compresión en barras y la tracción en cables, hace que la tensión necesite de lo ligero para sobreponerse a la compensación de cargas. Una estructura red (distribuida) o una tensión interna (superficial) en la espuma. Las estructuras de Le Ricolais, quizás manifiesten la mejor forma de entender las posibilidades arquitectónicas de tipos para estructuras ligeras. Pero por el contrario, la tensegridad social de Sloterdijk, remiten a las tensiones no reveladas, no conectadas o visibles que por el contrario reflejarían el carácter cargante de lo ligero.
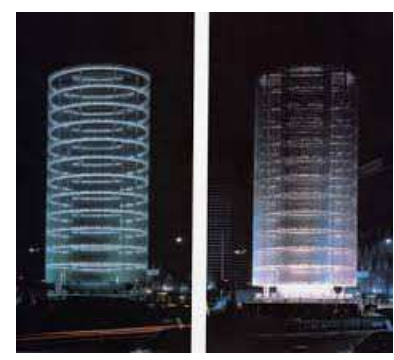

Más allá de lo ligero. La información es aparentemente ligera, sin peso, sin materia. Según Paul Davies "es su "inexistencia" como ente físico, su imposible reducción a manifestación alguna del sustrato material. Pero la información detona las acciones de agentes, actores. Es visible o invisible. Toyo Ito materializa las relaciones en constante performación de las relaciones producidas ya entre los cuerpos, las tecnologías digitales y los flujos de datos producidos en esta múltiple relación. 


\subsection{Volatilidad}

Hablar de las condiciones de estabilidad es hablar del mantenimiento de las condiciones iniciales en el tiempo. Es hablar de procesos duraderos. La ciudad es, de por sí, un proceso duradero en muchos casos, que no estable ni inestable, sino sujeto a consideraciones variables en el tiempo. La ausencia de estabilidad produce nuevas condiciones donde lo volátil se presenta en las prácticas urbanas: la volatilidad de la vida social, quién está, dónde, a quién puedes querer, qué es asumible, dónde vives... La corrosión del presente y la ilusión de permanencia no dejan entrever el estado de volatilidad que sí que es continuo. Las comunidades, como el dinero, están en permanente circulación. Como dijo Simmel:" la divisa posmoderna cambia estabilidad por liquidez"124, y esta ya viene articulada en la idea de la máquina de habitar. La casa moderna facilita el traslado, la circulación del morador. De esta manera la volatilidad será también el proceso de búsqueda de la estabilización en el aligeramiento o en la caída libre ${ }^{125}$.

\section{Aproximaciones / Descripciones}

La RAE define volátil, en sus diversas acepciones, como lo que puede volar, se mueve ligeramente o es mudable e inconstante. Sobre los precios de los mercados los califica de inestables u oscilantes y de la condición física de un líquido sobre su transformación espontánea en vapor. La condición de volatilidad, podrá emerger en arquitecturas, que, como acompañamientos de la existencia humana, también devienen volátiles.

\section{Volatilidad en la espuma}

Una espuma es "una mezcla gas-líquido en el que la fracción de volumen de la fase líquida es pequeña." ${ }^{126}$ Para que estas sobrevivan y duren (por ejemplo con un líquido como el agua) se debe añadir un "agente activo de superficie" de componentes volátiles (como el jabón) para estabilizarla. Estos componentes tienden a situarse en la superficie cerca del contacto con el aire y reducir la tensión superficial de la "interface" de la espuma.

La espuma se estabilizará si contiene un segundo líquido formado por componentes volátiles con una tensión superficial diferente (como el jabón). Pero estos componentes son volátiles porque pueden evaporarse. En esta condición "el aire vuelve a estar libre, el agua se evapora en vapor, una nube la reúne de nuevo, el calor crea presión, cae la lluvia y esta se mezcla con la tierra. El barro asienta la temporalidad que fluye en otro lugar con nuevas evaporaciones, en un ciclo de

${ }^{124}$ Cita de P. Sloterdijk en Esferas III. p.194.

${ }^{125}$ Desarrollado en el punto anterior: aligeramiento.

${ }^{126}$ Cfr. Breward, C. J. William The mathematics of foam. Thesis doctoral, Oxford, 1999. 
combinaciones elementales que mantiene un sistema en permanente cambio. La materia es animada." ${ }^{127}$

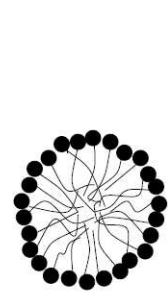

(a)

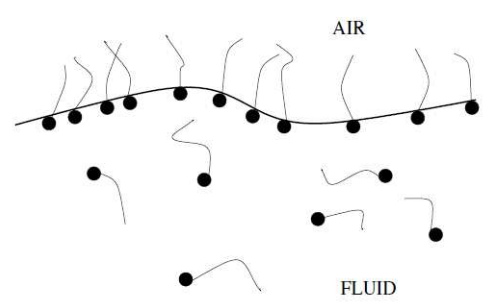

(b)

Fig. 22. Diagrama de moléculas de surfactante (a) que forman una micela espumosa y (b) a una superficie libre de Christopher J. W. Breward en The mathematics of foam

Las espumas, como la sociedad, por lo tanto, se mantienen en condiciones de volatilidad. Adquieren su estabilidad debido a sus cambios de estado. Se forman y se destruyen en continuidad y circularidad.

\section{Agentes activos}

Bajo la noción de "agente activo de superficie" como estabilizador de una espuma por su capacidad volátil, podemos entender que la inclusión de lo no-humano en las redes de mediación que opera en la ANT, facilita también la estabilización de los procesos. En el artículo "La tecnología es la sociedad hecha durable", B. Latour explica cómo la alineación de agentes y puntos de observación establece definiciones fijas y estables, de dominación sobre la sociedad. Por el contrario, la inclusión de las infraestructuras materiales, opera como agente volátil, que no significa que sea desestabilizador, sino que permite proponer definiciones más abiertas. Sin por ello entrar en las herramientas académicas de poder y dominación, y aún así mantener la durabilidad del ensamblaje social. "Cuando los actores [también infraestructuras materiales] son inestables y los puntos de vista de los observadores se mueven continuamente, entramos en una situación altamente inestable y negociable en la que la dominación ya no se ejerce." ${ }^{128} \mathrm{La}$ inclusión de actores no humanos en los ensamblajes opera como agente activo, y gracias a él, la estabilidad es negociable y a la vez gana en estabilidad.

\section{Burbujas urbanas}

Podemos verlo en un titular cualquiera sobre los mercados financieros como este "Bajo volumen trae volatilidad al Nasdaq; Netflix sigue subiendo como la

\footnotetext{
${ }^{127}$ VV.AA. Grain Vapor Rain. Textures of the anthropocene. Berlin. Haus der Kulturen del welt, MIT press, 2013 , p.7.

${ }^{128}$ Latour, Bruno. "Technology is society made durable" The sociological review. v.38, 1990, p.129.
} 
espuma" 129 Por un lado la volatilidad en los mercados sucede bajo un ámbito de volatilidad debida a situaciones de estados virtuales, como la afección, las sensaciones, los supuestos, etc. Y, por otro, estas reacciones generan concentración o dispersión del capital.

En el caso de las burbujas urbanas, estas suceden por la concentración de expectativas sobre una empresa, un mercado concreto o una ciudad. Esta concentración intensa provoca el aparecimiento de burbujas. Estas burbujas (como la inmobiliaria) detonan un crecimiento desmesurado de la ciudad. Por ejemplo "Madrid construyo en 10 años más viviendas que Alemania, Italia y Francia juntos." ${ }^{130}$ Como explica David Harvey, en "El derecho a la ciudad", la imposición de los mercados tiene consecuencias directas en el desarrollo urbano. $^{131} \mathrm{Al}$ igual que estas burbujas aparecen en un lugar, desaparecen rápidamente de este para situarse en otro. Al igual que la espuma y los procesos de evaporación, la ciudad modifica su condición debido a la volatilidad.

\section{Redes virtuales/actuales y su volatilidad}

De esta manera el "El mercado con sus anticipaciones, sus juegos, sus movimientos especulativos, su volatilidad, interdependencia y contingencia se convierte en el modelo paradigmático del actuar. " 132 Y esta situación volátil, deviene de principios no explicables matemáticamente ni predecibles. Es una volatilidad que proviene de una virtualidad. ${ }^{133}$

Es por esta volatilidad, por lo que los estudios de la ciencia y la tecnología (STC) y la (ANT) no pueden dar respuesta eficaz a los estudios urbanos. Si bien ha desarrollado el estudio de objetos y espacios complicados como laboratorios científicos, grandes sistemas sociotécnicos, mercados financieros, bolsas de comercio, oficinas de arquitectos globales, hospitales, etc., no es capaz de articular el estudio de lo cotidiano en la ciudad.

La cuestión de la volatilidad asociada a lo "social" tiene que ver con una condición de lo virtual. Entendemos lo virtual como algo que frente a lo actual ${ }^{134}$, deviene en intereses y expectativas no controlables. "Fuerzas no actualizadas que empujan lo real hacia actualizaciones no previstas." ${ }^{135}$

\footnotetext{
${ }^{129}$ Noticia aparecida en Rankia.com http://www.rankia.com/blog/ruido-en-el-sistema/2828384nuestra-cronica-semanal-volumen-trae-volatilidad-nasdaq-netflix-sigue-subiendo-como-espuma ${ }^{130}$ Coger la referencia.

${ }^{131}$ Ver Op. Cit., Harvey, David. "El derecho a la ciudad".

${ }^{132}$ Mahal, Mona \& Serbest, Asli. How Architecture Learned to Speculate. Stuttgart, Gerd de Bruyn, IGMA, 2009.

${ }^{133}$ Virtualidad Deleuze a diferencia de lo actual. Op. Cit., Deleuze, El pliegue. Leibniz y el barroco, 1988.

${ }^{134}$ Ibid.

${ }^{135}$ Farías, Ignacio. "Ensamblajes urbanos: la TAR y el examen de la ciudad”. Op. Cit., p.29.
} 
"La ciudad y la vida urbana ponen, sin embargo, en evidencia que la complejidad equivale más bien a un horizonte virtual de posibilidades que resulta de la imbricación de múltiples ensamblajes urbanos. [...] El estudio de lo cotidiano en la ciudad implica entonces dar cuenta de las posibilidades y tendencias no actualizadas, de los cabos sueltos, de aquello que no participa directamente en ningún programa de acción, pero que puede irrumpir de pronto y transformar la acción." ${ }^{136}$

La volatilidad hace de esta manera que las redes urbanas deban actualizarse constantemente en base a la complejidad que detentan. "La multiplicidad no resulta así solo de las distintas redes de prácticas en las que se actualiza un objeto, sino que resulta de las potencialidades y tendencias virtuales [afectos, estados de ánimo, capacidades] internas al objeto y que implican múltiples posibilidades de devenires conjuntos." ${ }^{137}$

Ante esta actualización de lo virtual, la ciudad al igual que los mercados produce en su volatilidad el fenómeno de la especulación. "Las clásicas oposiciones de racional e irracional, divertido-serio, real o ficción, se cuestionan. Estas formas inestables contemporáneas anticipan una lógica especulativa con la interacción, globalización, fluctuación, flexibilidad y volatilidad. "138 Lo inestable y lo durable se simultanean en lo volátil, como una condición de inestabilidad-estable. Si la volatilidad es la desviación sobre una trayectoria dada, mientras la trayectoria no se rompa, esta seguirá siendo durable en su inestabilidad. Es lo que por ejemplo el economista Joseph Schumpeter llama la "destrucción creativa", en el que lo nuevo o lo innovador, destruye industrias, empresas, edificios, o ciudades existentes.

Por último, la presentación de J. Law, en la ANT, propone una topología fluida para el estudio de las sociedades y su espacializar en la metáfora de una "topología del fuego" ${ }^{139}$. A esta tendremos que añadirle la gasolina como el componente volátil de variabilidad y expansión. Lo virtual, como hemos enunciado, podría funcionar como la gasolina o la espuma, que enciende o apaga el fuego. La volatilidad vista desde las redes (ANT) o las espumas, aparece como la condición de fragilidad de la existencia contemporánea.

\footnotetext{
${ }^{136} \mathrm{Ibidem}$

${ }^{137}$ Ibidem

${ }^{138}$ Cfr. Gunter,Valerie \& Kroll-Smith, Steve. Volatile Places: A Sociology of Communities and Environmental Controversies. London, Pine Forge press, 2007, p.60.

${ }^{139}$ Hemos explicado este concepto en el epígrafe 1.3.2. "El espacializar y la topologías fluida de la red".
} 


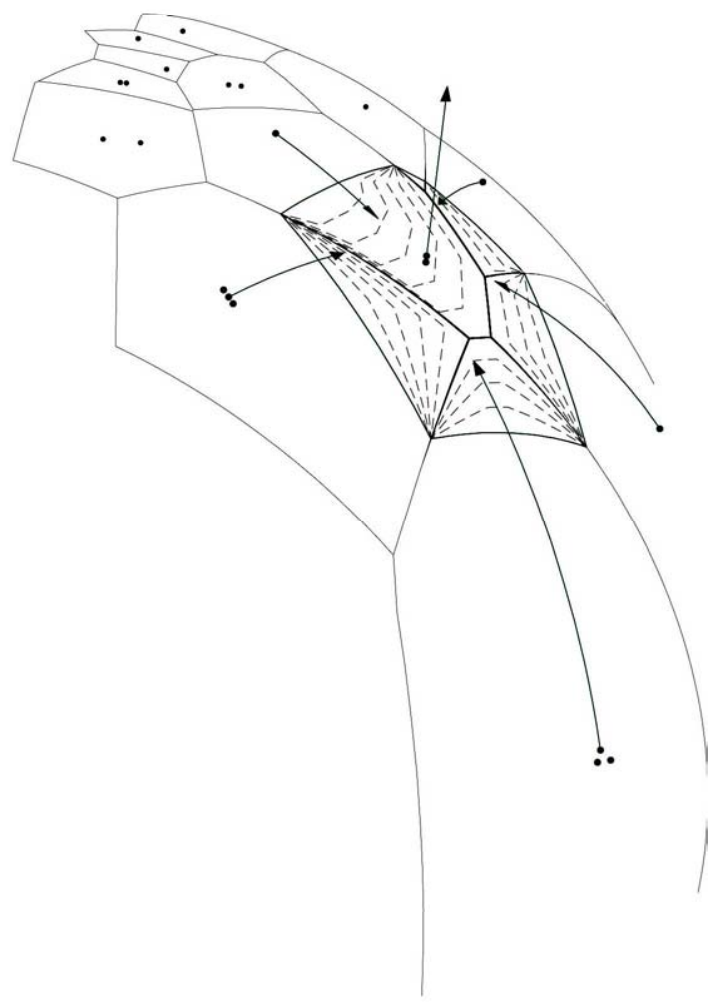

"Fenómeno que visibiliza la frecuencia e intensidad de los cambios en un horizonte temporal específico sin perder por ello estabilidad. Si asumimos que nuestras condiciones de vida son volátiles, también será de interés observar como la arquitectura deviene volátil y asumirla como herramienta operativa para intervenir en la realidad." 


\section{Operatividades}

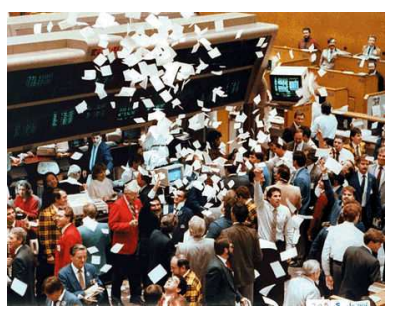

El Parquet. Las espacialidades de los entornos físicos donde se negociaban las transacciones financieras devienen volátiles en muchas situaciones de euforia colectiva o de depresión. Los papeles que "vuelan" modifican su estado sedentario y acumulado, por un cambio de estado, se convierten en elementos aéreos, que explicitan la situación de volatilidad.

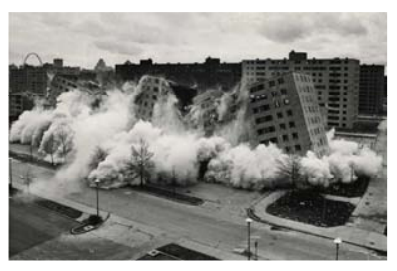

Pruitt-Igoe. Si la volatilidad es un fenómeno que visibiliza la frecuencia e intensidad de los cambios estos como hemos dicho son tanto creadores como destructores. La voladura de Pruitt-Igoe en St. Louis se produjo a las 15:32 del 15 de julio de 1972. El arquitecto

Charles Jenks

lo bautizó como "la hora cero del posmodernismo". En ese momento el complejo

habitacional como una versión premiada de la "máquina para la vida moderna" de Le

Corbusier entra en crisis. La bancarrota habitacional de la arquitectura "vulgar" y social se produce en un entorno también volátil y asimétrico donde la población afroamericana que allí vivía estaba ya estigmatizada y cargada. El lugar fue dinamitado por considerárselo un lugar inhabitable. En ese momento cientos de celdas, de microinsulamientos desaparecen tras la voladura.

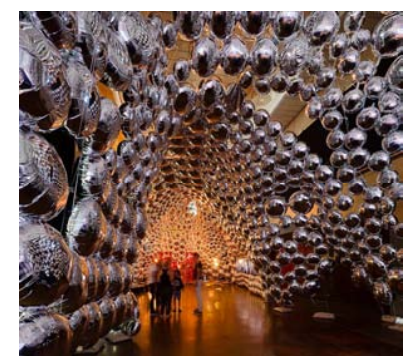

Virtualidad. Es interesante comprobar cómo la imagen aparentemente estable del proyecto Polivagina.

C+Arquitectos. Nerea Calvillo. Fan Riots en Murcia 2014 se ha construido de la volatilidad, virtualidad e interacción de las entidades humanas y no humanas que lo componen: Globos plateados de helio, personas no expertas que lo han ido construyendo, etc. Tensiones no previstas que lo hacen cambiar de forma. Bomberos que cuidan de que no se "caiga" y sature el espacio. Al igual que su levantamiento, su desmontaje deviene volátil. Los afectos, el globo como objeto de deseo, hicieron de él un proyecto construido en base a esta condición que se convirtió en un experimento en el proyecto. ${ }^{140}$

${ }^{140}$ Desarrollado en la comunicación de Nerea Calvillo en el Congreso de Sociología Ordinaria. Madrid. 2015. "Odiando intensamente un globo de $90 \mathrm{~cm}$ : experimentos afectivos con nohumanos"

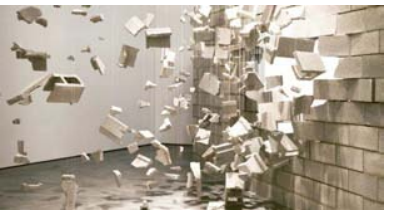

Construyendo la destrucción. Si como hemos dicho la destrucción es creativa en los mercados financieros. Los artistas cubanos de "Los carpinteros", lo que hacen es invertir el proceso para explicitar el estado de volatilidad en el que están sometidas las vidas. "Este tipo de imagen de la explosión es algo con lo que todos estamos muy familiarizados, está en las noticias de televisión todos los días. Pero nosotros no

explicamos nada, no hay rastro de humo, ni de fuego, ni nada. No hay un porqué. Puede ser algo natural, una bomba, un ciclón." ${ }^{141}$

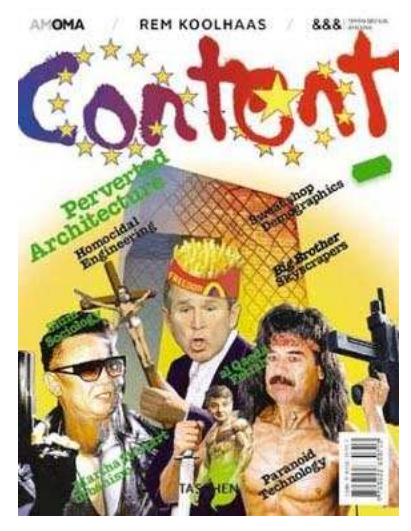

Content. OMA-AMO. 2004.

es un producto de la volatilidad de comienzos del siglo XXI.

Globalización y el mercado cortan la estabilidad de toda faceta contemporánea. Como dice Koolhaas "Utiliza la volatilidad como una licencia a lo inmediato, lo informal, lo prefabricado. La inestabilidad como una nueva fuente de libertad. "

\footnotetext{
${ }^{141}$ Jarque, Fietta. El País

Semanal $N^{\circ} 1.793$ del 6 febrero.
} 


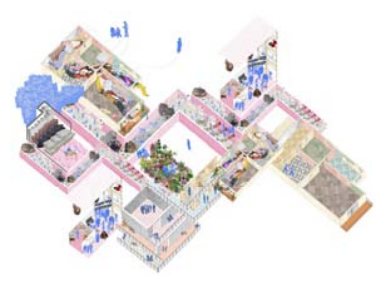

Volatilidad doméstica. La volatilidad de la vida urbana, llega a lo doméstico en forma de desahucios. Las viviendas de los ciudadanos con ejecución hipotecaria crean domesticidades desahuciadas que conforman redes y espumas de situaciones en fragilidad. Componen redes de afectos para el soporte frente a la actualización de los mercados financieros y por otro lado son espumas como sistemas coincidentes. Un desahucio, lleva a otro (el de los padres por ejemplo) al igual que un desahuciado apoya otros procesos de desahucios y así sucesivamente. Este fenómeno ha sido investigado por el autor de esta tesis. ${ }^{142}$

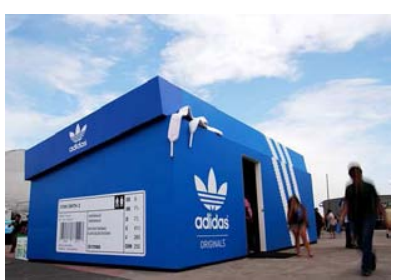

Pop-up. Al pop-up o aparición le sigue una desaparición. $\mathrm{La}$ ciudad instantánea aparece y desaparece sin aparente patrón. Los pop-up stores son tiendas efímeras que se insertan en locales comerciales existentes o se crean como arquitecturas efímeras. La volatilidad de este fenómeno urbano hace de él un poderoso ejemplo que explicita como no es tanto la propiedad como el acceso lo que cambia con los procesos de volatilidad urbanos. Como esto, toda una cultura del aparecerdesaparecer se instala en nuestras ciudades,

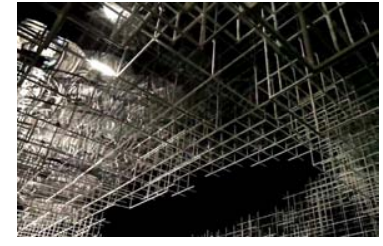

Volatilidad en la estabilidad Como la que se dio en el pabellón de la instalación de Sou Fujimoto en la Serpentine Gallery de Londres. A la estructura metálica del pabellón se le "acoplaron" un sistema de luces dinámico que en detonaba la aparición y desaparición de luz en la estructura desvelando la capacidad también de lo volátil de mostrarnos entidades, lugares, procesos donde antes no los observábamos. La volatilidad

es también una herramienta para mirar de otra forma lo aparentemente estable.
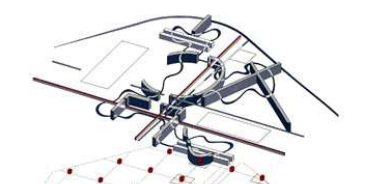

$\therefore \therefore \therefore$
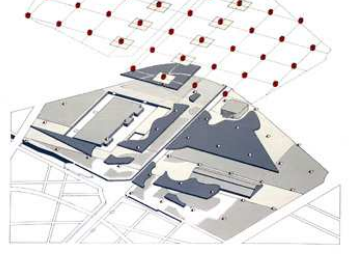

Acontecimientos volátiles. Se da a nuestro juicio, una aparente contradicción en B. Tschumi, entre la necesidad de intensificar el programa como acontecimiento y sus guiones posibles, y la necesidad de que el proyecto generare capas de información contingente. Los guiones son aproximaciones ficcionales que aseguran la posibilidad pero no conforman la contingencia. Las foliesdel Parc de L'Villete Paris 1982 detonan la aparición de lo contingente.

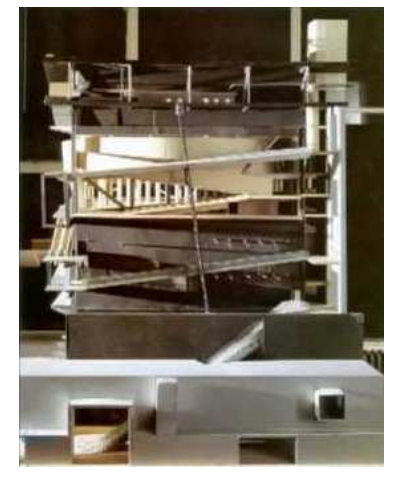

Licuaciones del programa. $\mathrm{Si}$ el programa da paso al acontecimiento y este utiliza las infraestructuras de aceleración arquitectónicas como el ascensor, la rampa mecánica, la cinta transportadora o el plano oblicuo. Tras lo aprendido por Koolhaas sobre la cultura de la congestión en NY, su aplicación a la cultura europea se da en proyectos como el ZKM en Karlsruhe de 1989. En él el paso del programa como elemento sólido, estable y cuantificable da paso a una noción líquida o gaseosa ${ }^{143}$, es decir espumoso, con propiedades más complejas como la volatilidad de las posibles acciones y su interacción debido precisamente a la autonomía de estos programas en el mismo edificio. Los programas operan como "islas autónomas" o como insulamientos dentro de una espuma más grande que es el ZKM

${ }^{142}$ Gil-Fournier, M, Jaenicke, M., Acosta, E. "The urban citizens" Extitutional process in Madrid. 2000-2015."

Rotterdam. MONU Magazine 2015, n.23, Oct, pp.89-96. 


\subsection{Disper $(\mathrm{X})$ ión}

Las tradicionales formas de la exterioridad se han representado mediante la concentración y la cohesión cuando hablamos de la ciudad, las casas, y los cuerpos. El territorio, la naturaleza y otros exteriores se han nombrado como exteriores por la incapacidad de nombrar y controlar la dispersión. Hoy en día la dispersión es un fenómeno cotidiano. Nuestra vida urbana se despliega y se encuentra dispersa y conectada con otras entidades. Esta condición simultánea de dispersión y conexión, es lo que podemos nombrar como Disper(x)ión. No confundir con fragmentación. Así como el aislamiento está hoy conectado en la noción que hemos desarrollado de coaislamiento. La dispersión se realiza en conexión. Podemos distinguir dos modos principales. Por ejemplo, internet funciona como una red que reúne y favorece esta dispersión conectada en diferentes grados de distanciamientos relacionales y geográficos; y, por el otro, en nuevos procesos de reconcentración que se generan desde la conexión.

\section{Aproximaciones / Descripciones}

Las espumas llevan la dispersión en su raíz genética. Las espumas son dispersiones coloidales. Esto quiere decir que "son un sistema formado por dos o más fases, principalmente: una continua, normalmente fluida, y otra, dispersa en forma de partículas generalmente sólidas." ${ }^{144}$ La dispersión de la espuma está relacionada con las fases de su formación y con los agentes de dispersión.

\section{Inmunidad}

Como ya hemos argumentado, si Sloterdijk habla más de inmunidad que de comunidad, es porque la sociedad se ha individualizado, y este proceso de individualización es paralelo, como diría Sloterdijk, a los procesos de construcción de los auto-insulamientos.

La conexión no obliga a la concentración, al igual que la dispersión no obliga a la desconexión. El enlace social contemporáneo tendría que ver más con la dispersión que con la cohesión, con la inmunidad que con la comunidad. La disper(xi)ón provoca entonces comunidades flotantes, ligeras o sin compromiso. ${ }^{145}$ El cuerpo establece diferentes modos de conexión, compromiso o despliegue de sus capacidades con los otros. Podemos entender que la dispersión aparece también como fenómeno de la inmunidad.

\footnotetext{
${ }^{144}$ Sobre la química de las dispersiones coloidales.

${ }^{145}$ Ver capítulo "Your Private Sky. Pensar el aligeramiento" en P. Sloterdijk Esferas III. p.553-564.
} 


\section{Distanciamiento}

La dispersión entendida como el distanciamiento remite a la noción de proxicuidad que hemos desarrollado. El distanciamiento geográfico no es suficiente para romper los vínculos entre entidades distanciadas. Por eso la dispersión no es fragmentación. Pensemos que en botánica, la dispersión es la forma de asegurar la descendencia y la supervivencia de la especie por medio de mediadores como el viento o los animales.

\section{Dispersión en densidad}

Las redes, no son dispersas en sí mismas. Las redes (ANT) distribuyen, reparten, enlazan, pero no dispersan por sí mismas. Lo que permiten es visibilizar la dispersión existente por cualquier medio, sea este económico, territorial, tecnológico o social. Las redes permiten elaborar herramientas para la conexión heterogénea en distintos niveles y esta manera explícita, o visibiliza, la dispersión de lo aparentemente fraccionado, pero continuo, simultáneo o instantáneo. "La dispersión, la destrucción y la desconstrucción no son las metas a ser alcanzadas sino lo que debe superarse. Es mucho más importante comprobar cuáles son las nuevas instituciones, procedimientos y conceptos capaces de reunir y reconectar lo social" 146

Los móviles inmutables ${ }^{147}$, como entidades que mediante la inscripción trasladan, desplazan y diseminan un determinado plan de acción son el canal o entidad por que el que se realizan nuevas asociaciones que dispersan el plan de acción a otras entidades.

La dispersión en un mundo saturado produce dos fenómenos complementarios. El primero es que amplifica la densidad de las conexiones. La distancia obliga a más demanda de conexión y por otro lado en una espuma saturada, la dispersión obliga, como en el significado de la química del medio ambiente, a que las entidades pasen de unos compartimentos atmosféricos (burbujas y espumas) a otros, o se diluyan dentro de otros, o sean absorbidos por otro.

\footnotetext{
${ }^{146}$ Latour, Bruno. Reensamblando lo social. Op. Cit., p.11.

${ }^{147}$ Concepto de la ANT desarrollado en el epígrafe 1.3.3. "In/Móviles in/mutables".
} 


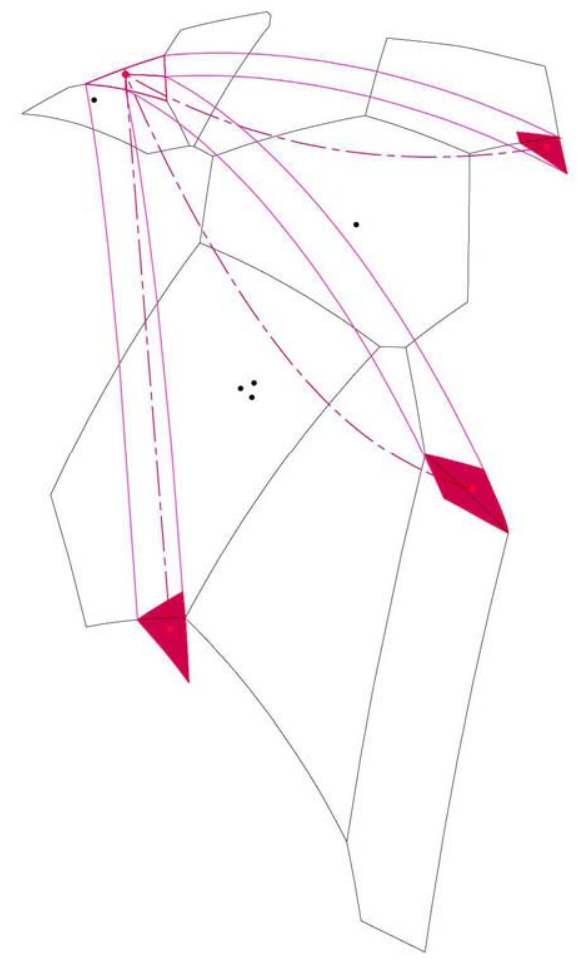

"La lógica de la dispersión y la conexión de manera simultánea y continua es la del desplazamiento de compartimentos ambientales iniciales a lugares espacio-temporales alejados donde se diluyen. Su aparición no tiene porque ser durable y depende de las condiciones de circulación.” 


\section{Operatividades}

Vecindarios. Si el mundo son
espumas múltiples y opera
como un "palacio de cristal del
confort" este palacio no tiene
límites visibles, aunque a veces
se materializan por diversas
causas. Los muros que se
construyen en el planeta son la
materialización del exterior, del
impedimento de acceso al
palacio de cristal. A más muros
más dispersión. Cuando los
"soportes de vida" se hacen
imposibles se provoca la
dispersión. Estos muros a veces
son físicos como la valla de
Ceuta, y otras, como en el caso
de Brasil, se construyen por
drones y sistemas de
televigilancia.

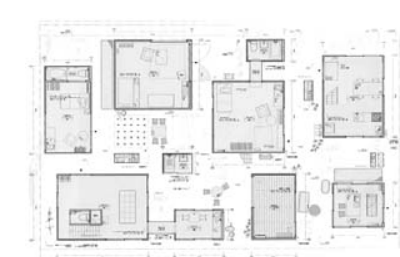

Dispersión doméstica. La

dispersión de las actividades domésticas se realiza no solo como nuestras prácticas diarias sino como proyecto. La Moriyama HouseRyue Nishizawa 2002 establece en la dispersión de los programas domésticos entre interiores y exteriores de la parcela el motor de proyecto. El límite de la casa parece no existir y la casa se diluye con la ciudad. Una ciudad casa hecha de separaciones, conexiones, dispersiones con habitaciones, paisajes, cocinas,

aparcamientos, donde llueve dentro. Ya no hay cas pues todo es casa en la dispersión. $\mathrm{Ni}$ interior, ni exterior. La mujer nómada de Toyo Ato que habita en la dispersión de su práctica por la ciudad habita ahora en un cercado con una dispersión conectada y concentrada.

${ }^{148}$ Fuente del mapa : Élisabeth Vallet, Josselyn Guillarmou, and Zoé Barry, Raoul-

Dandurand Chair, University of Quebec in Montreal; The

Economist.

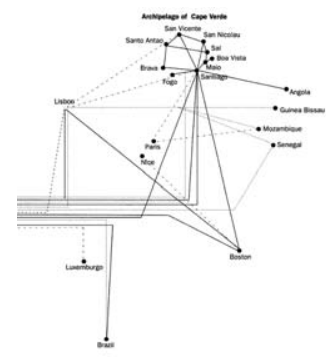

Paisajes de dispersión. El

fenómeno estudiado por el arquitecto Diego Barajas como el de la dispersión de Cabo Verde ${ }^{149}$ da lugar a un archipiélago de relaciones entre nuevas Islas en Brasil, Londres, u Rotterdam que forman, archipiélagos que son también paisajes de la dispersión. Estos paisajes que van más allá de lo geográfico remiten a

"tecnopaisajes, mediapaisajes, ideopaisajes". Estos, forman archipiélagos que se conectan por tecnologías abstractas como la telecomunicaciòn, $o$ espacios físicos como las tiendas étnicas, o los centros religiosos y los imaginarios simbólicos que estas entidades construyen en la dispersión. Los archipiélagos son entonces relaciones híbridas en conexión de la dispersión de los habitantes de entidades humanas y no-humanas de Cabo Verde.

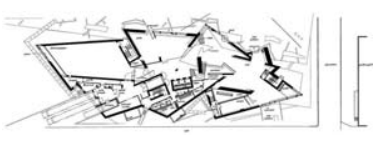

Vacíos dispersos. El museo judío de Daniel LIbeskind en Berlín, 2001 es un espacio de memoria. En una analogía simple entre el vacío y la ausencia. El museo "deja" espacios vacíos que dispersa por la planta y el espacio del museo que quieren materializar la ausencia de los judíos muertos en la segunda guerra mundial.

${ }^{149} \mathrm{Cfr}$. Barajas, Diego Dispersion: A Study of a Global Mobility and the Dynamics of a Fictional

Urbanism. Rotterdam. Episode. 2003.

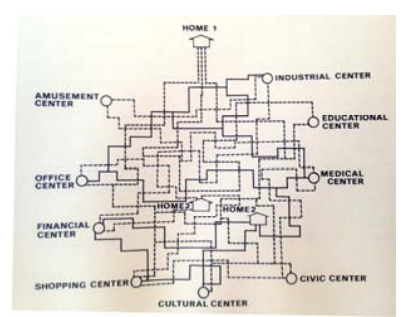

Islas de Conexión. Como hemos explicado el caso del arquitecto Víctor Gruen es paradigmático en la tensión entre dispersión / concentración. La vida suburbana americana de los años 50 y 60 definida por la extensión y la dispersión hace que Gruen piense en nuevos centros, en otras

concentraciones o en islas de conexión que serán los malls como espacios públicos interiores de la ciudad dispersa. Las redes de movimientos en el sprawl entre la casa, el trabajo y los servicios, detecta la necesidad de nuevos espacios para el ocio y la creación de comunidades que "obligue" a los ciudadanos de disponer de tiempo fuera del automóvil. De esta manera los centros comerciales suburbanos nacen como nuevos centros urbanos frente a la dispersión geográfica.

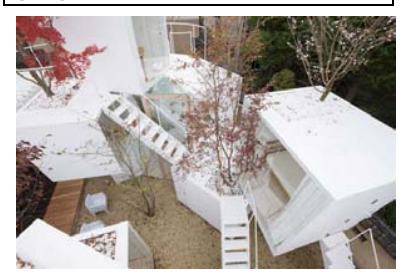

Disper(x)ión. Tras la

Moriyama House $\mathrm{SOu}$

Fujimoto proyecta "House

before house” Una

espacialización completa de la dispersión doméstica. A diferencia de Moriyama. La casa tiene diferentes niveles y las conexiones se hacen materiales en escaleras, barandillas y puntos de paso entre una estancia y otra. En ambas situaciones las celdas, como espacios de insulamiento se han distribuido, separado, extendido en sus límites creando una casa sin exterior ni interior. La propia celda material ha sufrido un autoemparejamiento material múltiple consigo misma. La casa es literalmente una red y una espuma. 


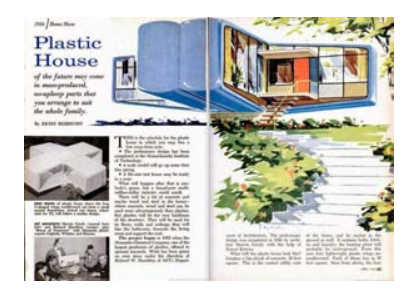

Inscripción para la

dispersión. Cómo hemos ya analizado, la inscripción es el proceso por el cual los "móviles inmutables" pueden traducir los programas de acción a diferentes localizaciones. La Casa del Futuro de Monsanto, es para esta tesis la casa que desplego mayor influencia en la sociedad. La casa como programa de acción para introducir el plástico en los hogares norteamericanos de los 50 y 60 dispersa el conocimiento de consumo de productos domésticos para su venta en otros lugares. El prototipo en el parque Disney de California, las revistas de Disney, Monsanto y la cadena de televisión $\mathrm{ABC}$, componen la mediación para dispersar una forma de consumo doméstico.

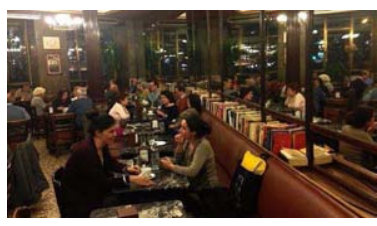

Reconcentración-reterritorialización. Ante la ciudad dispersa estudiada por

Francesc. Muñoz en su término "Urbanalización" donde aeropuertos, gasolineras, cafeterías como estaciones de consumo en la ciudad aparecen como materialización de la ciudad dispersa, prácticas ciudadanas como el Bookcrossing, aparecen como practicas de reconfiguración de la dispersión. Como por ejemplo, las bibliotecas para jóvenes en las gasolineras donde los jóvenes de la ciudad dispersa gastan su tiempo. Proyectos de reconcentración o re-territorialización de procesos urbanos para compensar la dispersión urbana que lleva paradójicamente a la posibilidad de acceso a muchos servicios pero también a la imposibilidad de acceso a muchos otros.

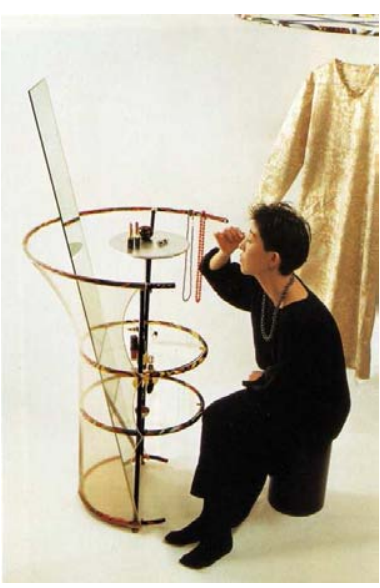

Domesticidades dispersas. La mujer nómada de Toyo Ito. Tokio. 1988 habita en agencia compartida con su Pao. Esta cabaña se compone de una cama y 3 muebles. Un mueble de información inteligente, un mueble para el coqueteo y un mueble para la comida ligera. La casa no necesita nada más pues el resto está disperso en la ciudad. Su casa se distribuye en la ciudad contemporánea pues esta, reúne dispersas pero conectadas el resto de actividades "no intimas" que puede abastecer la vida doméstica de la mujer nómada. Esta vida nómada, se realiza junto con la agencia que comparte con los objetosmuebles de su casa. Estos la permiten disponer de necesidades domésticas fuera de su casa.

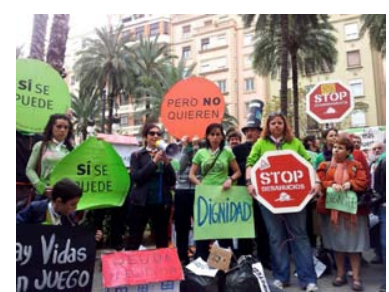

Disper(x)ión concentrada. Ante la dispersión de la información, de las afecciones, y de la práctica urbana, también esta dispersión produce una particular" concentración dispersa" y distribuida en el espacio público de la ciudad con los escraches ${ }^{150}$. Estos suceden dispersos en el tiempo y el espacio de la ciudad, reconcentrando a la ciudadanía y la información que se ofrece a una persona específica. Manifestaciones "customizadas" en la ciudad como por ejemplo las que realiza la PAH en la ciudad de Madrid.

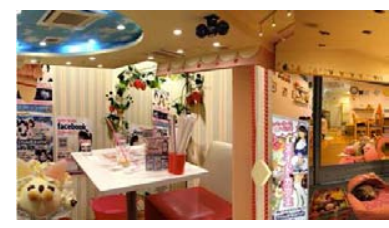

Disper(x)ión afectiva. No solo son actividades las que se sacan fuera de la vivienda.

También afectos y relaciones de intimidad (éxtimas) se dispersan en la ciudad. Outsourced domesticity es una investigación de E. Acosta A.

Balmaseda y C. Larcher 2013. que muestra como en el insulamiento extremo de la ciudad de Tokio, el ciudadano paga por tener afectos por horas en espacialidades dispersas como lugares para cuidar gatos, microceldas para abrazarse a otros y toda una red de entidades que abastecen de afectos que ya no está en casa sino que se dispersan por la ciudad conectada. Aparecen "espumas afectivas" donde el aislamiento es conectado y coincidente en la ciudad.

${ }^{150}$ Los "escraches", son acciones informativas que realizan los ciudadanos a personas del ámbito político, administrativo o militar. Consiste en dar difusión ante los domicilios particulares de estas o en cualquier lugar público donde se las identifique, a los abusos cometidos durante su gestión. 


\subsection{Interescalaridad}

La escala geográfica ha definido la construcción de nuestros exteriores. De la casa, al territorio o de la región a lo doméstico. Es decir, las escalas se han utilizado como un objeto de estudio a priori establecido y estructurante. Lo regional o lo doméstico necesitaban estudios con herramientas particulares para cada caso. Una sensación de lejanía se situaba en las herramientas de estudio de lo geográfico y otras se necesitaban en relación al estudio de lo próximo. Pero, como hemos enunciado en el concepto de proxicuidad, las distancias son pragmáticas y relacionales. La escala próxima de lo doméstico es cercana también a la escala lejana de otras localidades. Es decir hoy tratamos de investigar cómo se articulan las diferentes escalas unas con otras. "Cómo actores diferentes tienen accesos diferentes a diferentes escalas, y cómo algunos actores "saltan" de una escala a otra, de un lugar a otro, y cómo otros actores tienen dificultades para escapar de lo local” ${ }^{151}$. Se produce entonces una situación de interescalaridad en los procesos.

\section{Aproximaciones / descripciones}

Pero si hoy es el globo el que es urbano y hablamos del concepto de urbanización planetaria ¿cómo situar escalas próximas o lejanas? Como situábamos con el concepto de "proxicuidad", la anulación de las distancias métricas y euclidianas lleva consigo una modificación del concepto de escala. Microscópicos y telescópicos son herramientas que hacen cercano lo lejano. El microscopio revolucionó la biología introduciendo una nueva escala de observación. Hoy en día los mapas digitales, nos acercan a una noción de escala progresiva. Donde lo macro y lo micro aparecen en continuidad. La interescalaridad, también será un proceso por el que se conforma la continuidad entre interior y exterior como veremos a continuación. Si tanto Sloterdijk como la ANT nos dicen que no hay local, ni global. Ni tampoco una situación "Glocal". La construcción de las escalas se da en procesos de continuidad y simultaneidad.

\section{Micro-Macro progresivo}

Si en las redes de actores, hemos planteado la necesidad de componer entidades que son híbridas, con agencia compartida y no delimitadas en el tiempo ni en el espacio, pensar en las entidades como actores que desarrollan su plan de acción en una escala estable es, simplemente innecesario, y también peligroso. ${ }^{152}$

\footnotetext{
${ }^{151}$ Massey Doreen. "Lugar, identidad y geografías de la responsabilidad en un mundo en proceso de globalización". Conferencia presentada a la Sociedad Catalana de Geografía el 26 de septiembre de 2003, en el marco de la clausura del XVIII. Congreso de la Asociación de Geógrafos Españoles.

${ }^{152}$ B. Latour. "La Tecnología es sociedad hecha durable". Op. Cit., p.119.
} 
Para Latour, la diferencia entre micro y macro no existe. Al igual que lo local y lo global. Esta condición se da en procesos de continuidad de localidades específicas y situadas. Con las herramientas de la ANT podemos dar cuenta de una progresividad debida a las inscripciones, dispersiones que permiten que una innovación, por ejemplo, se traslade del garaje de Steve Jobs, al resto de los garajes del mundo. "El mundo socio-técnico no tiene una escala fijada ni permanente"153 La explicitación de definiciones micro o macro "revelan en su fracaso, la explicación de la presencia de mediaciones técnicas." ${ }^{154}$

Por último, el tiempo, también forma parte de la condición interescalar. ${ }^{155}$ Los acontecimientos son producto de las alianzas entre agentes y acciones "Los actantes, de manera libre, determinan sus relaciones y asociaciones, transformaciones y tamaños. Son otros actantes también los que marcan su propia medida del tiempo. Tanto el número como la velocidad de los acontecimientos tan solo depende de las alianzas o rupturas ejecutadas por los actores" 156

Si rechazáramos la distinción entre micro y macro nos remitiríamos al concepto de delegación en Latour. Desplazamiento del significado y la traducción de la acción en una expresión diferente. La delegación permite que una acción ejecutada hace tiempo por un actor siga estando activa "Una acción, episodio o acontecimiento social acaecido en el pasado, en un contexto lejano, de dimensión no humana, realizado por actores ahora ausentes o que desbordan la escala de la microinteracción, están aún presentes bajo la condición de que sea trasladada, traducida, delegada o desplazada a otros tipos de actantes o guiones, no humanos: a los objetos." 157 De esta manera si "ser humano requiere compartir con los nohumanos" y los humanos permiten que un orden social sea más o menos duradero y que se intercambien las propiedades entre los niveles micro y macro de la interacción social" "158, la ANT se propone, de esta manera, seguir translocalmente las asociaciones entre diferentes actores o entidades en una línea de acción determinada. "En consecuencia, la ANT permite dar cuenta de importantes diferencias cuantitativas en la extensión de las asociaciones, así como de asimetrías en las capacidades de acción de distintos actor-redes, pero sin distinguir a priori distintos tipos de espacio o de niveles para actores de distintos tamaño." 159

\footnotetext{
${ }^{153}$ Ibidem.

${ }^{154}$ B. Latour "De la mediación técnica" Op. Cit., p.51.

${ }^{155}$ Lo hemos mencionado en el ejemplo del Fracking del capítulo primero.

${ }^{156}$ Fogué, Uriel. Op. Cit., p.150.

157 Tirado y Domenech "Asociaciones heterogéneas y actantes: el giro postsocial de la teoría del actorred" Op. Cit., p.18.

${ }^{158}$ Ibidem.

${ }^{159}$ Ignacio Farías. "La TAR y el examen a la ciudad". Op. Cit., p.22.
} 


\section{$\underline{\text { Local-Global }}$}

Para Sloterdijk en las espumas hay situaciones referidas a los tamaños autónomos indiferentes a la escala del contexto donde se sitúan. En la espuma hay microinsulamientos y macroinsulamientos ${ }^{160}$. Estos los acompañan innumerables y variables espumas en covecindad que se sitúan como un límite más, pues todas las espumas son límite.

En este contexto para Sloterdijk, lo global ha implicado un agrandamiento del mundo. La interescalaridad no puede entenderse como una suma de localidades. A la expresión de lo global "es lo local sin muros" (glocal), que determina el mundo como una suma de provincias, no implica globalidad ninguna pues no es válida para Sloterdijk. El error de relacionar lo local y lo global como el punto y el campo se homogeniza con lo global y lo local. Para Sloterdijk, lo local hoy pone el acento en una localidad extendida en sí misma. "La extensión de las situaciones incluyentes [...] es el cómplice natural de lo persistente"161 Entonces lo global es la saturación de la espuma en un mundo finito. ${ }^{162}$ No hay escala en la espuma, pues esta "engloba" todo el mundo terrestre y simbólico.

\section{Aescalaridad}

Otra de las aproximaciones a las nociones contemporáneas sobre la escala viene de la acepción de una cierta aescalaridad en la arquitectura. Esta noción remite a una cierta idea de ambigüedad escalar. La naturaleza difusa del entorno contemporáneo implicaría una idea de una manifestación flexible y ambigua. La escalaridad remitiría a "una arquitectura que no distingue límites, que se disuelve." ${ }^{163}$ Esta idea de una arquitectura difusa, sin forma, ambigua, no es la que estamos tratando de desarrollar aquí. En la idea de aescalaridad esta implícita una idea de disolución de límites físicos, materiales, etc. Pero la interescalaridad precisamente disuelve los límites conceptuales que imponemos a las escalas en donde actuamos, no visibilizando o no materializando procesos que se dan en otras escalas en continuidad o, en relación.

\section{$\underline{\text { Sin escala }}$}

La noción de la no-escala que desarrolla Federico Soriano, remite a los objetos arquitectónicos que por su tamaño, su relación o su composición no atienden a una relación de proximidad con la escala del entorno. La noción de "sin escala" remite a una autonomía en el objeto, una referencia a sí mismo. No hay relación de escala ni con el hombre (pues no solo hay humanos en un edificio), ni tampoco su

${ }^{160}$ Cfr. P. Sloterdijk, Esferas III.

${ }^{161}$ P. Sloterdijk. En el mundo interior del capital. Op. Cit., p.305.

${ }^{162}$ Cfr. Morin, M.-Eve. "Cohabiting in the globalised world: Peter Sloterdijk's global foams and Bruno Latour's cosmopolitics" Environmental and planning D: Society and space. v.27, 2009, pp.58-72.

${ }^{163}$ Aescalaridad. Op. Cit., AAVV Diccionario Metápolis. 
entorno es siempre estable (como en lo barcos, aviones) ni los procesos derivados de su montaje (como un ordenador). La idea de "sin escala" remite entonces a las características específicas de esos objetos. Esta noción de escala, en su autonomía no contempla la existencia de otras relaciones y mediaciones que se dan en la configuración de los objetos arquitectónicos. Esta consideración nos permitiría pensar que también los objetos "sin escala" están atravesados por múltiples relaciones interescalares en su conformación.

\section{Escalas en continuidad}

Quizás ha sido desde la geografía crítica desde donde se han articulado otras nociones de escala que pueden ayudarnos a situar la noción de interescalaridad. Como explica Steven M. Manson ${ }^{164}$, podemos establecer tres aproximaciones al problema de la escala. La visión realista donde la premisa es que los observadores pueden tener un acceso objetivo a la realidad. La escala jerárquica donde se interviene de manera ascendente y descendente sobre ellas. Y por último la aproximación constructivista de la escala que establece que la escala es una construcción social ${ }^{165}$.

Ciertamente, esta geografía crítica coincide con la ANT en que estos espacios o escalas se corresponden con redes de actores y objetos, "pero la diferencia clave es que comprenden estos espacios como subyacentes a las prácticas de estos agentes. Este 'subyacer' supone una separación entre agentes y espacios que no es solo analítica, sino también una separación histórica y real. Esta es precisamente la tesis de que las escalas espaciales son productos históricos." ${ }^{166}$

Si establecemos una continuidad en las escalas, por ejemplo, pensemos en cómo la mirada desde una perspectiva de género, de las unidades familiares y lo doméstico, transforma la manera de entender lo doméstico antes analizado como un sistema atomizado de unidades discretas y sin relación. ${ }^{167}$ Las distinciones que la modernidad estableció entre el espacio privado y doméstico, y el espacio público invisibilizan la construcción procesual y en continuidad entre ambas esferas que son el resultado de un proceso, de una identificación separada y nominativa.

Los trabajos de Sallie A. Marston estudian la continuidad de los "planes de acción” de la modernidad que alcanzaron todas las escalas, desde el espacio

\footnotetext{
${ }^{164}$ Manson, Steven M. "Does scale exist? An epistemological scale continuum for complex humanenvironments” System. Scient Direct, Minnesota, 2006.

${ }^{165}$ Marston. Sallie A. "The social construction of scale." Progress in Human Geography n.24, v.2, 2000, pp.219-242.

${ }^{166}$ Tirado y Montaner Op. Cit., p.18.

${ }^{167}$ Para la escala de observación mirar: Lam y Quattrochi,1992 y para la escala de explicación mirar Schoerder y Suryanata, 1996.
} 
urbano, el estado o las instituciones, al hogar, la familia, la identidad personal o el género. Los interiores domésticos no se encuentran desvinculados de la ciudad y viceversa. Ambos se construyen en simultaneidad. Desde este punto de vista podemos citar tres características de la interescalaridad

1. La escala no es un hecho exterior esperando ser descubierta sino concepciones de la realidad enmarcadas. ${ }^{168} \mathrm{O}$ como sugiere Neil Smith no hay una escala ontológicamente dada acerca de la división tradicional entre casa y lo local. Urbano y regional, nacional y de escala global. La diferenciación de las escalas geográficas se establece mediante estructuras geográficas de las interacciones sociales ${ }^{169}$

2. Los resultados de los marcos escalares son tangibles y tienen consecuencias materiales en el día a día las estructuras macro. Luego no es un concepto abstracto, sin repercusiones materiales. La escala no es exterior a la realidad.

3. Los marcos escalares, con consecuencias retóricas y materiales, son siempre contradictorios y en disputa, y no siempre son duraderos. Luego no existe un observador objetivo externo ni a la escala ni a la realidad.

\section{La escala no es un producto estructurante}

Según la ANT y los ensamblajes urbanos la cuestión no es que no hay escalas, sino redefinir lo que entendemos en la noción de escala como producto histórico, sin desligar la escala de las prácticas y los procesos que lo originan. De esta manera, entender la escala como un efecto colateral de la formación de redes y ensamblajes, ni anterior ni estructurante. ${ }^{170}$

En este contexto sobre la construcción relacional de la escala, más que la disposición geográfica, cartográfica u operacional ${ }^{171}$, hace que desplacemos el interés desde el espacio o desde la escala de la ciudad a preguntarnos por cómo se produce y se performa la ciudad o la arquitectura. La pregunta será ¿cómo se compone el "espacializar" o el "temporalizar" en situaciones específicas interescalares?

\footnotetext{
${ }^{168}$ Delaney y Leitner. 1997, pp.94-95.

${ }^{169}$ Smith, Neil. Op. Cit., The limits to scale.

${ }^{170}$ Cfr. Farías, Ignacio. "The politics of Urban Assemblages" City: analysis of urban trends, culture, theory, policy, action. 2011. v.15, n.3-4, p.370.

${ }^{171}$ Op. Cit., Lam y Quattrochi. Libro sobre las escalas.
} 


\section{$\underline{\text { Arquitectura interescalar }}$}

Ante la imposibilidad de "fijar" una escala operativa para la arquitectura podemos caracterizarla o ofrecer un marco operativo que la sitúe. El texto del arquitecto Eduard Bru ${ }^{172}$ explica con suficiente claridad lo que estamos tratando de decir, y no podríamos decirlo mejor.

"Atender tanto a lo que está entre las cosas como a las cosas en sí mismas. Constatar la variabilidad y el cambio desde experiencias a gran escala pero extrapolable a muchas otras. La acción del proyecto como compromiso entre escalas. La conciencia de que el proyecto se determina e influye en multitud de ámbitos más allá de los que se le otorgan por razón de mera contigüidad física. La consideración de la labor del proyectista como capacidad de traslación, de viaje entre escalas. Hoy somos capaces de entender y sentir simultáneamente diversas escalas y ámbitos de percepción acción Actuar sobre lo próximo, lo inmediato, lo táctil y entender al tiempo muchos otros receptáculos y dimensiones que modifico también con mi acción, es un buen programa de trabajo para los próximos años." ${ }^{173}$

172 Bru, Eduard. "La mirada larga" en Nuevos Paisajes, nuevos territorios. Barcelona, Actar/Macba, 1997.

${ }^{173}$ Ibidem 


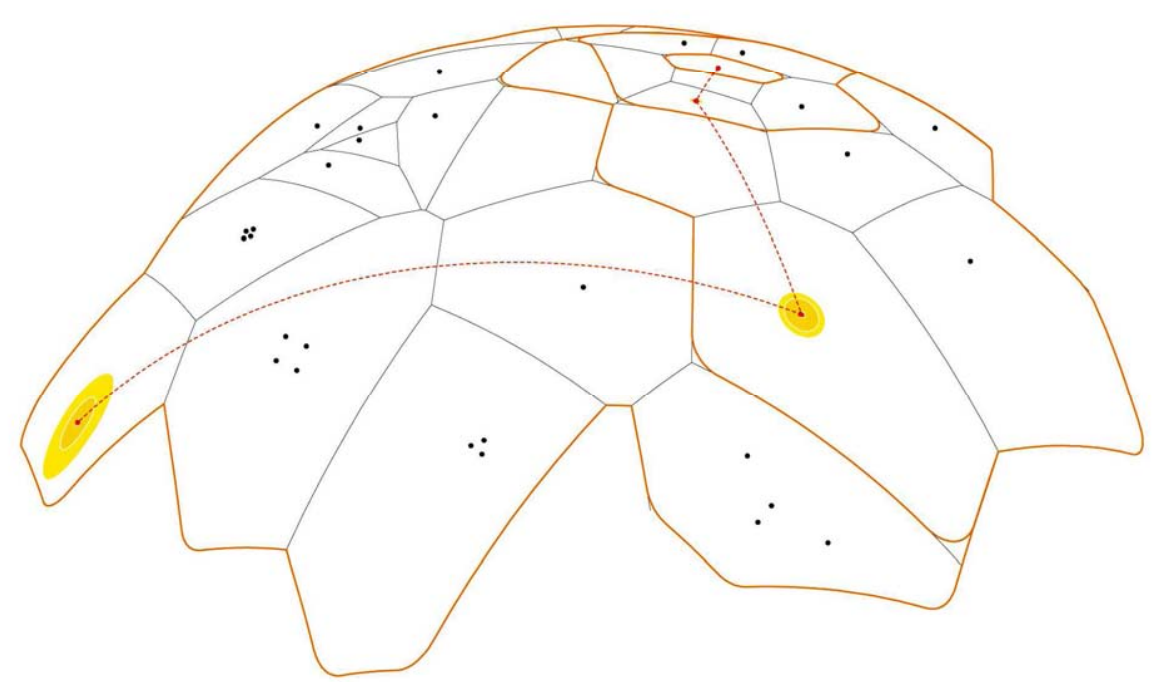

"Los procesos arquitectónicos y urbanos tienen continuidades en el espacio y en el tiempo, y estos a su vez afectan a diversas escalas al mismo tiempo. No se trata de pensar desde la ausencia de la escala, sino de pensar en la acción arquitectónica como un detonante de trayectorias y afecciones en agencias múltiples, embebida en procesos de múltiples escalas simultáneamente.” 


\section{Operatividades}

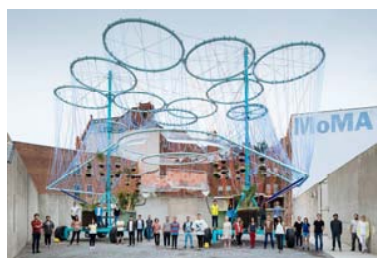

Redes interescalares. La red interescalar se materializa en el proyecto "Cosmo" de Andrés Jaque MOMA PS1. NY. 2015 en una ecomáquina de depuración de agua. El planteamiento de la escasez de agua se plantea como un sistema interescalar en nuestras prácticas diarias.

Tubos, tanques, sistemas de irrigación provenientes de la industria estandarizada provocan junto con microorganismos y especies vegetales la depuración y filtrado de 3000 galones de agua. Por un lado los actores del proyecto provienen de lugares y escalas diferentes desde los tubos españoles a los microorganismos americanos. Por otro lado, la arquitectura del proyecto se desmonta ofreciendo una nueva vida a las infraestructuras en otros lugares y las plantas que se distribuyen en el vecindario expandiendo lo local a otras escalas.

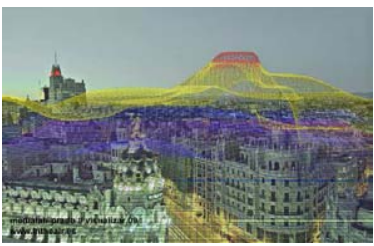

Inmateriales interescalares. El problema de la contaminación del aire no puede plantearse sin una aproximación interescalar e híbrida sobre sus agencias y materializaciones. La tesis de Nerea Calvillo y sus investigaciones explicitan la necesidad de componer una "sociedad ampliada" para visibilizar la cuestión. Dispositivos tecnológicos, sistemas de medición, prácticas ciudadanas, políticas públicas, movilidad e industria, etc.

Todo un ensamblaje interescalar con repercusiones espaciotemporales delegadas de un actor a otro y de una espacialidad a otra en continuidad y

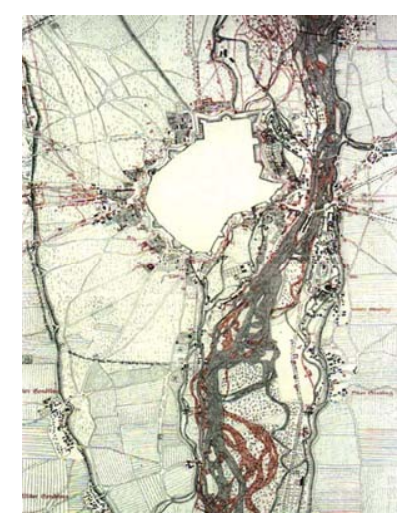

La escala no es un producto estable. Los ríos son entidades socio-técnicas. Estas entidades se co-construyen por actores híbridos. En el caso del río Isar en Munich, la activación del plan de la Bavarian Water Management Agency de Munich, coproduce el río bajo el slogan "New Life for the River Isar". Es decir, la institución, junto con otros actantes dará una nueva vida (y con ello nueva morfología, caudal, calidad del agua, etc.) al río Isar. La intervención no posee una escala concreta pues esta, como puede verse en el mapa evolutivo, estará compuesta por las interven-ciones de multitud de agentes a distancia del ámbito del río en la ciudad, y en temporalidades diferentes. No se trata de una construcción socio-ambiental sino de una cosmopolítica en el antropoceno. ${ }^{174}$

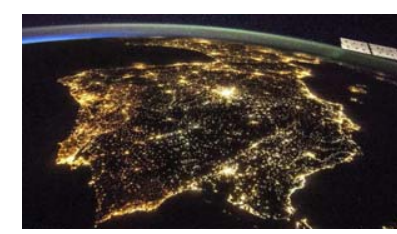

Interescalaridad progresiva El impacto de las farolas y luminarias como elemento discreto se visibiliza en dos pasos (potencia de 10) en su impacto como contaminación lumínica. La imagen de la península Ibérica, tomada desde la ISS) es un lugar, al igual que lo es el espacio de la farola en una calle de Madrid. Lo global, es una red de actores localizados.

${ }^{174}$ Para saber ver Cordula Kropp en "River Landscaping in Third Modernity: Remaking Cosmopolitics in the Anthropocene" en Op. Cit., Yaneba, Zaera-Polo.(Eds.)

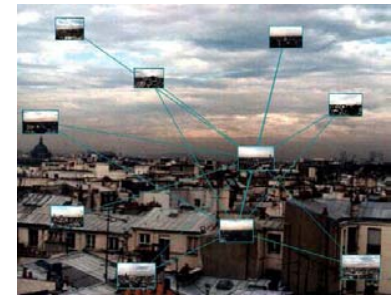

La performación de la ciudad. Si como hemos dicho hoy no se trata de la producción del espacio o las escalas, la ciudad deviene en una producción interescalar de infraestructuras, materialidades y prácticas. El proyecto de Investigación de Bruno Latour Paris Invisible city muestra como la ciudad "ni es fragmentada, fracturada, atomizada ni desestructurada, pero tampoco homogénea, uniforme, global, estandarizada, racionalizada o americanizada." Describir las trayectorias interescalares de la ciudad es su propósito.

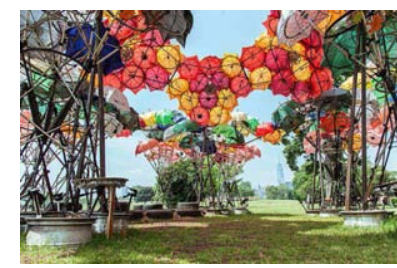

Devenir Arquitectura. Pensar la operatividad de la interescalaridad es intervenir en un proceso donde en un instante determinado un objeto como los paraguas de NY, trípodes de fotografía o ruedas de bicicleta devienen arquitectura de sombreo en un parque. El proyecto de Izaskun Chinchilla arquitectos. NY, 2015, recoge paraguas abandonados de NY para construir el pabellón que más tarde se fraccionara para ser una sombrilla doméstica y lámparas de araña. La arquitectura es un instante dentro de un proceso de vida de objetos que transitan por múltiples escalas espaciales y temporales. 


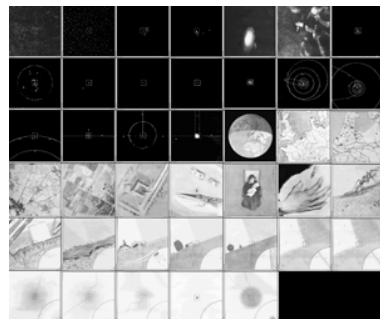

La escala es un logro del propio actor. En 1957, se publica el libro de "Cosmic View” de Kees Boeke. El libro subtitulado como el universo en 40 saltos ofrece una visión secuencial hacia fuera y hacia adentro, estableciendo como punto de partida en ambos casos el cuerpo, en este caso de una mujer. Una escala secuencial en escala logarítmica de base 10 muestra las diferentes vistas de la mujer, la mujer en el espacio público, el edificio donde se alberga, la ciudad donde se encuentra, el territorio local que habita, la nación donde se encuentra. Este libro, antesala de la famosa película de "Powers of ten" de Charles y Ray Eames, describe la realidad como la suma de escalas diferentes que nos ofrecen percepciones diferentes, pero de alguna manera percepciones, secuenciales, direccionales, escalares en distancias que aumentan en la misma proporción o que disminuyen hasta los límites conocidos en ese momento entre microscopios electrónicos o satélites interespaciales. Como dice B. Latour “¿Dónde está el microscopio capaz de captar el ADN de la célula? ¿Dónde está montada una cámara para mostrar la galaxia entera? ¿Qué regla podría ordenar imágenes en una gradación tan regular? The powers of Ten es un video maravilloso pero perfectamente engañoso"

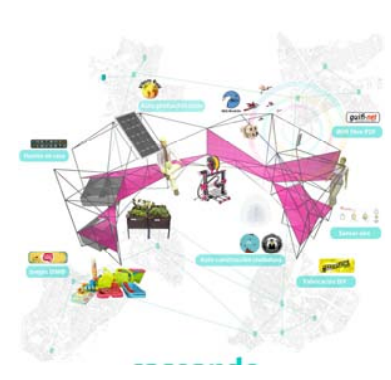

Lo doméstico desde pequeños objetos

tecnológicos ciudadanos. El

proyecto caseando del autor de esta tesis, junto a VIC, explicita como un prototipo pequeño opera desde una enorme variedad de escalas en el territorio. Caseando construye una casa en el tiempo de una semana con dispositivos ciudadanos autoproducidos como impresoras 3D, paneles solares, pequeños huertos urbanos, casas de pájaros, redes de wiki $\mathrm{p} 2 \mathrm{p}$, etc. Todo un conocimiento ciudadano que se pone en práctica en el espacio público a diario pero que en el proyecto se confronta con lo doméstico. El prototipo se piensa en interescalaridad desde la transferencia de prácticas urbanas deslocalizadas al interior de la casa. El conocimiento adquirido lo transfiere cada visitante a su propia casa replicando los objetos y tecnologías. De esta manera se construye un espacio colectivo en la ciudad desde prácticas individuales domésticas. El proyecto en su itinerancia recorre diferentes ciudades haciendo recursivo su procedimiento interescalar. No es una cuestión de tamaño sino de alcance y capacidad transformadora en diversas escalas.

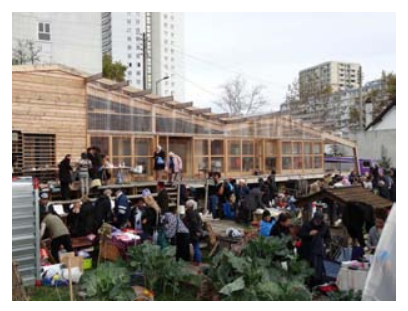

Resiliencia Urbana. Los proyectos R-Urban de Atelier d'architecture autogérée se componen desde el ensamblaje de entidades híbridas y diversas con recursos propios en afecciones domésticas, de vecindarios y escalas locales. Los procesos de resilencia urbana trata de reconfigurar los procesos interescalares y transnacionales en procesos de una interescalaridad más local. Una re-circulación del consumir para producir a un producir-consumir lo producido de la manera más local posible. ${ }^{175}$

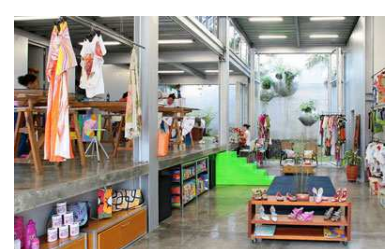

\section{Interescalaridad y} agencialidad híbrida. Ediciojardín nectarífero hospedero para mariposas de Husos Arquitectura. Cali 2008. El edificio como entidad híbrida (edificio-jardín) y la composición de la entidad entre humanos (empresa privada de elaboración de telas) y no humanos (plantas hospederas, mariposas, clima de Cali) Estas agencias compartidas, distribuyen roles para proponer un proyecto que se piensa desde afecciones en distintas escalas espaciales y temporales como garantía para continuar e incrementar la diversidad de la ciudad de Cali. Las mariposas es un agente afectado por este proyecto y motor de la arquitectura del edificio que se manifiesta en las distintas especies de plantas hospederas de mariposas, trepadoras y arbustivas que a su vez, dan la imagen del edificio. La mariposa es un actor no tan visible receptor de las políticas ecosistémicas del edificio.

\footnotetext{
175 http://r-urban.net/accueil/
} 


\subsection{Transparencia}

Los límites entre el interior y el exterior se han materializado en muros y fachadas. "Y una fachada revela en la misma medida que oculta" ${ }^{176}$. A su vez, los límites separan de la misma manera que unen. En este entorno, el concepto de transparencia puede tener otras nociones más allá de la transparencia material.

\section{Aproximaciones / descripciones}

La RAE define transparencia en su primera acepción sobre un cuerpo "A través del cual pueden verse los objetos claramente" y en su tercera como "que se deja adivinar o vislumbrar sin declararse o manifestarse" y a su vez en la cuarta acepción como "claro, evidente, que se comprende sin duda ni ambigüedad." ${ }^{177} \mathrm{La}$ misma definición posee significados paradójicos entre claridad y ausencia de ambigüedad, y lo que se deja adivinar sin declararse." sería lo difuso, lo no accesible, lo que intuimos. El término, es en sí mismo un término en conflicto. Y esto lo hace tremendamente atractivo para indagar en la amplitud de sus aproximaciones.

La arquitectura ha venido utilizando las acepciones que, Colin Rowe y Robert Slutzky, manifestaron como "transparencia literal y fenomenal." ${ }^{178}$ Estas acepciones parten de una definición de transparencia definida por Gyorgi Kepes en "El lenguaje de la visión" que establece un punto de partida.

"La transparencia significa la percepción simultánea de distintas locaciones espaciales. El espacio no sólo se retira sino que fluctúa en una actividad continua. La posición de las figuras transparentes tiene un sentido equívoco puesto que tan pronto vemos las figuras distantes como próximas." 179

Así. C. Rowe y R. Slutzky, sitúan la transparencia literal como una cualidad material, por ejemplo en una pared de vidrio o una cualidad inherente a una organización compositiva, por ejemplo el cuadro de "El Portugués" de Braque. Los autores establecen una distinción entre una transparencia real o literal y otra aparente o fenomenal. Pero hoy tras la extensión de las capacidades de agencia entre humanos y objetos tecnológicos, nuevas materialidades y nuevas instituciones urbanas con sus correspondientes procesos de comunicación y organización, aumentan más si cabe la polisemia del término.

\footnotetext{
${ }^{176}$ Pardo, J.L. Las formas de la exterioridad. Op. Cit., p.209.

177 RAE. Transparente.

${ }^{178}$ Escrito en 1955-1956 en colaboración con Robert Slutzky y publicado por primera vez en Perspecta, 1963. Reeditado bajo el título Transparency, por B. Hoesli (ed.), Birkháser, Basilea, 1968.

${ }^{179}$ En Kepes, Gyorgi. Language of vision. Paul Teolbald and company, 1969.
} 


\section{Transparencias turbias}

Las espumas como sistemas de vecindades, aislamientos y conexiones, al igual que las sociedades, dice Sloterdijk, son medio transparentes medio opacas. ${ }^{180}$ "Desde la perspectiva técnico-mediática la sociedad de celdas espumas es un medio turbio que posee cierta conductibilidad para informaciones y una cierta permeabilidad para materiales." 181 Aunque las visiones panorámicas y transparentes resultan imposibles. "Desde la espuma se abren perspectivas a lo colindante, $[. .$.$] pero las$ super-visiones concluyentes del mundo-uno no solo resultan inaccesibles, sino imposibles y si se entiende bien tampoco deseables." ${ }^{182} \mathrm{El}$ medio turbio en el que se mueve la espuma, es decir las sociedades y sus arquitecturas, se entienden desde lo plural como la imposibilidad e indeseabilidad de una transparencia panorámica y total. Las acepciones de transparencia están también ligadas al control. El panóptico como estructura transparente ha dado paso hoy al holóptico. Todos en la labor colectiva de la vigilancia se miran y se hacen semi-transparentes al resto. Esta transparencia también podíamos denominarla transparencia en modos de extimidad. $Y$ es una transparencia turbia.

Por otro lado, el palacio de cristal es una estructura transparente pero no accesible para todos. La transparencia, pone en duda la posibilidad de acceso. Para nosotros será importante en esta tesis la noción de transparencia ligada a la idea de acceso. Una vez dentro del invernadero de cristal, Europa por ejemplo, se facilita el acceso a muchos medios. La transparencia también es una cortina de aire caliente que uno atraviesa al entrar en un centro comercial.

\section{$\underline{\text { Redes opacas o transparentes }}$}

La noción de red (ANT), es en sí misma una noción que implica transparencia. Las descripciones del actor-red visibilizan las redes ocultas, las agencias no desveladas. Internalizan en la red lo que está en el exterior, lo conectado o lo no visible. De esta manera el proceso de inclusión y descripción es también un proceso de transparencia.

Pero para la ANT el proceso de acceso a la capacidad de acción, a la información, por lo tanto también a la idea de transparentar, es el de descajanegrizacion. La cajanegrización o encerrar en una caja negra, según la expresión de los STS, en la definición de Bruno Latour es "el modo en el que un trabajo científico y técnico se vuelve invisible como consecuencia de su propio éxito. Cuando una máquina funciona eficazmente, [...] basta con fijarse en los datos de entrada y salida, es

\footnotetext{
${ }^{180}$ P. Sloterdijk. Esferas III. Op. Cit., p.53.

${ }^{181}$ Ibidem

182 Ibidem
} 
decir, no hace falta fijarse en la complejidad interna del aparato o del hecho." ${ }^{183}$ Lo que sucede entonces es que cuando más éxito tiene un producto, objeto o hecho, más opaco se vuelve.

Por el contrario, el proceso inverso, el de abrir la caja negra el de hacerla más transparente y accesible, podemos denominarlo descajanegrizar. Según Andrés Jaque, este proceso podemos definirlo como una herramienta operativa para la arquitectura como uno de sus objetivos. "Abrir las cajas negras con arquitecturas que permitan acceder a la lectura, la evaluación y la toma de decisiones." ${ }^{184}$ Esta aproximación, implica la posibilidad que otros agentes no arquitectos puedan acceder al nivel de toma de decisiones sobre los procesos que la arquitectura conlleva. Esta noción de transparencia, basada en la posibilidad de acceso a informaciones y conocimiento que se cajanegriza, permite que la arquitectura también sea un proceso que pueda desvelarse más transparente en sí mismo.

\section{$\underline{\text { Interficie }}$}

Relacionado con la cajanegrización de las tecnologías, la transparencia también pone en juego a la información. "La transparencia de esta información es el resultado de una mediación técnica" ${ }^{185}$ La virtualidad de la transparencia aparece entonces en procesos de mediación como las interfaces. La virtualidad o la apariencia de transparencia aparece en la sensación de inmediatez de la interface. Latour dirá que es también una caja negra.

Hoy en día, muchas de estas mediaciones se han convertido en inespaciales. La transparencia no remite solamente entonces a una relación material con el entorno inmediato. La interface como extensión del cuerpo garantiza la continuidad y conexión de las relaciones, las formas y las diferentes espacialidades se han convertido en interfaces, superficies de contacto y mediación entre sistemas de funcionamiento independiente. No nos referimos a las interfaces como instrumentos o extensiones, en la versión de McLuhan, que podríamos llamar extensiones del cuerpo exosomáticas, como lo es el ratón de ordenador que extiende nuestra mano y la transforma en cursor, o la pantalla de la computadora como interfaz entre el usuario y el disco duro; sino a la posibilidad de pensar en la evolución de la superficie y la interfaz como una interficie ${ }^{186} \mathrm{La}$ interficie como la superficie que no permite delimitar una exterioridad ni una interioridad pues media en las relaciones entre ambas. Por ejemplo cuando la superficie de un objeto, actual o virtual, nos habla por medio de sus formas, texturas, colores, etc.

\footnotetext{
${ }^{183}$ Latour Bruno. La esperanza de pandora. Op. Cit., p.362.

${ }^{184}$ Definición en el glosario abierto de VIC.

${ }^{185}$ Muniesa, F. Luque, E. Chinchilla, I. Jaque, A."Ejercicios de empirismo conceptual en Arquitectura" AIRB. Revista de Antropología Iberoamericana. 2005, Ed. Electrónica. Nov-Dic. Madrid, p.6.

${ }^{186}$ Interficie: Superficie + Interfaz.
} 
convierte a esta interficie en el lugar de la interacción, el espacio donde se desarrollan las mediaciones.

Por ejemplo, la SuperSurface de Superstudio, podría leerse como una protointerfice. Y sería una interficie en desarrollo pues a pesar de su conexión total y su infraestructura energética, la superficie no reacciona al uso que de ella se esté teniendo o no. La superficie no manifiesta una reacción al uso, no interactúa con la disposición de los cuerpos sobre ella. Las grandes pantallas interactivas de hoy en día comienzan a funcionar como interficies donde el usuario, no solo está fuera de la pantalla-objeto, sino también dentro de ella, y no de una manera estática. Sus movimientos, interacciones y órdenes, mediadas por la tecnología específica del sistema que sea, modifican la conducta del individuo en ese entorno y la performación de su espacio. Si pensamos, no en pantallas pequeñas, sino en grandes superficies urbanas de interacción, como la desarrollada por BIG y Audi en el proyecto "Driveless city "187, podemos entender el concepto de interficie. Pero en este proceso establece una transparencia aparente, si opera como una cajanegrización de la propia tecnología de mediación de la interficie.

\section{Superposición}

Otra acepción, sería la enunciada por Federico Soriano de la superposición, como transparencia fenomenal. ${ }^{188}$ En el mismo sentido Amadeu Santacana lo explicará como "la superposición fenomenológica de todas las capas arquitectónicas como solapamiento transparente que hace que los distintos elementos entren en relación y se mantengan las máximas intensidades de sus propiedades." ${ }^{189}$

Lo interesante de esta acepción es pensar la transparencia también en términos temporales y no solo espaciales o de relaciones híbridas. "La discontinuidad es consecuencia y al mismo tiempo causa de superposición. El tiempo contemporáneo es una dispersión de puntos, de fechas, de muchos tiempos y de tiempos diversos compartiendo simultáneamente. Tiempos complementarios, tiempos simultáneos, Tiempos contrapuestos." ${ }^{190}$ Este fenómeno de la superposición también está asociado al de la información. "La sobreinformación, produce borrosidad e incertidumbre" ${ }^{191}$ Esta acepción nos llevaría nuevamente a la primera. La transparencia hoy es aparente y también turbia, difusa, borrosa.

\footnotetext{
${ }^{187}$ Para ver el proyecto consultar: http://audi-urban-future-initiative.com/blog/bjarke-ingels-and-big ${ }^{188}$ Soriano, Federico. Sin tesis. Op. Cit., p.140.

${ }^{189}$ Santacana, Amadeu. "El acontecimiento como un mundo en yuxtaposición" Tesis doctoral. UPC. Barcelona. 2013.p.8,

${ }^{190} \mathrm{Ibidem}$.

${ }^{191}$ Ibidem.
} 


\section{Transparencia}

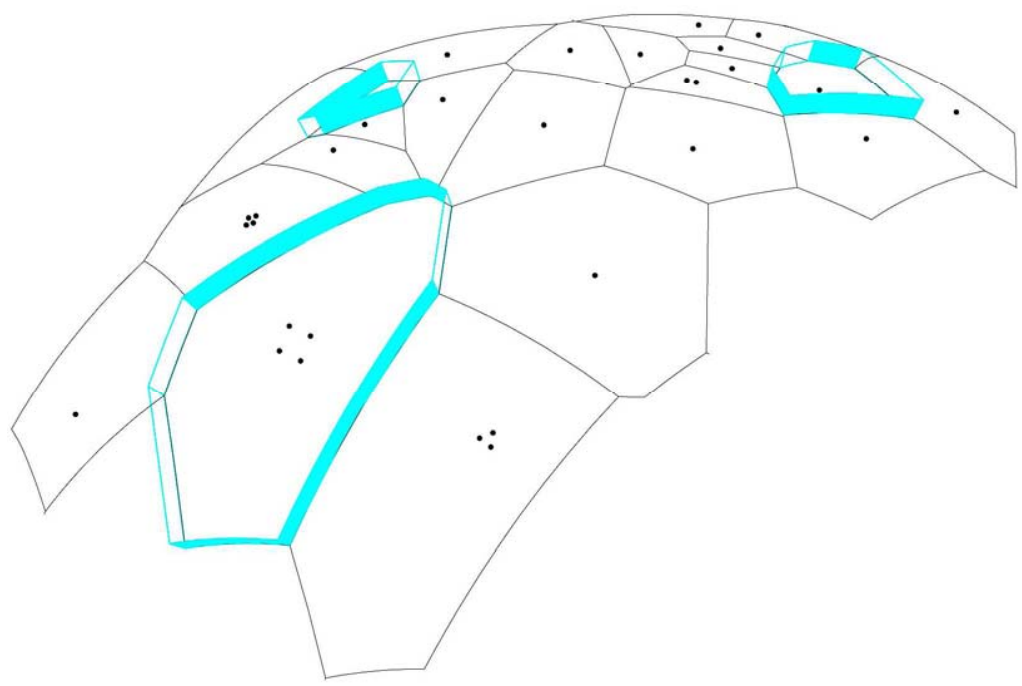

"Es la percepción simultánea, superpuesta de distintas localizaciones espaciales y temporales. Ante la imposibilidad de acceso a procesos, objetos o hechos, la descajanegrización aparece como una nueva aproximación a la transparencia, también, arquitectónica." 


\section{Operatividades}

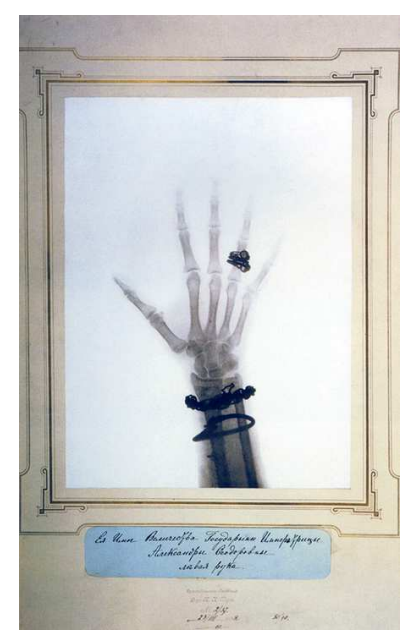

$\mathrm{El}$ acceso al interior del cuerpo. Si el cuerpo humano hace público su interior mediante los rayos-X la arquitectura desde ese momento, también hace públicos sus interiores, estructuras, esqueletos. Para Beatriz Colomina la transparencia en las casas de vidrio como la Farnsworth va de la mano de los avances médicos en la investigación de tecnologías para la transparencia o el acceso al interior del cuerpo.

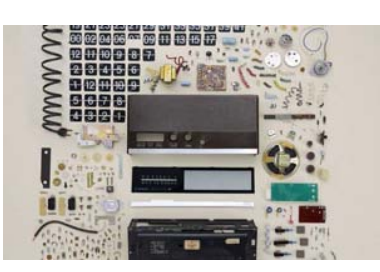

Descajanegrizar. El objeto, es más transparente desmontado y por piezas que ensamblado como caja negra. Pero esto no es suficiente para tener acceso a él. El conocimiento, los datos no solo deben ser expuestos "sino repuestos, representados, reconstruidas, reintroducidos y modificados para que su transparencia no sea aparente y pueda generar confianza." 192 Que también puede entenderse como una transparencia personal. Es transparente porque confío en él.

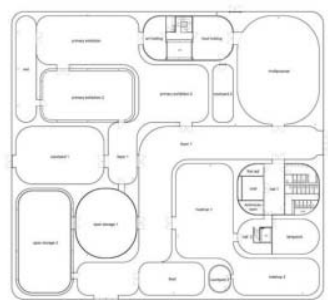

Transparencia turbia. Quizás la noción de Sloterdijk, sobre la transparencia turbia de las espumas, puede materializarse en el proyecto de Sanaa en Toledo, Ohio 2007. Decenas de burbujas de vidrio componen el proyecto como si de aire y agua conformaran las "paredes de Plateau". El vidrio ya no es transparente como lo era en la Farnsworth sino que su transparencia literal deviene en transparencia turbia. Como dice B. Colomina "va más allá de producir un reflejo del interior o del exterior. Todo el espacio es un límite. No hay claramente una distinción entre exterior e interior" ${ }^{193}$ Como las espumas, el proyecto tiene una transparencia turbia.

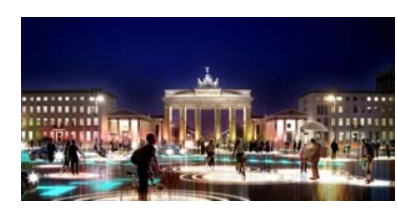

Interficies. Transparencia aparente. Podemos decir que las mediaciones tecnológicas que hacen las interfaces se han expandido al ámbito urbano en interficies( superficies mas interfaces) Estas pantallas que alimentan la transparencia de imágenes y conexiones, lo hacen solo de manera aparente, como en el proyecto Driveless city de BIG. La mediación sigue siendo una caja negra que no es accesible para una mayoría. No se puede discutir, ni participar en ella. Está cajanegrizada.

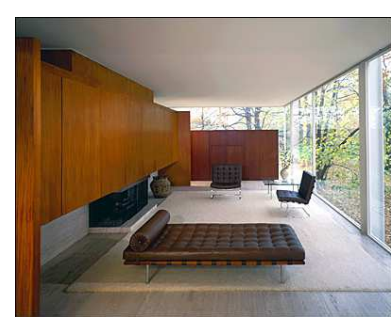

Lo público y lo privado es un efecto óptico. La casa farnsworth muestra tanto como oculta. Si el modernismo construye un nuevo régimen visual como una

transformación de los límites de la privacidad - una dictadura cultural sobre cómo debemos vivir. Si como dice J.L.Pardo

"Una fachada revela en la misma medida que oculta" $\mathrm{La}$ casa Farnsworth construye la opacidad del armario, como símbolo de la supuesta homosexualidad oculta de Edit Farnsworth según Preciado. "Ella vive en un espacio postdoméstico, al exponer las estructuras teatrales de ocultamiento y exhibición que fundan los regímenes de visibilidad privados y públicos durante los años cincuenta." 194
192 Op. Cit., Izaskun Chinchilla, Izaskun, et all. ."Ejercicios de empirismo conceptual en Arquitectura”.

\footnotetext{
${ }^{193}$ Op. Cit., B. Colomina

"Blurring trasparency"
}

${ }^{194}$ Op. Cit., Preciado, Paul B.

"Mies-conception: La casa Farnsworth y el misterio del armario transparente". 


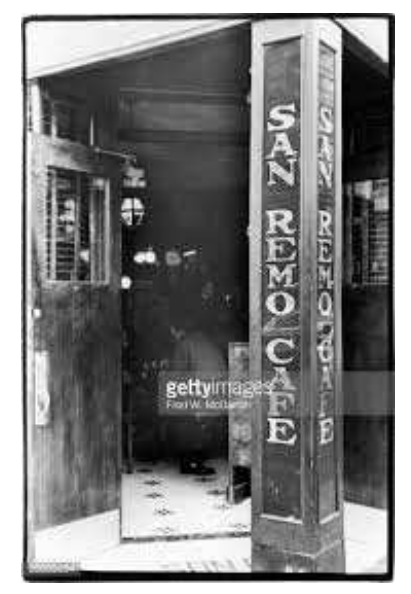

Gestión de la visiblidad. El club San remo en NY, era un lugar para exponerse. Su fachada de vidrio, no sería particularmente interesante si no fuera porque ponía en juego la gestión de la visibilidad sobre esa transparencia. Como explica P.B.Preciado durante los años cincuenta, el "cristal", la "invisibilidad" y la "transparencia" son tropos que nombran condiciones de ciudadanía ambiguas en relación a la visibilidad pública, como en los casos del inmigrante, el judío o el homosexual." ${ }^{195} \mathrm{La}$ fachada de vidrio del Club San Remo trasgrede los límites de la visibilidad impuestos en el espacio público a otros cuerpos no heterosexuales.

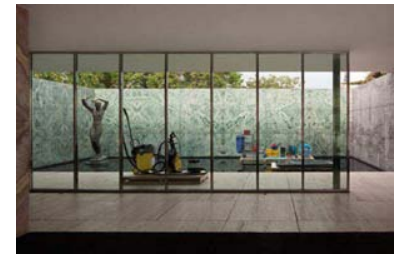

La transparencia del día a día. La instalación Phantom de A. Jaque 2013 dispone todos los "soportes de vida" que hacen que el pabellón se mantenga inalterable su imagen tal como la concibió su autor M.V.d.R para la exposición de 1929. El proyecto describe la red de relaciones que normalmente queda oculta en su representación del día a día. "La intervención saca a la luz todo este contexto invisible formado por el tejido de personas, tecnologías e instituciones que todavía hoy hacen posible que siga adelante." 196

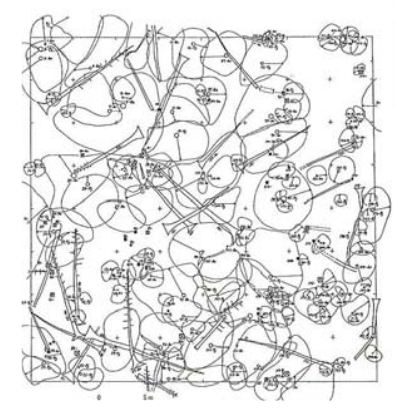

Transparentar urbanidades En el Kanagawa Institute of Technology de Junya Ishigami, lo local y lo global fluctúan en un espacio de límites ambiguos. La transparencia de M.V.d.R obligaba a arquitecturas de lugares universales. Ishigami proyecta una nueva flexibilidad "Revelando la realidad en lugar de darle forma."

Transparentar la realidad del funcionamiento contingente y volátil del instituto permite a Ishigami construir nuevas redes de relación entre los objetos, muebles y humanos no establecida anteriormente. El "espacializar" es diferente al dar forma al espacio. El proyecto se conforma con la complejidad de un lugar urbano, en interacción entre lo móvil y lo inmóvil, lo micro y lo macro, lo humano y lo no humano.

\footnotetext{
${ }^{196}$ De la memoria del proyecto.
}

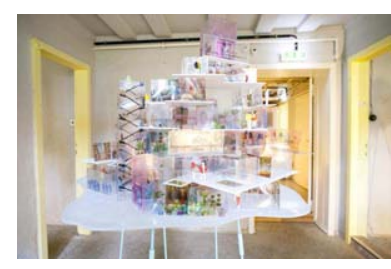

La invisibilidad doméstica.

Algunos procesos urbanos, como los desahucios, siguen siendo formas de

desplazamiento poco visibles y desconocidas para muchos. En este proceso, la ciudad invisibiliza en la individualidad de cada caso, un problema colectivo de primer orden. El del acceso a la vivienda. El proyecto del autor y VIC-SIC Gropius Evicted transparenta las redes interescalares que los stakeholders o agentes interesados del proceso tienen sobre los shareholders o agentes afectados por el proceso. Decisiones que se toman por entidades como Blackstone en NY tienen afecciones sobre la domesticidad de Marcheline, por ejemplo. La investigación instalación con la

Hypermaqueta de domesticidades desahuciadas encuentra en la transparencia el modo de visibilizar lo oculto y los procesos personales tras los desahucios generalizados en la ciudad de Madrid.

\footnotetext{
195 Preciado, Paul B. Ibidem.
} 


\subsection{Colocalidad}

Existe una situación que sin englobar a todas las demás, puede deducirse de una explicitación mayor de relación con muchos de los conceptos operativos desarrollados como conclusiones en esta tesis. Esta situación puede explicitarse como un fenómeno de colocalidad o localidad múltiple. Y este fenómeno podemos darle al menos en dos sentidos. El primero, como la colocalidad de una entidad, pues esta se sitúa simultáneamente en dos o más lugares. La segunda, como la colocalidad de un lugar, pues de este, participan múltiples redes o ensamblajes simultáneamente.

\section{Aproximaciones / descripciones}

La RAE no define colocalidad. Es por lo tanto un neologismo. Sobre la palabra local la RAE lo define como una "cualidad de las cosas que las sitúa en lugar fijo."197 y localidad como " lugar o pueblo." ${ }^{198}$. En la Teoría de la Relatividad Especial se demuestra la relatividad de la colocalidad como una dilatación temporal. Es decir, dos acontecimientos que suceden en el mismo lugar, pero no necesariamente al mismo tiempo. ${ }^{199}$

\section{Localizar lo global}

La (ANT) explicita las innumerables conexiones entre entidades híbridas que la hacen pertenecer a varias situaciones locales, diferentes a la vez, que en su misma localidad aparecen situaciones "otras" junto a ellas.

Por un lado, B. Latour explica como lo local y global son conceptos que se adaptan mal a las redes, lo hemos explicado en el punto de interescalaridad. Si las redes son la interiorización del exterior, no hay redes globales ahí afuera que observar. "No hay acceso para lo global por la sencilla razón de que uno siempre se mueve de un lugar a otro a través de estrechos corredores sin si quiera estar afuera." 200

Lo local, por un lado, asume una condición de variabilidad y multiplicidad, de cambio y contingencia. En condiciones de simultaneidad y ubicuidad espacial y temporal, la situación de un entorno deberá hacer explícitas las singularidades del mismo en base a un amplio espectro de relaciones híbridas situadas o trayectorias que las atraviesan. En lo local será posible determinar condiciones como la

\footnotetext{
${ }^{197}$ RAE local.

${ }^{198}$ Ibid. Localidad.

${ }^{199}$ Tai L. Chow Gravity, Black Holes, and the Very Early Universe: An Introduction to general relativity and cosmology. NY, Springler, 2008, p.254.

${ }^{200}$ Latour, Bruno. "Spheres and networks: two ways to reinterpret globalization." Harvard Design

Magazine, 2009, n.30, p.141.
} 
intensidad, los vectores de interés múltiples, los conflictos, las apariencias, lo invisible. Lo local se convertirá en un lugar múltiple. No según el punto de vista que se mire, sino ontológicamente múltiple. "El lugar se puede producir por la coincidencia de muchos lugares y no por los rasgos comunes o coincidentes a los mismos. No es una selección de lo concurrente sino una suma de la contextualidad simultánea del sitio. “201

La colocalidad conformará entonces lugares localizados que serán derivados de prácticas, dispositivos, estados de cosas, cuerpos, políticas, geografías transnacionales. La colocalidad remitirá a "la puesta en común de lo previamente no confrontado, situaciones en las que cuerpos y cosas se ponen en presencia del otro forzados a confrontar la multiplicidad de lo urbano." ${ }^{202}$ Por otro lado la colocalidad de una entidad remitirá a la presencia simultánea de esa misma entidad en diferentes localizaciones espaciales y temporales. Para Latour lo local, es entonces "la interacción de un ensamblaje con otras interacciones locales que se distribuyen en otros tiempos y espacios y que se traen a una situación particular a través de series concretas de actores no-humanos." ${ }^{203}$ Ofreciendo de esta forma la explicitación de la primera noción que planteamos para la colocalidad.

\section{Localidad en extensión}

En las espumas, la situación no difiere mucho. En la localidad de una espuma, existen otras muchas espumas contiguas, en covecindad, y cuando una desaparece otra suplanta su existencia. En las espumas también se da el fenómeno de la colocalidad. El aislamiento conectado, produce la conexión necesaria para su permeabilidad y su localidad transferida. Lo local, para Sloterdijk, hoy pone el acento en una localidad extendida.

\section{Deslocalización}

La deslocalización ${ }^{204}$ es la paradoja de la colocalidad. Algo nunca está deslocalizado ${ }^{205}$ sino que ha transferido su localidad a otros lugares, sean estos relacionales o geográficos. Por ejemplo, la deslocalización industrial offshoring es una colocación múltiple del centro de producción en estrecha vinculación con el lugar local original. ${ }^{206}$ Estas deslozalizaciones producen como dice Saskia Sassen

\footnotetext{
201 Soriano, Federico en AAVV Metápolis. p.379. también en Hipermínimos p.24.

${ }^{202}$ Farías, Ignacio \& Blok, Anders. "Introducing urban cosmopolitics: Multiplicity and the search for a common world" Forthcoming Urban cosmopolitics: Agencements, assemblies, atmospheres. London, NY, Routledge, 2016, p.7.

${ }^{203}$ Tirado, Francisco. Recensión crítica sobre el libro de Latour "Reensamblando lo social" AIBR. Revista de Antropología Iberoamericana, Ed. Electrónica Núm. Especial. Noviembre-Diciembre 2005. ${ }^{204}$ La deslocalización o colocalización económica es la transferencia, a iniciativa de una sociedad o institución internacional, de actividades, capitales, y empleos, entre diferentes países o diferentes regiones, de modo de así obtener algún tipo de ventaja competitiva o estratégica. ${ }^{205}$ No está ni sin localidad ni afuera de la localidad ni en sentido contrario de la localidad. ${ }^{206}$ Cfr. VV.AA, El atlas geopolítico 2010, Valencia, Ediciones Cybermonde, 2009.
} 
nuevas distribuciones, pero también nuevas centralidades. La colocalización, no es sinónimo de dispersión o distribución en red. Simplemente, es una localización simultánea en el espacio o en el tiempo." Lo macro, la globalización, no describe un lugar más ancho o más grande donde se inserta lo micro, como en una muñeca Matrioshka rusa, sino otro lugar igualmente local, igualmente micro, que está conectado con muchos otros." ${ }^{207}$ Y más que el "tamaño del lugar (micro o macro) lo que sí puede suceder, como se da en las geografías de la centralidad de Sassen, es que algunos lugares cuentan con conexiones más seguras y duraderas que otros. "Lo que antes estaba arriba o abajo, o fuera o dentro, queda colocado en el mismo plano que los otros lugares [...] Lo macro no está arriba ni abajo de las interacciones sino agregado a la entidad como otra de sus conexiones." 208

Por lo tanto no existe un lugar que pueda decirse que es un no-local o un "nolugar". Si una entidad se deslocaliza, es que se está trasladando de un lugar a un lugar "otro", no de un lugar a ningún lugar. Deslocalizar, entonces para Latour, debe significar colocalizar, aunque él no emplee esta palabra.

Por otro lado, la arquitectura internacional, como la arquitectura que prescinde del lugar, es una arquitectura que no se liga a a las redes locales existentes y deviene en independiente de su localización. En Le Corbusier "La casa se instala frente al lugar, no en el lugar" 209 "La concordancia de la casa no es una cuestión de lugar o contexto inmediato" ${ }^{210}$ Le Corbusier rompe con la idea del Genius $\operatorname{Loc}^{21}$ descrito por Christian Norberg-Schulz y en su lugar se impone la deslocalización o la localización múltiple de los principios de la arquitectura de Le Corbusier en la negación del contexto local, que no del lugar, pues para Le Corbusier el lugar se convierte en una imagen donde mirar ${ }^{212}$. Pero este, como hemos visto en el capítulo de contingencia, nunca puede ser totalmente eliminado. El lugar como localidad expandida, es una forma de revelar la simbiosis de lo local relacionado con otras localidades, por lo tanto no eliminado.

\section{Concurrencia y copresencia}

Donde la ANT no está tan desarrollada y donde los estudios urbanos y los ensamblajes tienen un desafío para la ANT, es en la noción de colocalidad desde el estudio de las múltiples redes y ensamblajes que componen un lugar. No es ya solo la noción de F. Soriano sobre la experiencia propia del lugar. "El lugar se puede producir por la coincidencia de muchos lugares y no por los rasgos comunes o

\footnotetext{
${ }^{207}$ B. Latour. La esperanza de pandora. Op. Cit., p.253.

${ }^{208}$ Ibidem.

${ }^{209}$ Le Corbusie \& Pierrefeu, Pierre La casa del hombre. Barcelona, Poseidón, 1979, p.79.

${ }^{210}$ Le Corbusier Une petite Maison. Zurich, Editions d'Architecture, 1954, pp.22-23.

${ }^{211}$ Norberg-Schulz, Christian. Genius Loci. Paesaggio, ambiente, architettura. Milá, Electa, 1979, p.5.

${ }^{212}$ Cfr. Op. Cit., Beatriz Colomina Publicidad y privacidad.
} 
coincidentes a los mismos. No es una selección de lo concurrente sino una suma de la contextualidad simultánea del sitio. [...] El lugar será el lugar sentido personalmente, el tiempo pasado por mi experiencia, los pensamientos y la ciencia a través de mis pensamientos. " 213

Lo local, no es solo la experiencia personal del lugar, sino las múltiples superposiciones de lo heterogéneo. El entorno conformará lugares que serán derivados de prácticas, dispositivos, estados de cosas, cuerpos, políticas, geografías transnacionales que conforman nuestra noción de entorno. A la afirmación de F. Soriano tendremos que superponer la idea del espacio como el "sense of place"; es decir, del sentido y la sensación del lugar en la conceptualización de Doreen Massey como "La esfera de la posibilidad de la existencia de la multiplicidad en el sentido de la pluralidad contemporánea; como la esfera en la que conviven distintas trayectorias; como la esfera, por tanto, de la heterogeneidad coexistente." ${ }^{214}$

No será solo el lugar para uno, sino el lugar entendido como una copresencia de sentidos de lugares diferentes para diferentes cuerpos en su interacción con diferentes ensamblajes. El lugar podrá definirse, entonces, como la copresencia de entidades diferentes en una localización específica. Y esta copresencia no será consensuada ni tiene que referirse a situaciones sin conflicto. La copresencia debe hacer aflorar lo presente pero también lo ausente. "Será la puesta en común de lo previamente no confrontado, situaciones en las que cuerpos y cosas se ponen en presencia del otro forzados a confrontar la multiplicidad de lo urbano.” ${ }^{215}$

\section{Coinsistencia}

Lo que estamos queriendo explicar, es que más allá de los ensamblajes como entornos donde observar los objetos y las prácticas de actores en redes translocales y los lugares como espacialidades donde se enactan formas particulares de urbanismo, la copresencia de lo local. La idea de copresencia, nos permite situarnos específicamente en un lugar para entender su multiplicidad. "No es solamente un punto de colisión entre grupos sociales en conflicto, sino un asunto de concurrencia pública en las controversias del desarrollo urbano, permitiendo mezclas, enredos y nuevas formas de articulación colateral de conflictos previamente imprevistos" 216

\footnotetext{
${ }^{213}$ Soriano, Federico. AAVV Metápolis. p.379 también en Hipermínimos. p.24.

${ }^{214}$ Massey, Doreen "For Space” Los Ángeles. Londres. Sage.

${ }^{215}$ Farías, Ignacio \& Blok, Anders. "Introducing urban cosmopolitics: Multiplicity and the search for a common world" Forthcoming Urban cosmopolitics: Agencements, assemblies, atmospheres. London, NY, Routledge, 2016, p.11.

${ }^{216} \mathrm{Ibidem}$.
} 
Para I. Farías "El ensamblaje urbano trata del cofuncionamiento ${ }^{217}$ de entidades ontológicamente heterogéneas, topográficamente dispersas y temporalmente asincrónicas." ${ }^{218}$ Pero el ensamblaje, como herramienta, no es suficiente para describir la complejidad de la ciudad, de los "cosmos" diferentes de la ciudad. Desde el punto de vista de la propuesta cosmopolítica urbana, Farías, observa que se trata de describir la coexistencia de ensamblajes urbanos múltiples y no solo el cofuncionamiento de los mismos. "La copresencia como coexistencia de ensamblajes." 219

Pero si la coexistencia remite, según Sloterdijk a una idea de comunidad. La copresencia podíamos entenderla mejor como coinsistencia ${ }^{220}$. Como la copresencia de ensamblajes que en su propia existencia se forman por el aislamiento; aunque conectado, aislado de otros ensamblajes. La necesidad de investigar cómo se conforman los aislamientos, las membranas impermeables y las imposibilidades de acceso, podría ofrecer resultados diferentes al estudio de la conexión.

Los ensamblajes, como aglomeraciones de espumas, se estabilizan por la tensión interior o tensegridad. Barcelona, representa esa condición de tensegridad entre los ensamblajes del turismo y los de los habitantes. Pues en realidad, ambos se componen en situaciones de coaislamiento. La cosmopolítica urbana, podría entonces pensarse desde la coinsistencia, desde la inmunidad.

De esta manera, tras viajar con la ANT y las espumas por múltiples lugares, la pregunta por situar podría ser la de quedarse quieto: Stay put. "El estudio de las cosmopolíticas urbanas a menudo nos obligan también a "quedarnos" en la intersección entre las redes y regiones, ensamblajes y lugares, con el fin de observar cómo la realidad urbana se ensambla y desensambla, comprender cómo los lugares median entre múltiples ensamblajes urbanos, para estudiar la coexistencia de las acciones. Para quedarse en el "sitio múltiple". ${ }^{221} \mathrm{Y}$ este lugar, siempre será un lugar colocalizado.

\footnotetext{
${ }^{217}$ Siguiendo a Deleuze. Cfr. Deleuze, G. and Parnet, C. Dialogues. NY, Columbia University Press, 1987.

${ }^{218}$ Farías \& Blok. Op. Cit. p.10.

${ }^{219}$ Ibid., p.11.

${ }^{220}$ Ver epígrafe 2.5 Coinsistencia.

${ }^{221}$ Farías \& Blok. Op. Cit. p.12.
} 


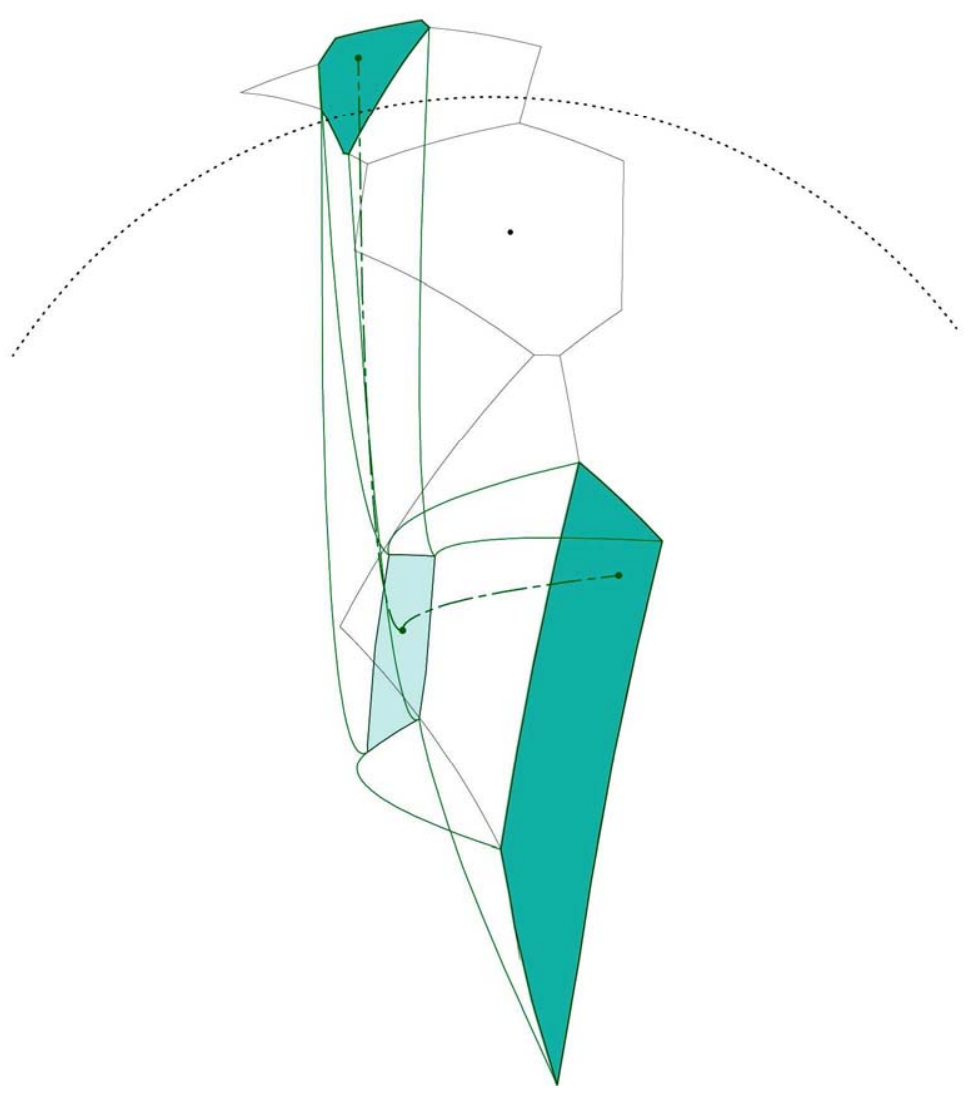

"Remite a la doble condición de la simultaneidad de localizaciones espaciotemporales diversas de una entidad localizada o bien a la conformación del lugar urbano como una localidad múltiple desde la copresencia de redes, espumas y ensamblajes que transitan y operan en instantaneidad desde lugares diversos también colocalizados." 


\section{Operatividades}

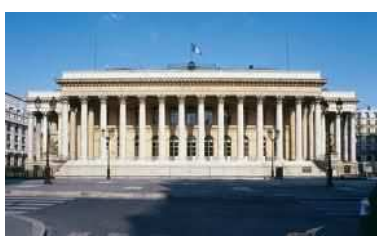

Recolocalización El High-

Frecuency Trading HFT o

Negociación de alta frecuencia

es un tipo de negociación de los

mercados financieros donde

son los algoritmos, como

agentes no humanos, los que

dan órdenes de compra venta

en menos de un milisegundo.

La bolsa de Paris, situada en el

Palais Brongniart ya realiza una

tercera parte de sus

transacciones por

especuladores de alta

frecuencia. El Palais Brongniart

ha trasladado su sede

operacional de Paris a una

inmensa nave de $5.000 \mathrm{~m} 2$ en la

ciudad de Basildon al sur de

Londres. La proximidad

geográfica a la centralidad

financiera deviene en

primordial. La localidad en un

territorio acelerado y quasi-

instantáneo se vuelve

fundamental. Las nuevas

centralidades se desarrollan

más, antes que dispersarse

deslocalizadamente. 3. La

localización de la bolsa de Paris

no tiene un lugar físico único

sino varios lugares geográficos

(Paris y Basildon) y otros

lugares relaciones. La bolsa de

Paris está colocalizada

simultáneamente en múltiples geografías locales relacionales.

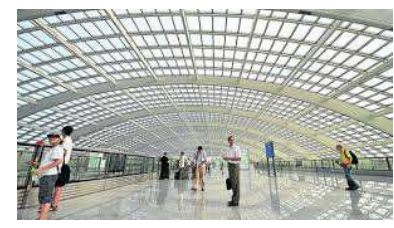

¿No-lugar? La noción de no lugar que ofrece Marc-Auge ha recibido muchas críticas desde la ANT por no ser capaz de articular una idea de lugar conectado y desde una perspectiva múltiple sino bastante antropocentrista y europeísta. B. Latour abrirá su estudio refiriéndose a la idea de que los antropólogos deben volver de los trópicos para estudiar con la misma intensidad el mundo contemporáneo. Por otro lado la idea de lugar sin identidad en mundo múltiplemente localizado anula la diversidad de actores y agencias en los aeropuertos por ejemplo.

$¿$ ¿Hablamos del turista o del emigrante? No es lo mismo transitar libremente que estar penalizado constantemente en aduanas, migraciones,

vigilancias, etc.

\section{angheringerst}

Rastrear lo local. El ejercicio de A. Jaque sobre la Sabana de Tromso, donde se marcan, como anotaciones, los rastros de otras localidades y situación que se dan en la aparente sábana blanca y neutra con la que comienza el ejercicio, es toda una declaración de intenciones sobre la noción de lugar y con ella de colocalidad.

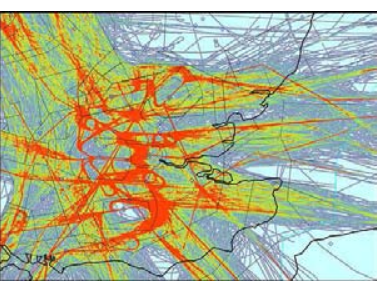

\section{Concurrencia. La}

concurrencia podemos

observarla a cualquier escala.

No se trataría solo de lo que

sucede de un acontecimiento, como se ve en la imagen de los aviones que despegan y

aterrizan en un día en la ciudad de Londres y componen una de las intensidades del lugar. Sino que junto con ellos, $\mathrm{La}$

construcción urbanística, las infraestructuras de movilidad de comunicación y su construcción permanente, la ciudad turística, las olimpiadas el mercado inmobiliario, la vigilancia, sus redes de residuos líquidos, sólidos y gaseosos, la contaminación del aire,

dispositivos digitales urbanos, etc. componen los ensamblajes que componen la concurrencia en el lugar. A una escala micro sucedería de la misma manera.

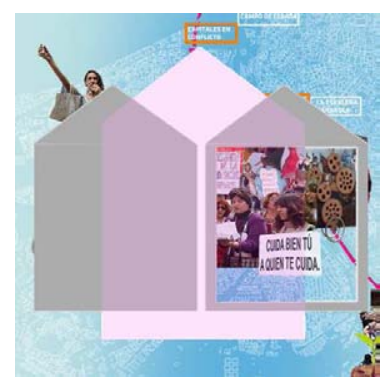

La tercera casa. Las empleadas de hogar migrantes del proyecto madrileño "Territorio doméstico" explicitan en sus cuerpos la condición de la colocalidad.

Ellas habitan la casa-debajo-dela-casa. Su casa se colocaliza al menos en tres lugares diferentes. El primero la casa familiar del país de origen. Segundo la casa donde trabajan y cuidan. Su tercera casa es el lugar donde pueden realizar actividades personal es e íntimas los domingos por la tarde. En este caso, el espacio colectivo donde se reúnen: $\mathrm{La}$ EsKalera Karakola en Madrid. 


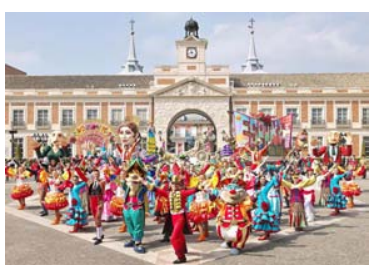

Colocalidad híbrida. Las relaciones de colocalidad se producen mediadas por diferentes agencias que forman lo simbólico, lo ficcional, lo tematizado y lo mediatizado. $\mathrm{Al}$ mirar el reloj de La Puerta del Sol de Madrid cabría preguntarnos sobre el verdadero reloj. El que estamos viendo, el que aparece cada Nochevieja en la televisión asociada al ritual de las uvas o la réplica del Shima Spain Village, un parque temático en Japón. Pero en una relación de colocalidad no importa cuál es el verdadero, sino las relaciones heterogéneas que componen su localidad múltiple. ${ }^{222}$

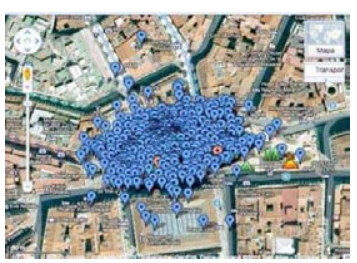

Copresencia. Si como hemos afirmado ya, la ciudad es un objeto ontológicamente múltiple, esta noción es importante para entender la colocalidad en un sentido específico. Un lugar determinado como La Puerta del Sol, es un lugar donde los ensamblajes del turismo, el consumo, la protesta, la indignación, la fascinación, lo simbólico, lo administrativo, lo infraestructural, lo popular y lo cotidiano conviven

simultáneamente en el mismo lugar. Como hemos dicho el lugar será aquel que dispone "lo previamente no confrontado, situaciones en las que cuerpos y cosas se ponen en presencia del otro forzados a confrontar la multiplicidad de lo urbano

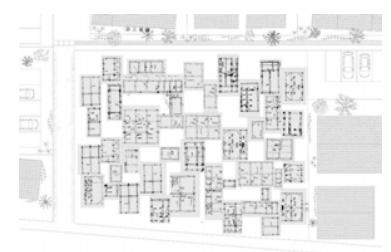

Colocalidad ambiental. El proyecto de J. Ishigami Home for elders se forma del ensamblaje de las tipologías tradicionales de los mayores que van a conformar la nueva residencia de mayores en Akita. (Japón). El proyecto configura una arquitectura elemental de cada entidad asociada a la tipología del lugar de procedencia del mayor. La arquitectura del proyecto es la composición de las diferentes arquitecturas trasladadas de una localización a otra o reproducidas en múltiples configuraciones de tipos de distintas localidades de Japón.

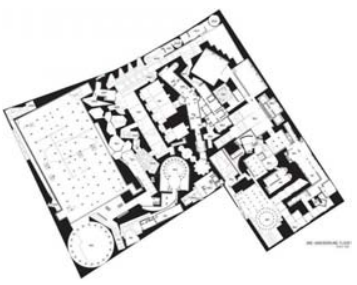

\section{Colocalidad temporal. El} museo de todos los museos en Taipei de Federico Soriano 2012, produce un lugar en colocalidad. La localización como suma de contextualidades locales de diferentes interiores distantes en el espacio y en el tiempo, de otros museos produce un proyecto que localiza simultáneamente una diversidad y multiplicidad de lugares y localizaciones otras. Las localizaciones parciales, como "fragmentos de espuma" operan como un sistema coincidente en la producción del lugar como la coinsistencia de todas las localizacones otras. Transferidas mediante la copia, la traslación y delegación de los interiores en otras materialidades que conforman una nueva localidad desde lo múltiple. Este ejemplo de arquitectura ilustra como la colocalidad se conforma también por relaciones de proxicuidad.

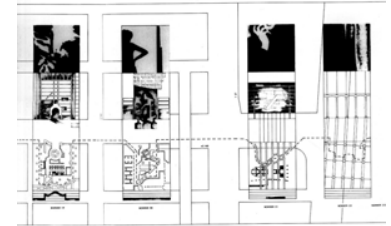

Acontecimiento co-local. Los Manhattan Transcripts de Bernard Tschumi,1978, tratan de desvelar una realidad no representada. Esta realidad la elabora desde una metodología que incluye simultáneamente a los edificios como objetos, los movimientos y los eventos o acontecimientos. Una taxonomía de diferentes tipos urbanos como parques, la calle, la torre, establecen una perspectiva sino totalmente colocalizada si parcialmente ofreciendo una mirada al lugar localizado como una suma de vectores instantáneos en movimiento de lo que allí sucede.

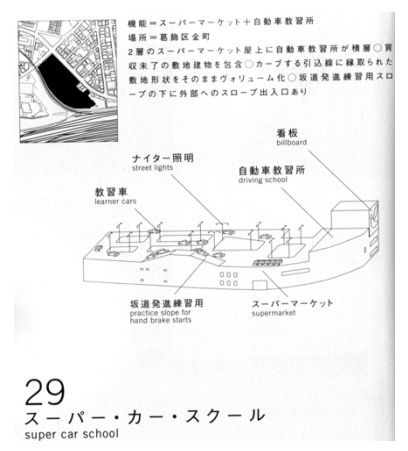

\section{Localidad extendida. La}

colocalidad será la

simultaneidad de situaciones,

cada una de ellas con sus redes extendidas en una localización.

Made in Tokio de Atelier $>$ Bow. Wow 2001 hace un esfuerzo por visibilizar la complejidad y las

superposiciones de redes, programas y espacios en una ciudad congestionada como Tokio.
${ }^{222}$ Madrid Theme City, es una investigación de Eugenio Fernández de Atelier Teratoma. 


\subsection{Set de operaciones}

Las nueve operaciones componen un "set de operaciones" que esta tesis doctoral elabora a modo de diagrama de conclusiones abiertas. Estos conceptos podrán problematizarse, expandirse o contraerse si se han extendido demasiado. A estos conceptos podrán sumarse otros que elaboren nuevas prospecciones investigadoras en base a ambas teorías o, al menos, a partes de las enunciadas. El "set de operaciones" compone un diagrama-topológico completo aplicable a multitud de situaciones cotidianas fenómenos urbanos o proyectos de arquitectura que quieren desarrollar y continuar este proceso. Este diagrama topológico problematiza en sí mismo la hipótesis de partida. El diagrama podrá leerse por algunos como una situación cerrada, aunque este no lo sea, como una situación única, aunque este es múltiple; como una situación aislada, aunque esté conectada; como una situación fragmentada, aunque este sea continuo; como una situación estable, aunque este sea instantáneo; como un diagrama global, aunque sea local; como un concepto universal, aunque este diagrama esté situado.

Este diagrama topológico resulta de la demostración de la complementariedad de ambas teorías (ANT-Espumas). Este diagrama se articula en base a la disolución de las dualidades como antagónicas para situarse como modos o gradientes para pensar en los conceptos enunciados como conceptos en continuidad, simultaneidad o instantaneidad. Luego este diagrama tiene tres características principales respecto a los principios que lo definen.

El diagrama es topológico pues es un diagrama sin forma, pero con relaciones construidas más o menos duraderas según el caso. El diagrama garantiza en los conceptos operacionales y las herramientas de la ANT y las espumas la continuidad de los procesos. Como la topología, el diagrama explicita cómo dos situaciones, formas o acontecimientos aparentemente diferentes unas de otras, pueden no serlo tanto y se forman en continuidad. Para ellos utiliza las distancias pragmáticas y relacionales ya enunciada, de la proxicuidad o la interescalaridad, para explicitar en su aplicación las formas en continuidad de un caso específico.

El diagrama es politópico pues puede presentar múltiples heterotopías en una misma situación. Si la heterotopía es "Un lugar real en el que se yuxtaponen diferentes espacios incompatibles." 223 Esta situación heterotópica se presenta como la simultaneidad de situaciones espaciales o temporales aparentemente

\footnotetext{
${ }^{223}$ Foucault, Michel. "Des espaces autres" \& "Le Corps utopique." Architecture, Mouvement, Continuité, n.5, 1984.
} 
incompatibles. Esta característica hace de él un diagrama sin exterior ni interior pues ambos se pliegan y repliegan en múltiples situaciones. Reensamblan la exterioridad y la interioridad habitual de los espacios, localizados o extendidos, diluyendo las relaciones entre forma y función, localización y deslocalización, presencia y ausencia o lo permanente y lo temporal.

El diagrama es performativo. Presenta, junto a todas las herramientas de la ANT y las espumas desarrolladas, como las relaciones y los aislamientos se componen en situaciones temporales aceleradas, casi instantáneas. Donde, como hemos enunciado cada acontecimiento, localización, relación o mediación, se produce en un "espacializar" un "temporalizar" y un "agencializar" de entidades híbridas para cada situación. Todas estas performaciones pueden componer un ensamblaje urbano como entidad de mayor rango en el diagrama.

Por último y no menos importante: no existe un diagrama único ni estable. Este diagrama puede aplicarse a multitud de situaciones urbanas y arquitectónicas para describir su composición, el cómo se conforma, pero también para manejar una determinada forma de operar con el proyecto y ampliar el repertorio de situaciones posibles. Dicha composición formará parte de un ensamblaje más amplio que a su vez extenderá sus redes de una forma más amplia, aunque finita. A esta situación de le superpone otro ensamblaje y así sucesivamente. La ciudad, es la localización donde se da una intensidad de ensamblajes mayor. El diagrama no es la ciudad, pero sí ayuda a componer la idea procesual de lo urbano. Esto también es aplicable a las otras formas de la exterioridad, el cuerpo, la casa, el espacio público o la naturaleza. Porque las entendemos ya como entidades procesuales, heterogéneas y dinámicas. Todas ellas podrán formar parte de este diagrama pues, precisamente, lo que hace es componer "mundos previamente no asociados o situaciones anteriormente separadas"; construyendo, según la ANT y las Espumas, situaciones no definidas por un exterior o un interior, ni de la entidad, ni de las formas, ni de la propia disciplina arquitectónica.

Desde la perspectiva de esta tesis doctoral, no hay ya un exterior y un interior de la disciplina arquitectónica, como tampoco hay una naturaleza, una ciudad, un espacio público, una casa o un cuerpo. Intervenir en la realidad será intervenir en los procesos de conformación de estas entidades, antes denominadas formas de la exterioridad. La arquitectura será la práctica, donde componer y visibilizar estos procesos del día a día, desde la interacción permanente y heterogénea de la sociedad, la naturaleza y la tecnología. 


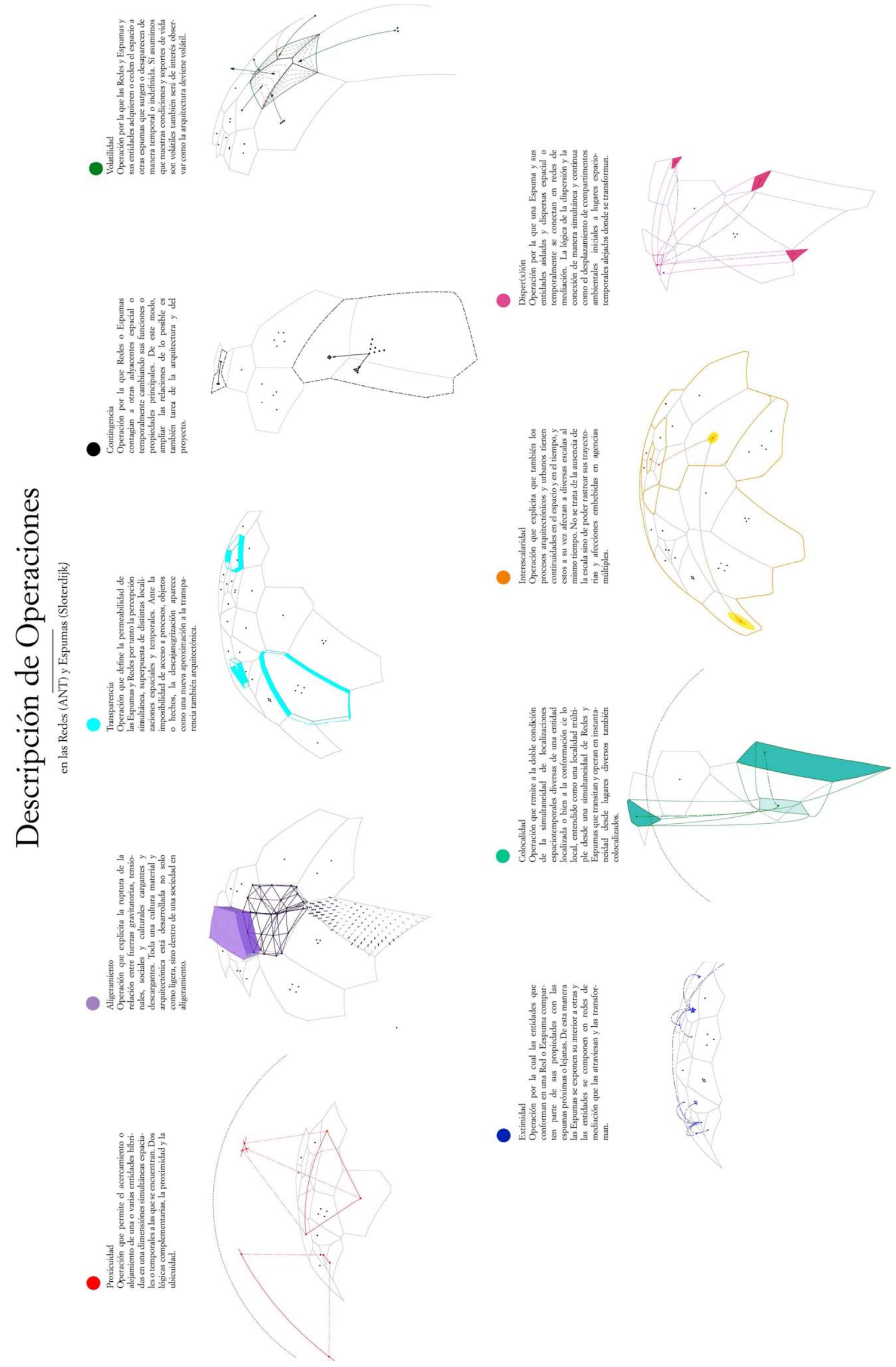




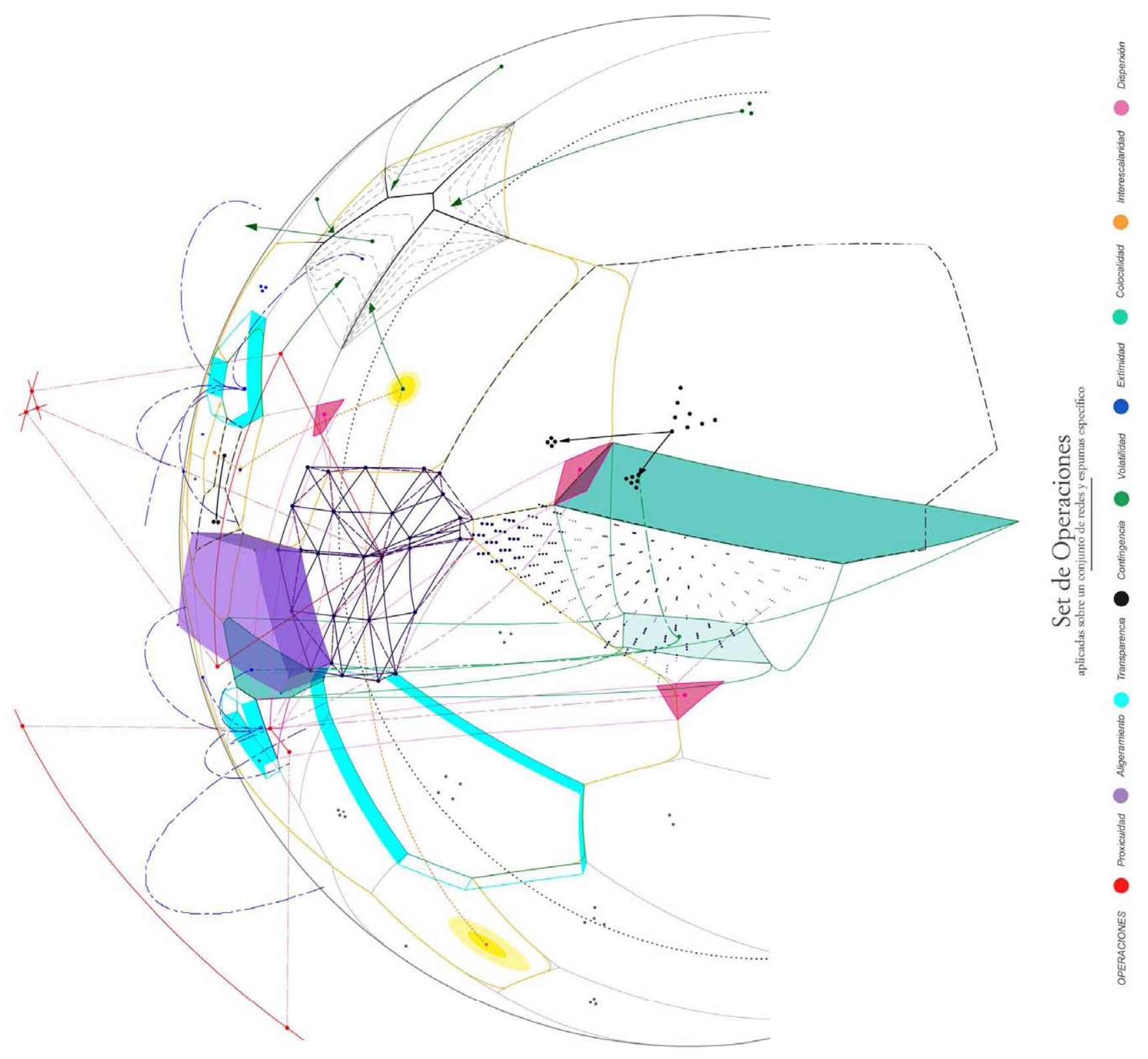




\section{4. Índice desarrollado}


Índice Resumido I

Agradecimientos III

Resumen | Abstract $\quad$ V-VI

0. Introducción IX

0.1 Dos herramientas complementarias XIV

0.2 Metodología XX

0.3 En el Interior de la tesis XXIII

0.4 Pertinencia XXXII

1 Redes: la exterioridad adentro 1

1.1 Las diferentes acepciones del concepto red 4

1.1.1 Actor-Red 6

1.1.2 Actante-Rizoma 8

1.2 Asociaciones y mediaciones 9

1.2.1 La continuidad de la acción $\quad 11$

1.2.2 Agencia Distribuida 15

1.3 El espacio en la red $\quad 18$

1.3.1 Topología y espacialidades de la red 19

1.3.2 Espacializar y la topología fluida de la red 24

1.3.3 In/mutables In/móviles 29

1.4 Entidades sin exterior 32

1.4.1 El mundo es un laboratorio 34

1.4.2 Ciudades sin afuera 36

1.4.3 La intimidad en el espacio público 41

1.4.4 El cuerpo urbano socio-técnico 46

1.5 Ensamblajes múltiples 51

1.5.1 Agenciamientos 52

1.5.2 Ensamblajes 54

1.5.3 Ensamblajes urbanos 57

1.5.3.1 La ciudad objeto múltiple $\quad 60$

1.5.3.2 Crecimiento simultáneo 61

1.5.3.3 Temporalidades del ensamblaje $\quad 64$

1.6 Problematizando los límites de la ANT 70

2 Espumas: el gran interior $\quad 75$

2.1 Pompas de jabón 83

2.1.1 El Invernadero 89

2.1.2 Europa es una invernadero sin exterior 91

2.1.3 Tensegridad 96 
2.2 Covecindad 98

2.2.1 Autoemparejamientos Humanos 99

2.2.2 Autoemparejamientos tecnológicos 101

2.3 Multiplicidades-espacio 106

2.3.1 Aislamientos conectados 108

2.3.2 Sistemas coincidentes 109

2.3.3 Arquitecturas de la cohabitación 110

2.3.3.1 Islas Absolutas 111

2.3.3.2 Islas Atmosféricas $\quad 115$

2.4 Entidades sin exterior 121

2.4.1. El apartamento 122

2.4.2. El cuerpo acondicionado $\quad 127$

2.5 Coinsistencia 130

2.5.1 Ubicuidad 133

2.5.2 Espumas genéricas 136

2.5.3 Tecnologías Urbanas Ubicuas 137

2.5.4 Puntos de paso 143

2.6 Problematizando los límites de la espuma 148

3 Conclusiones: principios y operatividades 153

3.1 Continuidad, simultaneidad e instantaneidad 157

3.1.1 Simetría (ANT) y asimetría (Sloterdijk) 158

3.1.2 Principio de Continuidad 161

3.1.3 Principio de Simultaneidad 162

3.1.4 Principio de Instantaneidad 163

3.1.5 Operatividades 164

3.2 Proxicuidad 166

$\begin{array}{lll}3.3 & \text { Extimidad } & 175\end{array}$

3.4 Contingencia 182

3.5 Aligeramiento 190

$\begin{array}{ll}3.6 & \text { Volatilidad } \\ & 197\end{array}$

3.7 Disper(x)ión 204

$\begin{array}{lll}3.8 & \text { Interescalaridad } & 209\end{array}$

3.9 Transparencia 218

3.10 Colocalidad 225

3.11 Set de operaciones 233

4 Índice desarrollado $\quad 237$

5 Bibliografía 241 
5. Bibliografía 
VV.AA. Forthcoming Urban cosmopolitics: Agencements, assemblies, atmospheres. Farías, Ignacio \& Blok, Anders. (Eds.). London, NY. Routledge.2016

VV.AA. What Is Cosmopolitical Design? Design, Nature and the Built Environment. Yaneba, Albena \& ZaeraPolo, Alejandro (Eds.) Surrey/Burligton. Ashgate. 2015

VV.AA. Concepts and critique of production of space. Urbanismo Afectivo. Knierbein, Sabine \& Krasny, Elke \& Viderman Tihomir. (Eds.). Raum-Skuor-TUM. 2015

VV.AA. Encyclopedia of Critical Psychology Thomas Teo (Eds.). New York: Springer.2014

VV.AA. Grain Vapor Rain. Textures of the antrophocene. Berlin. Haus der Kulturen del welt, MIT press, 2013

VV.AA. Teoría del Actor Red. Más allá de los estudios de la ciencia y la tecnología. Tirado, francisco y López Daniel (Eds.). Barcelona. Amentia. 2012

VV.AA. Sloterdijk Now. Stuart Elden (Ed.). Cambridge. Polity Press. 2012

VV.AA. Urban Constellations. Matthew Gandy (Ed.). Berlin. Jovis. 2011

AA.VV. In Medias Res: Peter Sloterdijk's Spherological Poetics of Being Schinkel, Willem \& NoordegraafEelens Liesbeth (Eds.). Amsterdam Amsterdam University Press. 2011.

VV.AA. Lo Ordinario. Walker, Enrique.(Eds.). Barcelona, GG, 2010

VV.AA. Urban Assemblages. How actor-network theory change urban studies. Farías Ignacio. \& Bender, Thomas. (Eds.). London. NY. Routledge. 2010

VV.AA. Ontología de la distancia. Filosofías de la comunicación en la era telemática. Abada, Madrid, 2010

VV. AA. Proceeedings of the 2008 Annual International Conference of the Design History Society. Fal mouth: 3-6 septiembre,e-books, Universal Publishers. 2009

VV.AA. Cold War Hothouses. Colomina, Beatriz. (Eds.) Nueva York. .Princeton University Press. 2004

VV.AA. Diccionario Metápolis de arquitectura avanzada. Barcelona. Actar.2001

VV.AA. Architecture Theory since 1968. Hays, Michael. (Eds.) Cambridge. The MIT Press. 2000

VV.AA. Heidegger, authenticity and modernity. Mark A. Wrathall y Jeff Malpas, (Eds.) Oxford. The MIT Press. 2000

VV.AA. Discovery of polypropylene and the development of a newhigh-density polyethylene. Oklahoma. Phillips Petroleum Company. 1999

VV.AA. Actor network theory and after. Law, John y Hassard, John, (Eds). Oxford: Blackwell.1999

VV.AA. Sociología Simétrica: ensayos sobre ciencia, tecnología y sociedad. Tirado y Montaner. (Eds.).

Barcelona. Gedisa.1998

VV.AA. Variations on a Theme Park: The New American City and the End of Public Space, Michael Sorkin (Ed.) Hill and Wang, New York. 1992

VV.AA. La science telle qu'elle se fait. Anthologie de la sociologie des sciences de langue anglaise. Callon, Michel \& Latour, Bruno. (Dir). Paris: La Découverte.1991 [1990]

VV.AA. Plastics in Building: the uses, past and present and the part III. Washington. Building Research Institute. 1955

Ábalos, Iñaki. La buena vida. Visita guiada a las casas de la modernidad. Barcelona. GG. 2014

Abalos, Iñaki \& Herreros,Juan. “Toyo Ito, el tiempo ligero.” El Croquis.Madrid. n71

Agamben, Giorgio. “¿Qué es un dispositivo?” Revista Sociológica. 2011 v 26, n73, p249-264

Allen, Stan. Forces of nature. NY. Princeton Architectural Press. 2012

Álvarez, Paula. Entrevista a Paula Álvarez en “Espacios Sensibles” Descargable en:

http://vibokworks.com/es/blog/pueblo-al-instante/entrevista-a-paula-alvarez-domenico-di-siena/ 
Akrich, M. \&. Latour, B “A Summary of a Convenient Vocabulary for the Semiotics of Human and Nonhuman Assemblies" en Bijker \& Law en Shaping Technology / Building Society: Studies in Sociotechnical Change. Cambridge. London. The MIT press.1992. pp. 259-264

Amin, Ash \& Thrift, Nigel Cities. Reimagining the urban. Cambridge. Oxford 2002

Anderson, Wilda. Diderot's dream. Baltimore. The Johns Hopkins University Press. 1990

Arsenault, R. "The End of the Long Hot Summer: the Air Conditioner and Southern Culture." The Journal of Southern History.1984 .n50 v4 p 597-628

Auge, Marc. Los no-lugares espacios del anonimato. Antropología sobre la modenidad. Barcelona Gedisa. 1993

Baldauf, Anette Shopping Town USA: Victor Gruen, the Cold War, and the Shopping Mall. Berlin. Mute. 2008

Baldauf, Anette \& Weingartner Katharina: The Gruen Effect. Victor Gruen and the Shopping Mall.

Documentary, Austria/US 2010, $54 \mathrm{~min}$

Banham, Reyner. The architecture of the well-temporede Enviroment. The Architectural Press. London. 1969

Baptista, Luis Santiago, et all Social Architecture. Three Critical Perspectives.Lisboa. Garagem Sulexposicoes arquitectura. 2014

Barajas, Diego Dispersion: A Study of a Global Mobility and the Dynamics of a Fictional Urbanism. Rotterdam. Episode. 2003

Baudrillard, Jean. Cultura y simulacro. Barcelona. Kairós. 1995

Benjamin, Walter. The arcades project. Tiedemman, Rolf. (Ed.) Mass. Harvard University Press. 1999 [18921940]

Boeri, Stephano Viaggio nell'Europa che cambia. Milan. Skira. 2003.

Boltanski, Luc. El amor y la justicia como competencias. Tres ensayos de sociología de la acción. Buenos Aires. Amorrortu. 2000

Braidotti, Rosi. The Posthuman. Cambridge. Polity Press. 2013

Brennan, Teresa. Globalization and its Terrors: Daily Life in the West. London. Routledge. 2003

Brenner, Neil. "The Urban Question as a Scale Question: Reflections on Henri Lefebvre, Urban Theory and the Politics of Scale”. International Journal of Urban and Regional Research v.24.n.2 June. 2000

Brenner, Neil ."The limits to scale? Methodological reflections on scalar structuration." Progress in Human Geographyv.25. n.4. 2001. pp. 591-614

Brenenn, Neil. Implosions/Explosions: Towards a Study of Planetary Urbanization. Berlin. Jovis Berlag. 2014

Bru, eduard. "La mirada larga” Nuevos Paisajes, nuevos territorios. Barcelona. Actar/Macba, 1997

Byung-Chul Han. La sociedad de la transparencia. Raúl Gabas (trad.). Barcelona. Herder. 2013

Callon, Michel. "Society in the Making: the Study of Technology as a Tool for Sociological Analysis." En Bijker, W. E. Hughes T. P. y Pinch T. J. (Eds.) The Social Construction of Technical Systems: New Directions in the Sociology and History of Technology. Cambridgge, Mass. London.The MIT Press. 1987 pp. 83-103.

Callon, Michel. "Techno-economic networks and irreversibility" en A sociology of Monsters: Essays on power, technology and domination. John Law (Ed.) London. Routledge Sociological Review. Monograph. v.38. 1992. pp.132-164

Callón, Michel. "Le travail de la conception en architecture." Situations Les Cahiers de la recherche architecturale n.37.pp.25-35. 1996

Callon, Michel The Laws of the Markets. Oxford. Blackwell and the Sociological Review. 1998

Callon, Michael \& Rip Ariel. Acting in an uncertain world. Cambride, London. The MIT Press. 2009

Calvillo, Nerea. "Odiando intensamente un globo de $90 \mathrm{~cm}$ : experimentos afectivos con no-humanos" III Congreso de Sociología Ordinaria. Madrid. MedialabPrado. 2015 
Canavera, Julián. "Del «afuera del pensamiento» al «pensamiento del afuera»: Deleuze entre Blanchot y Foucault" Thémata. 2015. n51. p423-432

Castro, Edgardo. El vocabulario de Michel Foucault. Buenos Aires. Universidad Nacional de Quilmes. 2004

Castells, Manuel. La sociedad Red. Madrid. Alianza. 2006

Castells, Manuel. La cuestión Urbana. México. siglo XXI. 2004

Cirlot, Lourdes. Andy Warhol. Gipuzcoa. Nerea. 2001

Colodro, Max. Reflexiones sobre el Caos. Santiago de Chile. Editorial Universitaria. 2002

Colomina, Beatriz. La domesticidad en guerra. Actar D ediciones. Barcelona. 2006

Colomina. Beatriz. "Reflexiones sobre la casa Eames". RA9. Revista de Arquitectura. Madrid. Junio. 2007. pp.

3-16

Colomina, Beatriz. "Unclear Visions: architectures of surveillance" en Enginereed transparency. NY. Princeton University Press. 2008. pp.78-87

Colomina, Beatriz. Publicidad y privacidad. Murcia. CDEAAC . 2010 [1994]

Connor, Steve. "Topologies: Michael Serres and the shapes of thought" Anglistik. v.15, 2004, pp.105-107

Cooper, Gail. Air-conditioning America: Engineers and the Controlled Environment, 1900-1960. Maryland, John Hopkins University Press, 2002

Constant. New Babylon Manifiesto. Hans Locher(Ed.) The Hague. Haags Gemeente Museum, 1974

Crary, Jonathan. "24/7 and the end of sleep". Londres, NY. Verso. 2013

Crawford, Margaret. "The world in a shopping mall." en Variations on a Theme Park: The New American City and the End of Public Space, Michael Sorkin (Ed.) Hill and Wang, New York. 1992 pp.3-30

Crimp, Douglas. Posiciones críticas. Ensayos sobre las políticas del arte y la identidad. Madrid. Akal. 2005

Debord, Guy. La sociedad del espectáculo. Trad. José Luis Pardo. Valencia. Pre-textos 1998

De Diego, Estrella. Tristísimo Warhol. Cadillacs, piscinas y otros síndromes modern os. Madrid. Siruela. 1999

De Landa, Manuel $A$ Thousands Years of Nonlinear History. New York. Swerve Editions. 2000

De Landa, Manuel A New Philosophy of Society. Assemblage Theory and Social Complexity.

London, New York: Continuum. 2006

Deleuze, Gilles \& Guatari Felix. Mil mesetas, capitalismo y esquizofrenia Valencia. Pre-textos. 1980

Deleuze, Gilles. "Postscript on the Societies of Control" October. v 59.1992p 3-7

Deleuze, Gilles. El pliegue. Leibniz y el barroco. Barcelona. Paidos. 1998

Deleuze, Gilles. Foucault. S. Hand (trad.) London, NY. Continuum. 2006.

Delgado, Manuel. “Elogio del viandante.” en Barcelona y la diversidad. Barcelona. Quórum, Institut de Cultura, 2005

Delgado, Manuel. "El espacio urbano como universo derretido” Arquitectura Viva. n136. 2013.

Doyle, Jennifer \& Flatley Jonathan, Muñoz \& J. Esteban. Pop Out: queer Warhol. Durham. Duke University Press. 1996

Elden, Stuart \& Mendieta, Eduardo. "Being-with as making worlds : the 'second coming' of Peter Sloterdijk.", Environment and planning D : society and space., v27 n1. 2009. pp. 1-11.

Eliasson, Olafur. Leer es respirar, es devenir. Barcelona. GG. 2012

Echevarría, Javier. Telépolis. Barcelona. Destino. 1994

Farías, Ignacio. "Entrevista a Manuel de Landa. Hacia una nueva ontología de lo social”. Persona y sociedad/ Universidad Alberto Hurtado v.23. n1. 2008. pp.75-85

Farias, Ignacio. "Ensamblajes urbanos: la TAR y el examen de la ciudad”. Athenea Digital. 2011. v11 n1 p15-40

Farias, Ignacio. "The politics of Urban Assemblages" City: analysis of urban trends, culture, theory,

policy, action. 20. v15 n3-4 p365-374 
Farias, Ignacio. "Planes Maestros como cosmogramas: la articulación de fuerzas oceánicas y formas urbanas tras el Tsunami de 2010 en Chile”. Pléyade. 2014. n14 p119-142

Farías Ignacio. \& Bender, Thomas. Urban Assemblages. How actor-network theory change urban studies. London. NY. Routledge. 2010

Farías, Ignacio \& Blok, Anders. "Introducing urban cosmopolitics: Multiplicity and the search for a common world" Forthcoming Urban cosmopolitics: Agencements, assemblies, atmospheres. London, NY.

Routledge.2016

Fdez. Valderrama. Luz. La construcción de la mirada: tres distancias. Sevilla. Universidad de Sevilla. 2004

Finkelstein, Nat. Andy Warhol. The factory years. 1964-1967. Nueva York PowerHouse. 2000

Fogué, Uriel. Ecología política y economía de la visibilidad de los dispositivos tecnológicos de la escala urbana durante el siglo XX. Abriendo la caja negra. Madrid. UPM. 2015

Foucault, Michel. Microfísica del poder. Madrid. La Piqueta. 1980

Foucault, Michel. Vigilar y castigar. Madrid. Siglo XXI. 2004

Foucault, Michel. El pensamiento del afuera. Manuel Arranz (trad.). Valencia. Pre-Textos.1988.

Foucault, Michel. "Des espaces autres" \& "Le Corps utopique." Architecture, Mouvement, Continuité, n 5 , 1984

Foucault, Michel. (1998a) [1967] 'Different Spaces', in J. D. Faubion (ed.), Aesthetics, Method, and Epistemology: Essential Works of Foucault Volume 2, London: Penguin. pp.175-185.

Foucault, Michel. Historia de la Locura. Madrid. Fondo de Cultura Económica de España. 2006

García-German, Jacobo. Estrategias operativas en Arquitectura. Madrid. Nobuko. 2012

García D., Paloma. Bruno Latour y los límites de la descripción en el estudio de la ciencia. Tesis Doctoral.

Departamento de Filosofía I. Universidad de Granada. 2007

Giedon, Sigfried. Espacio, tiempo y arquitectura. Barcelona. Reverté. 2009. [1941]

Gil-Fournier, Mauro. “Arquitectura y Espacio Público. Fenómenos Gemelos” Proyecto y Ciudad. n2. 2010 pp. 79-92.

Gil-Fournier, Mauro. "HotRods y Lowrider: habitando una práctica" Sevilla. La Ciudad Vida. Rev. electrónica. 2013. Descargable en: http://www.laciudadviva.org/blogs/?p=17529

Gil-Fournier, M, Jaenicke, M., Acosta, E. “The urban citizens' extitutional process in Madrid. 2000-2015.” Rotterdam. MONU Magazine n.23 Oct. 2015. pp. 89-96

Gómez, Valentín. Tensegridad. Estructuras Tensegríticas en Ciencia y Arte. Santander. Servicio de Publicaciones de la Universidad de Cantabria. 2007

Griscom, John H. The Uses and Abuses of Air: Showing Its Influences in Sustaining Life, and Producing Disease. With Remarks on the Ventilation of Houses. New York. J. S. Redfield. 1848.

Gruen, Victor. The heart of our cities. Ed, Simon and Schuster, Wisconsin University Press. Madison 1964.

Gruen, Victor. Centers for the Urban Environment: survival of the city. New York, Van Nostrand Reinholds. 1973

Guggenhaim, Michael. "Inmovile mutable" en Urban Assemblages. How actor-network theory change urban studies, en Farías Ignacio. \& Bender, Thomas.(eds) London NY. Routledge. 2010

Gunter,Valerie \& Kroll-Smith, Steve. Volatile Places: A Sociology of Communities and Environmental Controversies. London. Pine Forge press.2007

Hall, Eduard T. The Hidden dimension. NY Random House. 1966

Haraway, Donna."Las promesas de los monstruos: una política regeneradora para otros inapropiados/bles." Política y sociedad. n.30. 1999. pp.121-163

Haraway, Dona. Ciencia, cyborgs y mujeres. La reinvención de la naturaleza. Madrid, Cátedra.1995 [1991] 
Hardwic, M. Jeffrey. Mall Maker: Victor Gruen, Architect of an American Dream. University of Pennsylvania Press. 2004

Harman, Graham. Prince of Networks. Bruno Latour and Metaphysics. Melbourne. Re.press. 2009.

Harvey, David. Explanation in geography. Londres. Arnold. 1969

Harvey, David. The condition of posmodernity. Cambridge, Mass. Blackwell. 1992

Harvey, David. Ciudades rebeldes Del derecho de la ciudad a la revolución urbana. Salamanca. Akal. 2013. [2012]

Heinrichs, Hans-Jürgen \& Sloterdijk, Peter. El sol y la muerte. Investigaciones dialógicas. Madrid. Siruela. 2004. [2001]

Hetherington, K.\& Law, J. “After Networks”. Guest editorial en Environment and Planning D: Society and Space. v.18, 2000, pp.127-132

Irigaray, Luce. The Forgetting of Air in Martin Heidegger. London: The Athlone Press, 1999

Irigaray, Luce. Conferencia en El Festival de Literatura de Mantua. Septiembre de 2006.

Ito, Toyo. Escritos. Murcia. Colegio Oficial de Aparejadores y Arquitectos Técnicos de Murcia. 2000

Jameson, Fredic. Postmodernism, or The Cultural Logic of Late Capitalism. Durham . Duke University Press. 1991

Jameson, Fredric. "Future City". New Left Reviewn21, May-June 2003

Jameson, Fredric. "The end of temporality" Critical Inquiry. 2003 v29 n.4. p. 695-718

Jameson, Fredic. Aesthectis and politics. California.Verso.2010

Jaque, Andrés. Dulces Arenas Cotidianas. Sevilla. Lugardero. 2013

Jaque, Andrés. Arquitectura Parlamento: Primer sello de calidad democrática para acciones arquitectónicas. Web de la Oficina de Innovación Política. 29 de Enero de 2007.

Jarque, Fietta. "Los carpinteros.” en El País Semanal Nº 1.793 del 6 febrero

Joseph, Isaac. Retomar la ciudad. El espacio público como lugar de la acción. Medellín. Universidad Nacional de Colombia. 1999

Kaijima, M. \& Kuroda, J. \& Tsukamoto Y. (Atelier Bow-Wow). Made in Tokyo. Tokyo. Kajima Institute. 2001

Kaufmann, Emil. De Ledoux a Le Corbusier. Reinlad Bernet (trad.). Barcelona. Gustavo Gili. 1985 [1933]

Kern, Stephen. The culture of time and space. Cambridge. London. harvard University Press. 2003 [1983]

Kipnis, Jeff. “Recent Koolhaas”, El Croquis n79. 1996

Koolhaas, Rem, Delirio de Nueva York. Barcelona. GG 2004 [1978]

Koolhaas, Rem. "Junkspace". Guide to shopping. Harvard Project on the city. Mass. Taschen. 2001

Koolhaas, Rem, Content. London. Taschen. 2004

Koolhaas, Rem. La Ciudad Genérica. Barcelona. GG. 2008

Koolhaas \& AMO \& Irma Boom. Elements of Arquitecture. Venice Architecture Biennale. Marsilio. 2014 Lacan, Jacques. El seminario. Libro 7.La ética del psicoanálisis. 1959-1960. Barcelona. Paidós Ibérica. 1990 Latham, Alan \& McCormack, Derek P. "Globalizations big and small. Notes on urban studies ANT and geographical scale" en Urban Assemblages. How actor-network theory change urban studies. Farías Ignacio. \& Bender, Thomas. (Eds.) London. NY. Routledge. 2010

Lasén, Amparo. "Ritmos sociales y arritmias de la modernidad”.Madrid. Política y Sociedad. n.25 1997, pp.185203

Lasén, Amparo. "Mobile sentimental education: Attachment, recognition and modulations of intimacy." Gerard Goggin and Larissa Hjorth (eds.) The Routledge Companion to Mobile Media. NY. Routledge, 2014. pp.396-406 
Lasén, Amparo. "Rhythms and flow. Timing and spacing the digitally mediated everyday". Forthcoming publication. Handbook of children and youth studies. London. 2015

Latour, Bruno. "Give me a laboratory and i will raise the world" Science observed: Perspectives on the social study on science. London. Sage. 1983. pp.141-170

Latour, Bruno. Science and values. The aims of science and their role in scientific debate. California. California Press. 1984.

Latour, Bruno." Science in Action: How to Follow Scientists and Engineers Through Society" Milton Keynes: Open University Press. 1987

Latour, Bruno. "Technology is society made durable" The sociological reviewv. 38, 1990 p103-131

Latour. Bruno. "On actor-network theory. A few clarifications plus more than a few complications." Soziale Welt, vol. 47,, 1996 [1990] pp. 369-381

Latour, Bruno. Nunca Fuimos modernos. Buenos Aires. Siglo XXI 2007 [1993]

Latour, Bruno. "Trains of thought. Piaget, formalism and the fifth dimension.” Common Knowledge.1996 . v3 p170-191

Latour, Bruno. Aramis, or the Love of Technology. Cambridge, MA: Harvard University Press.1996

Latour, Bruno. "On Recalling ANT" The Editorial Board of The Sociological Review. 1999

Latour, Bruno. La esperanza de Pandora. Tomás Fernandez (trad.). Barcelona. Gedisa. 2001 [1999]

Latour, Bruno. Pasteur: guerre et paix des microbes suivi de irreductions. Paris. La Découverte, 2001.[1984]

Latour, Bruno. "Atmospheres, atmospheres. Laboratory inside out.” Introducción al catálogo de Olafur Eliasson en la exposición de la Tate Modern. London. Tate Modern. 2002

Latour, Bruno. "De la mediación técnica: filosofía, sociología y genealogía." en Sociología Simétrica: ensayos sobre ciencia, tecnología y sociedad. Tirado y Montaner.(Eds). Barcelona. Gedisa.1998. pp249-302

Latour, Bruno. Reensamblar lo social. Buenos Aires. Manantial. 2008. [2005]

Latour, Bruno. "Spheres and networks: two ways to reinterpret globalization." Harvard Design Magazine. n30 2009 p138-144

Latour, Bruno. "A Cautious Prometeus? A Few Steps Towards a Philosophy of Design (with Special Attention to Peter Sloterdijk)", en VV. AA. Proceeedings of the 2008 Annual International Conference of the Design History Society. Fal mouth: 3-6 septiembre,e-books, Universal Publishers, 2p.2009

Latour, Bruno "Networks, Societies, Spheres: Reflections of an Actor- network Theorist” International Journal of Communication n5. 2011. pp.796-810

Latour, Bruno. Políticas de la naturaleza. Enric puig (trad.). Barcelona. RBA. 2013 [2004]

Latour,Bruno. “¿El cosmos de quién? ¿Qué cosmopolítica? “. Pléyade. n14 2014. pp 43-59

Latour, Bruno \& Camacho-Hübner, Eduardo. "Entering a Risk Territory: space in the age of digital navigation” Enviroment and Planing D Society and Space. 210 v28 p 581-599

Latour, Bruno \& Yaneva, Albena. "Give me a gun and i will make all buildings move: an ant's view of architecture." en Geiser, Reto (ed.), Explorations in Architecture: Teaching, Design, Research, Basel: Birkhäuser, 2008 pp. 80-89.

Law, John. "Objects, Spaces and Others” Centre for Science Studies. Lancaster. 2000

Law, John. "Materialities, spacialities, globalities" Centre for Science Studies. Lancaster. 2003

Law, John. After Method: Mess in Social Science Research. London. Routledge.2004

Law, John “Actor-Network Theory and Material Semiotics.” En Bryan S. Turner. The New Blackwell

Companion to Social Theory. London. Blackwell. 2008

Law, J. \& Mol, A. "Notes on Materiality and Sociality." The Sociological Review 43. 1995 pp. 274-294. 
Law, J. \& Mol, A. "Spacialities of globality . Situating technoscience: An inquiry into spatialities.” Environment and Planning D: Society and Space. n19. 2003. p 609-621

Le Corbusier. The city of to-morrow and its planing. Dover Architecture. 2000 [1929]

Le Corbusier. The Radiant City. London: Faber and Faber. 1967

Lee, Nick \& Brown, Steve. "Otherness and the Actor Network: The Undiscovered Continent" American Behavioral Scientist. 1994. v.37 n.6 pp.772-790

Lefebvre, Henri. The Production of Space. London: Basil Blackwell.1991

Lipovetsky, Gilles. La era del vacío. Ensayos sobre el individualismo contemporáneo. Barcelona. Anagrama. 2002 [1983]

Lobsinger, Marye Luise. "Cybernetic Theory and the Architecture of Performance: Cedric Price's Fun Palace" en Anxious Modernisms. Experimentation in Postwar Architectural Culture. Montreal \& London. Canadian Center for Architecture \& MIT Press. 2000

López Daniel. "Aplicación de la teoría del actor-red al análisis espacial de un servicio de teleasistencia domiciliaria.” AIBR. Revista de Antropología Iberoamericana, Ed. Electrónica Núm. Especial. Nov-Dic 2005

López-Ibor, J.J. El cuerpo y la corporalidad. Madrid. Gredos. 1974

López, Leví. Centros comerciales: Espacios que navegan entre la realidad y la ficción. Mx. Nuestro Tiempo. 1999.

Loredo, J.Carlos. “¿Sujetos o actantes? El constructivismo de Latour y la psicología constructivista.” AIBR. Revista de Antropología Iberoamericana, v.4 n.1 2009. pp.113-136

Luhmann, Niklas. Sistemas sociales: lineamientos para una teoría general . Anthropos..1988. [1984] p.157

McFarlane, Colin “The city as assemblage: dwelling and urban space." Environment and Planning D: society and space. v29 2011. p649-671

Mahal, Mona \& Serbest, Asli. How Architecture Learned to Speculate. Stuttgart. Gerd de Bruyn. IGMA. 2009

Manson, Steven M. "Does scale exist? An epistemological scale continuum for complex human-environments System." Scient Direct. Minnesota. 2006.

Marmisolle, Gaston. "La sociología pragmática de Bruno Latour” VII Jornadas de Sociología de la UNLP. La Plata. 2012

Marston. Sallie A. "The social construction of scale”. Progress in Human Geography n24 v2 2000 pp. 219-242

Massey, Doreen. For Space Los Ángeles. Londres. Sage.2008 [2005]

Massey, Doreen. Space, Place and Gender. Minneapolis . University of Minnesota Press. 1994.

Massey, Doreen. ”Lugar, identidad y geografías de la responsabilidad en un mundo en proceso de globalización." Conferencia presentada a la Sociedad Catalana de Geografía el 26 de septiembre de 2003. XVIII Congreso de la Asociación de Geógrafos Españoles.

Melbín. M. Night as Erontier Colonizing rhe World afier Dark, N.York, Free Press Macmillan, 1987 Meyer, William B “Edward Bellamy and the Weather of Utopia," Geographical Review n94. v1. 2004 p 43-54 Miller, Arthur. I. Einstein y Picasso. El espacio, el tiempo y los estragos de la belleza. Barcelona. Tusquets. 2007 Miller, B.M. Air Conditioning advertising: imagining an ideal. Thesis, Harvard University, Cambridge. 1992

Mol, Annemarie. The Body Multiple: Ontology in Medical Practice. Durham, NC, and London, UnitedKingdom. Duke University Press. 2002

Montaner, Josep Ma . La modernidad superada Barcelona. Gustavo Gili. 2011

Moreira, Gonzalo C. "El concepto de mediación técnica en Bruno Latour. Una aproximación a la teoría del actor-red." Psicología, Conocimiento y Sociedad, v2 n1. 2012 pp. 54-79 
Morin, Marie-Eve. "Cohabiting in the globalised world: Peter Sloterdijk's global foams and Bruno Latour's cosmopolitics" Environmental and planning D: Society and space. v27 2009 pp.58-72

Muniesa, F. Luque, E. Chinchilla, I. Jaque, A.”Ejercicios de empirismo conceptual en arquitectura” Publicado en AIRB. Revista de Antropología Iberoamericana. Ed. Electrónica. Nov-Dic. Madrid. 2005

Nancy, Jean Luc. Corpus. Arena. Madrid. 2013. [2000]

Norberg-Schulz, Christian. Genius Loci. Paesaggio, ambiente, architettura. MIián. Electa. 1979

Pardo, José Luis. Deleuze: violentar el pensamiento. Madrid. Cincel. 1990

Pardo, José Luis. Las formas de la exterioridad. Valencia. Pre-textos.1992

Pardo, José Luis. Sobre los espacios: pintar, escribir, pensar. Barcelona. El Serbal. 2006

Pardo, José Luis. El cuerpo sin órganos. Valencia. Pre-textos. 2011

Pardo, José Luis. Políticas de la intimidad. Ensayo sobre la falta de excepciones. Madrid. Escolar y Mayo. 2012

Paris, Jean. El espacio y la mirada. Madrid. Taurus. 1967

Parks, Lisa. Cultures in Orbit: Satellites and the Televisual .Durham, NC. DukeUniversity Press, 2005.

Pavón-Cuéllar, David. 'Extimacy' in Thomas Teo (Ed.), Encyclopedia of Critical Psychology. New York: Springer.2014

Petre, Antonio. Tratado de la lejanía. Valencia. Pre-textos.2011

Picozzi, Sofía. "El urbanismo de lo doméstico. Comentarios a la entrevista a Martha Stewart." Buenos Aires.

Ramona n.51.2005

Preciado, Paul B. Testo Yonqui. Madrid. Espasa Calpe. 2008

Preciado, Paul B. Pornotopía. Barcelona. Anagrama. 2010

Preciado, Paul B. "Mies-conception: La casa Farnsworth y el misterio del armario transparente”, Zehar, Revista de Arteleku. Número especial espacio, género y arquitectura, n.44, 2000. pp. 26-32

Quesada, Fernando. "From the World without Objects to the Universal Grid” Delft Architecture Theory Journal. n8. 2011 pp.23-34

Ranciére, Jaques. El espectador emancipado. Pontevedra. Ellago. 2010

Rasmus, Kleis. Uneven Acelerations. NY. ColumbiaUniversity.2008

Ritzer, George. La McDonalización de la sociedad. Barcelona. Ariel. 1996

Riley, Terence. The Un-Private House. NY. MOMA. 2002

Rodriguez-Giralt, Israel. "De redes y otros enredos: acerca de la ontología política de la red” en Teoría del Actor Red. Más allá de los estudios de la ciencia y la tecnología. Barcelona. Amentia. 2012

Row, Collin. \& Slutzky, Robert Transparency, por B. Hoesli (ed.), Birkháser, Basilea, 1968

Santacana, Amadeu. El acontecimiento como un mundo en yuxtaposición. Tesis doctoral. UPC. Barcelona. 2013

Saskia Sassen. Contrageografías de la globalización. Madrid. Traficantes de sueños. 2003

Schiffter, F. Contra Debord. Barcelona. Melusina. 2005

Scott Brown, Denise. Armada de palabras. Provocaciones arquitectónicas. México DF. Arquine. 2013 [2009]

Sennett, Richard. Carne y Piedra. El cuerpo y la ciudad en la civilización occidental. Cesar Vidal (trad.).Madrid. Alianza. 2010 [1997]

Serres, Michael. Atlas. Madrid. Cátedra. 1995 [1994]

Serres, Michel. El contrato natural. Valencia. Pre-textos. 2004

Shields, Rob. "Flanerie for cyborgs." Theory, Culture \& Society 2006 London. Thousand Oaks and New Delhi. Vol. 23(7-8) p.209-220

Sibilia, Paula. La intimidad como espectáculo. Buenos Aires. Ed Fondo de Cultura Económica Argentina. 2008.

Simmel, George. El individuo y la libertad. Barcelona. Península 2001 
Sloterdijk, Peter "El hombre operable. Notas sobre el estado ético de la tecnología génica" conferencia 19 de mayo de 2000, en el Centro de Estudios Europeos (CES) de la Universidad de Harvard, en Estados Unidos.

Sloterdijk, Peter. Esferas I. Burbujas. Microsferología. Madrid; Siruela; 2003 [1998]

Sloterdijk. Peter. Normas para el parque humano. Una respuesta a la 'Carta sobre el humanismo' de Heidegger. Madrid. Siruela. 2003 [1999]

Sloterdijk, Peter. Esferas II. Globos. Macrosferología. Madrid. Siruela. 2004 [1999]

Sloterdijk, Peter. Esferas III. Espumas. Esferología plural. Madrid. Siruela. 2006 [2004]

Sloterdijk. Peter. En el mundo interior del capital. Para una teoría filosófica de la globalización. Madrid. Siruela. 2007 [2005]

Sloterdijk. Peter. "El palacio de Cristal”. Conferencia trascrita de "Traumas urbanos. La ciudad y los desastres". Centro de Cultura Contemporánea de Barcelona , 7-11 julio 2004

Sloterdijk, Peter Terror from the Air. Los Angeles: Semiotext[e], 2009

Sloterdijk, Peter."Spheres Theory.Talking to myself about the poetics of Space”. Harvard Design Magazine. 2009 n30 p1-8

Sloterdijk, Peter . "Geometry in the colossal: the project of metaphysical globalization." Environment and planing D: Society and space 2009, v.27, pp105-118

Soja. Eduard W. "Inside Exopolis: Scenes from Orange County." en Variations on a Theme Park: The New American City and the End of Public Space. Hill and Wang, New York. 1992. pp.94-122

Soja. Eduard W. Posmodern Geographies . London , NY. Verso. 1995

Soja. Eduard W. Thirdspaces. Journeys to Los Angeles and Other Real-and-Imagined Places. Los Angeles. Wiley-Blackwell. 1996.

Soriano, Federico. Sin tesis. Barcelona. Gustavo Gili. 2004

Soriano, Federico. Hypermínimos. Madrid. Lampreave. 2009

Sorkin, Michael. "See you in Disenyland." en Variations on a Theme Park: The New American City and the End of Public Space. Michael Sorkin (Ed.). Hill and Wang, New York. 1992 pp.205-323

Stengers, Isabelle. “La propuesta cosmopolítica.” Pléyade. n14 2014. pp17-41

Stephen. Phillips, "Plastics," en Beatriz Colomina (Ed.) Cold War Hothouses. New York: Princeton Architectural Press, 2004

Steyerl, Hito "In Free Fall: A Thought Experiment on Vertical Perspective”. E-flux. n24 Abril. 2011 descargable en: http://www.e-flux.com/journal/in-free-fall-a-thought-experiment-on-vertical-perspective/

Strauven. Francis. Aldo Van Eyck: The shape of relativity. Amsterdam Natura Press.1998

Superstudio. “Continuos Monument” Domus Revista. Diciembre 1969. n.481

Superstudio. "Architettura interplanetaria" Casabella n.364. 1972

Tarde, Gabriel. Las leyes de la imitación y La Sociología. Madrid. Centro de investigaciones soclógicas. 2011

Tarde, Gabriel. Monadología y sociología. Buenos Aires, Cactus. 2006

Thrift. Nigel. "Different atmospheres: of Sloterdijk, China and site" Environment and planing D: Socierty and space 2009, volume27, pp119-138

Thrift, N \& May. J. Geographies of Temporality. London. NY. Routledge. 2001

Tirado, Francisco J. Los objetos y el acontecimiento: teoría de la socialidad mínima. Tesis doctoral. Universidad Autónoma de Barcelona. 2001

Tirado, Francisco J. "Recensión crítica. La teoría del actor-red y la reinvención de lo social". AIBR. Revista de Antropología Iberoamericana, Ed. Electrónica Núm. Especial. Noviembre-Diciembre 2005. pp.1-7

Tirado, F. J. \& Domènech, M. “Extituciones: Del poder y sus anatomías”. Politica y Sociedad, 36,2001 pp $183-196$ 
Tirado, FJ. \& Domenech M. “Asociaciones heterogéneas y actantes: el gripo postsocial de la teoría del actorred" AIBR. Revista de Antropología Iberoamericana, Ed. Electrónica Núm. Especial. Noviembre-Diciembre 2005.pp. $1-26$

Tomlinson. John. The Culture of Speed. The Coming of Immediacy London. Sage. 2007

Tshumi, Bernard. The Manhattan transcripts. NY. Wiley. 1994

Tshumi, Bernard, Questions of space. London. Architectural Association. 2004

Van Eyck, Aldo. Writtings. Amsterdam. Sun.1962

Van Tuinen. Sjoerd. “Air Conditioning Spaceship Earth: An Ethico-Aesthetic Paradigm” Environment and planing D: Socierty and space 2009, volume27, pp105-118

Van Tuinen, Sjoerd. "Transgenous Philosophy": post-humanism, anthropotechnics and the Poetics of natal Difference. en AA.VV.In Medias Res: Peter Sloterdijk's Spherological Poetics of Being Schinkel, Willem \& Noordegraaf-Eelens Liesbeth (Eds.).Amsterdam Amsterdam University Press. 2011. pp43-66

Vásquez Roca, Adolfo. "Sloterdijk y Heidegger: humanismo, deshumanización y posthumanismo en el parque humano.” Nómadas. Revista Crítica de Ciencias Sociales y Jurídicas v23 n3 2009

Vásquez Roca. Adolfo. “Sloterdijk; psicopolítica, globalización y mundo interior del capital." Nómadas. Revista Crítica de Ciencias Sociales y Jurídicas v28 n4 2010.

Virilio, Paul. Estética de la desaparición. Barcelona. Anagrama. 2003

Virilio, Paul. El cibermundo, o la política de lo peor. Madrid. Cátedra. 2005

Virilio. Paul. Speed and Politics. Los Ángeles. Semiotexte. 2006

Wall, Alex. Victor Gruen: from urban shop to new city. Barcelona. Actar D. 2005

Warhol, Andy. Mi filosofía de A a B y de B a A . Barcelona. Tusquets. 2010 [1975]

Warhol, Andy \& Hackett, Pat. POPism. Diarios (1960-1969). Barcelona. Alfabia. 1980

Warhol, Andy \& Hackett, Pat. Party Book. Nueva York. Crown. 1988

Wigley, Mark . Constant's New Babylon: The Hyper-architecture of Desire. Rotterdam. 010 Publishers. 1998

Wilda Anderson. Diderto's dream. Baltimore. The Johns Hopkins University Press. 1990

Wolfe, Tom. El coqueto, aerodinámico rocanrol color caramelo de ron. Barcelona. Tusquets. 1972

Woolf, Virginia. Un cuarto propio. Buenos Aires. Lumen 2013. [1929]

Yaneva, Albena. The Making of a Building: A Pragmatist Approach to Architecture. Berna. Peter Lang. 2009

Yaneva, Albena. Mapping controversies in Architecture. Surrey Burlington. Ashgate. 2012.

Young, Michael. "The Metronomic Society”, London, Sociétés, n.0 51, 1996

Zaera-Polo, Alejandro. "Metrópolis: Topografía de la Acumulación Flexible”. Madrid. El croquis 52. 1992

Zaera-Polo, Alejandro. "Politics of the envelope". Volume n17. 2008 pp.76-105

Zafra, Remedios. Un cuarto propio conectado. Madrid. Fórcola. 2010 